\title{
Copper-Catalyzed Regioselective Boracarboxylation of Vinyl Arenes: Catalytic Efficiency and Synthetic Utility
}

\author{
Trina M. Perrone \\ West Virginia University, tmperrone@mix.wvu.edu
}

Follow this and additional works at: https://researchrepository.wvu.edu/etd

Part of the Organic Chemistry Commons

\section{Recommended Citation}

Perrone, Trina M., "Copper-Catalyzed Regioselective Boracarboxylation of Vinyl Arenes: Catalytic Efficiency and Synthetic Utility" (2019). Graduate Theses, Dissertations, and Problem Reports. 4086. https://researchrepository.wvu.edu/etd/4086

This Dissertation is protected by copyright and/or related rights. It has been brought to you by the The Research Repository @ WVU with permission from the rights-holder(s). You are free to use this Dissertation in any way that is permitted by the copyright and related rights legislation that applies to your use. For other uses you must obtain permission from the rights-holder(s) directly, unless additional rights are indicated by a Creative Commons license in the record and/ or on the work itself. This Dissertation has been accepted for inclusion in WVU Graduate Theses, Dissertations, and Problem Reports collection by an authorized administrator of The Research Repository @ WVU.

For more information, please contact researchrepository@mail.wvu.edu. 


\title{
Copper-Catalyzed Regioselective Boracarboxylation of Vinyl Arenes: Catalytic Efficiency and Synthetic Utility
}

\section{Trina M. Perrone}

Dissertation submitted to the Eberly College of Arts and Sciences at West Virginia University

\begin{abstract}
in partial fulfillment of the requirements for the degree of
\end{abstract}

Doctor of Philosophy in Chemistry

\author{
Brian V. Popp, Ph.D., Committee Chair \\ Jessica M. Hoover, Ph.D. \\ Björn Söderberg, Ph.D. \\ Carsten Milsmann, Ph.D. \\ Tatiana Trejos, Ph.D.
}

Department of Chemistry

Morgantown, West Virginia 2019

Keywords: boracarboxylation, secondary ligand effects, fluorination, cross-coupling, non-steroidal anti-inflammatory drugs

Copyright 2019 Trina M. Perrone 


\section{Abstract \\ Copper-Catalyzed Regioselective Boracarboxylation of Vinyl Arenes: Catalytic Efficiency and Synthetic Utility}

\section{Trina Perrone}

Hetero(element) carboxylation is an appealing transformation that involves the installation of $\mathrm{CO}_{2}$ and another hetero(element) in one step. This transition metal-catalyzed one-pot synthesis provides a route to achieve highly functionalized carboxylic acid products with an abundant and cheap $\mathrm{C}_{1}$ feedstock. This difunctionalization also avoids the use of reactive metal hydride species, which is a prominent limitation of hydrocarboxylation chemistry. A copper-catalyzed regioselective boracarboxylation of vinyl arenes has been developed to access pharmaceutically relevant $\beta$-boryl- $\alpha$-aryl propionic acid products. One drawback of this reaction is the necessity for high catalyst loading to achieve catalytic turnover. To circumvent this issue, the reduction of catalyst loading by addition of a secondary phosphine ligand was examined to access previously reported substrates and an expanded scope for this transformation. Trends in reactivity and preliminary experiments to determine the role of exogenous phosphine in the catalytic system will be described. The synthetic utility of the boracarboxylated products was investigated through a contemporary carbon-boron bond transformation to afford fluorinated products. The reactivity and scope of a deboronofluorination pathway will be presented, along with mechanistic investigation. The synthetic utility of boracarboxylated products to form new carbon-carbon bonds through cross-coupling afforded 2,3-diarylpropionic acids. This synthetic pathway will allow for chemoselectivity that is not observed through traditional pathways, such as the hydrocarboxylation of stilbenes. 
Dedicated to my parents,

Cindy and Richard Perrone 


\section{Acknowledgments}

I would like to thank my advisor, Dr. Brian Popp, for his encouragement and constant guidance throughout my journey in graduate school. His dedication to research and mentoring graduate students is something I truly admire. I am beyond appreciative for the freedom he has given me to pursue research ideas and teaching opportunities that were afforded to me. Dr. Popp has trained me to be a careful and meticulous researcher. He is not only an amazing professor and mentor, he is a remarkable and kind person. I wish him nothing but the best in the future in all his personal and professional endeavors.

I would also like to thank my other committee members, Dr. Jessica Hoover, Dr. Björn Söderberg, Dr. Carsten Milsmann and Dr. Tatiana Trejos for taking time to serve on my committee. I appreciate all of their support and advice throughout my time at WVU. I thank Dr. Jeffrey Petersen for his time and talent in crystallographic analysis of my crystal structures and Dr. Novruz Akhmedov for his expertise and assistance with NMR experiments. Thank you to Dr. Osbourn, Dr. Battin, and all of the other TAPs. From getting guidance in teaching to recommendation letter writing, I appreciate all of their help. Also, thanks to Becky Secrist for her willingness to talk and help me at any time. Allan, Randy, and Sherman were also instrumental in helping me with set up and maintenance of the laboratory equipment. WVU truly has amazing faculty and staff.

Additionally, I would like to thank all of the members of the Popp group, past and present. Thanks to Dr. Vaishali Vajpayee, Dr. Brian Nichols, Rachael Pickens, Jessica Rogers, Notashia Baughman, Steven Knowlden, Randika Abeysinghe, and Alexa Martin. I would also like to thank undergraduates, Trevor Butcher, Ted McClain, Tyler Hamilton, Amy Gregory, Maxwell Reese, Leandra Forte, Kayla Kroner, Natalie Ziemer, Tiffany Taylor, Mason Hamilton, and Randy Koziel. My lab mates are truly my second family. I wish them all the best in chemistry and in life.

I thank my family for their never-ending support through my graduate school journey. Thanks to my mom, dad, sisters, brothers, nephews and niece for keeping me sane during my dissertation work. My mom's determination and hard work ethic through health problems has encouraged me 
to keep working in even the most difficult of times. Lastly, I would like to thank Brian. I admire that he never lost sight of his passion through all of the hard work and challenges of graduate school life. I would not be the researcher and person that I am today without his help and patience. He is my motivation. I can't wait to see what life has in store for us in the future. 
Table of Contents

\begin{tabular}{|l|r|}
\hline Abstract & ii \\
\hline Dedication & iii \\
\hline Acknowledgements & iv \\
\hline Table of Contents & vi \\
\hline List of Tables & viii \\
\hline List of Figures & $\mathrm{x}$ \\
\hline List of Schemes & xi \\
\hline List of Abbreviations & xiv \\
\hline
\end{tabular}

Chapter 1. Introduction

\begin{tabular}{|l|l|r|}
\hline 1.1 & Converting carbon dioxide into value added products & 1 \\
\hline 1.2 & Carboxylation strategies to yield carboxylic acids & 2 \\
\hline 1.3 & Hetero(element)carboxylation to afford highly functionalized carboxylic acids & 7 \\
\hline 1.4 & Borylcopper-catalyzed borylation reactions & 10 \\
\hline 1.5 & Carbon dioxide insertion into alkyl species utilizing copper catalysis & 14 \\
\hline 1.6 & Boracarboxylation of vinyl arenes & 16 \\
\hline
\end{tabular}

Chapter 2. Effect of Triphenylphosphine Additive in Boracarboxylation of Styrene Derivatives

\begin{tabular}{|l|l|r|}
\hline 2.1 & Introduction & 21 \\
\hline 2.2 & Results & 23 \\
\hline 2.3 & Conclusion & 41 \\
\hline 2.4 & Experimental Methods & 41 \\
\hline
\end{tabular}

Chapter 3. Selective Deboronofluorination of Boracarboxylated Products

\begin{tabular}{|l|l|r|}
\hline 3.1 & Introduction & 50 \\
\hline 3.2 & Results & 55 \\
\hline 3.3 & Conclusion & 76 \\
\hline 3.4 & Experimental Methods & 76 \\
\hline
\end{tabular}


Chapter 4. Progress in Suzuki Cross-Coupling of Boracarboxylated Products

\begin{tabular}{|l|l|r|}
\hline 4.1 & Introduction & 81 \\
\hline 4.2 & Results & 86 \\
\hline 4.3 & Conclusion & 92 \\
\hline 4.4 & Experimental Methods & 92 \\
\hline
\end{tabular}

\begin{tabular}{|l|r|}
\hline References & 94 \\
\hline Appendix I & 100 \\
\hline Appendix II & 140 \\
\hline
\end{tabular}




\section{List of Tables}

\begin{tabular}{|c|c|c|}
\hline Table 1.1 & Copper catalyst optimization for boracarboxylation of vinyl arenes & 17 \\
\hline Table 1.2 & Representative examples of boracarboxylation substrate scope & 18 \\
\hline Table 2.1 & $\begin{array}{l}\text { Addition of } \mathrm{PPh}_{3} \text { for enantioselective reductive coupling of aryl } \\
\text { alkenes and activated carboxylic acids }\end{array}$ & 22 \\
\hline Table 2.2 & $\begin{array}{l}\text { Optimization of boracarboxylation of vinyl arenes with secondary } \\
\text { ligand addition }\end{array}$ & 24 \\
\hline Table 2.3 & $\begin{array}{l}\text { Comparison of } 12 \mathrm{~mol} \% \mathrm{ICyCuCl} \text { and } 5 \mathrm{~mol} \% \mathrm{ICyCuCl}+5 \mathrm{~mol} \% \\
\mathrm{PPh}_{3} \text { catalyst systems for previously reported vinyl arene } \\
\text { boracarboxylation }\end{array}$ & 25 \\
\hline Table 2.4 & $\begin{array}{l}\text { Optimization of boracarboxylation for vinyl arenes bearing electron- } \\
\text { withdrawing groups }\end{array}$ & 27 \\
\hline Table 2.5 & $\begin{array}{l}\text { Expanded substrate scope for boracarboxylation with use of } \mathrm{PPh}_{3} \\
\text { additive catalyst system }\end{array}$ & 28 \\
\hline Table 2.6 & Screening of bases to determine role of $\mathrm{PPh}_{3}$ in boracarboxylation & 30 \\
\hline Table 2.7 & Investigation of role of $\mathrm{PPh}_{3}$ in $\mathrm{CO}_{2}$ insertion step & 31 \\
\hline Table 2.8 & $\begin{array}{l}\text { Competition studies between para-tert-butylstyrene and para- } \\
\text { fluorostyrene }\end{array}$ & 32 \\
\hline Table 2.9 & Competition studies between styrene and para-fluorostyrene & 33 \\
\hline Table 2.10 & $\begin{array}{l}\text { Competition studies between para-tert-butylstyrene and para- } \\
\text { trifluoromethylstyrene }\end{array}$ & 34 \\
\hline Table 2.11 & $\begin{array}{l}\text { Boracarboxylation of para-trifluoromethylstyrene at low styrene } \\
\text { loading }\end{array}$ & 35 \\
\hline Table 2.12 & $\begin{array}{l}\text { Competition studies between para-tert-butylstyrene and para- } \\
\text { trifluoromethylstyrene with para-trifluoromethylstyrene protoboration } \\
\text { product }\end{array}$ & 36 \\
\hline Table 2.13 & Investigation of HBpin as boron source in boracarboxylation & 38 \\
\hline Table 3.1 & Screening of silver catalysts for deboronofluorination & 57 \\
\hline Table 3.2 & Screening of reaction conditions for deboronofluorination & 58 \\
\hline Table 3.3 & $\begin{array}{l}\text { Substrate scope for the deboronofluorination of boracarboxylated } \\
\text { products }\end{array}$ & 59 \\
\hline Table 3.4 & Further screening to attempt to improve p-Me substrate fluorination & 62 \\
\hline
\end{tabular}




\begin{tabular}{|l|l|l|}
\hline Table 3.5 & $\begin{array}{l}\text { Unsuccessful substrates for the deboronofluorination of } \\
\text { boracarboxylated products }\end{array}$ & 64 \\
\hline Table 3.6 & $\begin{array}{l}\text { Deboronofluorination of tolyl boracarboxylated product in the presence } \\
\text { of radical trap reagents }\end{array}$ & 65 \\
\hline Table 4.1 & $\begin{array}{l}\text { Screening of catalyst conditions for the cross-coupling of } \\
\text { boracarboxylated products }\end{array}$ & 87 \\
\hline Table 4.2 & $\begin{array}{l}\text { Screening of reaction conditions for the cross-coupling of } \\
\text { boracarboxylated products }\end{array}$ & 87 \\
\hline Table 4.3 & Substrate scope of boracarboxylated products for cross-coupling & 88 \\
\hline Table 4.4 & Substrate scope of aryl bromides for cross-coupling & 90 \\
\hline Table 4.5 & Substrate scope of heterocycles for cross-coupling & 91 \\
\hline
\end{tabular}




\section{List of Figures}

\begin{tabular}{|c|c|c|}
\hline Figure 1.1 & $\begin{array}{l}\text { Common } \alpha \text {-aryl propionic acid non-steroidal anti-inflammatory drugs } \\
\text { (NSAIDs) }\end{array}$ & 5 \\
\hline Figure 1.2 & $\begin{array}{l}\text { Crystal structures of the boracarboxylation of alkyne intermediates: } \\
\text { alkyne insertion into } \mathrm{Cu} \text {-Bpin (left) and } \mathrm{CO}_{2} \text { insertion step (right) }\end{array}$ & 9 \\
\hline Figure 1.3 & $\begin{array}{l}\text { Boron-containing therapeutics approved by the US Federal Drug } \\
\text { Administration }\end{array}$ & 9 \\
\hline Figure 1.4 & X-ray crystal structure of boracarboxylated tert-butylstyrene & 19 \\
\hline Figure 2.1 & X-ray crystal structure of boracarboxylated isobutyl styrene, $2 \mathrm{~d}$ & 26 \\
\hline Figure 3.1 & Structures of important fluorine-containing pharmaceuticals & 51 \\
\hline Figure 3.2 & Structures of fluorine-containing PET tracers & 51 \\
\hline Figure 3.3 & Structures of some common electrophilic fluorinating reagents & 52 \\
\hline Figure 3.4 & Time course for $\mathrm{p}-\mathrm{Me}$ substrate fluorination & 61 \\
\hline Figure 3.5 & $\begin{array}{l}{ }^{19} \mathrm{~F} \text { NMR spectrum of crude reaction mixture of fluorination of } \\
\text { boracarboxylated flurbiprofen }\end{array}$ & 63 \\
\hline Figure 3.6 & Plausible mechanisms for deboronofluorination & 67 \\
\hline Figure 3.7 & $\begin{array}{l}{ }^{1} \mathrm{H} \text { NMR spectrum of boracarboxylation of trans- } \beta \text {-methyl styrene } \\
\text { showing the two diastereomers in a }>7: 1 \text { ratio }\end{array}$ & 68 \\
\hline Figure 3.8 & $\begin{array}{l}{ }^{1} \mathrm{H} \text { NMR spectrum of the two diastereomers of the trans- } \beta \text {-methyl } \\
\text { difluoroboralactones }\end{array}$ & 70 \\
\hline Figure 3.9 & Expanded portion of the 2D NOESY spectrum for the trans-boralactone & 71 \\
\hline Figure 3.10 & Expanded portion of the 2D NOESY spectrum for the cis-boralactone & 72 \\
\hline Figure 3.11 & $\begin{array}{l}{ }^{19} \mathrm{~F} \text { NMR spectrum for the fluorination of trans- } \beta \text {-methyl styrene } \\
\text { boracarboxylated diastereomers }\end{array}$ & 73 \\
\hline Figure 3.12 & $\begin{array}{l}{ }^{19} \mathrm{~F}-{ }^{13} \mathrm{C} \text { HMBC from the fluorination of boracarboxylated trans- } \beta- \\
\text { methyl styrene }\end{array}$ & 75 \\
\hline Figure 4.1 & Biologically active 2,3-diarylpropionic acids & 81 \\
\hline Figure 4.2 & X-ray crystal structure of cross-coupling product, 9a & 89 \\
\hline
\end{tabular}




\section{List of Schemes}

\begin{tabular}{|l|l|l|}
\hline Scheme 1.1 & Industrial process for the formation of salicylic acid & 2 \\
\hline Scheme 1.2 & Production of urea & 2 \\
\hline Scheme 1.3 & $\begin{array}{l}\text { Reaction of epoxides with } \mathrm{CO}_{2} \text { to form cyclic carbonates and } \\
\text { polycarbonates }\end{array}$ & 2 \\
\hline Scheme 1.4 & Carboxylation of organozinc reagents catalyzed by Aresta's complex & 3 \\
\hline Scheme 1.5 & Mild carboxylation of aryl halides and aryl boronic esters & 3 \\
\hline Scheme 1.6 & Selected examples of hydrocarboxylation of alkynes & 4 \\
\hline Scheme 1.7 & Selected examples of hydrocarboxylation of vinyl arenes & 6 \\
\hline Scheme 1.8 & Schomaker's hydroboration/carboxylation strategy & 7 \\
\hline Scheme 1.9 & Skrydstrup's hydroboration/carboxylation strategy & 7 \\
\hline Scheme 1.10 & Hetero(element)carboxylation of alkynes & 8 \\
\hline Scheme 1.11 & Insertion of styrene into (IPr)CuBpin & 10 \\
\hline Scheme 1.12 & $\begin{array}{l}\text { Hydroboration transformation and mechanism using alkene insertion } \\
\text { into Cu-Bpin }\end{array}$ & 11 \\
\hline Scheme 1.13 & Copper-catalyzed enantioselective hydroboration & 12 \\
\hline Scheme 1.14 & Selective examples of carboboration utilizing copper-boryl species & 13 \\
\hline Scheme 1.15 & Selective examples of aminoboration utilizing copper-boryl species & 14 \\
\hline Scheme 1.16 & Carbon dioxide insertion into copper-alkyl bond and X-ray structure & 15 \\
\hline Scheme 1.17 & $\begin{array}{l}\text { Carboxylation of alkyl boranes with CO }{ }_{2} \text { X-ray structure of alkyl } \\
\text { borane adduct intermediate (left) and } \mathrm{CO}_{2} \text { insertion step (right) }\end{array}$ & 15 \\
\hline Scheme 1.18 & Proposed mechanism for the boracarboxylation of vinyl arenes & 16 \\
\hline Scheme 1.19 & Gram-scale boracarboxylation of tert-butylstyrene & 19 \\
\hline Scheme 1.20 & Hetero(element)carboxylation of alkenes utilizing photocatalysis & 20 \\
\hline Scheme 2.1 & Popp's copper-catalyzed boracarboxylation of vinyl arenes & 21 \\
\hline Scheme 2.2 & Scale-up boracarboxylation reactions employing a secondary ligand \\
\hline Scheme 2.3 & Carboxylation of copper tert-butoxide in presence of PPh ligand & 29 \\
\hline Scheme 2.4 & $\begin{array}{l}\text { Boracarboxylation reaction between styrene vs. para- } \\
\text { trifluoromethylstyrene (top) and deuterated styrene vs. para- }\end{array}$ & 31 \\
\hline
\end{tabular}




\begin{tabular}{|c|c|c|}
\hline Scheme 2.5 & $\begin{array}{l}\text { Boracarboxylation of } \mathrm{p}^{-\mathrm{CF}_{3}} \text { styrene with excess } \mathrm{p}-\mathrm{tBu} \text { styrene and } \\
\text { HBpin as a boron source }\end{array}$ & 38 \\
\hline Scheme 2.6 & Boracarboxylation of $\mathrm{p}-\mathrm{CF}_{3}$ styrene with addition of $\mathrm{D}_{2} \mathrm{O}$ to reaction & 39 \\
\hline Scheme 2.7 & Metal-free boration of styrene & 40 \\
\hline Scheme 2.8 & $\begin{array}{l}\text { Boracarboxylation of } \mathrm{p}^{-\mathrm{CF}_{3}} \text { styrene without copper catalyst and } \mathrm{CO}_{2} \text { to } \\
\text { test for base-catalyzed hydroboration }\end{array}$ & 40 \\
\hline Scheme 2.9 & $\begin{array}{l}\text { Boracarboxylation of } \mathrm{p}-\mathrm{CF}_{3} \text { styrene using } \mathrm{DCl} \text { and } \mathrm{D}_{2} \mathrm{O} \text { in the work-up } \\
\text { step }\end{array}$ & 40 \\
\hline Scheme 3.1 & Balz-Schiemann reaction & 52 \\
\hline Scheme 3.2 & Halex reaction & 52 \\
\hline Scheme 3.3 & Ritter's silver-mediated fluorination of boronic acids & 53 \\
\hline Scheme 3.4 & Fluorination of alkenyl boronic acids and trifluoroborates & 53 \\
\hline Scheme 3.5 & Metal-free electrophilic fluorination of alkyl trifluoroborates & 54 \\
\hline Scheme 3.6 & Aggarwal's fluorination of boronate esters & 54 \\
\hline Scheme 3.7 & Li's silver-catalyzed fluorination of alkylboronates & 54 \\
\hline Scheme 3.8 & Li's silver-catalyzed decarboxylative fluorination & 55 \\
\hline Scheme 3.9 & 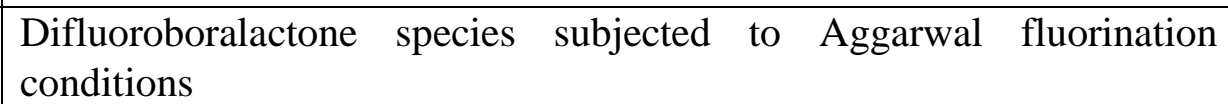 & 55 \\
\hline Scheme 3.10 & Boracarboxylated products subjected to Li fluorination conditions & 56 \\
\hline Scheme 3.11 & Synthesis of fluorinated ibuprofen (using iridium and ruthenium) & 60 \\
\hline Scheme 3.12 & Investigation of the decarboxylative fluorination process & 66 \\
\hline Scheme 3.13 & Copper-catalyzed boracarboxylation of trans- $\beta$-methyl styrene & 67 \\
\hline Scheme 3.14 & $\begin{array}{l}\text { Conversion of the trans- } \beta \text {-methyl boracarboxylated diastereomers to the } \\
\text { difluoroboralactone species }\end{array}$ & 69 \\
\hline Scheme 3.15 & Fluorination of trans- $\beta$-methyl styrene boracarboxylated diastereomers & 73 \\
\hline Scheme 4.1 & $\begin{array}{l}\text { Traditional alkylation approaches to synthesize 2,3-diphenylpropionic } \\
\text { acids }\end{array}$ & 82 \\
\hline Scheme 4.2 & $\begin{array}{l}\text { Skrydstrup's hydroboration/carboxylation strategy to access 2,3- } \\
\text { diarylpropionic acids }\end{array}$ & 83 \\
\hline Scheme 4.3 & Martin's catalytic hydrocarboxylation & 83 \\
\hline Scheme 4.4 & Shi's palladium-catalyzed hydrocarboxylation & 83 \\
\hline Scheme 4.5 & Cross-coupling of an alkylboronate ester & 84 \\
\hline
\end{tabular}




\begin{tabular}{|l|l|l|}
\hline Scheme 4.6 & Crudden's orthogonal cross-coupling methodology & 84 \\
\hline Scheme 4.7 & Yu's ortho-olefination strategy using a carboxylic acid directing group & 85 \\
\hline Scheme 4.8 & $\begin{array}{l}\text { Yu's ortho-arylation methodology using a carboxylic acid directing } \\
\text { group }\end{array}$ & 85 \\
\hline Scheme 4.9 & One-pot boracarboxylation/cross-coupling & 92 \\
\hline
\end{tabular}




\section{List of Abbreviations}

\begin{tabular}{|c|c|}
\hline acac & acetylacetonate \\
\hline atm & atmosphere \\
\hline $\mathrm{B}_{2} \mathrm{pin}_{2}$ & bis(pinacolato)diboron \\
\hline BBN & 9-borabicyclo[3.3.1]nonane \\
\hline Bdan & naphthalene-1,8-diamino boryl \\
\hline BHT & butylated hydroxytoluene \\
\hline $\mathrm{Bn}$ & benzyl \\
\hline Boc & tert-butyloxycarbonyl \\
\hline BPCP & 1-(biphenyl)-2,2-diphenylcyclopropane carboxylate \\
\hline Me-BPE & 1,2-bis(2,5-dimethylphospholano)ethane \\
\hline Ph-BPE & 1,2-bis(2,5-diphenylphospholano)ethane \\
\hline Bpin & boronic acid pinacol ester \\
\hline BQ & 1,4-benzoquinone \\
\hline COD & 1,5-cyclooctadiene \\
\hline CzIPN & 2,4,5,6-tetra(9H-carbazol-9-yl)isophthalonitrile \\
\hline $\mathrm{dba}$ & dibenzylideneacetone \\
\hline$\overline{\mathrm{DCM}}$ & dichloromethane \\
\hline DFT & density functional theory \\
\hline DMA & $N, N$-dimethylacetamide \\
\hline DMF & $\mathrm{N}, \mathrm{N}$-dimethylformamide \\
\hline DMMS & dimethoxy(methyl)silane \\
\hline DMSO & dimethyl sulfoxide \\
\hline DPEphos & bis[(2-diphenylphosphino)phenyl] ether \\
\hline dppbz & 1,2-bis(diphenylphosphino)benzene \\
\hline dppf & 1-1'-bis(diphenylphosphino)ferrocene \\
\hline DTBM-SEGPHOS & $\begin{array}{l}\text { 5,5'-bis[di(3,5-di-tert-butyl-4-methoxyphenyl)phosphino]-4,4'-bi-1,3- } \\
\text { benzodioxole }\end{array}$ \\
\hline Me-DuPhos & 1,2-bis(2,5-dimethylphospholano)benzene \\
\hline
\end{tabular}




\begin{tabular}{|l|l|}
\hline FDG & fludeoxyglucose \\
\hline HBpin & $4,4,5,5$-tetramethyl-1,3,2-dioxaborolane \\
\hline HFIP & hexafluoroisopropanol \\
\hline HMBC & heteronuclear multiple bond correlation \\
\hline ICy & 1,3-dicyclohexyl-imidazol-2-ylidene \\
\hline IMes & 1,3-bis(2,4,6-trimethylphenyl)-imidazol-2-ylidene \\
\hline IPr & 1,3-bis(2,6-diisopropylphenyl)-imidazol-2-ylidene \\
\hline mCPBA & meta-chloroperoxybenzoic acid \\
\hline NFSI & N-fluorobenzenesulfonimide \\
\hline NHC & $N$-heterocyclic carbene \\
\hline NMR & nuclear magnetic resonance \\
\hline NOESY & nuclear overhauser effect spectroscopy \\
\hline NSAID & non-steroidal anti-inflammatory drug \\
\hline PDI & pyridinediimine \\
\hline PET & positron emission tomography \\
\hline RuPhos & 2-dicyclohexylphosphino-2',6'-diisopropoxybiphenyl \\
\hline SIMes & 1,3 -bis(2,4,6-trimethylphenyl)-4,5-dihydroimidazol-2-ylidene \\
\hline TEMPO & (2,2,6,6-tetramethylpiperidin-1-yl)oxyl \\
\hline TESCl & triethylchlorosilane \\
\hline TFA & trifluoroacetic acid \\
\hline THF & tetrahydrofuran \\
\hline TMEDA & N,N,N',N'-tetramethylethylenediamine \\
\hline VLA-4 & very late antigen-4 \\
\hline Xantphos & 4,5 -bis(diphenylphosphino)-9,9-dimethylxanthene \\
\hline XPhos & 2-dicyclohexylphosphino-2',4',6'-triisopropylbiphenyl \\
\hline
\end{tabular}




\section{Chapter 1: Introduction}

\subsection{Converting carbon dioxide into value added products}

Catalysis plays a critical role in the development of sustainable chemistry. The use of catalysts in synthesis is a fundamental component of innovation to further improve eco-efficiency, economic growth, and our quality of life. ${ }^{1,2,3}$ The consistent efforts from the scientific community to develop new catalytic systems and advance methodology continue to economically and environmentally benefit our society. One way to reduce the environmental impact is to explore the utilization of biomass as a renewable source of carbon. An established strategy is to use catalytic processes to convert carbon dioxide $\left(\mathrm{CO}_{2}\right)$ into synthetically relevant, value added products. ${ }^{4,5}$

In recent years, there has been increasing awareness of the contribution of greenhouse gases to global warming. This has caused a redirection to replace steam reforming to dry reformation, involving the reaction of carbon dioxide with hydrocarbons to product synthesis gas, a mixture of hydrogen and carbon monoxide. ${ }^{6}$ An important subsequent product of synthesis gas is methanol, which can also be produced by the reaction of carbon dioxide with hydrogen gas. The current demand for methanol is estimated at 30 million metric tons, being employed as a fuel source. ${ }^{5}$ A similar methodology of reaction between carbon dioxide and hydrogen gas is used to produce formic acid, which is used as a preservative, de-icing agent, and in leather tanning. ${ }^{5}$

One of the oldest industrial processes utilizing $\mathrm{CO}_{2}$ is the synthesis of salicylic acid via the Kolbe-Schmitt reaction (Scheme 1.1). ${ }^{7}$ In this process, sodium phenolate reacts with high pressures of $\mathrm{CO}_{2}$ at high temperatures to yield an excellent ortho-selectivity through the chelation of sodium ions. ${ }^{5}$ Carbon dioxide is also used for the industrial-scale production of urea (Scheme 1.2). In 2011, the annual production of urea was 153 million metric tons while utilizing 112 million metric tons of $\mathrm{CO}_{2}$ as a feedstock. ${ }^{8}$ The largest portion of urea is used for agricultural fertilizers; however, urea finds many diverse applications in emission control of cars and power plants, as a moisturizer in the pharmaceutical industry, and in the tobacco industry to increase nicotine absorption. ${ }^{5}$ One contemporary utilization of $\mathrm{CO}_{2}$ involves the reaction with epoxides to form cyclic carbonates and polycarbonates (Scheme 1.3). ${ }^{9}$ Organic carbonates have a wide array of applications in the production of engineering plastics, as solvents used for lithium ion batteries, and its addition to gasoline results in an improved octane value. Owing to their high impact-resistance and optical 
transparency, polycarbonates can be utilized in DVDs, eyeglasses, and aircraft windows. ${ }^{10}$ This methodology has even attracted attention to produce Covestro's Makrolon, which is a highperformance, lightweight, and easy-to-shape plastic.

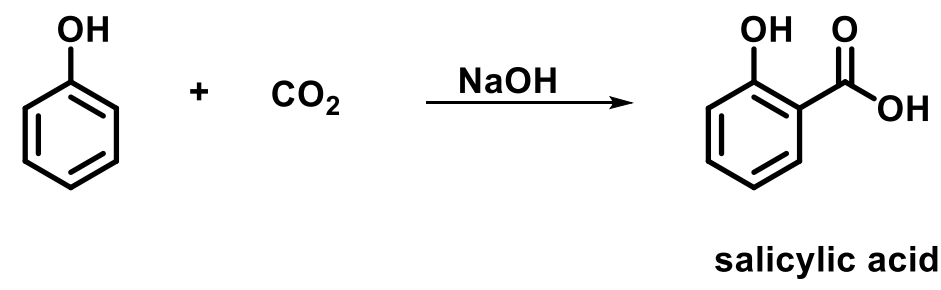

Scheme 1.1 Industrial process for the formation of salicylic acid

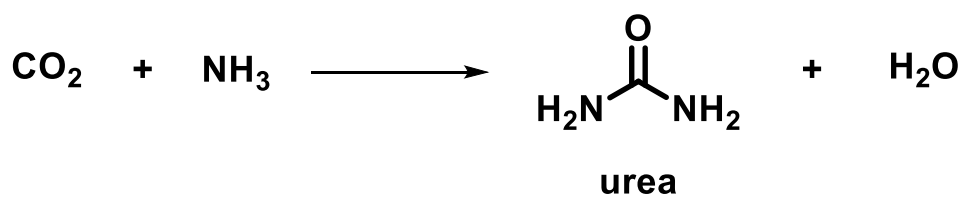

Scheme 1.2 Production of urea

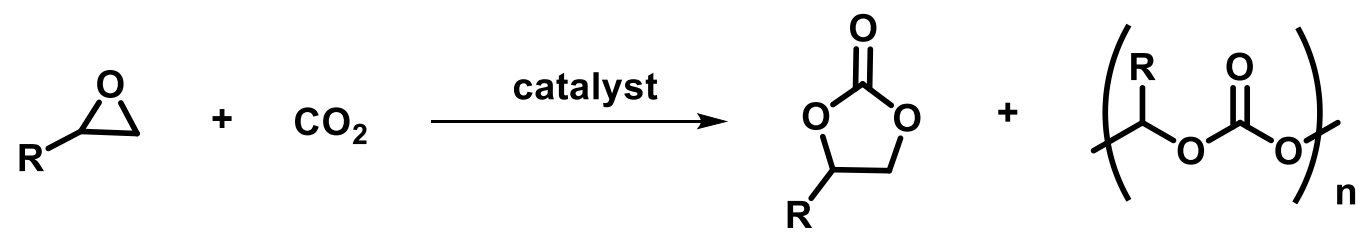

Scheme 1.3 Reaction of epoxides with $\mathrm{CO}_{2}$ to form cyclic carbonates and polycarbonates

\subsection{Carboxylation strategies to yield carboxylic acids}

The utilization of abundant and inexpensive $\mathrm{CO}_{2}$ has gained tremendous interest as a way to access carboxylic acids in an atom-economical manner. Carboxylic acids are versatile moieties in organic chemistry as they are common motifs in a variety of pharmaceuticals and are useful precursors to access alcohols, esters, and amides. One contemporary organometallic transformation with $\mathrm{CO}_{2}$ involves the carboxylation of organozinc reagents to yield carboxylic acids. The transformation is believed to proceed through an oxidative addition of $\mathrm{CO}_{2}$ to $\mathrm{Ni}(0)$ to generate Aresta's complex followed by transmetalation with the zinc reagent (Scheme 1.4$).{ }^{11}$ 
Reductive elimination would result in a new carbon-carbon bond, generating a zinc carboxylate that is hydrolyzed to afford the carboxylic acid product.
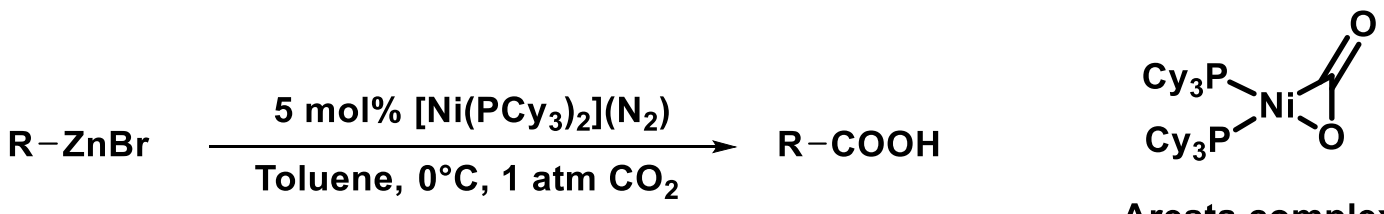

Aresta complex

Scheme 1.4 Carboxylation of organozinc reagents catalyzed by Aresta's complex

Two other organometallic pathways to access the carboxylic acid moiety utilize copper catalysis. Iwasawa reported a copper(I)-catalyzed carboxylation of aryl and alkenyl boronic esters under mild conditions. ${ }^{12}$ Another method by Daugulis utilizes copper catalysis to perform the carboxylation of aryl iodides. ${ }^{13}$ This process has excellent functional group tolerance with ester, bromide, chloride, fluoride, ether, amino, hydroxyl, and carbonyl functionalities. (Scheme 1.5).
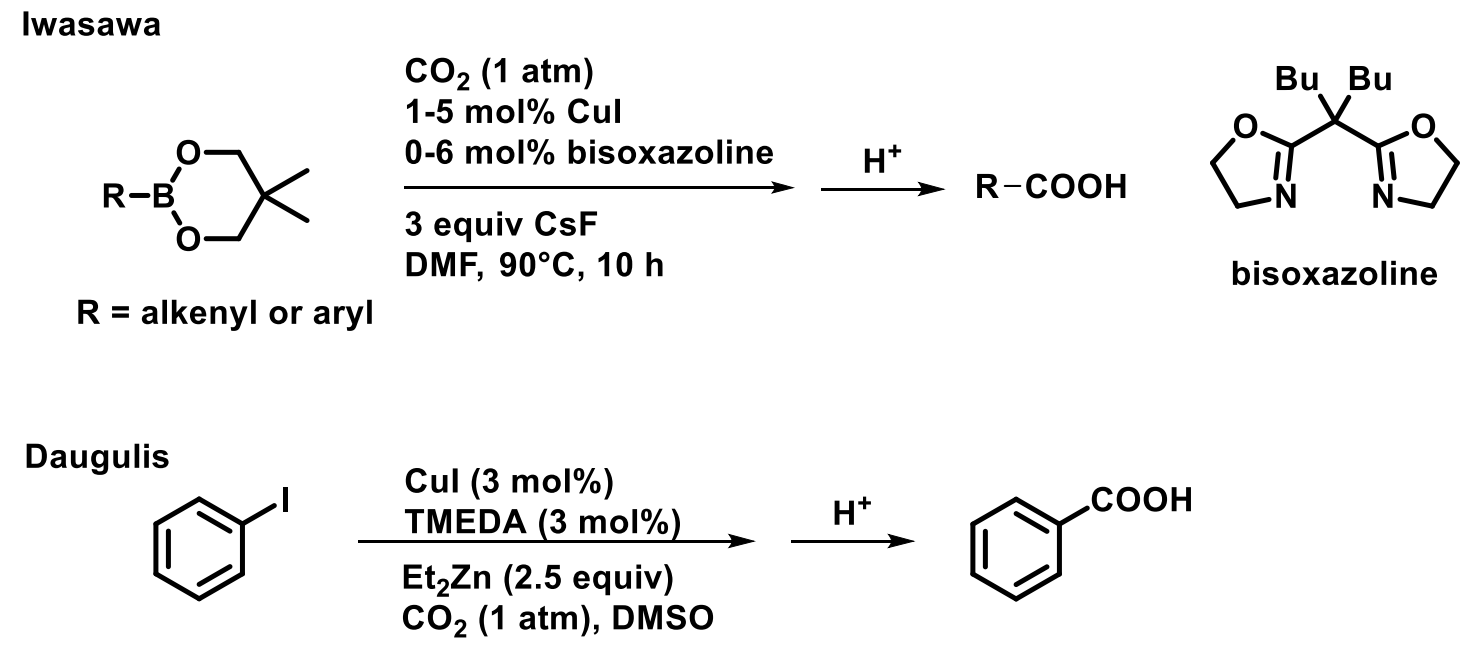

Scheme 1.5 Mild carboxylation of aryl halides and aryl boronic esters

The carboxylation of alkynes with $\mathrm{CO}_{2}$ could provide industrially relevant acrylic acids (Scheme 1.6). In 2011, Ma and co-workers developed the first example of a nickel-catalyzed regioselective hydrocarboxylation. It was the first nickel-catalyzed hydrozincation of alkynes to 
form syn selective alkenyl carboxylic acids mediated by cesium fluoride. ${ }^{14}$ It is proposed that the fluorine source reacts with $\mathrm{CO}_{2}$, increasing the reactivity of the carbon-oxygen double bond. Another protocol by Tsuji utilized a copper hydride species generated in situ from an $\mathrm{N}$ heterocyclic carbene bound copper fluoride and a hydrosilane, owing to the strong silicon-fluorine interaction. ${ }^{15}$ The copper hydride would then undergo insertion with the alkyne and subsequent reaction with $\mathrm{CO}_{2}$ to afford similar alkenyl carboxylic acids. These previously reported methodologies led to the development of a hydrocarboxylation strategy that avoided the use of airsensitive or organometallic reagents. The nickel-catalyzed process described by Martin still demonstrated excellent regioselective alkenyl carboxylic acids using commercially available, mild, and user-friendly alcohols as the proton source. ${ }^{16}$

$\mathrm{Ma}$

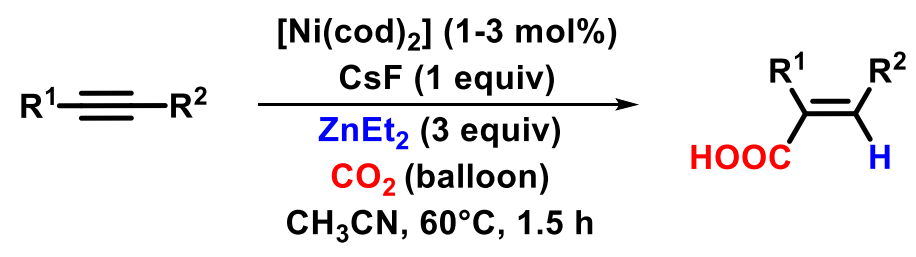

Tsuji
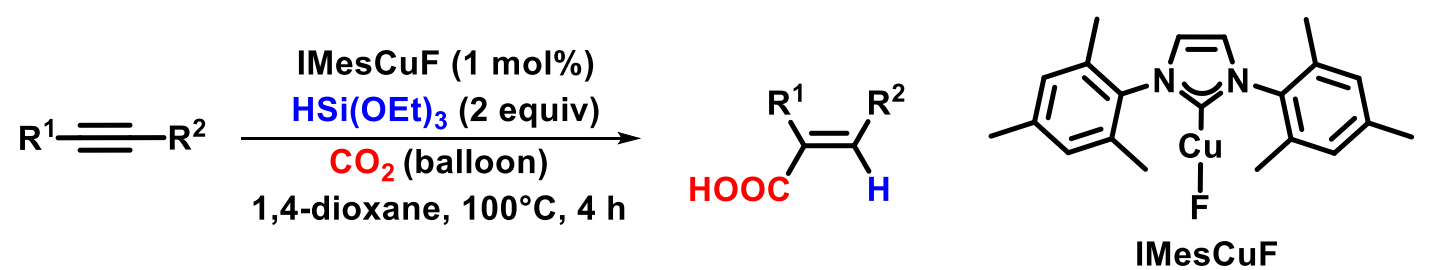

Martin
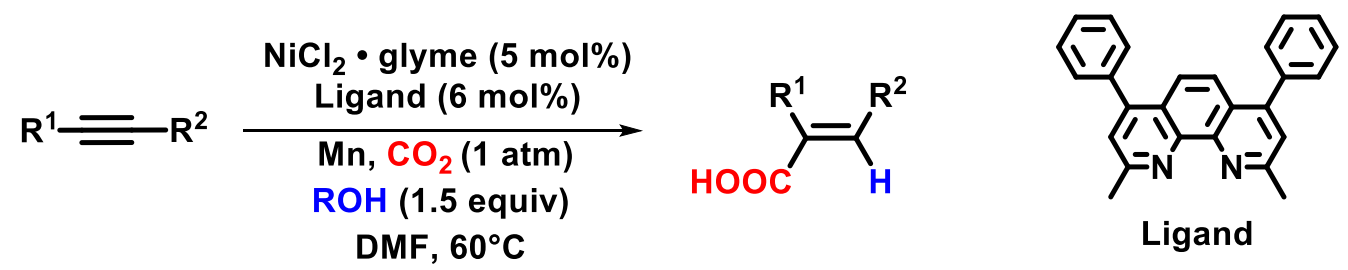

Ligand

Scheme 1.6 Selected examples of hydrocarboxylation of alkynes

Based on the catalytic systems involving the carboxylation of alkynes, the hydrocarboxylation of alkenes could also be implemented to achieve pharmaceutically relevant 
carboxylic acids. The important $\alpha$-aryl propionic acid pharmacophore is found in many nonsteroidal anti-inflammatory drugs (NSAIDs). In 2001, NSAIDs accounted for 70 million prescriptions and 30 billion over-the-counter medications used for pain and inflammation. ${ }^{17}$ Propionic acid derivatives comprise one of the largest class of these pain relievers (Figure 1.1). Due to their prevalence in pharmaceuticals, there are a number of transition metal-catalyzed processes to synthesize these moieties. Hydrocarboxylation of vinyl arenes has proven to be a viable route to access these NSAIDs (Scheme 1.7).

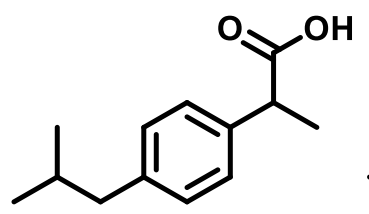

ibuprofen<smiles>COc1ccc2cc(C(C)C(=O)O)ccc2c1</smiles>

naproxen<smiles>CC(C(=O)O)c1cccc(C(=O)c2ccccc2)c1</smiles>

ketoprofen<smiles>CC(C(=O)O)c1cccc(Oc2ccccc2)c1</smiles>

fenoprofen<smiles>CC(C(=O)O)c1ccc(-c2ccccc2)c(F)c1</smiles>

flurbiprofen

Figure 1.1 Common $\alpha$-aryl propionic acid non-steroidal anti-inflammatory drugs (NSAIDs)

In 2008, Rovis reported a nickel-catalyzed hydrocarboxylation of vinyl arenes using diethyl zinc as the hydride source. ${ }^{18}$ This process is only tolerated for electron-deficient and electron-neutral styrene derivatives. A few years later, Thomas and co-workers were able to achieve the hydrocarboxylation of styrene substrates bearing electron-donating substituents. ${ }^{19}$ This protocol utilized an iron-catalyzed process starting from an inexpensive, nontoxic, bench-stable iron precatalyst. Excellent yields with control of regioselectivity were achieved through the use of a Grignard reagent bearing $\beta$-hydrogens. The iron hydride species generated is trapped by an alkene in a hydrometalation step and then reacted with carbon dioxide. A similar catalytic transformation uses $\mathrm{Cp}_{2} \mathrm{TiCl}_{2}$ as the catalyst and ${ }^{\mathrm{i}} \mathrm{PrMgCl}$ as the hydride source to gain access to $\alpha$-aryl carboxylic acids also bearing electron-donating groups. ${ }^{20}$ 
Rovis

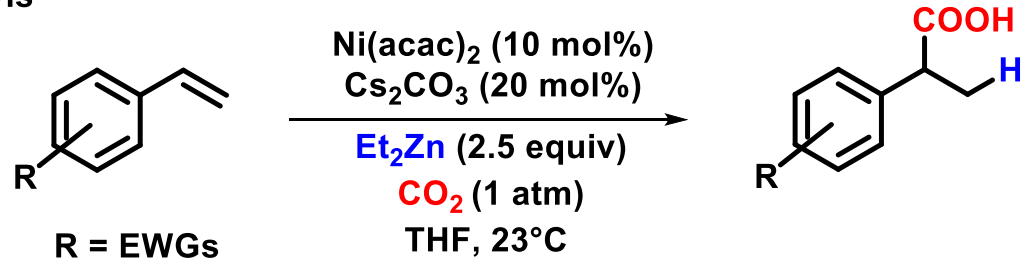

\section{Thomas}

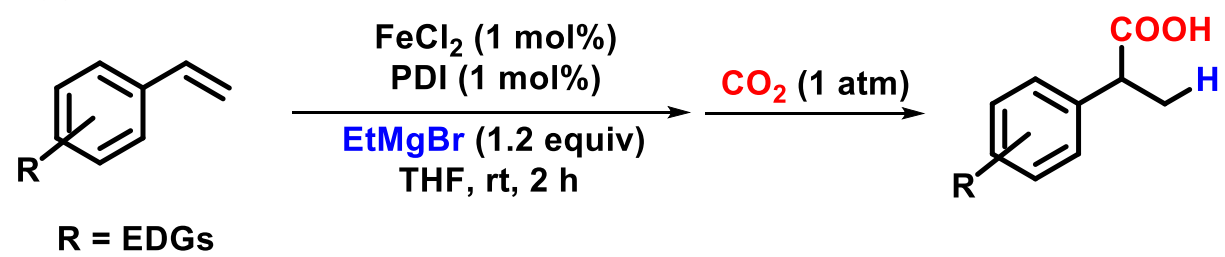

$\mathbf{X i}$

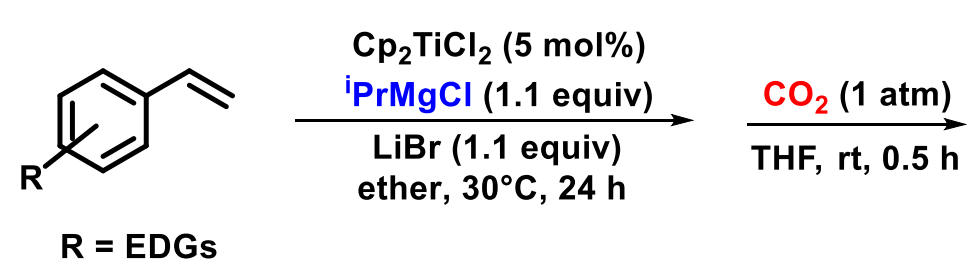

(C)

Scheme 1.7 Selected examples of hydrocarboxylation of vinyl arenes

Another interesting strategy to achieve these moieties is a hydroboration-carboxylation methodology. One approach to gain access to $\alpha$-aryl propionic acids is the generation of benzyl carbanions from styrenes. ${ }^{21}$ This route employs a copper-catalyzed Markovnikov hydroboration of styrenes. Attack of the bulky potassium tert-butoxide base at the boronic ester boron would generate the boronate that could then undergo heterolytic C-B bond cleavage (Scheme 1.8). The sterically induced cleavage gives a highly reactive benzyl carbanion that reacts with carbon dioxide. Another protocol relies on the hydroboration of vinyl arenes using 9-BBN followed by carboxylation with $\mathrm{CO}_{2}$ using a copper catalyst (Scheme 1.9), similar to Iwasawa's methodology described above. ${ }^{22}$ This chemistry was demonstrated with cyclic olefins, stilbenes, and styrenes. Terminal alkynes even underwent double carboxylation to produce malonic acid derivatives. 

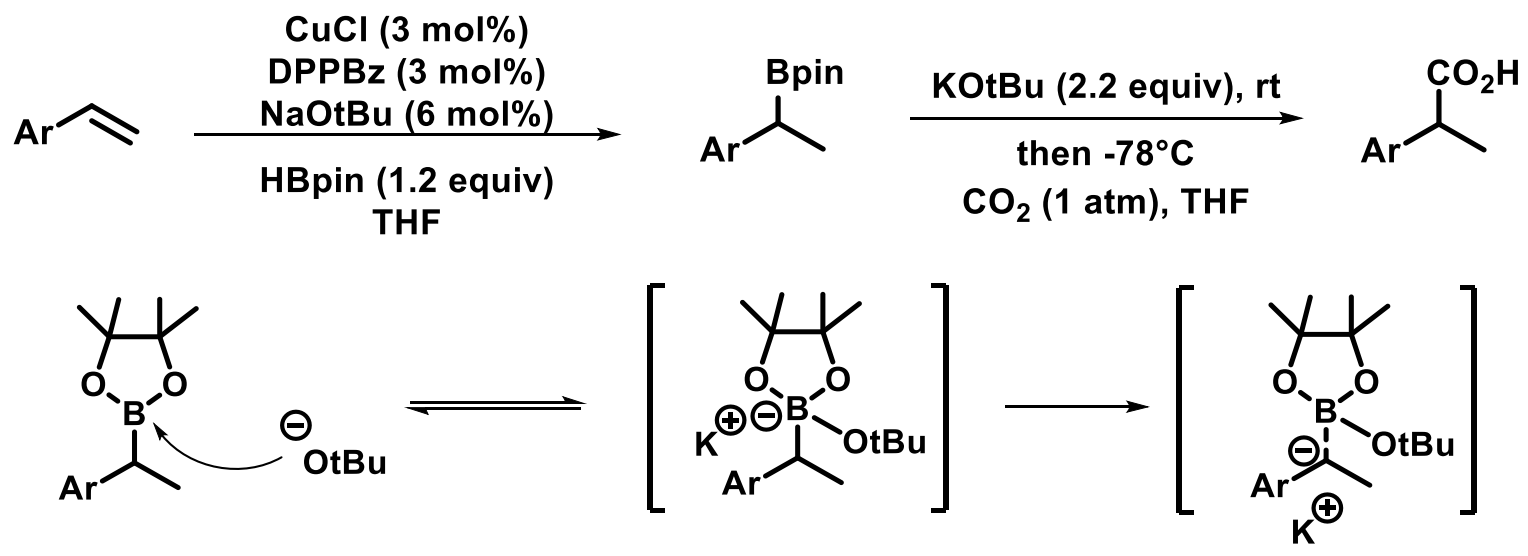

Scheme 1.8 Schomaker's hydroboration/carboxylation strategy

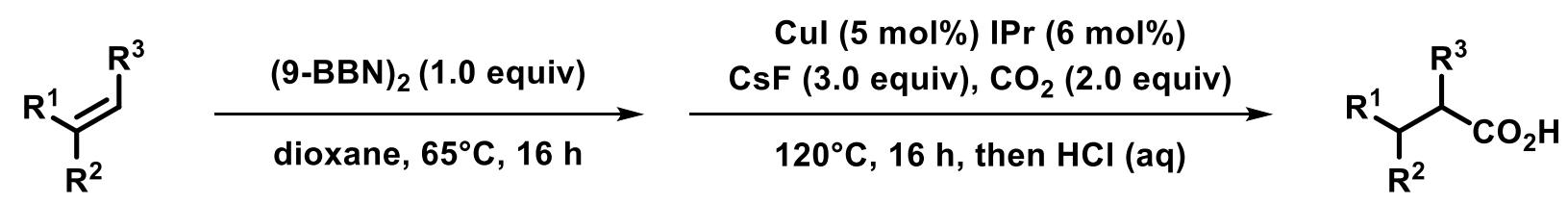

Scheme 1.9 Skrydstrup's hydroboration/carboxylation strategy

\subsection{Hetero(element)carboxylation to afford highly functionalized carboxylic acids}

Although hydrocarboxylation of vinyl arenes is a versatile transformation, there are a few drawbacks. The use of a reactive Grignard or zinc hydride source, as discussed above, results in limited functional group tolerance. This chemistry also proceeds through a reactive metal-hydride intermediate that can limit the scope of reactivity. A more appealing transformation includes the installation of $\mathrm{CO}_{2}$ and another hetero(element) in one step. This method would avoid reactivity issues previously observed in the hydrocarboxylation systems and install two functional groups in one step, accessing a more functionalized carboxylic acid product.

Hetero(element)carboxylations have been demonstrated for alkynyl and allenyl substrates using transition metal-catalyzed processes. Ma reported the first example of an antinucleometallation carboxylation of 2-alkynylanilines using $\mathrm{CO}_{2}$ activation. ${ }^{23}$ This coppercatalyzed process is an effective strategy to access indolyl-3-carboxylic acids and indolodihydropyran-2-ones in the presence of dimethylzinc and cesium fluoride (Scheme 1.10). Utilizing copper catalysis, the silacarboxylation of alkynes was achieved by using a silylborane as 
the silicon source. The sila-copper complex generated undergoes syn addition to the alkyne followed by $\mathrm{CO}_{2}$ insertion to afford silalactones in high yield. ${ }^{24}$ These unsaturated silalactones are excellent coupling partners under Hiyama cross-coupling conditions. In the same year, there was another similar difunctionalization with $\mathrm{CO}_{2}$ that was reported. Hou demonstrated the first catalytic boracarboxylation of alkynes to install Bpin and $\mathrm{CO}_{2}$ moieties across an unsaturated carbon-carbon triple bond. ${ }^{25}$ The diborane reagent, $\mathrm{B}_{2} \mathrm{pin}_{2}$, was used to access a boryl-copper complex ligated by a NHC ligand. Subsequent syn insertion of an alkyne into the copper-boron bond afforded a $\beta$-boryl alkenylcopper complex, which was isolated and crystallographically characterized (Figure 1.2). Nucleophilic addition of this intermediate to $\mathrm{CO}_{2}$ resulted in a cyclic structure in which the boron atom is bound to the carboxylate unit and the NHC-copper moiety is bonded to an oxygen atom of the boronic ester group. This structure was revealed through X-ray crystallographic analysis (Figure 1.2). Transmetalation finally afforded unsaturated boralactonate salt products.

$\mathrm{Ma}$
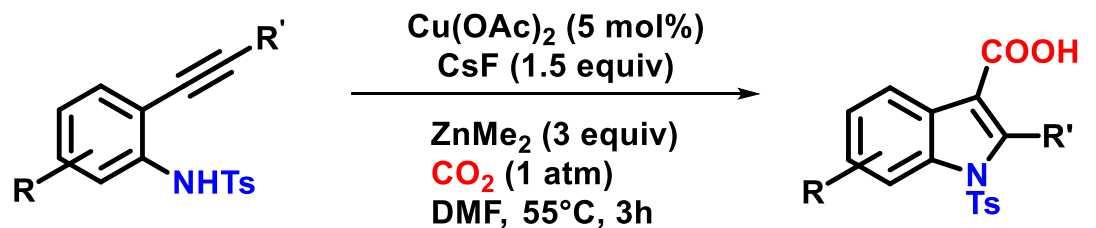

Tsuji
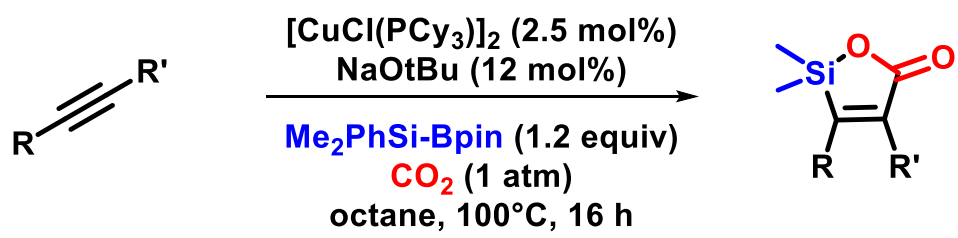

octane, $100^{\circ} \mathrm{C}, 16 \mathrm{~h}$

Hou
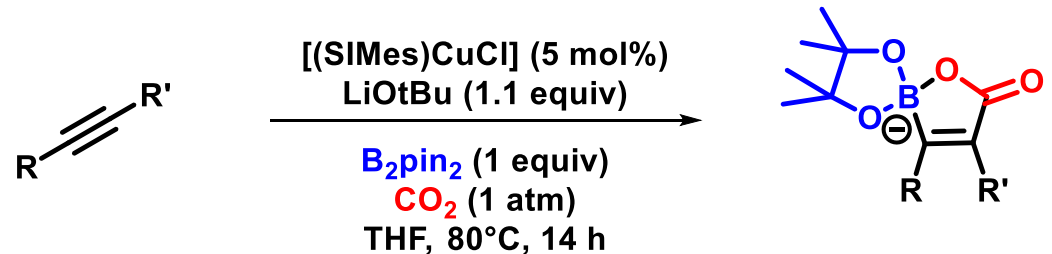

Li $^{\oplus}$

Scheme 1.10 Hetero(element)carboxylation of alkynes 

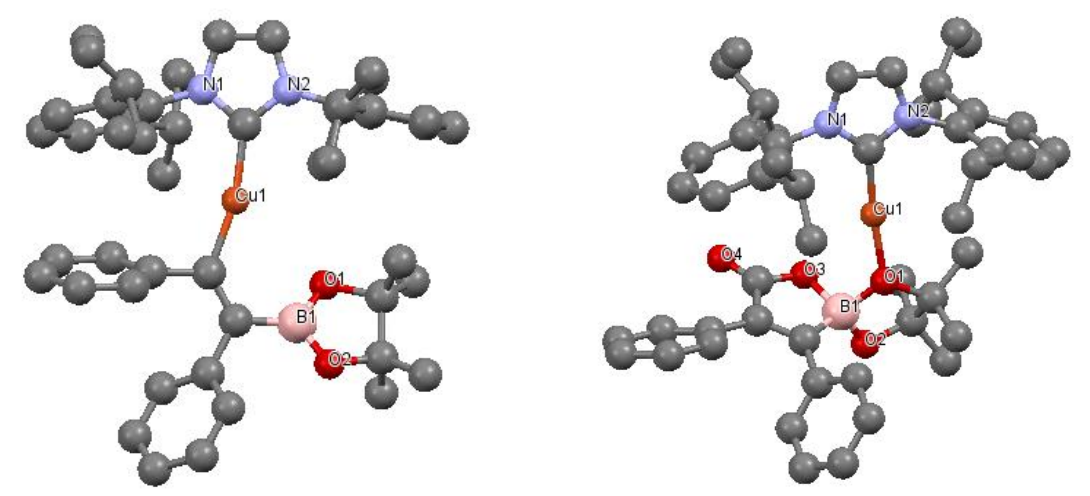

Figure 1.2 Crystal structures of the boracarboxylation of alkyne intermediates: alkyne insertion into $\mathrm{Cu}$-Bpin (left) and $\mathrm{CO}_{2}$ insertion step (right) ${ }^{26}$

The latter transformation is of particular interest to the Popp group due to the installation of the boron functionality. Boron has been long overlooked for its use in pharmaceuticals; however, recently it has gained more attention as an attractive moiety in medicine (Figure 1.3). Previously, there was a common belief that boron was toxic likely due to the fact that boric acid is an ingredient in ant poisons. ${ }^{27}$ Boric acid is also the main ingredient in the children's toy, Slime, with a $\mathrm{LD}_{50}$ similar to table salt. ${ }^{28}$ There is evidence that humans and animals use boron to play a role in calcium metabolism, bone growth, and insulin metabolism. ${ }^{29}$ A study in postmenopausal women showed that by increasing the amount of boron in their diet, it lead to more plasma estrogen and less calcium excretion, helping with the potential of bone loss. ${ }^{30}$

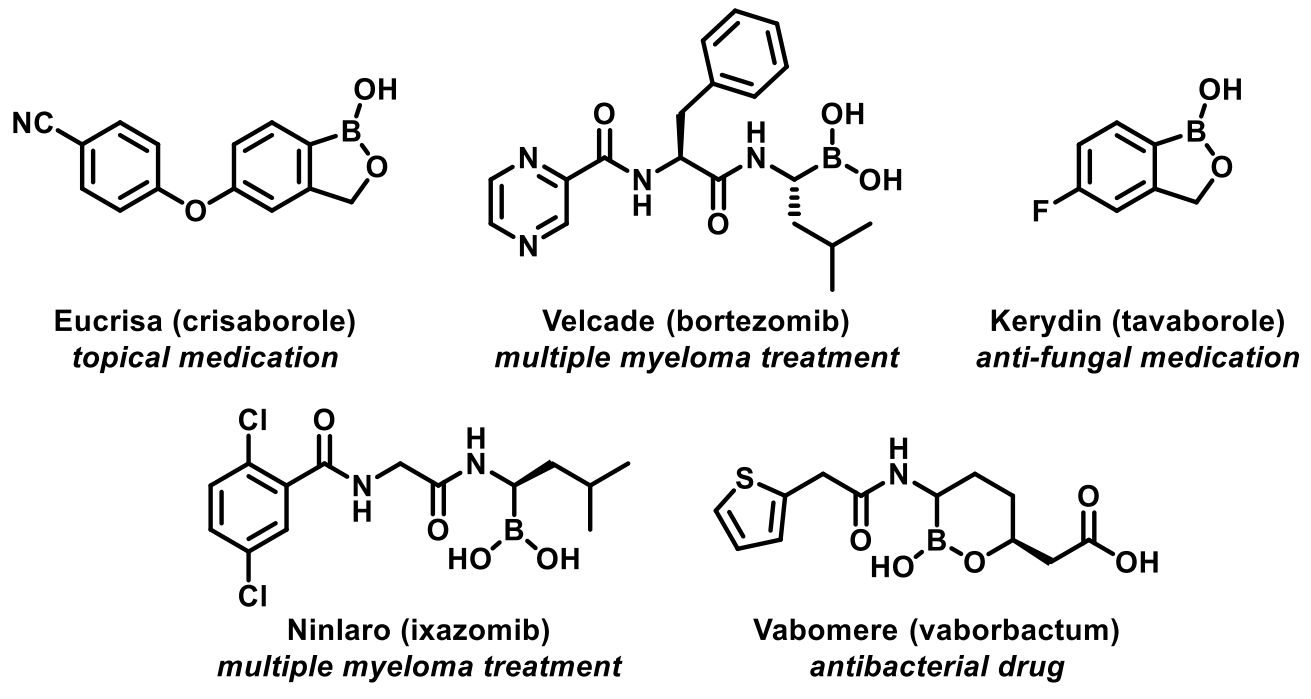

Figure 1.3 Boron-containing therapeutics approved by the US Federal Drug Administration 


\subsection{Borylcopper-catalyzed borylation reactions}

The idea of installing two functional groups in one step and the attractiveness of boron in organic molecules inspired the Popp group to investigate a transformation involving borylation chemistry. Borylcopper-catalyzed borylation is a highly effective route to access organoboron species that can be used for further derivatization in synthesis. ${ }^{31}$ The first example of an isolated borylcupration of a carbon-carbon unsaturated bond was reported by Sadighi and coworkers. ${ }^{32}$ It was demonstrated that styrene could regioselectivity insert into (IPr)CuBpin to give a $\beta$-boroalkyl complex, which was characterized crystallography (Scheme 1.11). Density functional theory (DFT) calculations showed that the regioselectivity of the insertion relies on the interaction between the filled $\mathrm{Cu}-\mathrm{B} \sigma$ molecular orbital and the alkene $\pi^{*}$ molecular orbital. ${ }^{33}$ This implies that the strong nucleophilicity of the $\mathrm{Cu}-\mathrm{B}$ bond and the electrophilicity of the alkene substrate both need to be considered to understand the regioselectivity observed through experimentation.
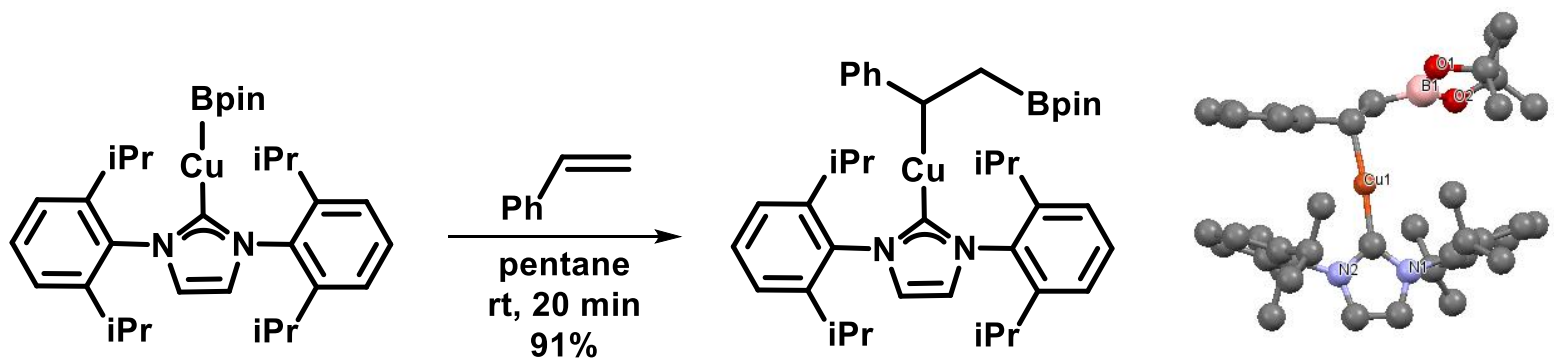

Scheme 1.11 Insertion of styrene into (IPr)CuBpin ${ }^{26}$

This type of alkene insertion into a $\mathrm{Cu}-\mathrm{Bpin}$ bond is also observed within catalytic systems. In the same year, Yun and coworkers took advantage of similar chemistry to achieve the hydroboration of $\alpha, \beta$-unsaturated carbonyl compounds. ${ }^{34}$ The $\mathrm{Cu}-\mathrm{OtBu}$ pre-catalyst reacts with the diboron source, $\mathrm{B}_{2}$ pin 2 , to generate the versatile $\mathrm{Cu}$-Bpin intermediate. Syn addition of the borylcopper to the double bond, followed by protonation by methanol, results in the formation of the desired hydroboration product and a copper alkoxide (Scheme 1.12). This is an efficient methodology for conjugate addition to unsaturated carbonyl compounds using catalytic amounts 
of $\mathrm{CuCl}, \mathrm{NaOtBu}$, and DPEphos with a cheap, alcohol additive. The first reported example of a copper-boryl complex used for conjugate addition was described by Miyaura. ${ }^{35} \mathrm{~A} \mathrm{CuCl} / \mathrm{KOAc}$ and diboron reagent mixture was employed to add a Bpin moiety to an enone in a similar manner. Hoveyda demonstrated the copper-catalyzed hydroboration of styrene derivatives could be achieved enantioselectively using a bidentate imidazolinum salt (Scheme 1.13). ${ }^{36}$
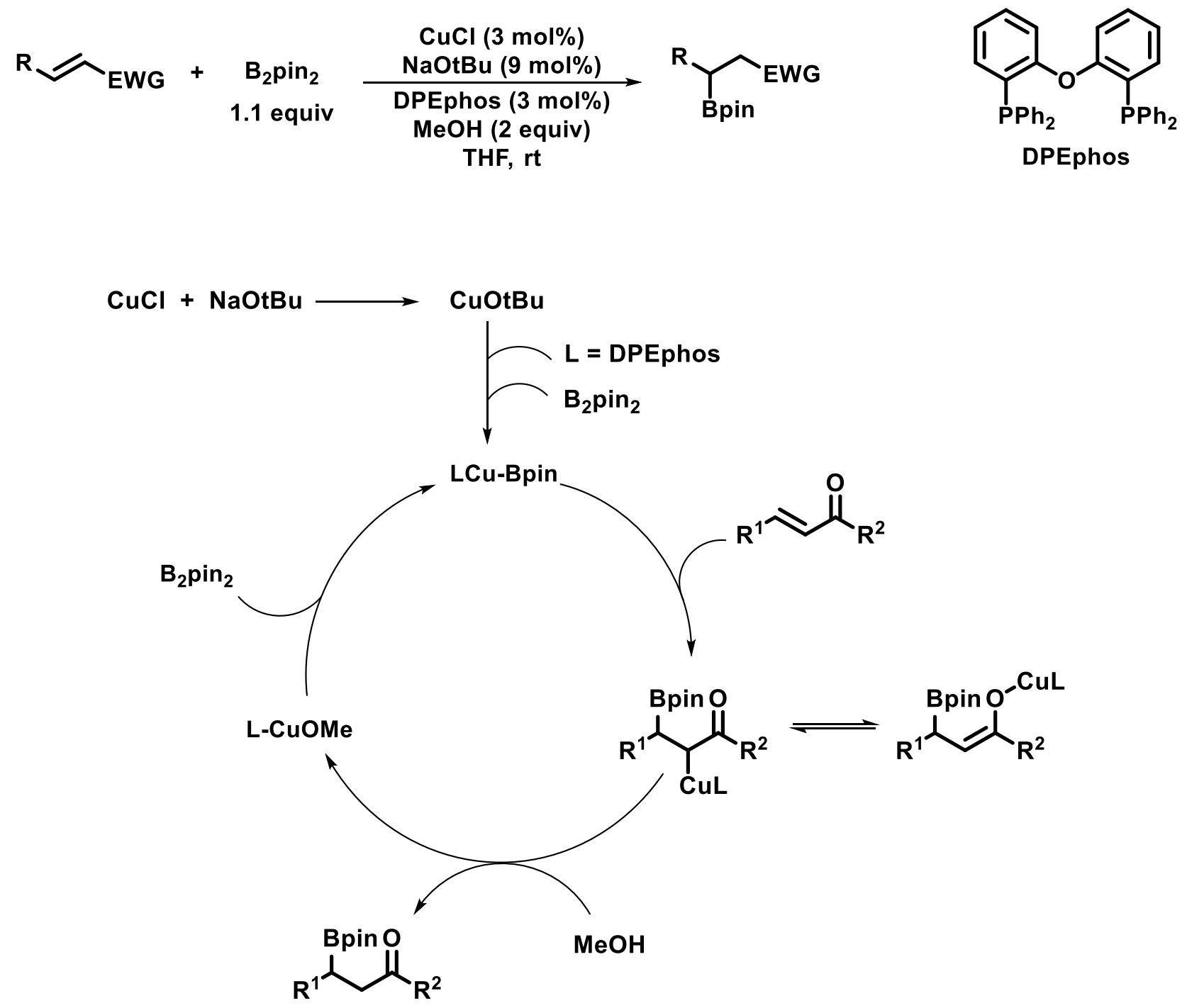

Scheme 1.12 Hydroboration transformation and mechanism using alkene insertion into $\mathrm{Cu}-\mathrm{Bpin}$ 


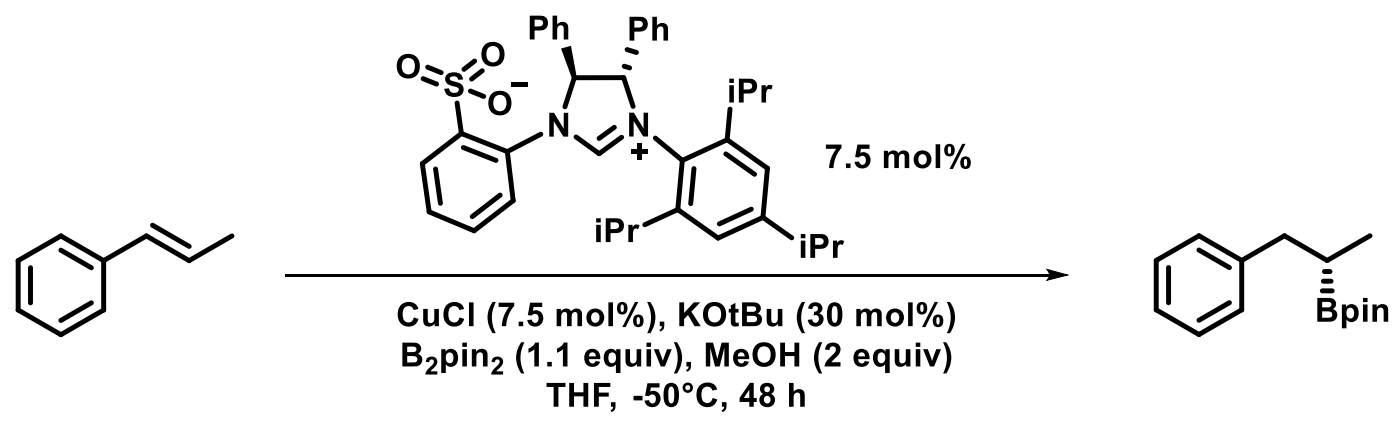

Scheme 1.13 Copper-catalyzed enantioselective hydroboration

Another interesting class of reactions known as carboboration involves the copper-boryl species capturing an alkyl electrophile. High yields have been observed in these cases due to either a more stable organocopper intermediate, more reactive methyl and benzylic electrophiles, or an intramolecular alkylation step. ${ }^{37}$ One protocol relies on the intramolecular alkylation mechanism to achieve cyclopropane derivatives. ${ }^{38}$ The selectivity for this reaction is driven by the interaction between the $\sigma$ of the $\mathrm{Cu}-\mathrm{C}$ and $\sigma^{*}$ of the $\mathrm{Si}-\mathrm{C}$ orbitals in the copper-boryl addition product (Scheme 1.14). This intermediate undergoes subsequent nucleophilic substitution to afford boron-silicon difunctional cyclopropanes. The synthetic versatility of these products was also investigated by subjecting the Bpin moiety to Suzuki-Miyaura cross-coupling conditions and then transforming the silicon to an alcohol through Tamao oxidation. Yoshida and co-workers also reported an example of a carboboration of alkenes involving a three component coupling with $\mathrm{B}_{2} \mathrm{pin}_{2}$ and an external carbon electrophile. ${ }^{39}$ This methodology takes advantage of using a reactive benzyl chloride electrophile under NHC-ligated copper catalyst conditions (Scheme 1.14). Recently, these copper-catalyzed alkylborations of alkenes have been extended to provide the first enantioselective example by Liao and co-workers. ${ }^{40}$ The alkylboration of styrenes was achieved by utilizing a chiral sulfoxide phosphine ligand developed in their own lab to install a singularly significant methyl group (Scheme 1.14). This protocol has proven to be an efficient method for the installation of a methyl group to achieve high yield and enantioselectivity of the pharmaceutically relevant NSAID, naproxen, after oxidation conditions. This chemistry also showed success in the late-stage functionalization of steroid derivatives. 

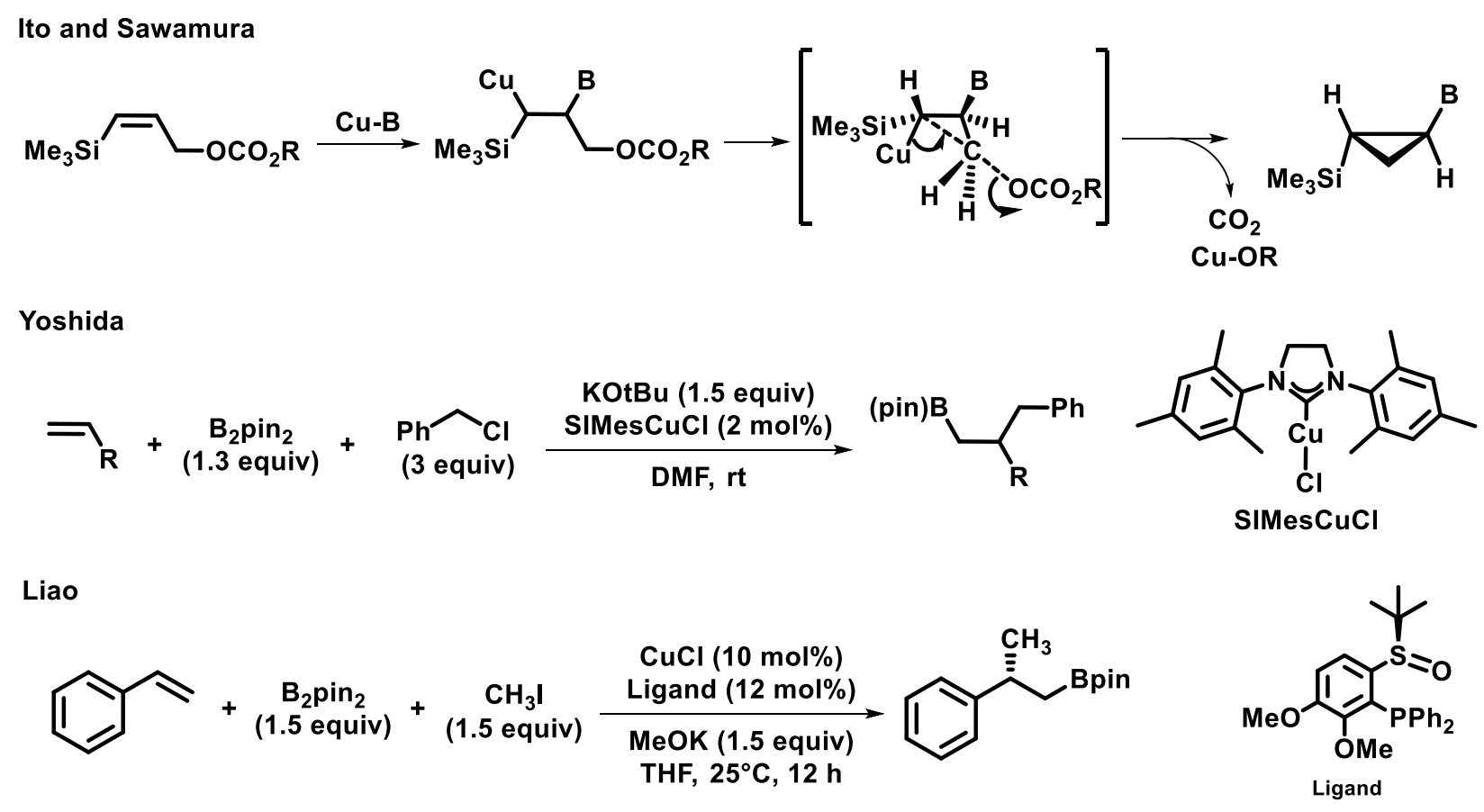

Scheme 1.14 Selective examples of carboboration utilizing copper-boryl species

Aminoboration is another transformation that utilizes the versatile copper-boryl complex. The catalytic cycle is similar to carboboration but using an amine electrophile to achieve the difunctionalization. One example focuses on the reaction of a cyclopropene with a O-benzoyl$N, N$-dialkylhydroxylamine and a diboron source to access highly functionalized cyclopropylboronates (Scheme 1.15). ${ }^{41}$ The capture of the cyclopropylcopper intermediate with electrophilic amines is significant due to the importance of cyclopropylamines in biologically active compounds. This is an interesting methodology to achieve three neighboring stereocenters. A similar process was carried out by Miura to perform the aminoboration of styrenes ${ }^{42}$ (Scheme 1.15). Using the same amine electrophile, $\mathrm{B}_{2} \mathrm{pin}_{2}$, and a chiral copper catalyst, the difunctionalization showed high regio- and stereoselectivity. Miura was also able to expand this reactivity to demonstrate a ligand-controlled regiodivergent copper-catalyzed aminoboration ${ }^{43}$ (Scheme 1.15). The xantphos-complexed copper results in the selectivity of the Bpin on the terminal position and the amino group on the internal position. The opposite regioisomer was observed under NHC-bound copper conditions. Both methods produce highly functionalized $\beta$ borylalkylamines. 
Tortosa

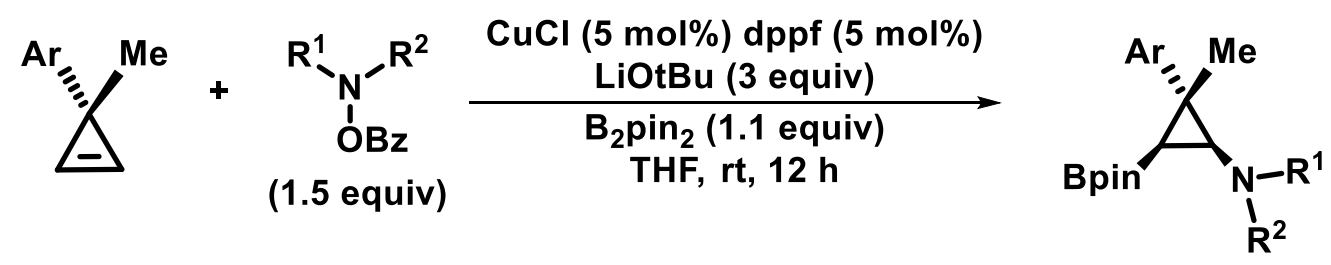

Miura

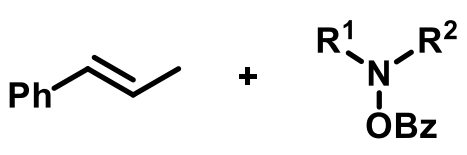

(1.5 equiv)

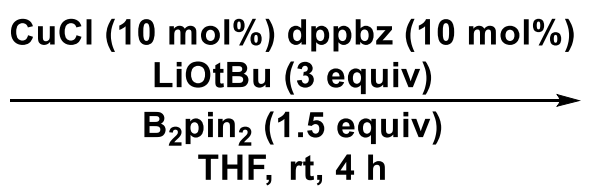

THF, rt, 4 h

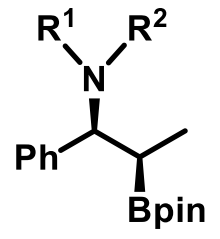

Miura

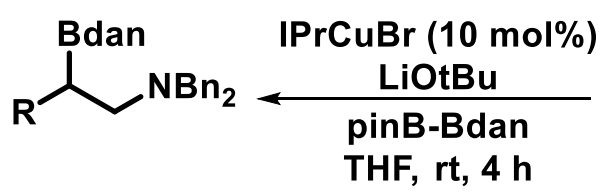

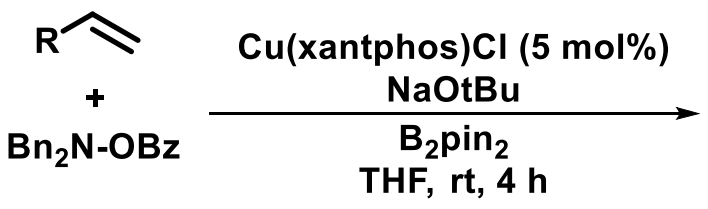

Scheme 1.15 Selective examples of aminoboration utilizing copper-boryl species

\subsection{Carbon dioxide insertion into alkyl species utilizing copper catalysis}

The previous section discussed many examples where alkenes are capable of inserting into copper-boryl species and then undergoing subsequent trapping with an electrophile to form difunctionalized products. Using this literature precedent, the Popp group was interested in taking advantage of this chemistry and partnering it with carboxylation chemistry, which its importance was described in previous sections of this introduction. Fortunately, there are examples in the literature where copper species can facilitate carbon dioxide insertion. Sadighi and co-workers reported a two-coordinate copper complex that could readily insert $\mathrm{CO}_{2}$ into a copper-methyl bond to form a copper acetate complex. ${ }^{44}$ This reaction occurred in near-quantitative yield and the isolated product was characterized crystallography (Scheme 1.16). Another example involves the carboxylation of alkyl boranes with carbon dioxide. ${ }^{45}$ The $[\mathrm{IPrCu}(\mathrm{OMe})]$ catalyst was mixed with alkyl borane and an adduct was obtained due to the interaction between the oxygen of the methoxy 
group and the boron atom (Scheme 1.17). When subjected to heat at $70^{\circ} \mathrm{C}$ under an atmosphere of $\mathrm{CO}_{2}$, the carboxylate complex was observed in high yield. Both the adduct intermediate and carboxylate showed high catalytic activity for the carboxylation of alkyl boranes, suggesting that these are the active catalysts in this system. This fundamental work also confirms that a bonding interaction between a metal alkoxide and organoboron is a critical step in many of these types of transition metal-catalyzed processes.
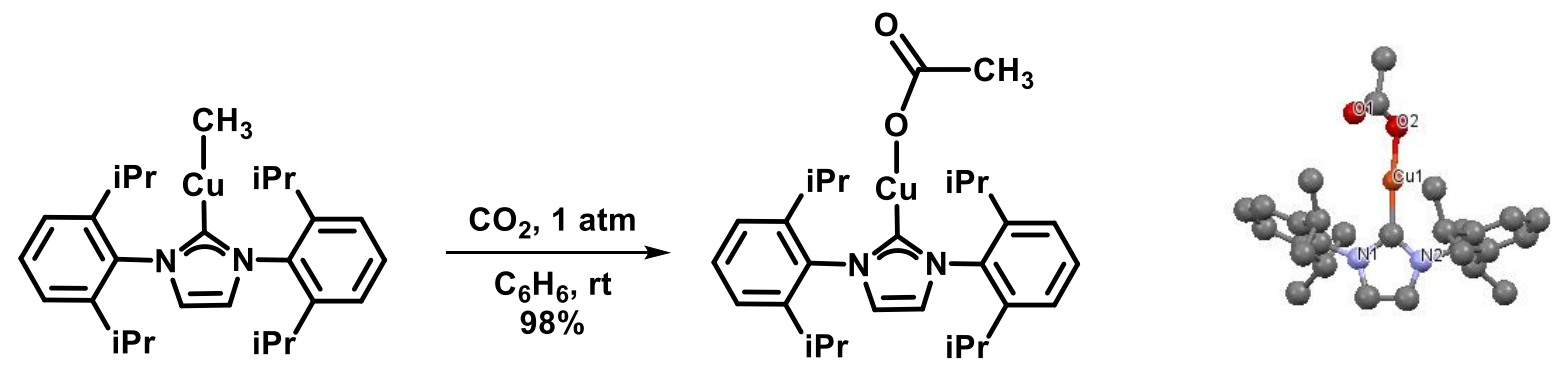

Scheme 1.16 Carbon dioxide insertion into copper-alkyl bond and X-ray structure ${ }^{26}$
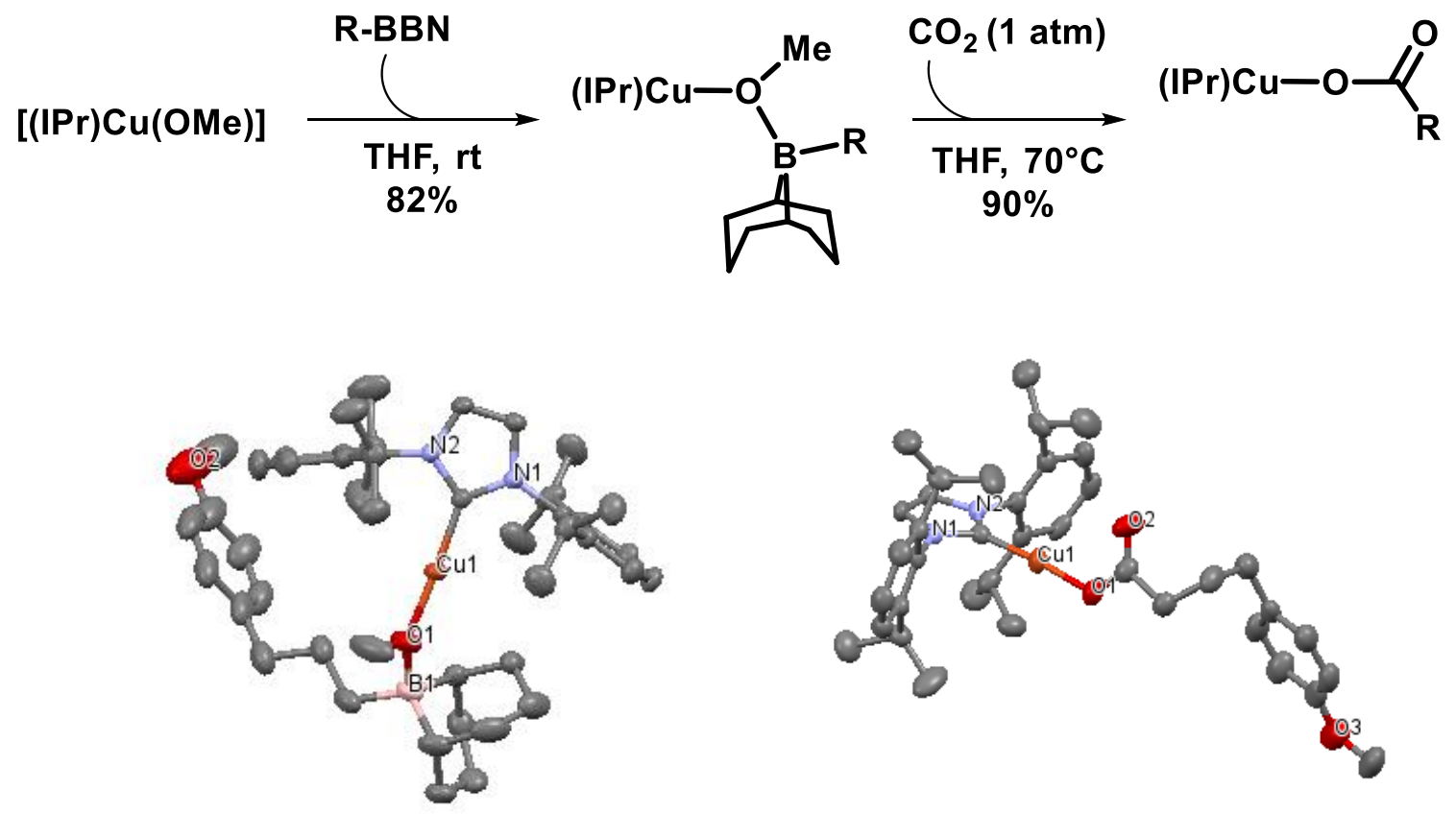

Scheme 1.17 Carboxylation of alkyl boranes with $\mathrm{CO}_{2}$ : X-ray structure of alkyl borane adduct intermediate (left) and $\mathrm{CO}_{2}$ insertion step (right) ${ }^{26}$ 


\subsection{Boracarboxylation of vinyl arenes}

The Popp group is interested in the utilization of $\mathrm{CO}_{2}$ to generate carboxylic acids, particularly $\alpha$-phenyl propionic acids. The importance of this pharmacophore in NSAIDs has prompted the design of a carboxylation strategy to transform vinyl arenes. With the recent attractiveness of boron in therapeutics, there is motivation to perform boracarboxylation difunctionalization chemistry. As discussed in the two previous sections, there is literature precedent for the insertion of alkenes into $\mathrm{Cu}$-boryl species and insertion of $\mathrm{CO}_{2}$ into $\mathrm{Cu}$-alkyl complexes. Based on the interests of the Popp group, a mechanism was proposed for the boracarboxylation of vinyl arenes (Scheme 1.18). The $\mathrm{Cu}-\mathrm{OtBu}$ pre-catalyst could undergo methathesis to generate a $\mathrm{Cu}$-Bpin that subsequently inserts the vinyl arene substrate. By overcoming side pathways of $\beta$-hydride elimination and protonation, $\mathrm{CO}_{2}$ could then undergo insertion into the copper-alkyl. The carboxylate product would be afforded from the transmetalation with a metal alkoxide to turn over the catalytic cycle.
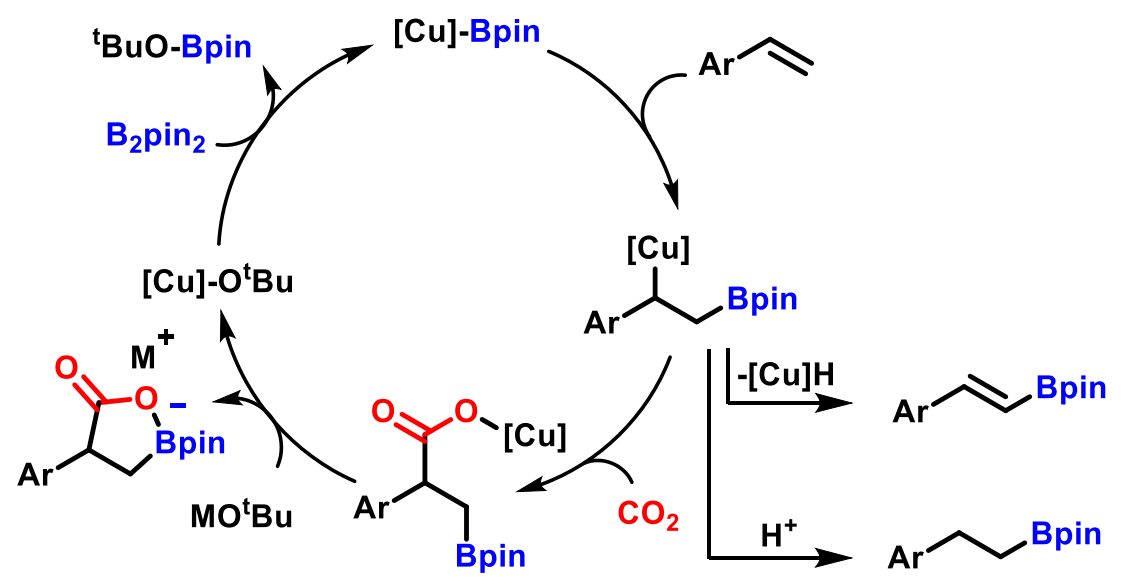

Scheme 1.18 Proposed mechanism for the boracarboxylation of vinyl arenes

Based on the plausible mechanism described above, the Popp group first sought to screen copper catalysts that would be able to achieve boracarboxylated styrene as the major product (Table 1.1). ${ }^{46}$ One side product could arise by way of protodemetallation of the copper-boryl insertion intermediate to afford the formal hydroboration product, which is labeled as 2 in Table 
1.1. The other side product observed during screening is due to a $\beta$-hydride elimination pathway from the versatile copper-boryl insertion intermediate, labeled as 3 . The first trend observed is that there is a necessity for an electron-donating ligand complexed to the copper metal. The yield of desired boracarboxylated product increases as the phosphine has more donating character, which is observed from exchanging the phenyl groups to alkyl substituents (Table 1.1, entries 1-4). When attempting to test bisphosphines for catalytic activity (Table 1.1, entries 5-7), the yield is significantly diminished when compared to the mono-coordinating tricyclohexylphosphine $\left(\mathrm{PCy}_{3}\right)$. Based on previous systems in the literature, NHC ligands have also shown success in similar copper catalysis. When screening NHC ligands (Table 1.1, entries 8-11), the ICyCuCl achieved a very high yield of boracarboxylated product. The control study was also performed (Table 1.1, entry 12) to confirm a ligand is necessary for the catalysis to occur.

Table 1.1 Copper catalyst optimization for boracarboxylation of vinyl arenes

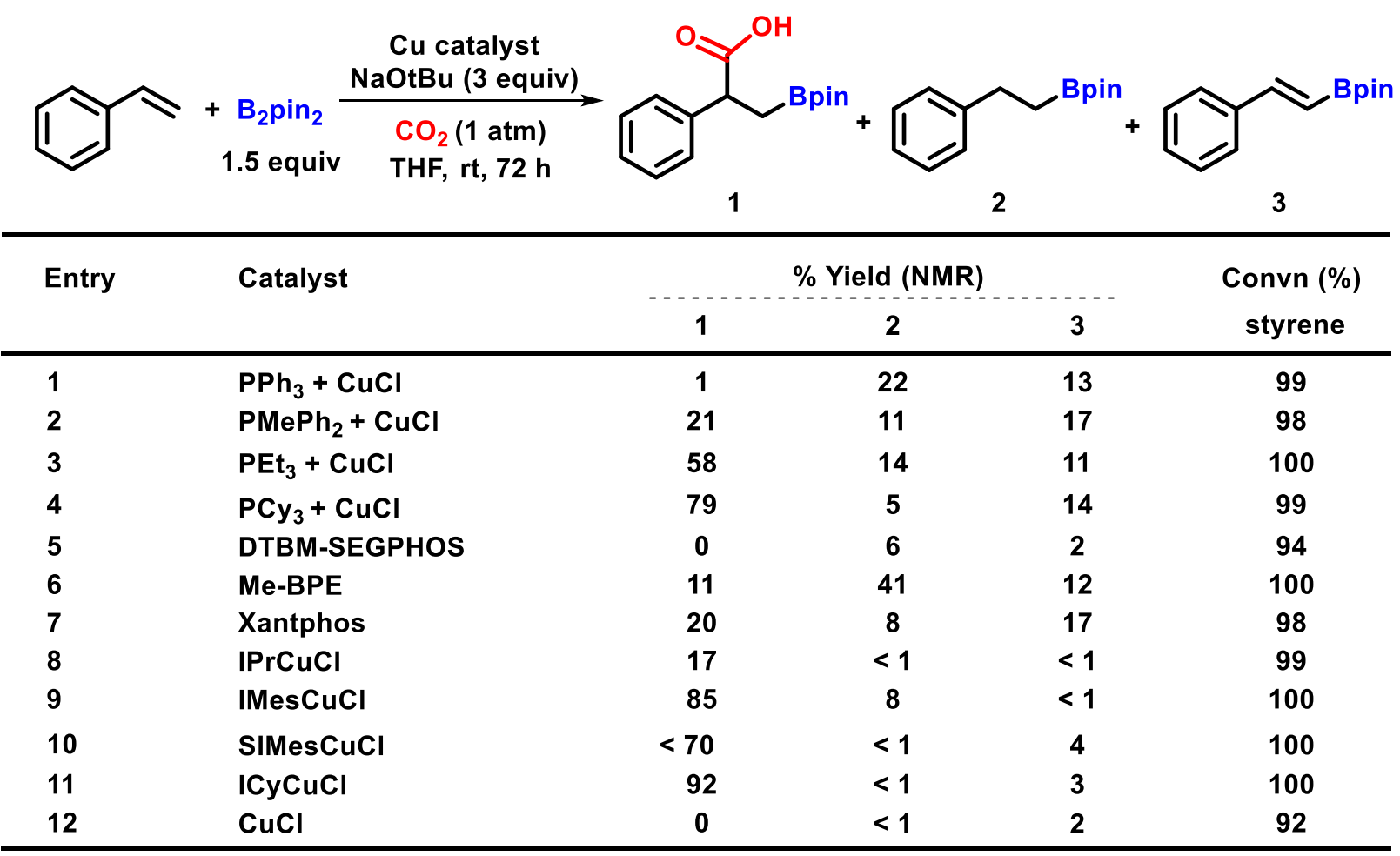

Styrene $(0.25 \mathrm{mmol})$ in THF $(4 \mathrm{~mL})$. Reactions quenched with $1 \mathrm{M} \mathrm{HCl}$. Catalyst system: $\mathrm{CuCl}(12 \mathrm{~mol} \%)$ and phosphine ligand (13 $\mathrm{mol} \%$ ) or $(\mathrm{NHC}) \mathrm{CuCl}(12 \mathrm{~mol} \%)$. Yield and conversion were determined by ${ }^{1} \mathrm{H}$ NMR spectroscopy using mesitylene as the internal standard. 
After optimization of the catalyst system and reaction conditions, the scope of the reaction was investigated. The boracarboxylation of vinyl arenes tolerated a number of styrene derivatives, as shown in the abbreviated substrate scope, Table 1.2. The catalysis was successful with substrates bearing a donating group in the para position such as the tert-butyl, methyl, methoxy, phenoxy, protected amide, naphthyl, and isobutyl groups. The reaction showed good yield for the slightly electron-withdrawing fluorostyrene. When extending the substrate scope to meta- and orthosubstituted styrenes, the yield diminished, which is demonstrated with the para-, meta-, and orthofluoro derivatives in Table 1.2. Unfortunately, the reaction did not tolerate electron-withdrawing groups, as observed with the para-trifluoromethyl analogue.

Table 1.2 Representative examples of boracarboxylation substrate scope
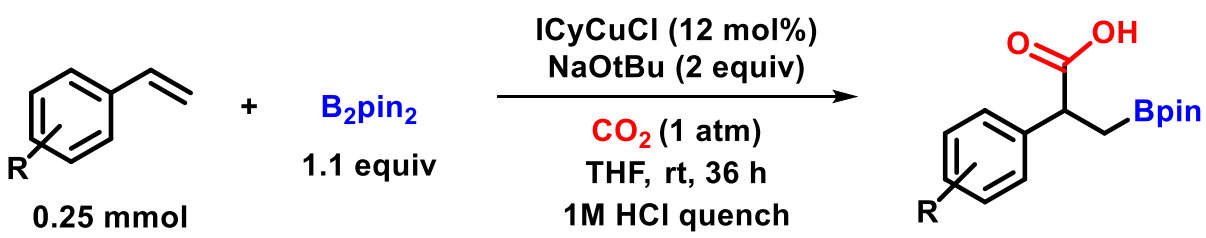<smiles>O=C(O)C(CBr)c1ccccc1</smiles>

82<smiles>O=C(O)C(CBr)c1ccc(Oc2ccccc2)cc1</smiles>

86<smiles>O=C(O)C(CBr)c1ccc(F)cc1</smiles>

63<smiles>CC(C)(C)c1ccc(C(C[R18](=O)c2ccccc2)C(=O)O)cc1</smiles>

86<smiles>CC(=O)N(C)c1ccc(C(C[R18](=O)c2ccccc2)C(=O)O)cc1</smiles>

42<smiles>O=C(O)C(C[18O]c1ccccc1)c1cccc(F)c1</smiles>

22<smiles>Cc1ccc(C(CC(C)C)C(=O)O)cc1</smiles>

79<smiles>COc1ccc2cc(C(CCc3ccccc3)C(=O)O)ccc2c1</smiles>

58<smiles>O=C(O)C(C[18CH2]c1ccccc1)c1ccccc1F</smiles>

17<smiles>COc1ccc(C(C[R18](=O)c2ccccc2)C(=O)O)cc1</smiles>

88<smiles>CC(C)Cc1ccc(C(CCc2ccccc2)C(=O)O)cc1</smiles>

86<smiles>O=C(O)C(Cc1ccccc1)c1ccc(C(F)(F)F)cc1</smiles>

0 
Due to the high yield and ease of purification, a gram-scale boracarboxylation of the tertbutylstyrene was carried out (Scheme 1.19). The ability to scale up the reaction would be necessary to demonstrate the relevance of these products in a pharmaceutical application. It is also important to perform this transformation on a larger scale to explore its synthetic utility. The crystallization of the tert-butyl analogue afforded the crystal structure to confirm the regioselectivity of the carboxylic acid and Bpin moieties (Figure 1.4, Appendix I).

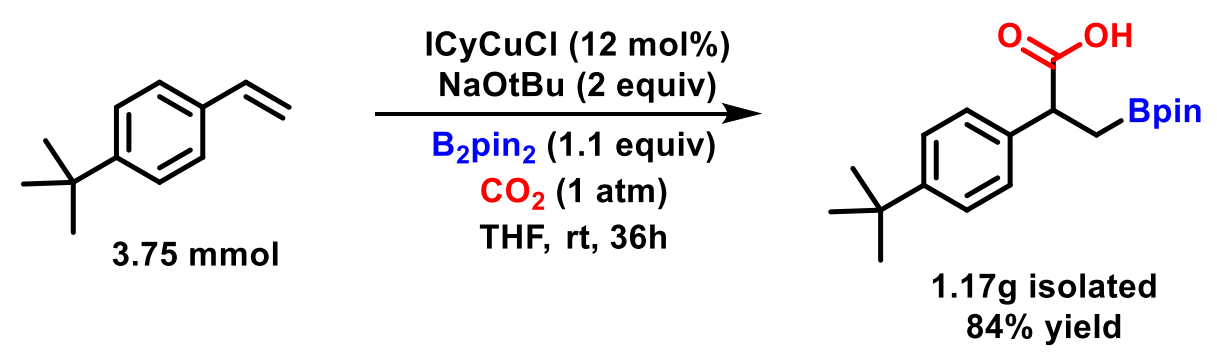

Scheme 1.19 Gram-scale boracarboxylation of tert-butylstyrene

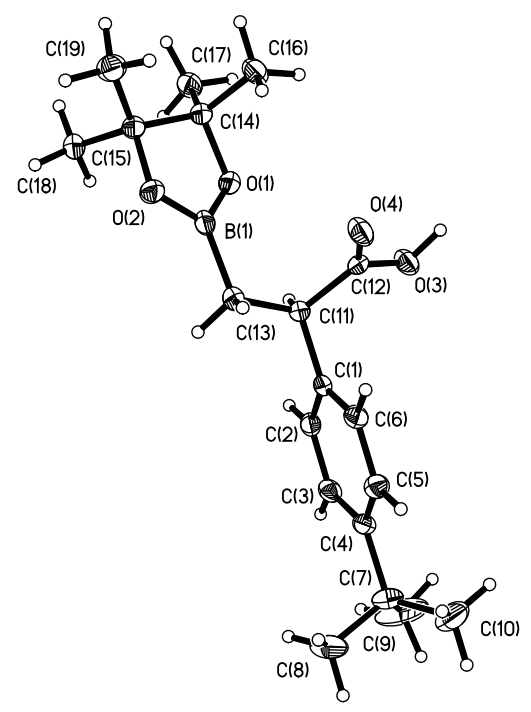

Figure 1.4 X-ray crystal structure of boracarboxylated tert-butylstyrene

Based on the preliminary findings for the boracarboxylation of vinyl arenes, the following chapters will detail the ability to lower catalyst loading in this catalytic system, expansion of substrate scope, and synthetic utility of the products. 
Since our publication, hetero(element)carboxylations have been achieved through visiblelight photoredox catalysis. This area of research highlights the versatility and utility of the hetero(element)carboxylation of alkenes. The Martin group demonstrated a catalytic intermolecular dicarbofunctionalization of styrenes with the use of $\mathrm{CO}_{2}$ under blue-light emitting diode (LED) irradiation. ${ }^{47}$ This provides a mild protocol to install a trifluoromethyl group and carboxylic acid moiety in one step (Scheme 1.20). In the same year, Yu published an ironpromoted methodology to achieve the first example of thiocarboxylation of styrenes and acrylates. ${ }^{48}$ These $\beta$-thioacids were produced in the opposite regioselectivity that is commonly observed in these systems with the carboxylic acid installation in the terminal position (Scheme 1.20). Only one year later, a similar process used a visible-light promoted and metal-free difunctionalization to achieve a silacarboxylation of alkenes. ${ }^{49}$ Through the combination of photoredox and hydrogen-atom transfer catalysis, a number of $\beta$-silacarboxylic acids are directly accessed from simple alkene starting materials (Scheme 1.20).

Martin
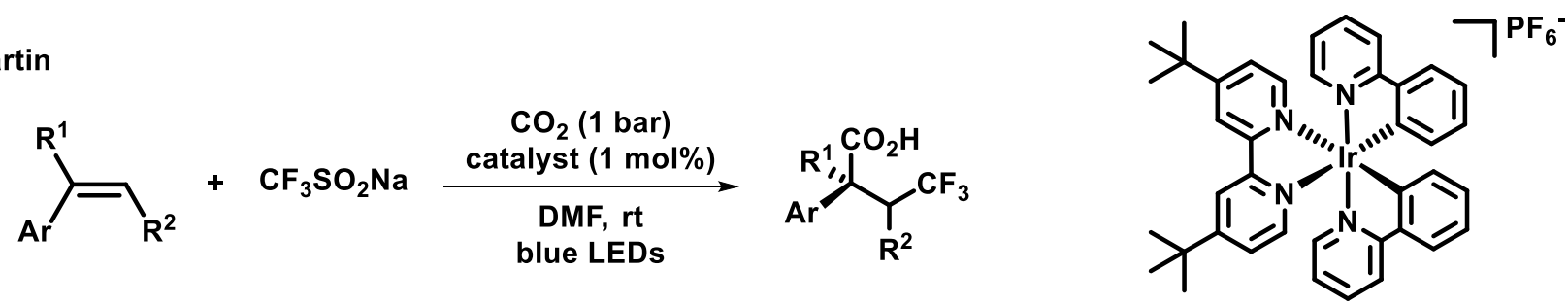

Yu
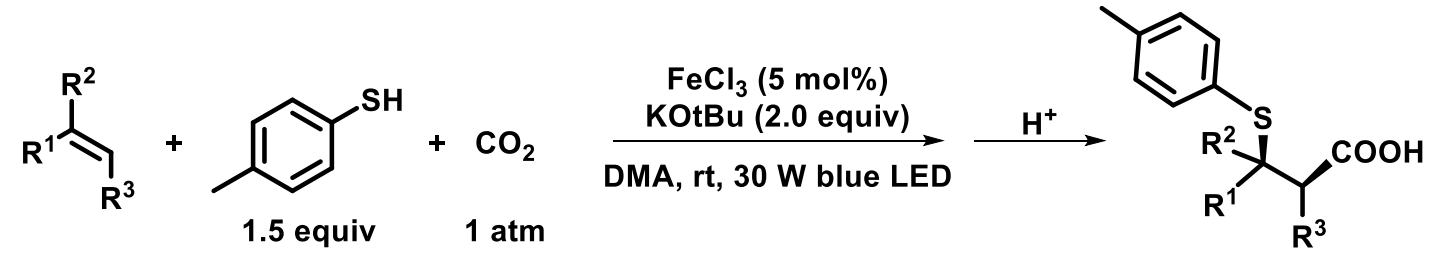

Wu
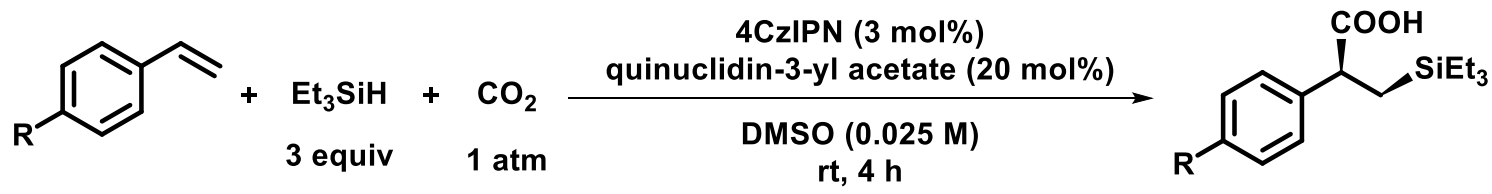

$18 \mathrm{~W}$ blue LED

Scheme 1.20 Hetero(element)carboxylation of alkenes utilizing photocatalysis 


\section{Chapter 2: Effect of Triphenylphosphine Additive in Boracarboxylation of Styrene}

Derivatives

\subsection{Introduction}

As described in Chapter 1, the boracarboxylation of vinyl arenes is an attractive transformation that can be used to access novel $\alpha$-aryl- $\beta$-boryl propionic acids. There are a number of economic and environmental benefits of this difunctionalization. The reaction employs easily accessible, abundant, and cheap styrene substrates. The diboron reagent, $\mathrm{B}_{2} \mathrm{pin}_{2}$ is stable and easy to handle. This protocol also exploits a recyclable, abundant electrophilic carbon source of carbon dioxide to synthesize highly functionalized carboxylic acid derivatives with minimal amount of undesirable by-products. Although utilizing a NHC-stabilized base-metal catalyst system, one drawback of this new methodology was the high catalyst loading (12 mol\%) necessary for the reaction to occur (Scheme 2.1).

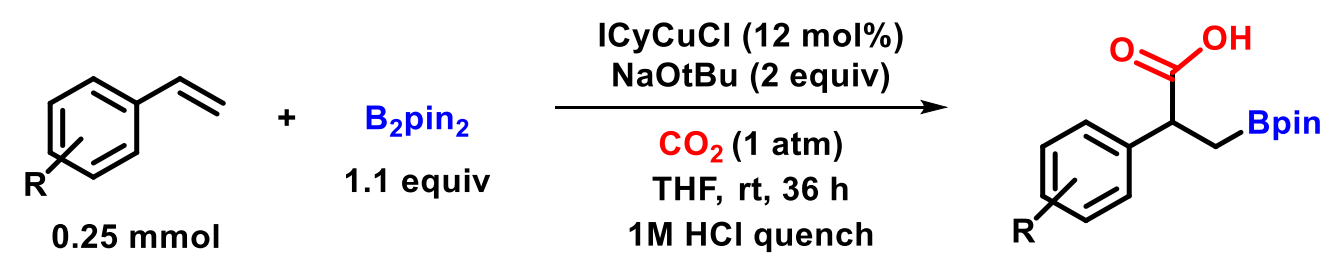

Scheme 2.1 Popp's copper-catalyzed boracarboxylation of vinyl arenes

In the same year, there was a methodology published by Buchwald that examined the reductive coupling of styrene and benzoic anhydride to yield chiral alcohol products. ${ }^{50}$ The copper catalyst system initially employed the chiral $(S)$-DTBM-SEGPHOS phosphine ligand to achieve a $25 \%$ yield of desired product (Table 2.1). The monoaryl bisphosphine $(R, R)$-Me-DuPhos increased the yield to 45\%; however, the stereoselectivity was drastically diminished. The trialkyl bisphosphine $(S, S)$-Ph-BPE increased the yield to $77 \%$ with high selectivity. By addition of the secondary ligand, $\mathrm{PPh}_{3}$, the reaction was driven to very high yield and selectivity. Buchwald also demonstrated this same effect in the enantioselective $\mathrm{Cu}-\mathrm{H}$ catalyzed synthesis of 2,3-disubstituted indolines $^{51}$ and the enantioselective $\mathrm{Cu}-\mathrm{H}$ catalyzed hydroamination of 1,1-disubstituted alkenes. ${ }^{52}$ In these examples, the addition of $\mathrm{PPh}_{3}$ as a secondary ligand improved catalytic turnover without impacting enantioselectivity, which allowed for reduced loadings of copper and ligand. This 
phenomena was first observed by Lipshutz and co-workers. ${ }^{53,54}$ In the asymmetric hydrosilylation of aryl ketones catalyzed by $\mathrm{Cu}-\mathrm{H}$, the addition of an equivalent of $\mathrm{PPh}_{3}$ was shown to help maintain the lifetime of copper hydride. It was shown that the "trick" of storing $\mathrm{Cu}-\mathrm{H}$ by inclusion of $\mathrm{PPh}_{3}$ derives from the fact that $\left(\mathrm{Ph}_{3} \mathrm{P}\right) \mathrm{CuH}$ itself cannot compete with the ligand-accelerated catalysis. We hypothesized that we would be able to take advantage of this secondary ligand effect to lower the copper catalyst used in the boracarboxylation of vinyl arenes.

Table 2.1 Addition of $\mathrm{PPh}_{3}$ for enantioselective reductive coupling of aryl alkenes and activated carboxylic acids

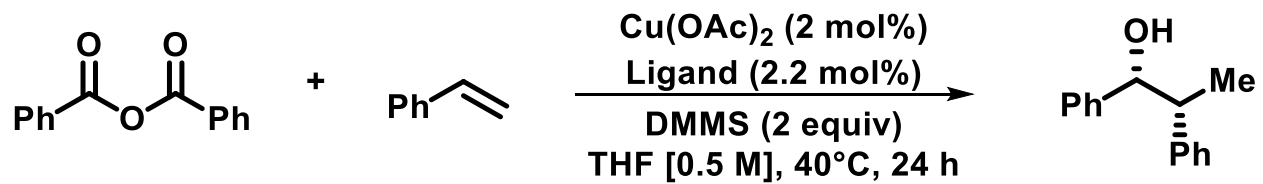

\begin{tabular}{|l|c|c|}
\hline Ligand & Yield $(\%)$ & ee\% \\
\hline DTBM-SEGPHOS & 25 & -95 \\
\hline Me-DuPhos & 45 & 7 \\
\hline Ph-BPE & 77 & 94 \\
\hline Ph-BPE + PPh3 & 91 & 94 \\
\hline
\end{tabular}<smiles>CCCCCc1ccc2c(c1-c1c(P)ccc3c1OCO3)OCO2</smiles>

(S) - DTBM- SEGPHOS Ar: $3,5-t-B u-4-O M e-C_{6} \mathrm{H}_{2}$

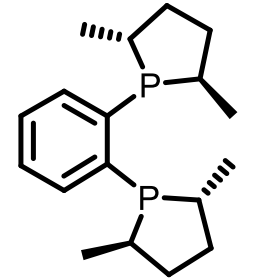

$(R, R)$ - Me- DuPhos<smiles>c1ccc([PH+]C2CC[C@@H](c3ccccc3)P2CCP2C(c3ccccc3)CC[C@@H]2c2ccccc2)cc1</smiles>

$(S, S)$ - Ph- BPE 


\subsection{Results}

2.2.1 Optimization of employing a secondary ligand in boracarboxylation

Owing to its previous high yielding boracarboxylation, para-tert-butylstyrene was used as our model substrate for investigating the ability to reduce catalyst loading with the addition of a secondary phosphine ligand. The previous copper catalyst system employed a strongly sigma donating $N$-heterocyclic carbene copper (I) source at a 12 mol\% loading to achieve a high yield of boracarboxylated product with minimal side products (entry 1, Table 2.2). This catalysis can also be achieved at the same yields in only 6 hours. Attempting to lower the $\mathrm{ICyCuCl}$ catalyst loading to $5 \mathrm{~mol} \%$ without a secondary ligand, resulted in a lower yield of desired product (entry 2, Table 2.2). We reasoned that the $\mathrm{ICyCuCl}$ catalyst was decomposing to an inactive species, promoting formation of unwanted borylation side products as well as polymerization as evidenced by near quantitative styrene conversion. When screening $\mathrm{PPh}_{3}$ as a ligand with copper (I) chloride, reactivity to give our desired boracarboxylated product $(2 b)$ was considerably diminished (entry 3, Table 2.2). Gaining inspiration from the literature, we sought to reduce catalyst loadings of the active $\mathrm{ICyCuCl}$ catalyst by incorporating a secondary phosphine ligand for the difunctionalization of vinyl arenes. To our delight, when decreasing the $\mathrm{ICyCuCl}$ catalyst to $5 \mathrm{~mol} \%$ with an addition of $5 \mathrm{~mol} \%$ of $\mathrm{PPh}_{3}$, the yield of boracarboxylated product was comparable to yields achieved with higher catalyst loading (entry 4, Table 2.2). Based on these results, we recognize that the $\mathrm{PPh}_{3}$ ligand with the copper (I) salt cannot itself be responsible as the active catalyst in this transformation; however, at reduced catalyst loadings, the phosphine must play a role in helping to stabilize a copper species to accomplish high yields of boracarboxylation. Other sources of exogenous secondary ligand were also screened. The addition of $\mathrm{P}(\mathrm{OPh})_{3}$ resulted in a reduced yield of boracarboxylation and a much higher amount of a formal hydroboration side product, $3 \mathrm{~b}$ (entry 5, Table 2.2). The addition of a more electron-rich phosphine additive, PCy3, did show similar reactivity to utilizing $\mathrm{PPh}_{3}$ as an additive (entry 6, Table 2.2). The addition of pyridine, which showed no reactivity as the primary ligand, was tolerated in the reaction but did not show a similar stabilizing role as the $\mathrm{PPh}_{3}$ and $\mathrm{PCy}$ ligands (entry 7, Table 2.2). Addition of excess $\mathrm{PPh}_{3}$ resulted in similar reactivity as having equivalent amounts of copper catalyst and secondary ligand (entry 8, Table 2.2). When attempting to further decrease the ICyCuCl loading, a 4-fold excess of exogenous $\mathrm{PPh}_{3}$ was necessary to achieve a moderate yield of $2 \mathrm{~b}$ (entry 9, Table 2.2). Finally, 
attempting to decrease the $\mathrm{ICyCuCl}$ and phosphine loading while applying heat to the reaction resulted in a lower yield of boracarboxylated product, higher yields of the undesired side products, and in the latter case, lower conversion of styrene (entries 10-11, Table 2.2). The control experiment in the absence of copper resulted in no reactivity (entry 12, Table 2.2).

Table 2.2 Optimization of boracarboxylation of vinyl arenes with secondary ligand addition ${ }^{a}$

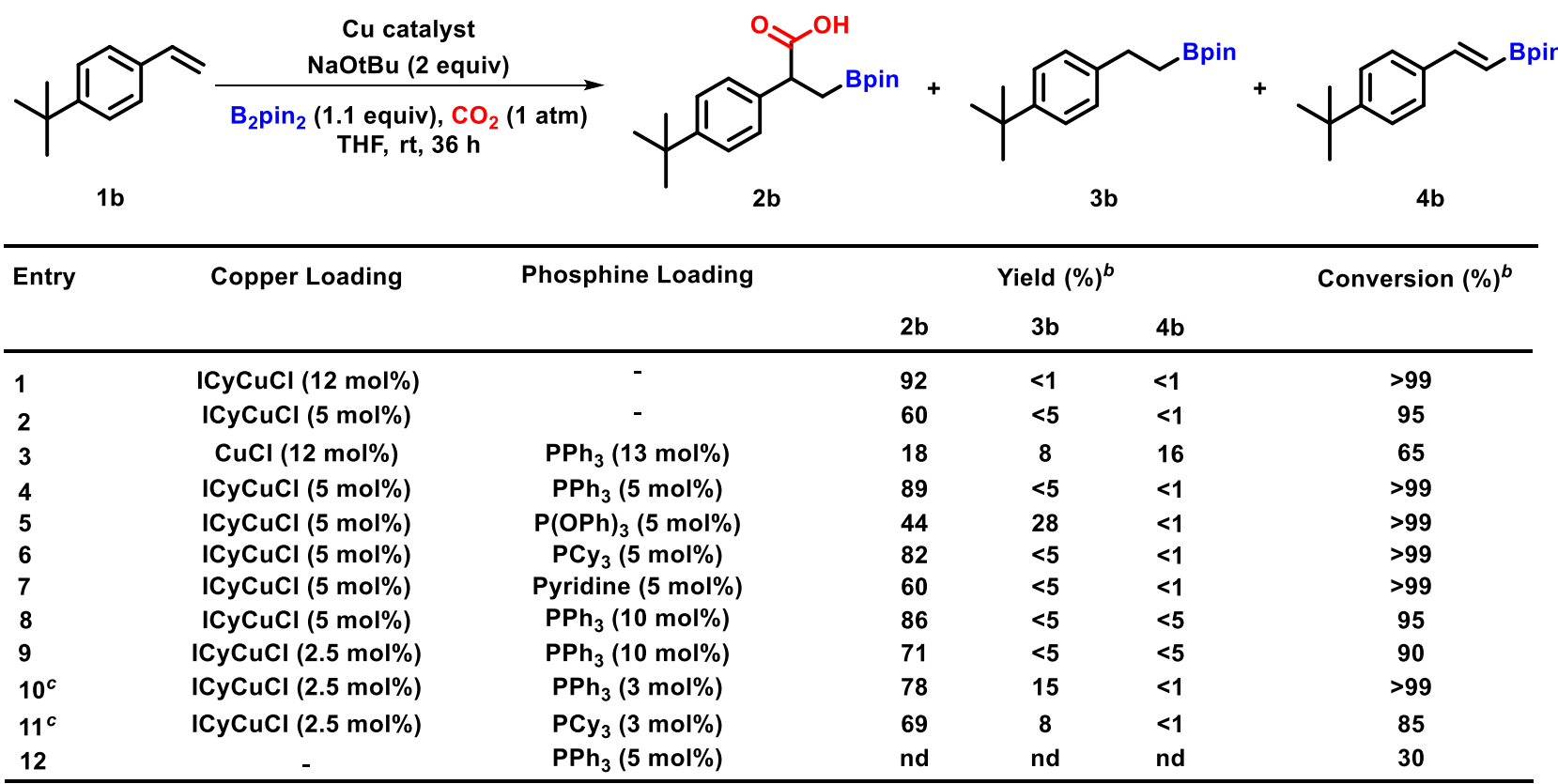

${ }^{a}$ p-tertbutyl styrene $(0.25 \mathrm{mmol})$ in THF $(4 \mathrm{~mL})^{b}$ Yields and conversion were determined by ${ }^{1} \mathrm{H}$ NMR spectroscopy using mesitylene as the internal standard, $\mathrm{nd}=$ not detected by $\mathrm{NMR}^{\circ}$ Reaction ran at $40^{\circ} \mathrm{C}$

\subsubsection{Substrate scope of employing a secondary ligand in boracarboxylation}

With our optimized conditions at hand, we sought to revisit the vinyl arene substrate scope that was previously reported. We have shown the yields for the boracarboxylation of vinyl arenes comparing the $12 \mathrm{~mol} \% \mathrm{ICyCuCl}$ catalytic condition to the $5 \mathrm{~mol} \% \mathrm{ICyCuCl}$ and $5 \mathrm{~mol} \% \mathrm{PPh}_{3}$ catalyst system. The unsubstituted and alkyl substrates (styrene, para-tert-butyl, para-methyl, and para-isobutyl styrenes) demonstrated comparable yields of boracarboxylated products (2a-2d) in both catalyst systems (entries 1-4, Table 2.3). The crystal structure of the isobutyl substrate, $2 \mathrm{~d}$, confirms the regioselectivity of the important bora-ibuprofen NSAID derivative, shown in Figure 2.1 (Appendix I). The electron-donating para-methoxystyrene (2e) was also tolerant to these reduced catalyst loading conditions (entry 5, Table 2.3). The $N$-methyl amide (2f) resulted in a 
relativity much higher yield in the case with lower catalyst loading (entry 6, Table 2.3). Similar reactivity was observed with the para-, meta-, and ortho fluorostyrene $(2 \mathrm{~g}-2 \mathrm{i})$ derivatives when comparing the two catalytic conditions (entries 7-9, Table 2.3). It should be noted that the metaand ortho- substituents were heated to an elevated temperature under both catalytic systems. Similar yields were also obtained when $12 \mathrm{~mol} \%$ of $\mathrm{PPh}_{3}$ was added to $12 \mathrm{~mol} \%$ of $\mathrm{ICyCuCl}$ for the meta- and ortho- fluorosubstituted styrenes. This led to using 2 equivalents of styrene at the lower catalyst conditions at elevated temperature (entries 8-9, Table 2.3) Another common NSAID pharmacophore was prepared with bora-naproxen $(2 \mathrm{j}$ ) achieving an increased yield under the reduced copper catalyst conditions (entry 10, Table 2.3). It can be observed that the isolated yields for the $\mathrm{PPh}_{3}$ additive conditions resulted in upwards of a $20 \%$ decrease from the NMR yields. We believe this is due to the presence of the phosphine ligand in our multi-step extraction method for purification.

Table 2.3 Comparison of $12 \mathrm{~mol} \% \mathrm{ICyCuCl}$ and $5 \mathrm{~mol} \% \mathrm{ICyCuCl}+5 \mathrm{~mol} \% \mathrm{PPh}_{3}$ catalyst systems for previously reported vinyl arene boracarboxylation

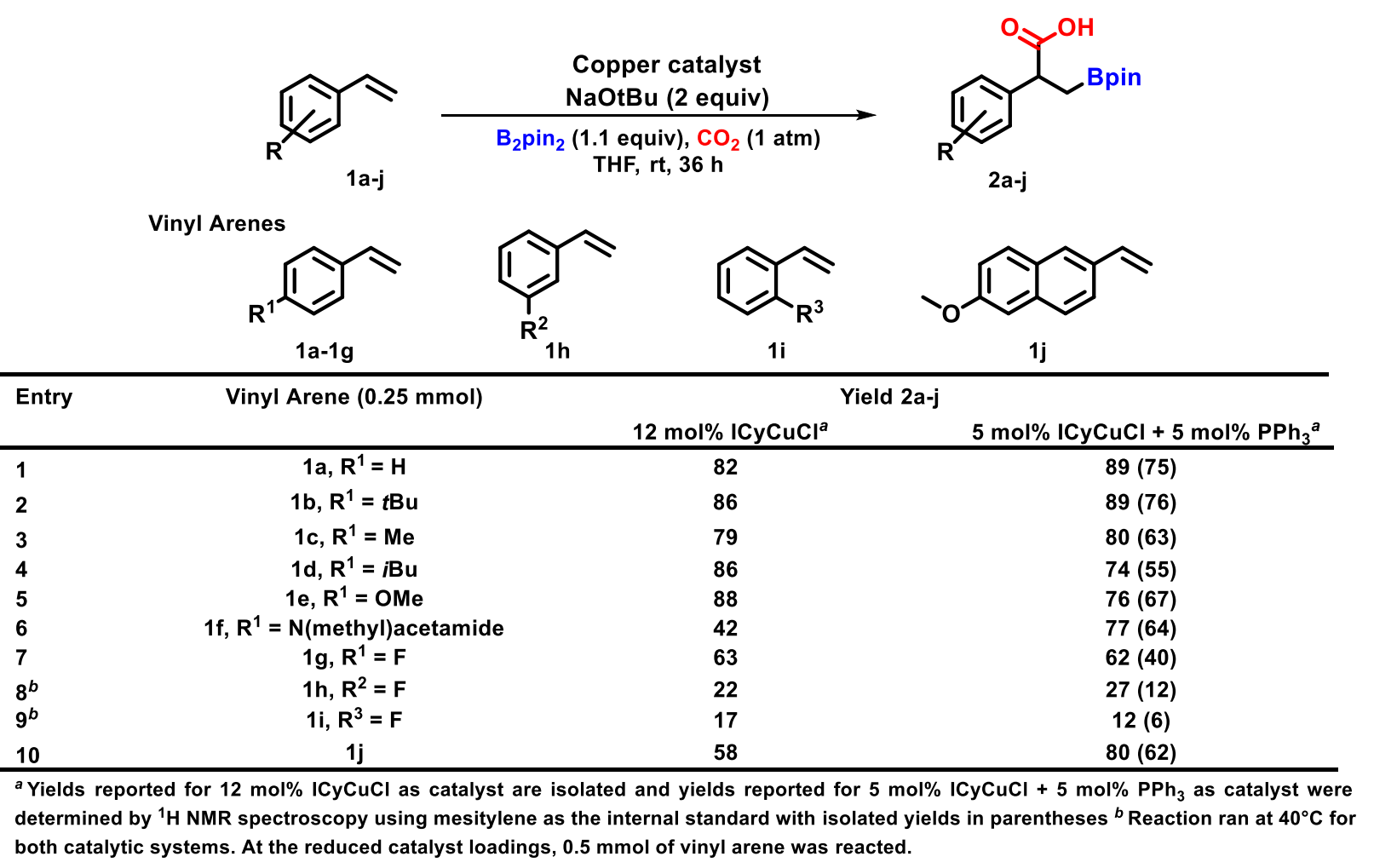




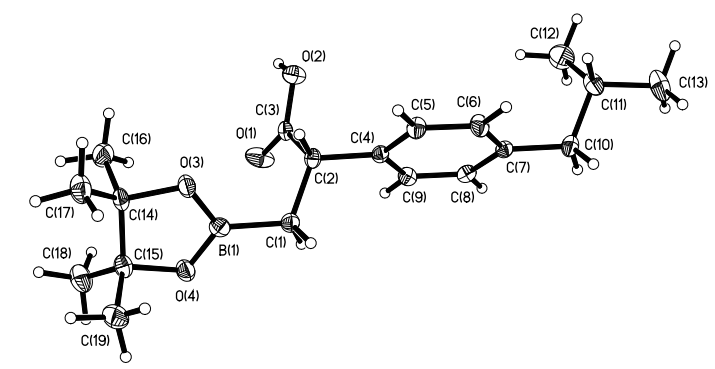

Figure 2.1 X-ray crystal structure of boracarboxylated isobutyl styrene, 2d

Other than being able to demonstrate similar reactivity with reduced catalyst loadings, another objective of our research in this area was the ability to expand the substrate scope of this transformation. Previously, we were unable to achieve boracarboxylation with vinyl arenes bearing electron-withdrawing groups. To our surprise, we were able to access the boracarboxylation of the electron-poor para-trifluoromethylstyrene $\left(\mathrm{p}-\mathrm{CF}_{3}\right)$ through excess addition of styrene. We originally screened this reaction using high loadings of $\mathrm{p}-\mathrm{CF}_{3}$ styrene (5 equiv) and $\mathrm{ICyCuCl}$ catalyst (12 mol\%), as shown in Entry 1, Table 2.4. We were pleased to observe $40 \%$ of the desired boracarboxylation product, $2 \mathrm{~m}$. When reducing catalyst loading to 5 mol\% with the addition of $5 \mathrm{~mol} \% \mathrm{PPh}_{3}$, the yield of $2 \mathrm{~m}$ decreased while the formal hydroboration side product, $3 \mathrm{~m}$, increased (entry 2 , Table 2.4). Heating the reaction to $40^{\circ} \mathrm{C}$ did seem to improve the product distribution at lower catalyst loading (entry 3, Table 2.4). Ultimately, we observed that the 5 equivalents of styrene could be reduced to 2 equivalents to achieve comparable yields, with and without heating the reaction (entries 4-5, Table 2.4). By increasing the catalyst system to 12 $\mathrm{mol} \% \mathrm{ICyCuCl}$ with the addition of $12 \mathrm{~mol} \% \mathrm{PPh}_{3}$ secondary ligand, we could obtain $2 \mathrm{~m}$ at a $53 \%$ yield with much lower yields of $3 \mathrm{~m}$ and at reduced styrene equivalence (entry 6, Table 2.4). Finally, we also showed the ability to access $2 \mathrm{~m}$ by using $\mathrm{PPh}_{3}$ as an additive with 1 equivalent of styrene (entry 7 , Table 2.4). 
Table 2.4 Optimization of boracarboxylation for vinyl arenes bearing electron-withdrawing groups

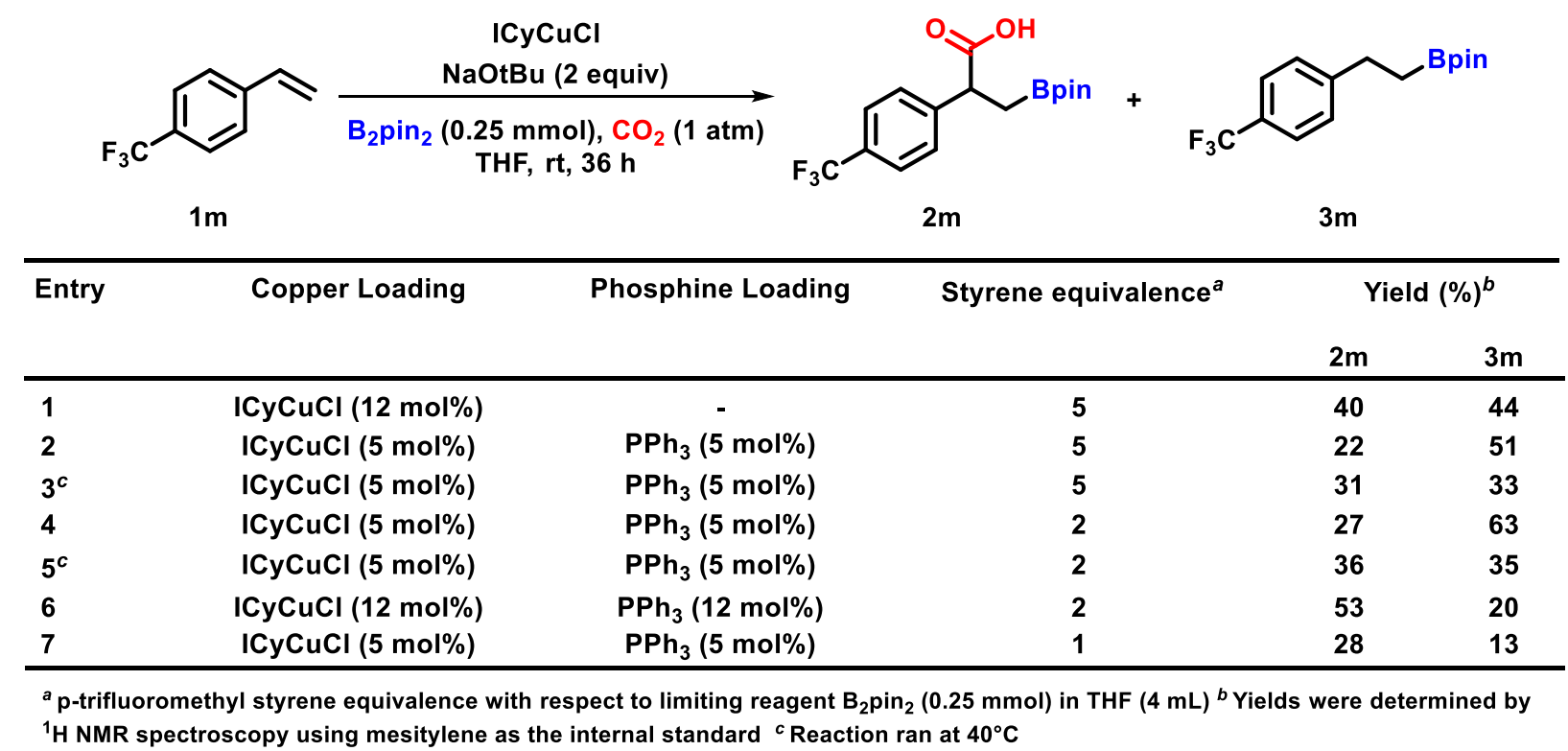

While investigating reactivity of electron-withdrawing styrene derivatives, we have also achieved catalysis for a new group of substrates that were previously not accessed. The borafenoprofen (2k) and bora-flurbiprofen (2l) substrates have been added to our library of boraNSAID derivatives (Table 2.5). This class of compounds are extremely important as there have been recent discoveries of boron's efficacy in medicine. ${ }^{27}$ By increasing the equivalence of styrene, as discussed above, we were able to achieve the boracarboxylated product of electrondeficient para-trifluoromethylstyrene $(2 \mathrm{~m})$ and para-cyanostyrene $(2 \mathrm{n})$. The para-acetoxy substrate (2o), which was also previously unable to be accessed, was attained with our new catalytic system employing $\mathrm{PPh}_{3}$ as a secondary ligand. Other electron-deficient/sterically demanding styrene derivatives still proved to be problematic in achieving catalysis, even at increased styrene equivalents and elevated temperature. The penta-fluorostyrene ( $2 p)$ and parachlorostyrene $(2 \mathrm{q})$ resulted in a poor crude yield $(\sim 10 \%)$ for boracarboxylation, which could not be isolated. With these substrates, the NMR analysis showed unreacted starting material and formal hydroboration product. These are the other two major species observed in the boracarboxylation of styrenes bearing electron-withdrawing substituents. Finally, the para-nitro (2r) and para-bromo (2s) substrates did not show any catalytic activity at higher equivalence, with and without the addition of $\mathrm{PPh}_{3}$. The para-nitro is the strongest electron-withdrawing substituent that was tested and the para-bromostyrene could possibly be undergoing some oxidative chemistry. 
Table 2.5 Expanded substrate scope for boracarboxylation with use of $\mathrm{PPh}_{3}$ additive catalyst system $^{a}$

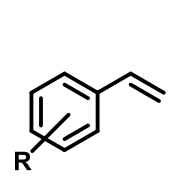

$1 \mathrm{k}-1 \mathrm{~s}$

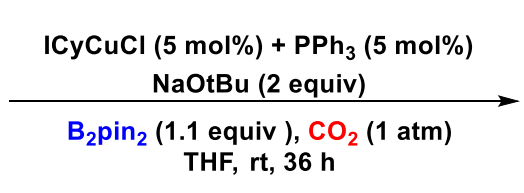

THF, rt, $36 \mathrm{~h}$

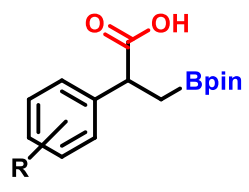

$2 k-2 s$

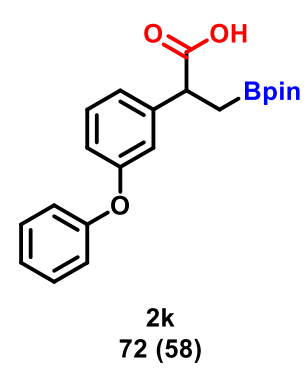

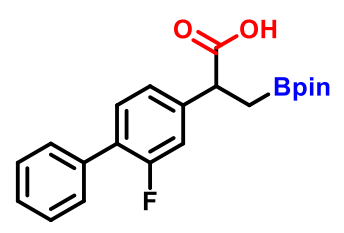

$40(22)$

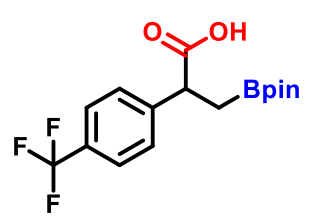

$2 m$
$36(18)^{h}$

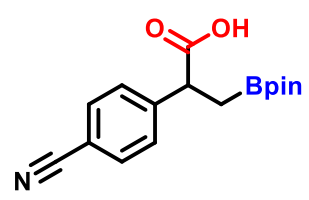

$2 n$ $58(39)^{b}$

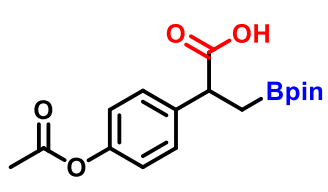

20

30 (17)

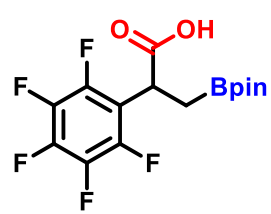

$2 p$ $10^{b}$

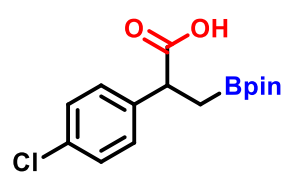

$2 q$
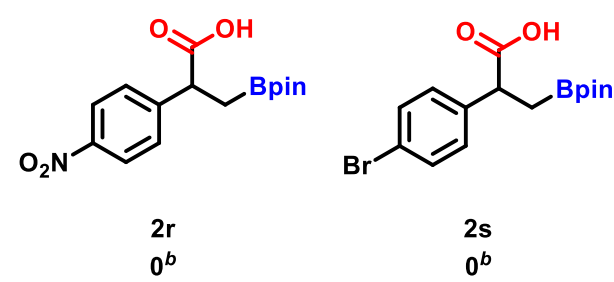

${ }^{a}$ Vinyl arene $(0.25 \mathrm{mmol})$ in THF $(4 \mathrm{~mL})$, yields were determined by ${ }^{1} \mathrm{H}$ NMR spectroscopy using mesitylene as the internal standard and isolated

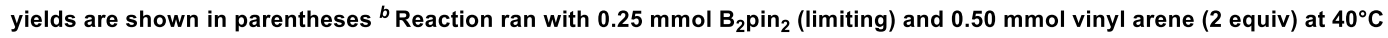

Along with substrate scope, we wanted to demonstrate the ability to run these lower catalyst loading reactions on a larger scale. The vinyl naphthalene substrate (1t), which was reported in the initial boracarboxylation results, showed that the transformation could be increased by a 10-fold scale. The larger scale resulted in a good yield of $65 \%$ of boracarboxylated vinyl naphthalene, $2 \mathrm{t}$ (Scheme 2.2). The ability to increase the scale of these reactions at lower catalyst loading was extended further to investigate multi-gram reactivity. The versatile tert-butyl substrate was reacted at an 80-fold scale to access $3.85 \mathrm{~g}$ of boracarboxylated product (Scheme 2.2). Our lab has also shown the ability to run this same reaction at a 160 -fold scale to access $8.1 \mathrm{~g}$ of product, which is slightly above a $60 \%$ yield. Although the yield of this product is typically much greater, we attribute the reduced isolated yield to the added challenge of removing $\mathrm{PPh}_{3}$ from the reaction. The ability to run these reactions on multi-gram scale is important not only from a pharmaceutical 
perspective, but it is also useful to access large amounts of product to test for its synthetic utility. Subsequent reactivity of these products will be discussed in chapters 3 and 4 of this report.

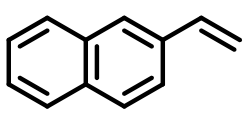

$1 \mathrm{t}$

$2.5 \mathrm{mmol}$

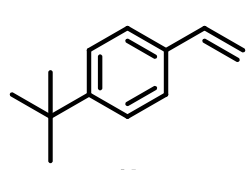

$1 \mathrm{~b}$

$20 \mathrm{mmol}$

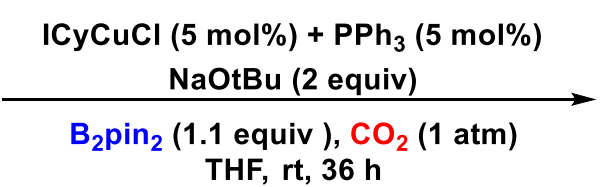

THF, rt, $36 \mathrm{~h}$

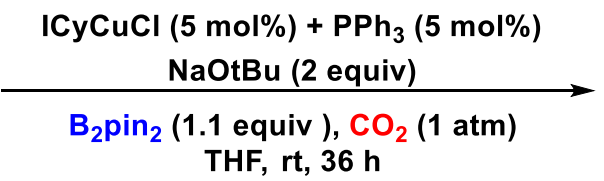

THF, rt, $36 \mathrm{~h}$

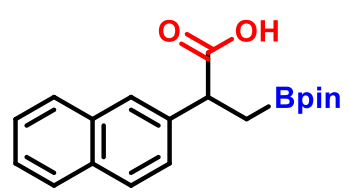

$2 \mathrm{t}$

$65 \%$

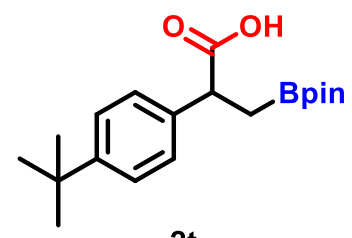

$58 \%, 3.85 \mathrm{~g}$

Scheme 2.2 Scale-up boracarboxylation reactions employing a secondary ligand

\subsubsection{Preliminary investigation of role of $\mathrm{PPh}_{3}$}

Due to the reactivity observed at lower $\mathrm{ICyCuCl}$ loading with the addition of a secondary phosphine ligand, we wanted to explore the potential role of $\mathrm{PPh}_{3}$ in the catalytic cycle of boracarboxylation. In order to gain insight into its role, each step of the proposed mechanism (Scheme 1.18) was investigated. The first series of experiments involve probing the generation of copper tert-butoxide and metathesis steps by screening different tert-butoxide bases at $12 \mathrm{~mol} \%$ $\mathrm{ICyCuCl}$ and $5 \mathrm{~mol} \% \mathrm{ICyCuCl}+5 \mathrm{~mol} \% \mathrm{PPh}_{3}$ catalyst conditions, shown in Table 2.6. It was observed that under both catalytic systems, the reactivity was comparable whether using $\mathrm{LiO}^{\mathrm{t}} \mathrm{Bu}$, $\mathrm{NaO}^{t} \mathrm{Bu}$, or $\mathrm{KO}^{\mathrm{t}} \mathrm{Bu}$ as the base. Although there was no significant difference between the two catalytic systems, employing sodium tert-butoxide as the base resulted in the highest yield of boracarboxylated product. Yields for potassium tert-butoxide were only slightly decreased; however, the reactions showed minimal amount of $2 b$ with lithium tert-butoxide (Table 2.6). The next series of experiments were conducted to probe the generation of the $\mathrm{Cu}-\mathrm{Bpin}$ species and subsequent alkene insertion. To gain insight into these steps in the mechanism, order of addition experiments were performed such as reactions involving $\mathrm{PPh}_{3}$ addition to the catalyst/base solution 
vs. addition to the styrene/ $\mathrm{B}_{2} \mathrm{pin}_{2}$ solution. Other reactions involved the addition of the $\mathrm{PPh}_{3}$ at later time intervals after reaction initiation. All of these reactions exhibited comparable boracarboxylation yields so there is no apparent evidence that $\mathrm{PPh}_{3}$ plays a role in the generation of copper tert-butoxide, generation of $\mathrm{Cu}$-Bpin, insertion of styrene, or metathesis.

Table 2.6 Screening of bases to determine role of $\mathrm{PPh}_{3}$ in boracarboxylation

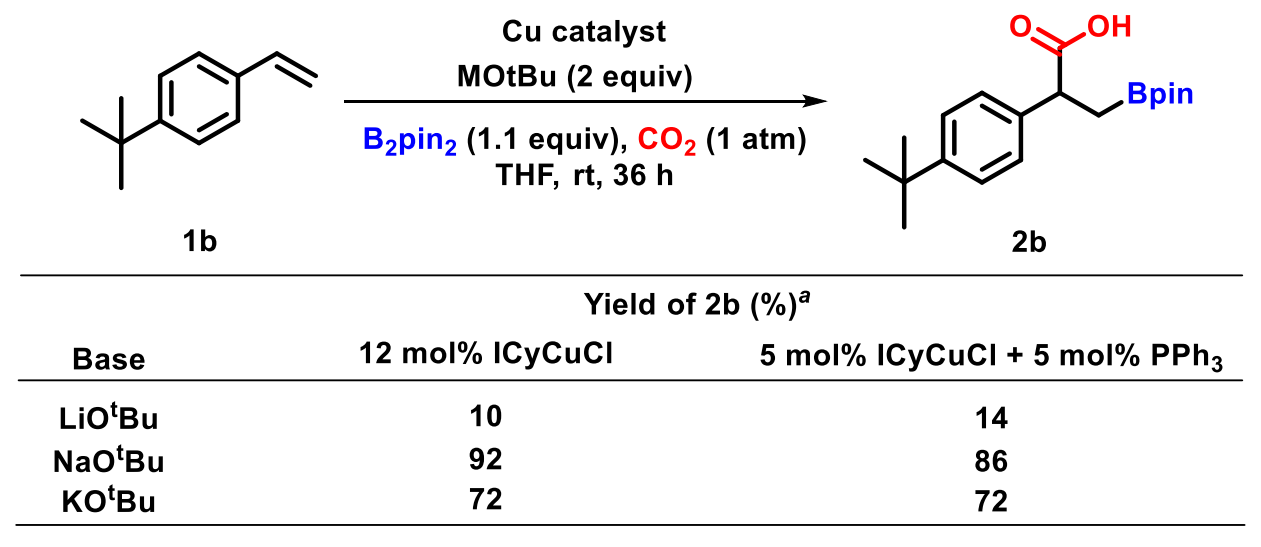

${ }^{a}$ Yields were determined by ${ }^{1} \mathrm{H}$ NMR spectroscopy using mesitylene as the internal standard

In order to study the potential effect of $\mathrm{PPh}_{3}$ on the $\mathrm{CO}_{2}$ insertion step, we used the trans$\beta$-methyl styrene to probe reactivity. Despite the syn addition of the $\mathrm{Cu}-\mathrm{Bpin}$, two diastereomers of the boracarboxylated product are observed, as shown in Table 2.7. The syn diastereomer, 2v, would be achieved via stereoretentive $\mathrm{CO}_{2}$ insertion into the $\mathrm{Cu}$-alkyl bond. The anti diastereomer, $2 \mathrm{v}$, would result from a stereoinvertive $\mathrm{S}_{\mathrm{E}} 2$ type pathway. When $12 \mathrm{~mol} \% \mathrm{ICyCuCl}$ was employed as the catalyst, a diastereomeric ratio of 7:1 syn:anti was observed (Table 2.7). Due to the steric hindrance of the methyl in the beta position, this substrate can only be afforded at high catalyst loading, elevated temperature, and increased reaction scale. When an additional $12 \mathrm{~mol} \% \mathrm{of} \mathrm{PPh}_{3}$ secondary ligand is added to the reaction, $2 \mathrm{v}$ is still favored; however, the ratio is reduced to 2:1 (Table 2.7). This has lead our group to believe that $\mathrm{PPh}_{3}$ has an effect on the $\mathrm{CO}_{2}$ insertion step. There is also literature precedent that this is a viable hypothesis. In 2016, Hou and co-workers reported a copper-catalyzed coupling of carbon dioxide, diboron, and aldehydes. ${ }^{55}$ In the report, the authors marveled at the ability to selectively and efficiently achieve catalysis even though a number of side reactions could be possible. One major side reaction mentioned involves the 
carboxylation of the copper tert-butoxide with $\mathrm{CO}_{2}$. This transformation had been investigated by Saegusa and co-workers over 30 years prior. ${ }^{56,57}$ This work describes carbon dioxide insertion into copper tert-butoxide to form carbonate species in the presence of a series of ligands, specifically $\mathrm{PPh}_{3}$. As shown in Scheme 2.3, these species are referred to as reversible carbon dioxide carriers. At present, our group believes that the addition of $\mathrm{PPh}_{3}$ is involved in this $\mathrm{CO}_{2}$ insertion process. Future investigation from our group will explore the potential formation of carbonates in the catalytic process. We are also interested to study the effect $\mathrm{PPh}_{3}$ has on reaction kinetics.

Table 2.7 Investigation of role of $\mathrm{PPh}_{3}$ in $\mathrm{CO}_{2}$ insertion step

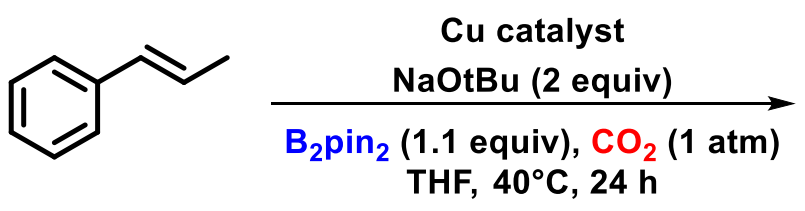

1v THF, $40^{\circ} \mathrm{C}, 24 \mathrm{~h}$

$12 \mathrm{~mol} \% \mathrm{ICyCuCl}$

$12 \mathrm{~mol} \% \mathrm{ICyCuCl}+12 \mathrm{~mol} \% \mathrm{PPh}_{3}$

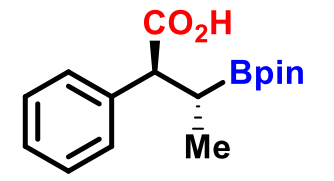

2v<smiles>CC(Cc1ccccc1)C(C(=O)O)C(=O)c1ccccc1</smiles>

$2 v^{\prime}$

$7: 1$

2:1

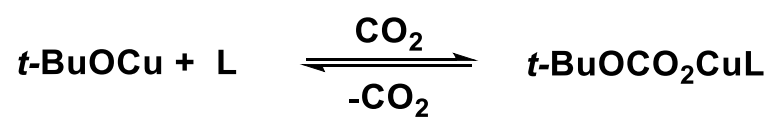

Scheme 2.3 Carboxylation of copper tert-butoxide in presence of $\mathrm{PPh}_{3}$ ligand

\subsubsection{Investigation of reactivity for boracarboxylation}

Given the ability to expand upon the previously explored substrate scope, we sought to gain more insight into reactivity. It was demonstrated through stoichiometric reactivity by Sadighi that more electron-deficient styrenes insert copper-boryl species at a faster rate than electron-rich styrenes. ${ }^{32}$ This was an interesting piece of data considering we had just recently gained access to the boracarboxylation of electron-withdrawing substrates. When performing the competition experiment between the electron-rich para-tert-butylstyrene (1b) and slightly electron- 
withdrawing para-fluorostyrene $(1 \mathrm{~g})$, the yields of boracarboxylation are higher for the parafluorostyrene, which may be the result of a favorable insertion (Table 2.8). This data also shows as the amount of $\mathrm{PPh}_{3}$ is increased, the yield of boracarboxylation also increases. The $5 \mathrm{~mol} \%$ $\mathrm{ICyCuCl}$ loading resulted in similar yields of $2 \mathrm{~g}$ regardless of the increasing $\mathrm{PPh}_{3}$ concentration. This trend revealed that the favorable insertion of $1 \mathrm{~g}$ followed by carboxylation seemed to peak at a yield of around 37\%. As more phosphine is added, the boracarboxylation of tert-butylstyrene increased, resulting in an increased overall yield of the two products (Table 2.8). The increase in $2 \mathrm{~b}$ as more $\mathrm{PPh}_{3}$ is added matches the previous results that $\mathrm{PPh}_{3}$ with $\mathrm{CuCl}$ can be utilized as a catalyst to achieve a minimal amount of boracarboxylated product ( 20\%). This data shows that the insertion of fluorostyrene into the copper-boryl species achieves a maximum yield and then the electron-donating styrene undergoes insertion/carboxylation until an equal amount of both $2 \mathrm{~b}$ and $2 \mathrm{~g}$ exists. In the final entry, $12 \mathrm{~mol} \% \mathrm{ICyCuCl}$ is employed as the catalyst system and the results resemble a similar product distribution as the $5 \mathrm{~mol} \% \mathrm{ICyCuCl}$, albeit in higher yields due to the increased loading.

Table 2.8 Competition studies between para-tert-butylstyrene and para-fluorostyrene
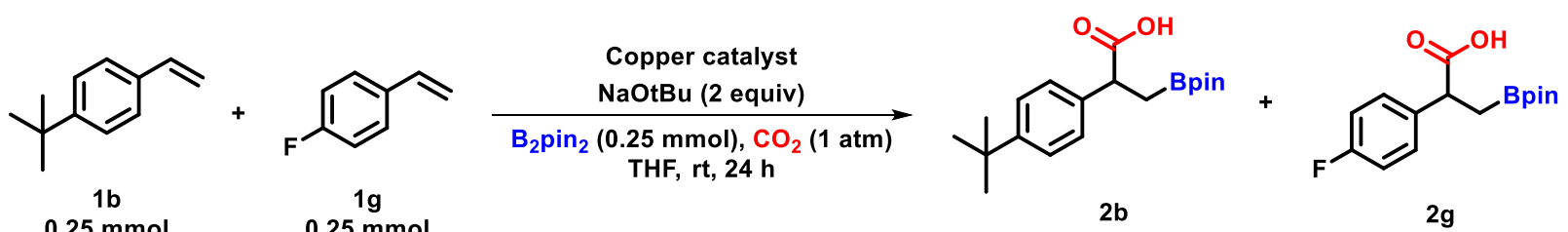

$0.25 \mathrm{mmol}$

$0.25 \mathrm{mmol}$

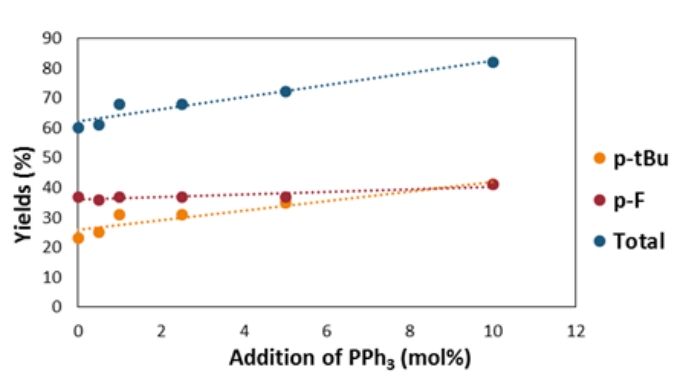

\begin{tabular}{|c|c|c|c|}
\hline \multirow[t]{2}{*}{ Copper catalyst } & \multicolumn{3}{|c|}{ Yield $(\%)^{a}$} \\
\hline & $2 b$ & $2 \mathrm{~g}$ & Total \\
\hline $5 \mathrm{~mol} \% \mathrm{ICyCuCl}$ & 23 & 37 & 60 \\
\hline $5 \mathrm{~mol} \% \mathrm{ICyCuCl}+0.5 \mathrm{~mol} \% \mathrm{PPh}_{3}$ & 25 & 36 & 61 \\
\hline $5 \mathrm{~mol} \% \mathrm{ICyCuCl}+1 \mathrm{~mol} \% \mathrm{PPh}_{3}$ & 31 & 37 & 68 \\
\hline $5 \mathrm{~mol} \% \mathrm{ICyCuCl}+2.5 \mathrm{~mol} \% \mathrm{PPh}_{3}$ & 31 & 37 & 68 \\
\hline $5 \mathrm{~mol} \% \mathrm{ICyCuCl}+5 \mathrm{~mol} \% \mathrm{PPh}_{3}$ & 35 & 37 & 72 \\
\hline $5 \mathrm{~mol} \% \mathrm{ICyCuCl}+10 \mathrm{~mol}^{2} \mathrm{PPh}_{3}$ & 41 & 41 & 82 \\
\hline $12 \mathrm{~mol} \% \mathrm{ICyCuCl}$ & 40 & 53 & 93 \\
\hline
\end{tabular}

${ }^{a}$ Total yields were determined by ${ }^{1} \mathrm{H}$ NMR spectroscopy using mesitylene as the internal standard and yields of boracarboxylated para-fluorostyrene were determined by ${ }^{19} \mathrm{~F}$ NMR spectroscopy using fluorobenzene as the internal standard 
In the competition experiment between para-tert-butylstyrene and para-fluorostyrene, there is a significant increase in the overall yield of the two boracarboxylated products when the copper catalyst was altered from $5 \mathrm{~mol} \% \mathrm{ICyCuCl}+5 \mathrm{~mol}_{\%} \mathrm{PPh}_{3}$ to $12 \mathrm{~mol} \% \mathrm{ICyCuCl}$. This is surprising because both catalytic systems seemed to perform more similarly in the substrate scope investigation. We believe this observation is attributed to the nature of the competition between the two styrenes at the different active catalyst loading. When styrene (1a) and para-fluorostyrene $(1 \mathrm{~g})$ were added in the same reaction, the boracarboxylated styrene (2a) was achieved in a slightly higher yield than $2 \mathrm{~g}$ (Table 2.9). The yields of $2 \mathrm{a}$ and $2 \mathrm{~g}$ were achieved in similar yields under both catalytic systems, which is different from what was observed in the para-tert-butylstyrene vs. para-fluorostyrene competition study. We believe this reactivity can be attributed to the fact that styrene and para-fluorostyrene have very similar Hammett $\sigma_{\text {para }}$ constants of 0.00 and 0.06 , respectively. ${ }^{58}$

Table 2.9 Competition studies between styrene and para-fluorostyrene

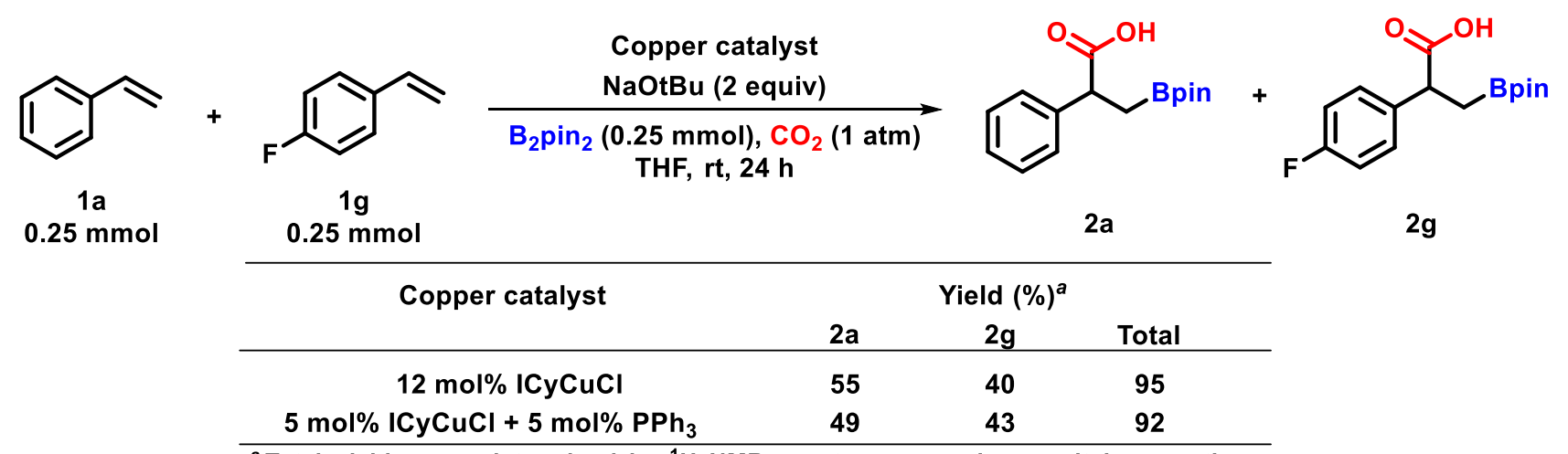

${ }^{a}$ Total yields were determined by ${ }^{1} \mathrm{H}$ NMR spectroscopy using mesitylene as the internal standard and yields of boracarboxylated para-fluorostyrene were determined by ${ }^{19} \mathrm{~F}$ NMR spectroscopy using fluorobenzene as the internal standard.

Because we have performed the competition experiment between two electronically similar styrenes, we also sought to run the competition experiment between the electron-rich para-tertbutylstyrene that has a Hammett $\sigma_{\text {para }}$ value of -0.20 and the electron-deficient paratrifluoromethylstyrene with a value of 0.54 . When carrying out the reaction with both styrenes added, only boracarboxylated product for the para-trifluoromethylstyrene, $2 \mathrm{~m}$, was observed (Table 2.10). This could be explained by competitive binding/insertion of the much more electron- 
deficient styrene, which could prevent the insertion of the electron-rich styrene. When the lower copper loading with secondary $\mathrm{PPh}_{3}$ was employed as the catalyst system, the yield of $2 \mathrm{~m}$ was significantly reduced. This may be due to the fact that only one equivalent of $1 \mathrm{~m}$, with respect to $\mathrm{B}_{2}$ pin $_{2}$, was added and that higher catalyst loading is needed to generate a more nucleophilic intermediate for carboxylation to occur. We also demonstrate that when the amount of $1 \mathrm{~b}$ is reduced to $0.025 \mathrm{mmol}$ or $10 \%$, reactivity is decreased but the $\mathrm{p}-\mathrm{CF}_{3}$ substrate still shows catalytic turnover (Table 2.10). When the boracarboxylation of $1 \mathrm{~m}$ was conducted at low styrene loading without the presence of another styrene (Table 2.11), boracarboxylated product was produced in minimal yields. Based on this data and preliminary stoichiometric experiments, we realize that even a catalytic amount of another electron-donating styrene will result in boracarboxylated p- $\mathrm{CF}_{3}$ substrate. Although it seems as no insertion of the para-tert-butylstyrene occurs, its presence in the reaction and potential binding to copper increases the yield of $2 \mathrm{~m}$. Stoichiometric reactivity and Hammett studies conducted in our group show a negative $\rho$ value for the carboxylation step in our proposed mechanism. Due to our previous challenges in accessing boracarboxylation with substrates bearing an electron-deficient substituent, we believe that the slow step in our reaction is the carboxylation step. This also makes sense based on the fact that our group, along with Sadighi, observe that insertion of electron-deficient styrenes occurs at a faster rate.

Table 2.10 Competition studies between para-tert-butylstyrene and para-trifluoromethylstyrene

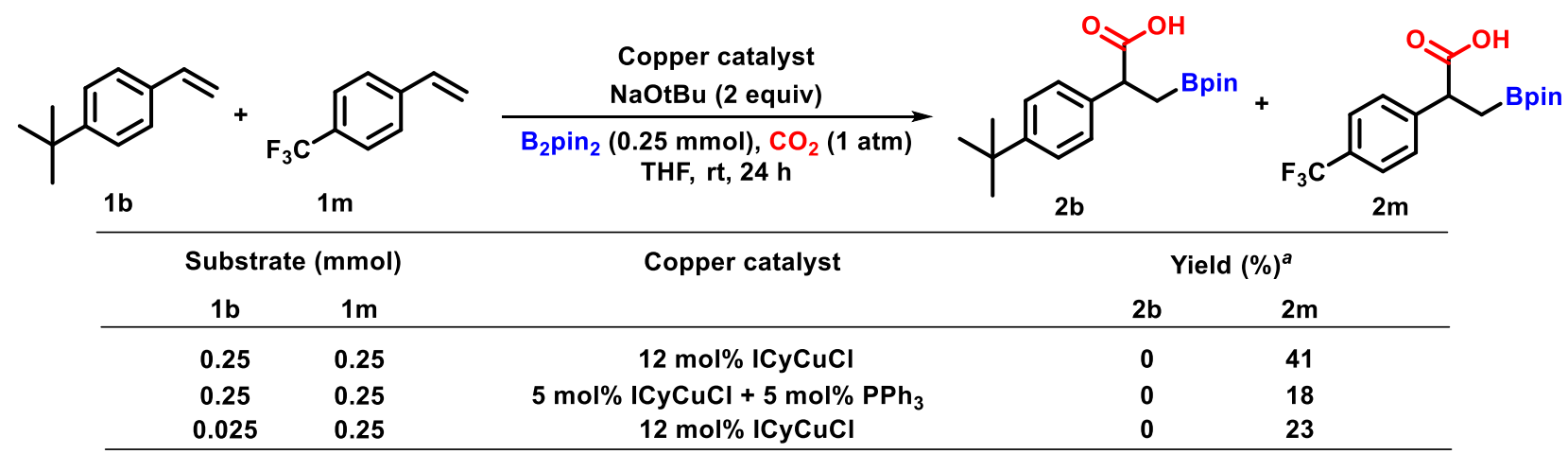

${ }^{a}$ Yields were determined by ${ }^{1} \mathrm{H}$ NMR spectroscopy using mesitylene as the internal standard and yields of boracarboxylated para-trifluoromethylstyrene were confirmed by ${ }^{19} \mathrm{~F}$ NMR spectroscopy using fluorobenzene as the internal standard 
Table 2.11 Boracarboxylation of para-trifluoromethylstyrene at low styrene loading

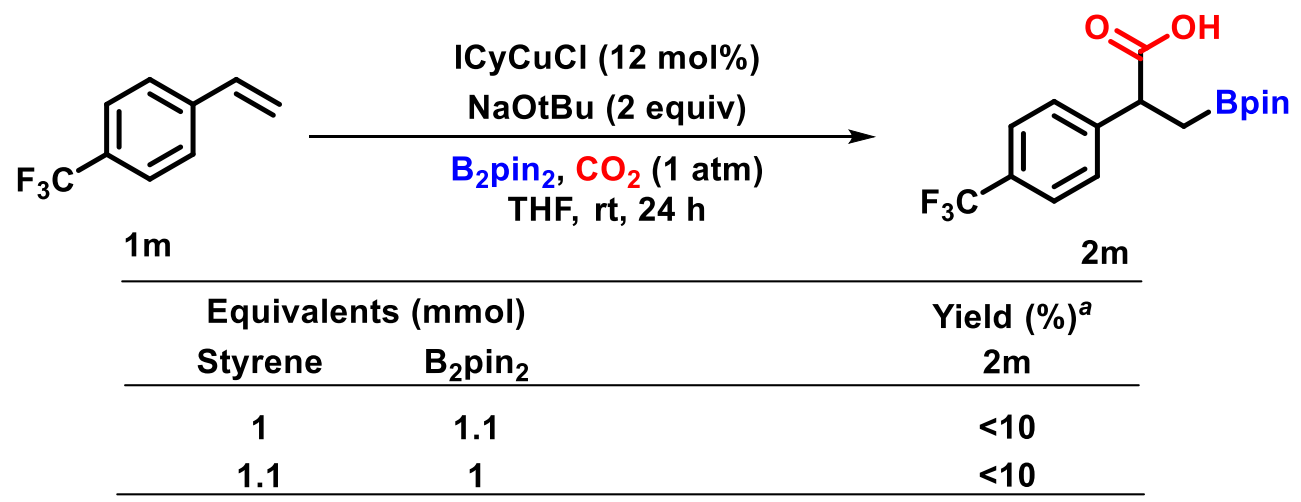

${ }^{a}$ Yields were determined by ${ }^{1} \mathrm{H}$ NMR spectroscopy using mesitylene as the internal standard and confirmed by ${ }^{19} \mathrm{~F}$ NMR spectroscopy using fluorobenzene as the internal standard

2.2.5 Investigation of proton source for protoboration by-product

One observation that was mentioned above while exploring the substrate scope of boracarboxylation with addition of $\mathrm{PPh}_{3}$ was that the electron-deficient substrates showed a relatively high amount of formal hydroboration by-product, $3 \mathrm{~m}$. This is observed in the screening of electron-deficient $\mathrm{p}-\mathrm{CF}_{3}$ styrene (Table 2.4). This product was also observed in the competition studies between $\mathrm{p}-\mathrm{tBu}$ and $\mathrm{p}-\mathrm{CF}_{3}$ styrenes. Highlighted in Table 2.12, 3m resulted in a relativity high yield compared to the amount of $2 \mathrm{~m}$. Based on the proposed mechanism, this product arises from the insertion of alkene into the $\mathrm{Cu}$-Bpin species, which is then trapped with a proton source, inhibiting the carboxylation step. This is a viable route, particularly because the carboxylation step is challenging with electron-deficient arenes. A major question that arises in these cases is the source of the proton in this reaction. Based on our observations, we sought to devise a series of experiments to determine the origin of the proton to result the protoboration side product. 
Table 2.12 Competition studies between para-tert-butylstyrene and para-trifluoromethylstyrene with para-trifluoromethylstryene protoboration product

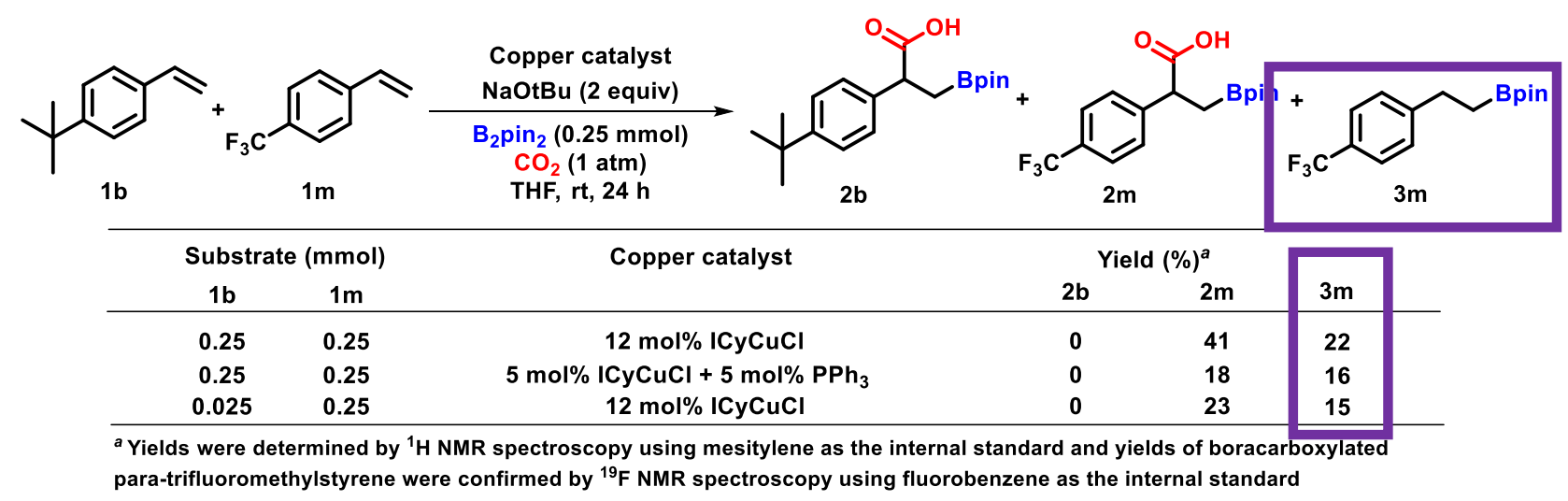

The first experiment performed to determine the source of proton, affording the protoboration product, was to utilize deuterated styrene. In the case of achieving boracarboxylation of electron-deficient substrates, it has been shown that additional equivalents of styrene can be added to the reaction to achieve higher yields. Because of this, we hypothesize that the source of proton may arise from the additional styrene present in the reaction. To test this theory, the boracarboxylation between $1 \mathrm{a}$ and $1 \mathrm{~m}$ was performed as a control experiment (Scheme 2.4). Similarly to other competition experiments with $\mathrm{p}-\mathrm{CF}_{3}$ styrene, there was no boracarboxylation of styrene (2a); however, there was a $30 \%$ yield of $2 \mathrm{~m}$ and a $21 \%$ yield of $3 \mathrm{~m}$. When testing with deuterated styrene, 1a', similar yields of $2 \mathrm{~m}$ and $3 \mathrm{~m}$ were observed (Scheme 2.4). There was also no deuterium incorporation into the protoboration product in the case of cross-over. The deuterium NMR only showed signals in the aromatic and vinyl regions, which would match left over deuterated styrene. 

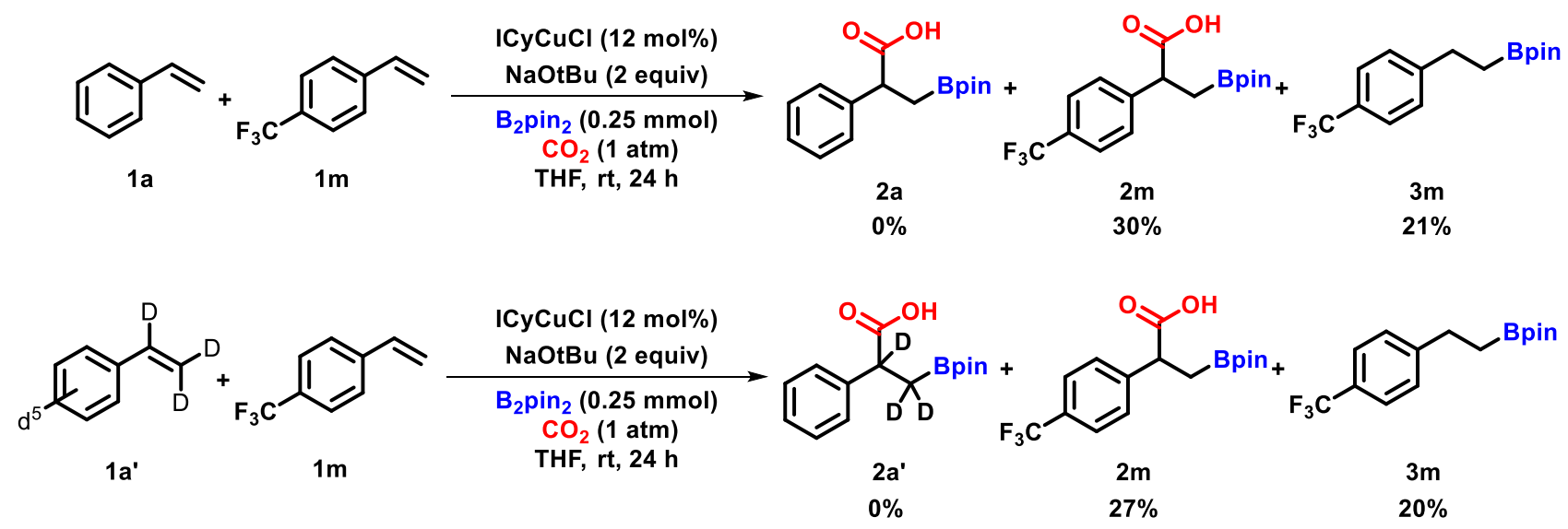

Scheme 2.4 Boracarboxylation reaction between styrene vs. para-trifluoromethylstyrene (top) and deuterated styrene vs. para-trifluoromethylstyrene (bottom) to test for proton source in protoboration by-product

Another hypothesis is that the proton arises from producing a source of HBpin, which could then generate a copper hydride species. To test this possibility, a mixture of $\mathrm{B}_{2} \mathrm{pin}_{2}$ and HBpin were used as the boron source in varying equivalents in the boracarboxylation of $1 \mathrm{~b}$ (Table 2.13). The data from these experiments show that boracarboxylation still occurs only when $\mathrm{B}_{2} \mathrm{pin}_{2}$ is present and $3 b$ was not detected in any of the reactions in this series (Table 2.13). Although it seems that the proton is not due to a source of HBpin in the reaction, we were able to provide evidence that HBpin is not even reactive in the catalytic cycle. When $\mathrm{B}_{2} \mathrm{pin}_{2}$ and HBpin were both added in equimolar amounts ( 0.55 equiv), the yield of $2 \mathrm{~b}$ was $42 \%$, which seems to be the result of using only a half of an equivalent of $\mathrm{B}_{2} \mathrm{pin}_{2}$, the active Bpin source. Similarly, when only 0.275 equiv of $\mathrm{B}_{2}$ pin $_{2}$ was used in the reaction, a $22 \%$ yield of $2 \mathrm{~b}$ was achieved. Finally, when only HBpin was used, there was no presence of $2 b$ or $3 b$. Due to the observation that electron-rich substrates afford little to no protoboration product, a similar experiment was conducted in the case of boracarboxylation of $\mathrm{p}^{-\mathrm{CF}_{3}}$ to determine whether more protoboration product, $3 \mathrm{~m}$, was observed when adding HBpin to the catalytic system. As observed in Scheme 2.5, when 0.5 equiv of $\mathrm{B}_{2} \mathrm{pin}_{2}$ and 0.5 equiv of HBpin were utilized, there was only a $15 \%$ yield of $2 \mathrm{~m}$. This data is in agreement because it is about half the yield of a boracarboxylation with "normal" conditions utilizing 1.1 equiv of $\mathrm{B}_{2}$ pin $_{2}$. There is also minimal amount of $3 \mathrm{~m}$ observed, which has led us to believe that HBpin is not an active source of Bpin and it is not the origin of proton in this transformation. 
Table 2.13 Investigation of HBpin as boron source in boracarboxylation

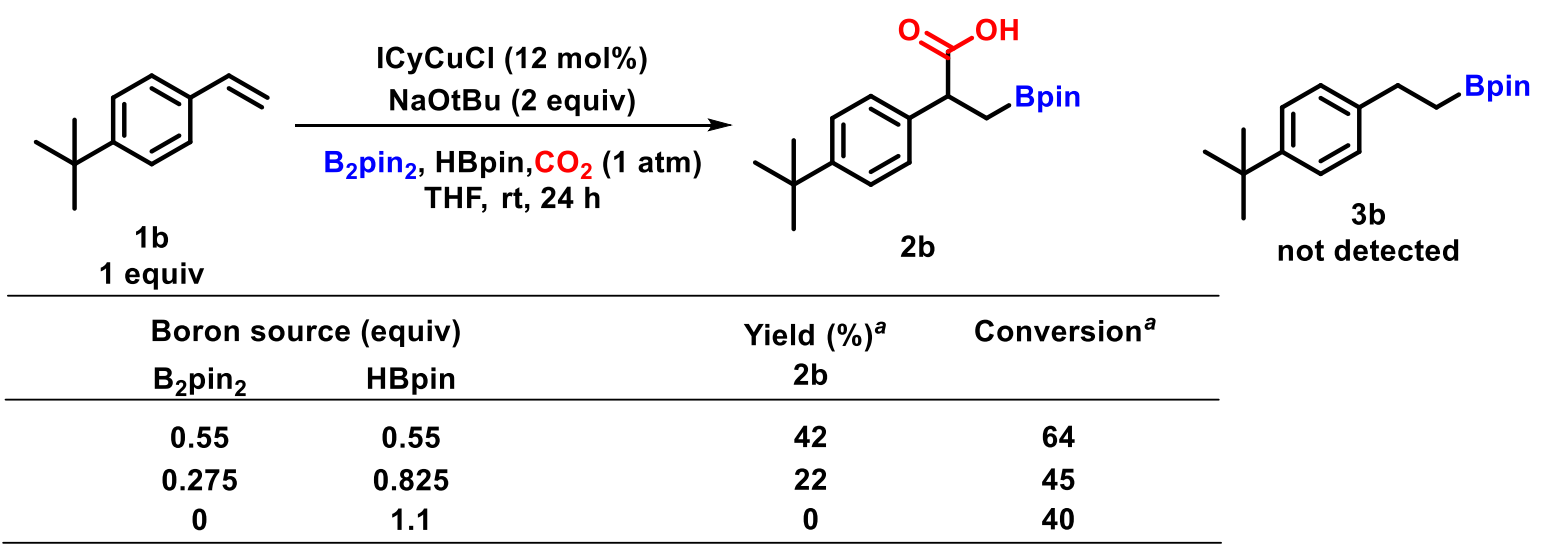

${ }^{a}$ Yields and conversion were determined by ${ }^{1} \mathrm{H}$ NMR spectroscopy using mesitylene as the internal standard

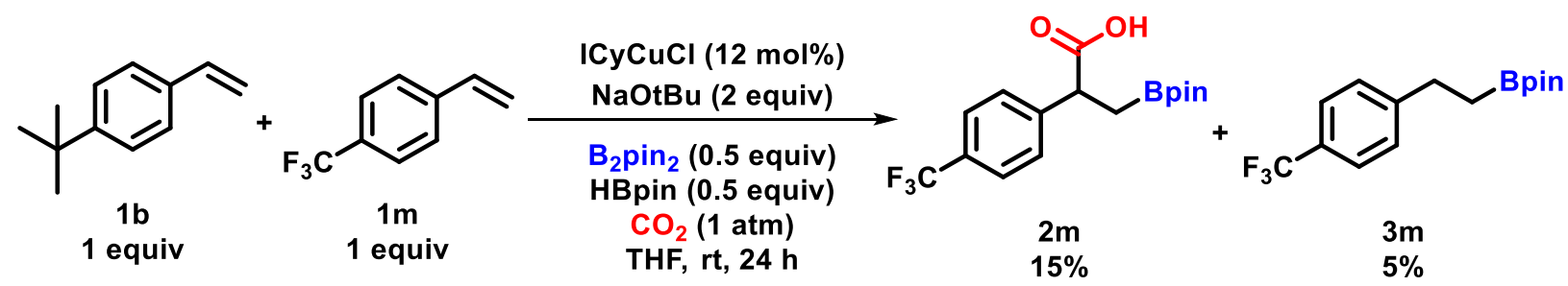

Scheme 2.5 Boracarboxylation of $\mathrm{p}-\mathrm{CF}_{3}$ styrene with excess $\mathrm{p}$-tBu styrene and $\mathrm{HBpin}$ as a boron source

Although the protoboration product is made in predictable yields depending on the conditions, we also sought to perform a type of control experiment by adding a small (ppm) amount of water to determine if the protoboration was arising from residual water during the reaction. In order to perform this control, we simply added 1-2 ppm of $\mathrm{D}_{2} \mathrm{O}$ after reaction initiation and looked for evidence of deuterium incorporation at the benzylic position. As shown in Scheme 2.6, an equivalent amount of $2 \mathrm{~m}$ and $3 \mathrm{~m}$ were obtained, which is typical with this substrate. More importantly, there was no evidence of deuterium incorporation at the benzylic position ( $3 \mathrm{~m}$ '). In the ${ }^{1} \mathrm{H}$ NMR spectrum, the benzylic proton still showed a broad triplet pattern and the ${ }^{2} \mathrm{H}$ NMR spectrum only showed deuterated $\mathrm{CDCl}_{3}$, which the sample was dissolved in. 


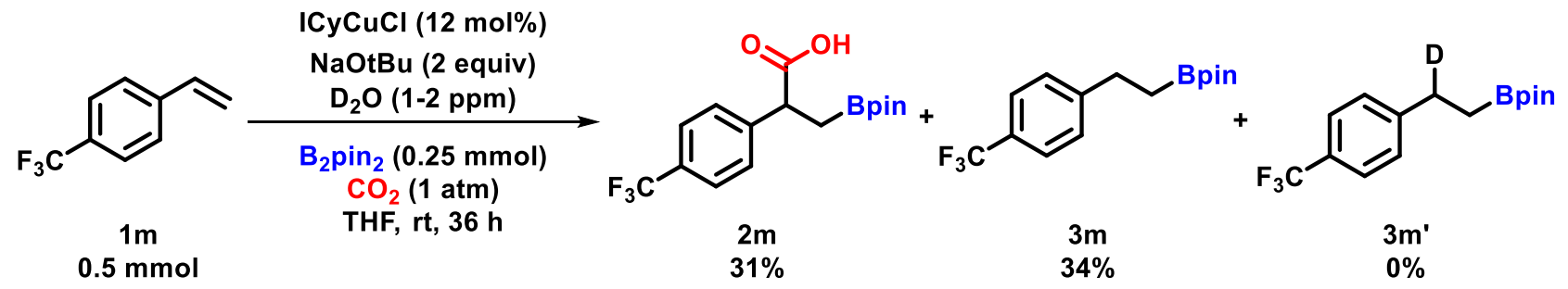

Scheme 2.6 Boracarboxylation of $\mathrm{p}-\mathrm{CF}_{3}$ styrene with addition of $\mathrm{D}_{2} \mathrm{O}$ to reaction

One hypothesis was that the hydroboration of styrene could be competitive under the boracarboxylation reaction conditions. In a recent report, Fernandez demonstrated a metal-free diboration of alkenes. ${ }^{59}$ The diboron reagent can be activated by alkoxides ${ }^{60}$ to increase the nucleophilic character of the trivalent boryl and subsequently force the olefin to act as an electrophile to achieve diboration. This methodology showed a substrate scope limitation where vinyl arenes only resulted in the hydroborated product (Scheme 2.7). The phenyl substituent of the alkene stabilizes the negative charge at the internal carbon, which can favor the hydroboration over diboration. Because the boracarboxylation conditions include a diboron reagent and a tertbutoxide base, we believed that we could potentially be undergoing a metal-free hydroboration of styrene derivatives. In order to test this hypothesis, we performed a reaction with 2 equivalents of $1 \mathrm{~m}$ and base, with respect to our diboron reagent, similar to our normal reaction conditions (Scheme 2.8). We omitted the copper catalyst and $\mathrm{CO}_{2}$ because the reaction should result from a base-catalyzed process in which the $\mathrm{CO}_{2}$ electrophile is not necessary. At the end of the reaction, we only observed styrene, $B_{2}$ pin $_{2}$, and tert-butoxide starting material signals in the ${ }^{1} \mathrm{H}$ NMR. These results have lead us to believe that if there is a competitive hydroboration side pathway, it is not a base-catalyzed process. 


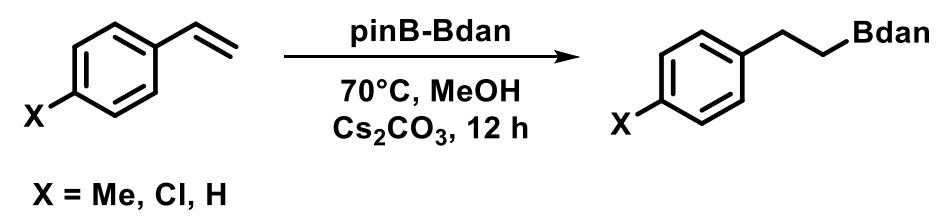

Scheme 2.7 Metal-free boration of styrene

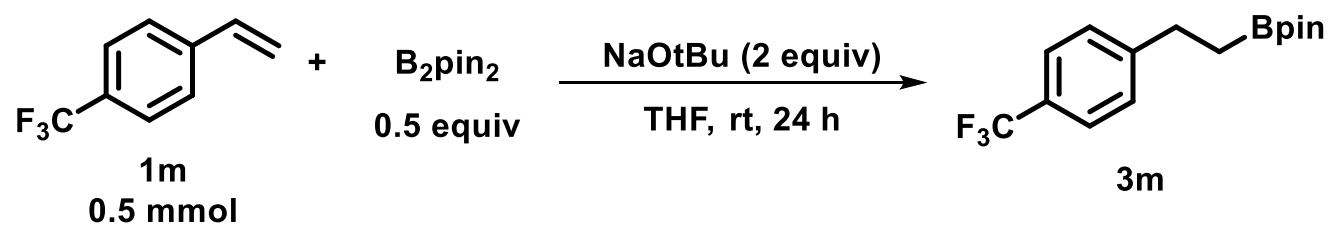

Scheme 2.8 Boracarboxylation of $\mathrm{p}-\mathrm{CF}_{3}$ styrene without copper catalyst and $\mathrm{CO}_{2}$ to test for basecatalyzed hydroboration

One last investigation of the source of proton was to study the protonation step. It could be proposed that diboration could be achieved and then the bulky tert-butoxide base could initiate a sterically induced cleavage (Scheme 1.8) that is then protonated. The boracarboxylation of $1 \mathrm{~m}$ was conducted under normal reaction conditions with $\mathrm{DCl}$ and $\mathrm{D}_{2} \mathrm{O}$ used in the work-up (Scheme 2.9). This same reaction was also attempted without the copper catalyst and carbon dioxide. In both cases, there was no deuterium incorporation observed. Specifically, no alkyl deuterium peaks were observed in the ${ }^{2} \mathrm{H}$ NMR spectra.

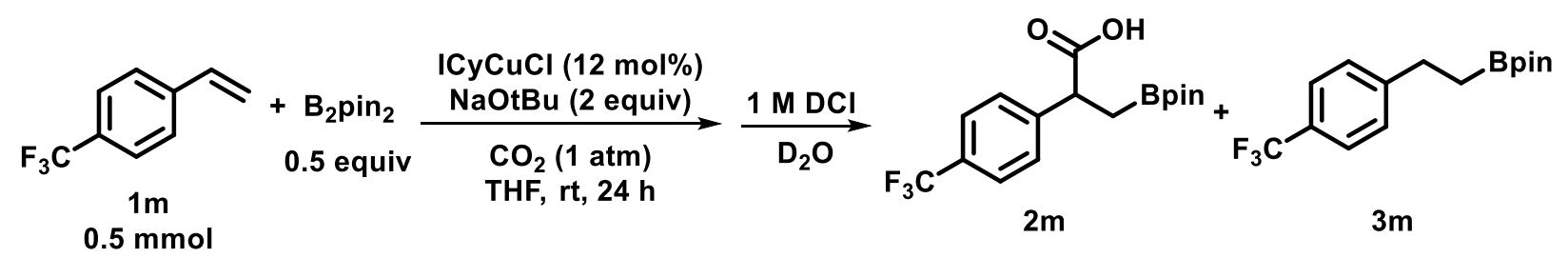

Scheme 2.9 Boracarboxylation of $\mathrm{p}-\mathrm{CF}_{3}$ styrene using $\mathrm{DCl}$ and $\mathrm{D}_{2} \mathrm{O}$ in the work-up step 


\subsection{Conclusion}

In summary, we have developed a catalyst system that allows for a reduced loading of copper with the use of a secondary $\mathrm{PPh}_{3}$ ligand. With this system, we were able to demonstrate the ability to achieve similar yields of some previously reported substrates. Access to the boracarboxylation of electron-deficient substrates was also achieved through additional equivalents of styrene. Preliminary experiments have been conducted to test the role of $\mathrm{PPh}_{3}$ in the catalytic cycle. Competition studies have revealed that electron-deficient substrates actually undergo insertion at a faster rate, which is in agreement with the literature. We attribute the challenge of boracarboxylation of electron-deficient substrates to be due to a slow $\mathrm{CO}_{2}$ step, which can be overcome by the presence of electron-donating styrene. Finally, experiments have been conducted to probe the source of proton, resulting in the relatively high amounts of protoboration product with electron-deficient substrates.

\subsection{Experimental Methods}

\subsubsection{General information}

Due to air and moisture sensitivity, all experiments were set up in a nitrogen-filled MBraun 200B dual-port glovebox. Dry tetrahydrofuran was used for all experiments from a Glass Contour solvent purification system and the deuterated $\mathrm{CDCl}_{3}$ was purchased from Cambridge Isotope Laboratories, Inc. NMR spectra were recorded on either a $400 \mathrm{MHz}$ Agilent or a $400 \mathrm{MHz} \mathrm{JEOL}$ NMR spectrometer. ${ }^{1} \mathrm{H}$ NMR experiments were run in $\mathrm{CDCl}_{3}$ using tetramethylsilane as an internal standard and ${ }^{13} \mathrm{C}$ NMR spectra used $\mathrm{CDCl}_{3}$ as a solvent and reference. ${ }^{19} \mathrm{~F}$ and ${ }^{11} \mathrm{~B}$ NMR experiments were also run in $\mathrm{CDCl}_{3}$ with ${ }^{11} \mathrm{~B}$ NMR spectra recorded using quartz NMR tubes and referenced to an external $\mathrm{BF}_{3} \cdot \mathrm{OEt}_{2}$ standard. High-resolution mass spectra were recorded on a Thermo Fisher Scientific Q Exactive Mass Spectrometer dissolving our samples in 1:1 methanol/acetonitrile. The $N$-methyl-4-vinylacetanilide substrate was prepared based on previous literature methods. ${ }^{61}$ The 4-isobutylstyrene and 3-phenyoxystyrene substrates were synthesized by subjecting the aldehyde precursor to Wittig conditions. The 2-methoxy-6-vinylnaphthalene and 3fluoro-4-phenyl styrene substrates were prepared by performing Suzuki cross-coupling from the commercially available bromide compounds with vinyl-Bpin. All other substrates were commercially available styrene derivatives. 


\subsubsection{Experimental procedures}

The procedure and characterization of the $\mathrm{ICyCuCl}$ complex were based on literature precedent. ${ }^{62}$ In a nitrogen-filled glovebox, a vial was charged with $\mathrm{ICyCuCl}(4.0 \mathrm{mg}, 0.012 \mathrm{mmol}$, $5 \mathrm{~mol} \%), \mathrm{PPh}_{3}(3.0 \mathrm{mg}, 0.011 \mathrm{mmol}, 5 \mathrm{~mol} \%$ ), sodium tert-butoxide (48.0 mg, $0.50 \mathrm{mmol}, 2.0$ eq.), and anhydrous, degassed THF from the solvent system $(0.90 \mathrm{~mL})$. The vial was sealed and stirred for at least 15 minutes to afford a clear, pale yellow solution. In a separate $25 \mathrm{~mL}$ roundbottom flask, bis(pinacolato)diboron (70.0 mg, $0.275 \mathrm{mmol}, 1.1$ eq.) and $3.1 \mathrm{~mL}$ of THF were added. To the solution, vinyl arene $(0.25 \mathrm{mmol}, 1.0$ eq. $)$ was added. The flask was charged with a stir bar, sealed with a septum, and taped. The catalyst solution in the vial was pulled up in a 1.0 $\mathrm{mL}$ syringe and the needle with capped into a septum. The syringe containing catalyst solution and the $25 \mathrm{~mL}$ round-bottom flask containing vinyl arene were taken out of the glovebox. The catalyst/base solution was added to the round-bottom and the vessel was fitted with a doublewalled $\mathrm{CO}_{2}$ balloon. The reactions were stirred at room temperature for 36 hours, replacing the balloons when deflated. With the substrates bearing electron-withdrawing groups, as reported above, the amounts of bis(pinacolato)diboron $(63.0 \mathrm{mg}, 0.25 \mathrm{mmmol})$ and vinyl arene $(0.50 \mathrm{mmol}$, 2.0 eq.) were altered. These reactions bearing electron-withdrawing vinyl arenes were also heated to $40^{\circ} \mathrm{C}$. Upon reaction completion, the reaction was quenched with $20 \mathrm{~mL}$ of $1.0 \mathrm{M}$ aqueous $\mathrm{HCl}$ and extracted with dichloromethane $(15 \mathrm{~mL}$ x 3$)$. The combined organic layers were collected in a $100 \mathrm{~mL}$ round-bottom flask and concentrated under vacuum to give the crude product. Mesitylene (20 mol\%) was added to the crude mixture as an internal standard and dissolved in $\mathrm{CDCl}_{3}$ to be analyzed by ${ }^{1} \mathrm{H}$ NMR. If boracarboxylated product was present in NMR, the crude product was taken up in $6 \mathrm{~mL}$ of diethyl ether and extracted with saturated $\mathrm{NaHCO}_{3}(6 \mathrm{~mL} \times 3)$. The combined aqueous layers were collected in a $50 \mathrm{~mL}$ Erlenmeyer flask and acidified with 12 $\mathrm{M} \mathrm{HCl}$. The product was transferred to a separate separatory funnel and extracted with dichloromethane (15 mL x 3). The combined organic layers were dried over sodium sulfate, filtered, and dried under vacuum to afford the boracarboxylated product. NMR characterization data was carried out on purified compound, along with high-resolution mass spectroscopy for new compounds. For the competition experiments between para-tert-butylstyrene and parafluorostyrene, mesitylene ( $20 \mathrm{~mol} \%$ with respect to $\mathrm{B}_{2} \mathrm{pin}_{2}$ ) was used as the internal standard in ${ }^{1} \mathrm{H}$ NMR to determine total yield of boracarboxylated product. Fluorobenzene $(20 \mathrm{~mol} \%$ with respect to $\mathrm{B}_{2}$ pin 2 ) was used as the internal standard in ${ }^{19} \mathrm{~F}$ NMR to determine the yield of 
boracarboxylated para-fluorostyrene. The difference between the two values provided the yield of the boracarboxylated para-tert-butylstyrene. This method was used due to overlapping methine and methylene product peaks. In the case of the competition studies performed between paratertbutyl styrene and para- $\mathrm{CF}_{3}$ styrene, there is only para- $\mathrm{CF}_{3}$ boracarboxylation product observed. When using mestiylene in ${ }^{1} \mathrm{H}$ NMR and fluorobenzene in ${ }^{19} \mathrm{~F}$ NMR to confirm integration accuracy, the yields in both spectra were within integration error of each other $(<5 \%)$, making this a viable method for yield determination. All competition studies were ran at a slightly shorter reaction time of 24 hours. Preliminary experiments to investigate the role of $\mathrm{PPh}_{3}$ or to determine source of proton in protoboration side product may have had slightly different conditions, which are noted in the text and schemes above.

\subsubsection{Characterization of isolated compounds}

${ }^{1} \mathrm{H},{ }^{13} \mathrm{C},{ }^{11} \mathrm{~B}$, and ${ }^{19} \mathrm{~F}$ NMR shifts for compounds $2 \mathrm{a}-2 \mathrm{j}$ and $2 \mathrm{t}$ matched our previously reported results. ${ }^{42}$ All NMR spectra can be found in Appendix II.

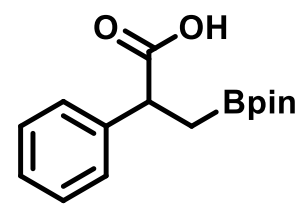

3-boronic acid pinacol ester-2-phenyl propionic acid 2a. white solid, yield 75\% ${ }^{1} \mathrm{H}$ NMR (400 MHz, $\left.\mathrm{CDCl}_{3}\right): \delta 7.30-7.22(\mathrm{~m}, 5 \mathrm{H}), 3.86(\mathrm{dd}, \mathrm{J}=9.4,7.4 \mathrm{~Hz}, 1 \mathrm{H}), 1.55(\mathrm{dd}, \mathrm{J}=$ 16.0, $9.3 \mathrm{~Hz}, 1 \mathrm{H}), 1.29(\mathrm{dd}, \mathrm{J}=16.0,7.4 \mathrm{~Hz}, 1 \mathrm{H}), 1.14(\mathrm{~s}, 6 \mathrm{H}), 1.13(\mathrm{~s}, 6 \mathrm{H}) ;{ }^{13} \mathrm{C}$ NMR $(101 \mathrm{MHz}$, $\left.\mathrm{CDCl}_{3}\right): \delta 180.47,140.30,128.47,127.82,127.13,83.37,46.79,24.61,24.50,15.81 ;{ }^{11} \mathrm{~B}$ NMR (128 MHz, $\mathrm{CDCl}_{3}$ ): $\delta 33.63$ (br s). The ${ }^{13} \mathrm{C} \mathrm{NMR}$ resonance at 15.81 (methylene carbon signal) has very low intensity due to ${ }^{11} \mathrm{~B}$ quadrupolar broadening

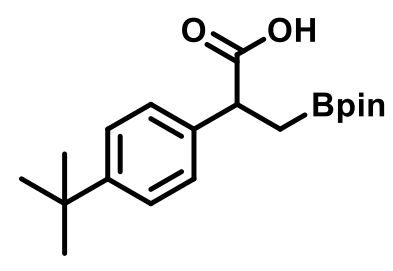

3-boronic acid pinacol ester-2-(4-tertbuylphenyl) propionic acid $\mathbf{2 b}$. white solid, yield 76\% ${ }^{1} \mathrm{H} \mathrm{NMR}\left(400 \mathrm{MHz}, \mathrm{CDCl}_{3}\right): \delta 7.31(\mathrm{~d}, \mathrm{~J}=8.4 \mathrm{~Hz}, 2 \mathrm{H}), 7.23(\mathrm{~d}, \mathrm{~J}=8.4 \mathrm{~Hz}, 2 \mathrm{H})$, 
$3.83(\mathrm{dd}, \mathrm{J}=9.6,7.1 \mathrm{~Hz}, 1 \mathrm{H}), 1.55(\mathrm{dd}, \mathrm{J}=15.9,9.6 \mathrm{~Hz}, 1 \mathrm{H}), 1.28(\mathrm{~s}, 9 \mathrm{H}), 1.27(\mathrm{dd}, \mathrm{J}=15.8,7.0$ $\mathrm{Hz}, 1 \mathrm{H}), 1.14(\mathrm{~s}, 6 \mathrm{H}), 1.11(\mathrm{~s}, 6 \mathrm{H}) ;{ }^{13} \mathrm{C}$ NMR $\left(101 \mathrm{MHz}, \mathrm{CDCl}_{3}\right): \delta 180.26,149.96,137.20$, 127.43, 125.37, 83.31, 46.24, 34.38, 31.29, 24.64, 24.46, 15.84; ${ }^{11} \mathrm{~B}$ NMR (128 MHz, $\left.\mathrm{CDCl}_{3}\right): \delta$ 33.21 (br s). The ${ }^{13} \mathrm{C}$ NMR resonance at 15.84 (methylene carbon signal) has very low intensity due to ${ }^{11} \mathrm{~B}$ quadrupolar broadening

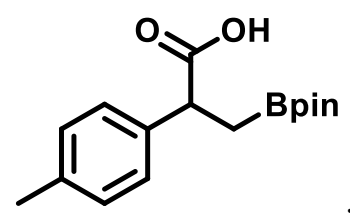

3-boronic acid pinacol ester-2-(4-methylphenyl) propionic acid 2c. white solid, yield 63\% ${ }^{1} \mathrm{H}$ NMR $\left(400 \mathrm{MHz}, \mathrm{CDCl}_{3}\right): \delta 7.32(\mathrm{~d}, \mathrm{~J}=8.5 \mathrm{~Hz}, 2 \mathrm{H}), 7.01(\mathrm{~d}, \mathrm{~J}=8.5 \mathrm{~Hz}, 2 \mathrm{H})$, $3.86(\mathrm{dd}, \mathrm{J}=9.3 \mathrm{~Hz}, 7.3 \mathrm{~Hz}, 1 \mathrm{H}), 2.27$ (s, 3H), 1.54 (dd, J = 16.0, $9.3 \mathrm{~Hz}, 1 \mathrm{H}), 1.27$ (dd, J = 16.1, $7.4 \mathrm{~Hz}, 1 \mathrm{H}), 1.14$ (s, 6H), 1.13 (s, 6H); ${ }^{13} \mathrm{C}$ NMR (101 MHz, CDCl $): \delta 180.21,137.45,136.69$, 129.14, 127.63, 83.30, 46.36, 24.63, 24.51, 21.00, 16.02; ${ }^{11} \mathrm{~B}$ NMR (128 MHz, $\left.\mathrm{CDCl}_{3}\right): \delta 33.01$ (br s).The ${ }^{13} \mathrm{C}$ NMR resonance at 16.02 (methylene carbon signal) has very low intensity due to ${ }^{11} \mathrm{~B}$ quadrupolar broadening

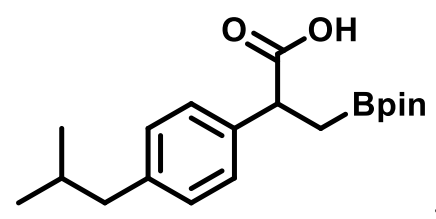

3-boronic acid pinacol ester-2-(4-isobutylphenyl) propionic acid 2d. white solid, yield 55\% ${ }^{1} \mathrm{H}$ NMR (400 MHz, $\left.\mathrm{CDCl}_{3}\right): \delta 7.20(\mathrm{~d}, \mathrm{~J}=7.5 \mathrm{~Hz}, 2 \mathrm{H}), 7.05(\mathrm{~d}, \mathrm{~J}=7.5$ $\mathrm{Hz}, 2 \mathrm{H}), 3.82(\mathrm{t}, \mathrm{J}=8.1 \mathrm{~Hz}, 1 \mathrm{H}), 2.42(\mathrm{~d}, \mathrm{~J}=7.1 \mathrm{~Hz}, 2 \mathrm{H}), 1.82(\mathrm{sept}, \mathrm{J}=6.7 \mathrm{~Hz}, 1 \mathrm{H}), 1.52(\mathrm{dd}, \mathrm{J}$ $=15.9,9.0 \mathrm{~Hz}, 1 \mathrm{H}), 1.29(\mathrm{dd}, \mathrm{J}=15.9,7.5 \mathrm{~Hz}, 1 \mathrm{H}), 1.12(\mathrm{~s}, 6 \mathrm{H}), 1.11(\mathrm{~s}, 6 \mathrm{H}), 0.87(\mathrm{~d}, \mathrm{~J}=6.6 \mathrm{~Hz}$, $6 \mathrm{H}) ;{ }^{13} \mathrm{C} \mathrm{NMR}\left(101 \mathrm{MHz}, \mathrm{CDCl}_{3}\right): \delta 180.73,140.49,137.54,129.16,127.55,83.27,46.44,45.01$, $30.13,24.60,24.49,22.33,22.30,15.89 ;{ }^{11} \mathrm{~B}$ NMR (128 MHz, $\left.\mathrm{CDCl}_{3}\right): \delta 33.29$ (br s). The ${ }^{13} \mathrm{C}$ NMR resonance at 15.89 (methylene carbon signal) has very low intensity due to ${ }^{11} \mathrm{~B}$ quadrupolar broadening 


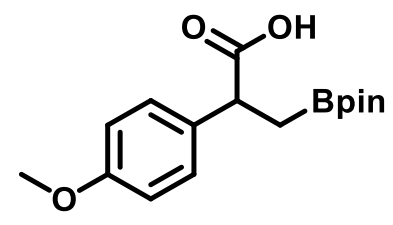

3-boronic acid pinacol ester-2-(4-methoxyphenyl) propionic acid $\mathbf{2 e}$. white solid, yield 67\% $\left.{ }^{1} \mathrm{H} \mathrm{NMR} \mathrm{(400} \mathrm{MHz,} \mathrm{CDCl}_{3}\right): \delta 7.21(\mathrm{~d}, \mathrm{~J}=8.7 \mathrm{~Hz}, 2 \mathrm{H}), 6.82(\mathrm{~d}, \mathrm{~J}=8.7 \mathrm{~Hz}, 2 \mathrm{H})$, $3.80(\mathrm{dd}, \mathrm{J}=9.3,7.2 \mathrm{~Hz}, 1 \mathrm{H}), 3.76(\mathrm{~s}, 3 \mathrm{H}), 1.51(\mathrm{dd}, \mathrm{J}=15.9,9.2 \mathrm{~Hz}, 1 \mathrm{H}), 1.25(\mathrm{dd}, \mathrm{J}=15.9,7.2$ $\mathrm{Hz}, 1 \mathrm{H}), 1.14(\mathrm{~s}, 6 \mathrm{H}), 1.13(\mathrm{~s}, 6 \mathrm{H}) ;{ }^{13} \mathrm{C}$ NMR $\left(101 \mathrm{MHz}, \mathrm{CDCl}_{3}\right): \delta$ 180.69, 158.63, 132.55, 128.84, 113.84, 83.32, 55.20, 46.00, 24.60, 24.52, 15.99; ${ }^{11} \mathrm{~B}$ NMR (128 MHz, $\left.\mathrm{CDCl}_{3}\right): \delta 33.20$ (br s). The ${ }^{13} \mathrm{C}$ NMR resonance at 15.99 (methylene carbon signal) has very low intensity due to ${ }^{11} \mathrm{~B}$ quadrupolar broadening

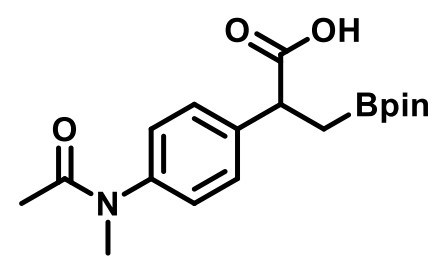

3-boronic acid pinacol ester-2-(4-N(methyl)acetamide phenyl) propionic acid 2f. white solid, yield $64 \%{ }^{1} \mathrm{H} \mathrm{NMR}\left(400 \mathrm{MHz}, \mathrm{CDCl}_{3}\right): \delta 7.37(\mathrm{~d}, \mathrm{~J}=8.3 \mathrm{~Hz}, 2 \mathrm{H})$, $7.11(\mathrm{~d}, \mathrm{~J}=8.3 \mathrm{~Hz}, 2 \mathrm{H}), 3.89$ (t, J = 8.3 Hz, 1H), $3.22(\mathrm{~s}, 3 \mathrm{H}), 1.85$ (s, 3H), 1.55 (dd, J = 15.9, 8.7 $\mathrm{Hz}, 1 \mathrm{H}), 1.33(\mathrm{dd}, \mathrm{J}=16.0,8.1 \mathrm{~Hz}, 1 \mathrm{H}), 1.14(\mathrm{~s}, 12 \mathrm{H}) ;{ }^{13} \mathrm{C} \mathrm{NMR}\left(101 \mathrm{MHz}, \mathrm{CDCl}_{3}\right): \delta 178.83$, 170.92, 143.21, 140.39, 129.33, 126.92, 83.30, 46.45, 37.20, 24.58, 24.53, 22.22, 16.02; ${ }^{11} \mathrm{~B}$ NMR (128 MHz, $\mathrm{CDCl}_{3}$ ): $\delta 32.66$ (br s). The ${ }^{13} \mathrm{C}$ NMR resonance at 16.02 (methylene carbon signal) has very low intensity due to ${ }^{11} \mathrm{~B}$ quadrupolar broadening

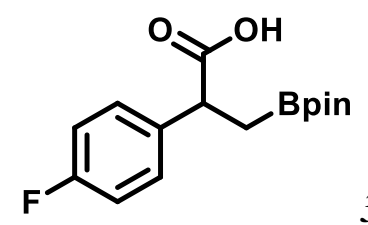

3-boronic acid pinacol ester-2-(4-fluorophenyl) propionic acid 2g. white solid, yield 40\% ${ }^{1} \mathrm{H}$ NMR (400 MHz, $\mathrm{CDCl}_{3}$ ): $\delta 7.27$ (dd, J = 8.6, $\left.5.4 \mathrm{~Hz}, 2 \mathrm{H}\right), 6.97$ (t, J = 8.7 Hz, 2H), $3.84(\mathrm{t}, \mathrm{J}=8.3 \mathrm{~Hz}, 1 \mathrm{H}), 1.52(\mathrm{dd}, \mathrm{J}=15.9,8.9 \mathrm{~Hz}, 1 \mathrm{H}), 1.30(\mathrm{dd}, \mathrm{J}=15.9,7.7 \mathrm{~Hz}, 1 \mathrm{H}), 1.13$ (s, 6H), 1.12 (s, 6H); $\left.{ }^{13} \mathrm{C} \mathrm{NMR} \mathrm{(101} \mathrm{MHz,} \mathrm{CDCl}_{3}\right): \delta$ 180.48, 161.95 (d, J = 245.4 Hz), 135.97 (d, $\mathrm{J}=3.2 \mathrm{~Hz}), 129.42(\mathrm{~d}, \mathrm{~J}=8.0 \mathrm{~Hz}), 115.24(\mathrm{~d}, \mathrm{~J}=21.4 \mathrm{~Hz}), 83.43,46.04,24.56,24.50,15.93 ;{ }^{11} \mathrm{~B}$ NMR (128 MHz, $\left.\mathrm{CDCl}_{3}\right): \delta 33.46$ (br s) $\left.{ }^{19} \mathrm{~F} \mathrm{NMR} \mathrm{(376} \mathrm{MHz,} \mathrm{CDCl}_{3}\right): \delta-115.65$ (tt, J = 9.0, 5.4 
$\mathrm{Hz}$ ). The ${ }^{13} \mathrm{C}$ NMR resonance at 15.93 (methylene carbon signal) has very low intensity due to ${ }^{11} \mathrm{~B}$ quadrupolar broadening

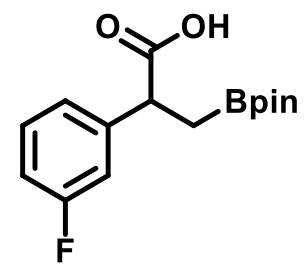

3-boronic acid pinacol ester-2-(3-fluorophenyl) propionic acid $\mathbf{2 h}$. clear oil, $12 \%{ }^{1} \mathrm{H} \mathrm{NMR}\left(400 \mathrm{MHz}, \mathrm{CDCl}_{3}\right): \delta$ 7.28-7.23 (m, 1H), 7.09-7.02 (m, 2H), $6.93(\mathrm{td}, \mathrm{J}=8.5,2.5$ $\mathrm{Hz}, 1 \mathrm{H}), 3.86(\mathrm{t}, \mathrm{J}=8.3 \mathrm{~Hz}, 1 \mathrm{H}), 1.53(\mathrm{dd}, \mathrm{J}=16.0,9.1 \mathrm{~Hz}, 1 \mathrm{H}), 1.26(\mathrm{dd}, \mathrm{J}=16.0,7.2 \mathrm{~Hz}, 1 \mathrm{H})$, $1.15(\mathrm{~s}, 6 \mathrm{H}), 1.14(\mathrm{~s}, 6 \mathrm{H}) ;{ }^{13} \mathrm{C} \mathrm{NMR}\left(101 \mathrm{MHz}, \mathrm{CDCl}_{3}\right): \delta 179.68,162.77$ (d, J = 246.0 Hz), 142.70 (d, J = 7.2 Hz), 129.92 (d, J = 8.2 Hz), 123.58 (d, J = 2.9 Hz), 114.95 (d, J = 21.8 Hz), 114.10 (d, $\mathrm{J}=21.1 \mathrm{~Hz}), 83.51,46.52,24.62,24.54,15.83 ;{ }^{11} \mathrm{~B} \mathrm{NMR}\left(128 \mathrm{MHz}, \mathrm{CDCl}_{3}\right): \delta 32.57$ (br s); ${ }^{19} \mathrm{~F}$ NMR (376 MHz, $\left.\mathrm{CDCl}_{3}\right): \delta-113.11\left(\mathrm{q}, \mathrm{J}=8.6 \mathrm{~Hz}\right.$ ). The ${ }^{13} \mathrm{C}$ NMR resonance at 15.97 (methylene carbon signal) has very low intensity due to ${ }^{11} \mathrm{~B}$ quadrupolar broadening

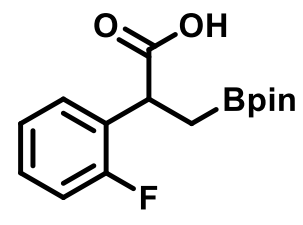

3-boronic acid pinacol ester-2-(2-fluorophenyl) propionic acid $2 \mathbf{i}$. clear oil, $6 \%$ ${ }^{1} \mathrm{H}$ NMR (400 MHz, $\left.\mathrm{CDCl}_{3}\right): \delta$ 7.30-7.20 (m, 2H), 7.10-7.00 (m, 2H), 4.19 (dd, J = 9.4, 7.0 Hz, $1 \mathrm{H}), 1.57(\mathrm{dd}, \mathrm{J}=16.0,9.4 \mathrm{~Hz}, 1 \mathrm{H}), 1.25(\mathrm{dd}, \mathrm{J}=16.0,7.1 \mathrm{~Hz}, 1 \mathrm{H}), 1.16(\mathrm{~s}, 12 \mathrm{H}) ;{ }^{13} \mathrm{C} \mathrm{NMR}(101$ $\left.\mathrm{MHz} \mathrm{CDCl}_{3}\right): \delta$ 179.32, $160.40(\mathrm{~d}, \mathrm{~J}=246.8 \mathrm{~Hz}), 129.18(\mathrm{~d}, \mathrm{~J}=3.9 \mathrm{~Hz}), 128.69(\mathrm{~d}, \mathrm{~J}=8.2 \mathrm{~Hz})$, $127.84(\mathrm{~d}, \mathrm{~J}=14.9 \mathrm{~Hz}), 124.15$ (d, J = 3.5 Hz), 115.43 (d, J = 22.3 Hz), 83.43, 40.01, 24.64, 24.55, 15.02; ${ }^{11} \mathrm{~B}$ NMR (128 MHz, $\left.\mathrm{CDCl}_{3}\right): \delta 33.46$ (br s); ${ }^{19} \mathrm{~F} \mathrm{NMR} \mathrm{(376} \mathrm{MHz,} \mathrm{CDCl}_{3}$ ): $\delta$-117.32 (dt, $\mathrm{J}=11.6,6.0 \mathrm{~Hz}$ ). The ${ }^{13} \mathrm{C}$ NMR resonance at 15.02 (methylene carbon signal) has very low intensity due to ${ }^{11} \mathrm{~B}$ quadrupolar broadening. 


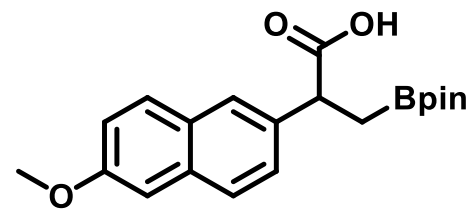

3-boronic acid pinacol ester-2-(6-methoxynaphthalene) propionic acid $\mathbf{2 j}$. white solid, yield $62 \%{ }^{1} \mathrm{H}$ NMR (400 MHz, $\left.\mathrm{CDCl}_{3}\right): \delta 7.57(\mathrm{dd}, \mathrm{J}=8.8,2.2 \mathrm{~Hz}, 3 \mathrm{H}), 7.31$ (dd, J = 8.5, 1.8 Hz, 1H), 7.02 (dd, J = 8.9, $2.5 \mathrm{~Hz}, 1 \mathrm{H}), 6.99$ (d, J = 2.5 Hz, 1H), 3.91 (dd, J = 9.1, $7.3 \mathrm{~Hz}, 1 \mathrm{H}), 3.80(\mathrm{~s}, 3 \mathrm{H}), 1.55(\mathrm{dd}, \mathrm{J}=16.0,9.1 \mathrm{~Hz}, 1 \mathrm{H}), 1.28(\mathrm{dd}, \mathrm{J}=16.0,7.3 \mathrm{~Hz}, 1 \mathrm{H}), 1.03(\mathrm{~s}$, $6 \mathrm{H}), 1.01(\mathrm{~s}, 6 \mathrm{H}) ;{ }^{13} \mathrm{C} \mathrm{NMR}\left(101 \mathrm{MHz}, \mathrm{CDCl}_{3}\right): \delta 180.66,157.53,135.52,133.69,129.27,128.83$, $127.04,126.46,126.39,118.81,105.55,83.38,55.24,46.75,24.60,24.53,15.96{ }^{11}$ B NMR (128 $\left.\mathrm{MHz}, \mathrm{CDCl}_{3}\right): \delta 33.79$ (br s). The ${ }^{13} \mathrm{C}$ NMR resonance at 15.96 (methylene carbon signal) has very low intensity due to ${ }^{11} \mathrm{~B}$ quadrupolar broadening

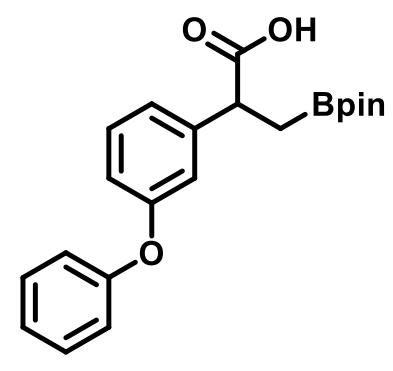

3-boronic acid pinacol ester-2-(3-phenoxyphenyl) propionic acid $\mathbf{2 k}$. clear oil, yield 58\% ${ }^{1} \mathrm{H}$ NMR (400 MHz, $\left.\mathrm{CDCl}_{3}\right): \delta 7.31(\mathrm{dd}, \mathrm{J}=8.6,7.4 \mathrm{~Hz}, 2 \mathrm{H}), 7.24(\mathrm{t}, \mathrm{J}=7.9 \mathrm{~Hz}$, 1H), 7.10-7.03 (m, 2H), 7.00-6.98 (m, 3H), 6.86 (ddd, J = 8.2, 2.4, $0.9 \mathrm{~Hz}, 1 \mathrm{H}), 3.83$ (dd, J = 9.3, $7.1 \mathrm{~Hz}, 1 \mathrm{H}), 1.53(\mathrm{dd}, \mathrm{J}=16.0,9.4 \mathrm{~Hz}, 1 \mathrm{H}), 1.26(\mathrm{dd}, \mathrm{J}=16.0,7.1 \mathrm{~Hz}, 1 \mathrm{H}), 1.16(\mathrm{~s}, 6 \mathrm{H}), 1.14(\mathrm{~s}$, $6 \mathrm{H}) ;{ }^{13} \mathrm{C}$ NMR (101 MHz, $\left.\mathrm{CDCl}_{3}\right): \delta 180.32,157.29,156.97,142.35,129.71,123.27,122.59$, 118.90, 118.46, 117.39, 83.45, 46.75, 24.66, 24.53, $15.90{ }^{11} \mathrm{~B}$ NMR (128 MHz, $\left.\mathrm{CDCl}_{3}\right): \delta 33.55$ (br s). The ${ }^{13} \mathrm{C}$ NMR resonance at 15.90 (methylene carbon signal) has very low intensity due to ${ }^{11} \mathrm{~B}$ quadrupolar broadening; HRMS (ESI) m/z calc. for $\mathrm{C}_{21} \mathrm{H}_{24} \mathrm{BO}_{5}^{-}[\mathrm{M}-\mathrm{H}]^{-} 367.17168$, found 367.17152 


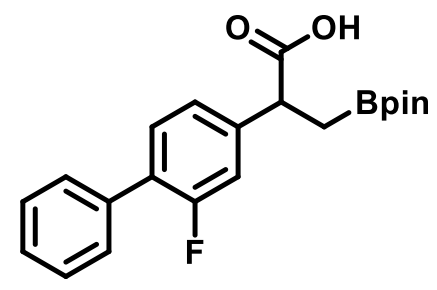

3-boronic acid pinacol ester-2-(3-fluorobiphenyl) propionic acid $2 \mathbf{2}$. white solid, yield 22\% ${ }^{1} \mathrm{H}$ NMR (400 MHz, $\left.\mathrm{CDCl}_{3}\right): \delta 7.51(\mathrm{~d}, \mathrm{~J}=7.8 \mathrm{~Hz}, 2 \mathrm{H}), 7.44-7.35(\mathrm{~m}, 4 \mathrm{H})$, 7.17-7.12 (m, 2H), $3.91(\mathrm{t}, \mathrm{J}=8.2 \mathrm{~Hz}, 1 \mathrm{H}), 1.58(\mathrm{dd}, \mathrm{J}=16.0,9.2 \mathrm{~Hz}, 1 \mathrm{H}), 1.32(\mathrm{dd}, \mathrm{J}=16.0,7.3$ $\mathrm{Hz}, 1 \mathrm{H}), 1.16$ (s, 6H), 1.15 (s, 6H); ${ }^{13} \mathrm{C}$ NMR $\left(101 \mathrm{MHz}, \mathrm{CDCl}_{3}\right): \delta 180.08,160.78,158.31,141.63$ $(\mathrm{d}, \mathrm{J}=7.8 \mathrm{~Hz}), 135.50,130.70,128.92,128.39,127.93,127.79,127.60,123.85,115.63$ (d, J = $23.7 \mathrm{~Hz}$ ), 83.55, 46.33, 24.63, 24.53, $16.00{ }^{11} \mathrm{~B}$ NMR (128 MHz, CDCl $)$ : $\delta 33.02$ (br s) ${ }^{19} \mathrm{~F}$ NMR (376 MHz, $\mathrm{CDCl}_{3}$ ): $\delta-117.76\left(\mathrm{t}, \mathrm{J}=9.8 \mathrm{~Hz}\right.$ ). The ${ }^{13} \mathrm{C}$ NMR resonance at 16.00 (methylene carbon signal) has very low intensity due to ${ }^{11} \mathrm{~B}$ quadrupolar broadening; HRMS (ESI) $\mathrm{m} / \mathrm{z}$ calc. for $\mathrm{C}_{21} \mathrm{H}_{23} \mathrm{BFO}_{4}^{-}[\mathrm{M}-\mathrm{H}]^{-} 369.16679$, found 369.16695

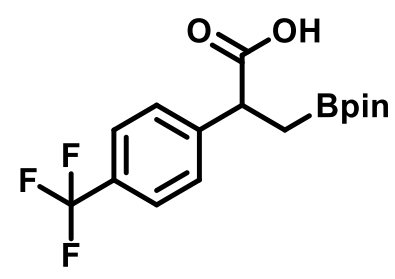

3-boronic acid pinacol ester-2-(4-trifluoromethylphenyl) propionic acid 2m. white solid, yield $18 \%{ }^{1} \mathrm{H}$ NMR $\left(400 \mathrm{MHz}, \mathrm{CDCl}_{3}\right): \delta 7.56(\mathrm{~d}, \mathrm{~J}=7.9 \mathrm{~Hz}, 2 \mathrm{H}), 7.43(\mathrm{~d}, \mathrm{~J}=$ $7.9 \mathrm{~Hz}, 2 \mathrm{H}), 3.93(\mathrm{t}, \mathrm{J}=8.0 \mathrm{~Hz}, 1 \mathrm{H}), 1.56(\mathrm{dd}, \mathrm{J}=15.9,9.1 \mathrm{~Hz}, 1 \mathrm{H}), 1.29(\mathrm{dd}, \mathrm{J}=15.9,7.5 \mathrm{~Hz}$, 1H), 1.13 (s, 6H), $1.13(\mathrm{~s}, 6 \mathrm{H}) ;{ }^{13} \mathrm{C}$ NMR (101 MHz, $\mathrm{CDCl}_{3}$ ): $\delta 179.65,144.29,129.47$ (q, J = $32.3 \mathrm{~Hz}$ ), 128.29, 125.42, 124.05 (q, J = 272.7 Hz), 83.52, 46.75, 24.55, 24.47, 15.87; ${ }^{11}$ B NMR (128 MHz, $\mathrm{CDCl}_{3}$ ): $\delta 33.04$ (br s) ${ }^{19} \mathrm{~F}$ NMR $\left(376 \mathrm{MHz}, \mathrm{CDCl}_{3}\right.$ ): $\delta-62.61$ (s). The ${ }^{13} \mathrm{C} \mathrm{NMR}$ resonance at 15.87 (methylene carbon signal) has very low intensity due to ${ }^{11} \mathrm{~B}$ quadrupolar broadening; HRMS (ESI) m/z calc. for $\mathrm{C}_{16} \mathrm{H}_{19} \mathrm{BF}_{3} \mathrm{O}_{4}^{-}[\mathrm{M}-\mathrm{H}]^{-} 343.13230$, found 343.13226

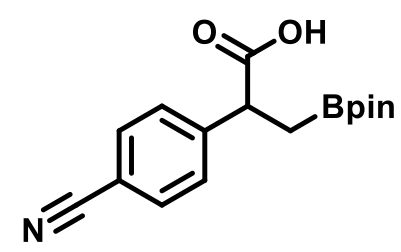

3-boronic acid pinacol ester-2-(4-cyanophenyl) propionic acid $\mathbf{2 n}$. white solid, yield 39\% ${ }^{1} \mathrm{H} \mathrm{NMR}\left(400 \mathrm{MHz}, \mathrm{CDCl}_{3}\right): \delta 7.60(\mathrm{~d}, \mathrm{~J}=7.7 \mathrm{~Hz}, 2 \mathrm{H}), 7.42(\mathrm{~d}, \mathrm{~J}=7.7 \mathrm{~Hz}, 2 \mathrm{H})$, 
$3.92(\mathrm{t}, \mathrm{J}=8.2 \mathrm{~Hz}, 1 \mathrm{H}), 1.55(\mathrm{dd}, \mathrm{J}=16.1,8.7 \mathrm{~Hz}, 1 \mathrm{H}), 1.30(\mathrm{dd}, \mathrm{J}=16.1,7.8 \mathrm{~Hz}, 1 \mathrm{H}), 1.13(\mathrm{~s}$, 12H); ${ }^{13} \mathrm{C}$ NMR (101 MHz, $\left.\mathrm{CDCl}_{3}\right): \delta 178.77,145.62,132.27,128.81,118.63,111.10,83.61$, 47.04, 24.56, 24.52, $15.58{ }^{11} \mathrm{~B}$ NMR (128 MHz, $\mathrm{CDCl}_{3}$ ): $\delta 33.22$ (br s). The ${ }^{13} \mathrm{C}$ NMR resonance at 15.58 (methylene carbon signal) has very low intensity due to ${ }^{11} \mathrm{~B}$ quadrupolar broadening; HRMS (ESI) m/z calc. for $\mathrm{C}_{16} \mathrm{H}_{19} \mathrm{BNO}_{4}^{-}[\mathrm{M}-\mathrm{H}]^{-} 300.14071$, found 300.14047

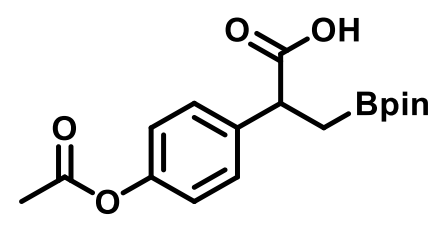

3-boronic acid pinacol ester-2-(4-acetoxyphenyl) propionic acid 20. white solid, yield 17\% ${ }^{1} \mathrm{H}$ NMR (400 MHz, $\left.\mathrm{CDCl}_{3}\right): \delta 7.31(\mathrm{~d}, \mathrm{~J}=8.0 \mathrm{~Hz}, 2 \mathrm{H}), 7.00(\mathrm{~d}, \mathrm{~J}=7.8$ $\mathrm{Hz}, 2 \mathrm{H}$ ), 3.85 (t, J = 8.1 Hz, 1H), 2.27 (s, 3H), 1.53 (dd, J = 16.0, $9.3 \mathrm{~Hz}, 1 \mathrm{H}), 1.27$ (dd, J = 16.0, $7.2 \mathrm{~Hz}, 1 \mathrm{H}), 1.14(\mathrm{~s}, 6 \mathrm{H}), 1.13(\mathrm{~s}, 6 \mathrm{H}) ;{ }^{13} \mathrm{C} \mathrm{NMR}\left(101 \mathrm{MHz}, \mathrm{CDCl}_{3}\right): \delta$ 179.87, 169.39, 149.69, $137.89,128.89,121.49,83.40,46.22,24.61,24.52,21.09,16.02 ;{ }^{11} \mathrm{~B} \mathrm{NMR}\left(128 \mathrm{MHz}, \mathrm{CDCl}_{3}\right): \delta$ 33.14 (br s). The ${ }^{13} \mathrm{C}$ NMR resonance at 16.02 (methylene carbon signal) has very low intensity due to ${ }^{11} \mathrm{~B}$ quadrupolar broadening; HRMS (ESI) m/z calc. for $\mathrm{C}_{17} \mathrm{H}_{22} \mathrm{BO}_{6}{ }^{-}[\mathrm{M}-\mathrm{H}]^{-} 333.15094$, found 333.15070

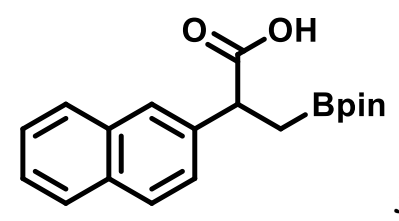

3-boronic acid pinacol ester-2-naphthyl propionic acid 2t. white solid, yield 65\% ${ }^{1} \mathrm{H}$ NMR (400 MHz, $\left.\mathrm{CDCl}_{3}\right): \delta$ 7.81-7.77 (m, 4H), 7.47-7.44 (m, 3H), $4.06(\mathrm{dd}, \mathrm{J}=$ 9.4, 7.2 Hz, 1H), 1.67 (dd, J = 16.0, 9.4 Hz, 1H), 1.39 (dd, J = 16.0, 7.2 Hz, 1H), 1.13 (s, 6H), 1.12 (s, 6H); ${ }^{13} \mathrm{C}$ NMR (101 MHz, $\left.\mathrm{CDCl}_{3}\right)$ : 180.57, 137.83, 133.34, 132.57, 128.19, 127.77, 127.53, 126.56, 125.98, 125.94, 125.69, 83.40, 46.95, 24.59, 24.51, 15.94; ${ }^{11} \mathrm{~B}$ NMR (128 MHz, $\left.\mathrm{CDCl}_{3}\right)$ : $\delta 33.01$ (br s). The ${ }^{13} \mathrm{C}$ NMR resonance at 15.94 (methylene carbon signal) has very low intensity due to ${ }^{11} \mathrm{~B}$ quadrupolar broadening 


\section{Chapter 3: Selective Deboronofluorination of Boracarboxylated Products}

\subsection{Introduction}

Based on our previous success of achieving boracarboxylation for a number of substrates, our next goal was to explore the synthetic utility of these compounds. One specific transformation that our group was interested in studying was the conversion of a carbon-boron bond to a carbonfluorine bond. One of the major reasons for the increasing interest of adding fluorine to an organic compound is derived from the unique properties that can be afforded in pharmaceuticals. Addition of fluorine to pharmaceutical targets can influence membrane permeability, potency, conformational changes, and pharmacokinetic properties. ${ }^{63}$ The influence that fluorination has on acidity, hydrogen-bonding, and lipophilicity affects the absorption and distribution, making it a very interesting and important moiety to biological activity. ${ }^{64}$

One major success has been in the development of fluorine-containing drugs used to treat disorders of the central nervous system. ${ }^{65}$ The antidepressant fluoxetine (Eli Lilly), more commonly known as Prozac, is one of the world's top 20 best-selling pharmaceuticals and achieves annual sales of one billion dollars in the United States. ${ }^{66}$ It has been shown that depression is linked to low levels of serotonin and that the inclusion of the fluorine functionality in Prozac can increase the potency for inhibiting serotonin uptake by 6-fold (Figure 3.1). ${ }^{67}$ Paroxetine (Paxil) is another treatment for depression which exhibits similar activity to Prozac but with a shorter duration of action. ${ }^{63}$ Other major fluorine-containing pharmaceuticals on the market are a cholesterollowering medication (Lipitor), nonsteroidal anti-inflammatory drug (Celebrex), and a treatment for type 2 diabetes (Januvia), all shown in Figure 3.1. ${ }^{68}$ It is interesting to note that $20 \%$ of all pharmaceuticals and $30 \%$ of agrochemicals contain at least one fluorine atom. ${ }^{69}$ Despite the abundance of fluorinated pharmaceuticals, the presence of an aliphatic fluorine is not as prevalent potentially due to the lack of methods to access these species. The first topical steroid for inflammation and pain associated with ocular surgery, difluprednate, contains two aliphatic fluorine moieties (Figure 3.1). ${ }^{70}$

The carbon-fluorine bond has also shown to have an integral role in tracers for positron emission tomography (PET). Some examples of fluorine-18 labeled PET imaging probes are $\left[{ }^{18} \mathrm{~F}\right] 6$-fluoro-L-DOPA, which is a PET ligand for probing cerebral dopamine metabolism and neuroendocrine tumors in humans, and $\left[{ }^{18} \mathrm{~F}\right] \mathrm{FDG}$ for studying glucose metabolism (Figure 3.2). 
The latter is the best clinically known and most successful commercial PET radiopharmaceutical. ${ }^{71}$ The prevalence of fluorine in this field is another motivation for the synthetic community to be able to effectively introduce a fluorine atom into an organic molecule.<smiles>CNCCC(Oc1ccc(C(F)(F)F)cc1)c1ccccc1</smiles>

Fluoxetine

(Prozac)

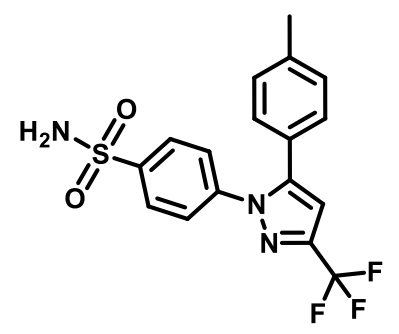

Celecoxib

(Celebrex)<smiles>Fc1ccc([C@H]2CCNC[C@H]2COc2ccc3c(c2)OCO3)cc1</smiles>

Paroxetine

(Paxil)

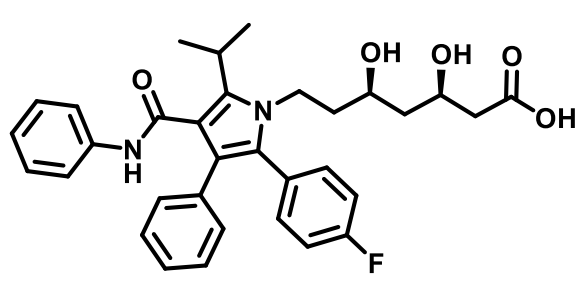

Atorvastatin

(Lipitor)

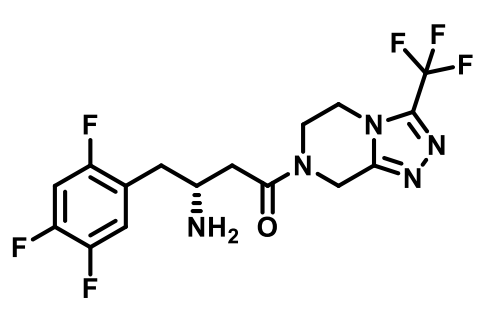

Sitagliptin

(Januvia)

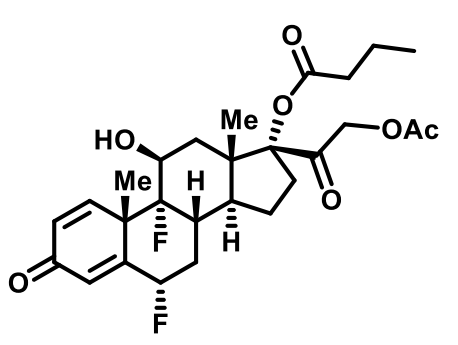

Difluprednate

(Durezol)

Figure 3.1 Structures of important fluorine-containing pharmaceuticals

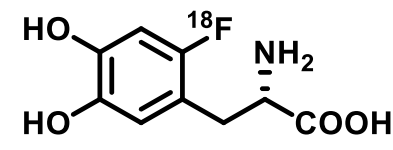

PET tracer for L-DOPA

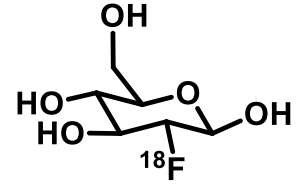

PET tracer for 2-deoxy-D-glucose

Figure 3.2 Structures of fluorine-containing PET tracers

Despite that fluorine's high electronegativity and small size can provide strong polar interactions in organic molecules, these properties also result in difficulties with carbon-fluorine bond formation. ${ }^{72}$ Based on its ability to form strong hydrogen bonds, fluorine is weakly nucleophilic in the presence of hydrogen-bond donors, which limits access to C-F bond formation via conventional nucleophilic substitution reactions. The Balz-Schiemann reaction is a traditional route to access aryl fluorides from anilines via the thermal decomposition of aryl diazonium tetrafluoroborate salts (Scheme 3.1). ${ }^{73}$ Published in 1927, it is the earliest example of the $\mathrm{BF}_{4}^{-}$ion 
as a nucleophilic fluoride source. ${ }^{74}$ Another traditional route is the Halex process, which involves the conversion of halogens to fluorine atoms. The first report in 1936 demonstrated the conversion of 2,4-dinitrochlorobenzene to 2,4-dinitrofluorobenzene, commonly known as Sanger's reagent (Scheme 3.2). ${ }^{75}$ Sanger's reagent is used for the labeling of peptides and terminal amino acid groups in proteins, which has promoted this $S_{\mathrm{N}} 2$ pathway to be routinely used on an industrial scale to synthesize a range of similar derivatives. ${ }^{76}$ Although versatile, the Balz-Schiemann and Halex reactions require high temperatures and highly reactive intermediates that limit substrate scope and feasibility. In an effort to develop new ways to selectively introduce fluorine into organic molecules, electrophilic fluorination has proven to be a viable route. The development of $N$-fluorobis(phenyl)sulfonamide (NFSI), $N$-fluoropyridium salts, and 1-chloromethyl-4-fluoro1,4-diazoniabicyclo[2.2.2]octane bis(tetrafluoroborate) (Selectfluor) provided bench-stable fluorination reagents that could be used to achieve selective reactivity (Figure 3.3). ${ }^{77}$

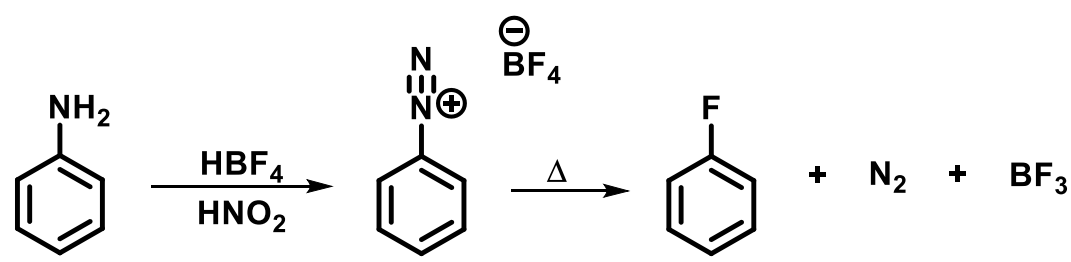

Scheme 3.1 Balz-Schiemann reaction

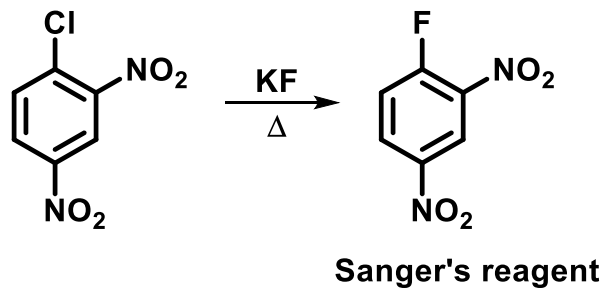

Scheme 3.2 Halex reaction

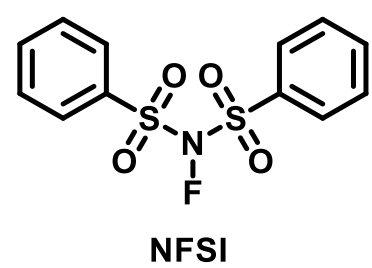

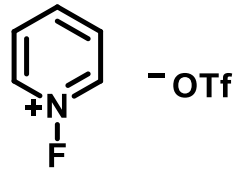

$\mathrm{N}$-fluoropyridium salt

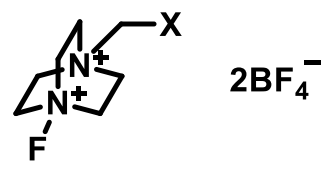

Selectfluor, $X=C I$ Selectfluor II, X= H

Figure 3.3 Structures of some common electrophilic fluorinating reagents 
Due to its fluorination performance and ease of handling, Selectfluor has become a prominent electrophilic fluorination reagent for many applications since its discovery in the 1990s. ${ }^{78,79}$ Through the use of Selectfluor, there have been a number of processes that investigate the transformation of the carbon-boron bond to a carbon-fluorine bond. One example by the Ritter group is a silver-mediated fluorination process involving the use of aryl and alkenyl boronic acids, along with the commercially available and versatile Selectfluor reagent, to achieve fluorinated aromatic compounds. ${ }^{80}$ When boronic acids are treated with $\mathrm{NaOH}$ in methanol, followed by AgOTf, an aryl silver intermediate was formed and isolated from this transmetalation step. Subsequent fluorination was then achieved with the use of Selectfluor (Scheme 3.3). Another methodology involves the electrophilic fluorination of alkenyl boronic acids and trifluoroborates. ${ }^{81}$ Because the fluorination of alkenyl boronic acids was deemed slow, the acid was transformed to the trifluoroborate salt and then reacted with Selectfluor to form the corresponding fluorinated alkenes (Scheme 3.4). This reaction has been described as synthetically appealing due to the use of mild conditions, relatively cheap and non-toxic reagents, and can be performed in acetonitrile or water.
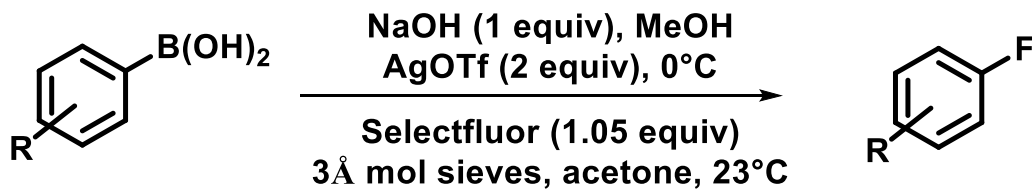

Scheme 3.3 Ritter's silver-mediated fluorination of boronic acids

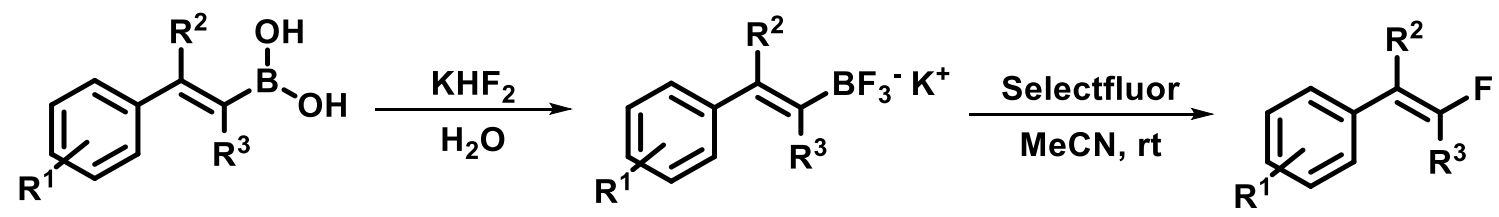

Scheme 3.4 Fluorination of alkenyl boronic acids and trifluoroborates

Although there has been extensive progress in the fluorination of aromatic and alkenyl organoboron compounds, it seems that aliphatic fluorination techniques have been less explored. In one report, Lemaire and co-workers developed a strategy to achieve metal-free electrophilic fluorination of aryl trifluoroborates and boronic acids in which they demonstrate one example of fluorination of an alkyl trifluoroborate. ${ }^{82}$ Fluorination was achieved at the benzylic position in a 
75\% isolated yield when starting from 1-phenylethyltrifluoroborate (Scheme 3.5). A few years later, Aggarwal demonstrated the ability to convert chiral boronic esters into alkylfluorides. ${ }^{83}$ The starting boronic ester was transformed into a boronate intermediate using $\mathrm{PhLi}$ as a nucleophile. Using styrene as a radial trap, Selectfluor II was used as the electrophilic fluorinating agent to afford alkylfluoride products with high enantiospecificity (Scheme 3.6).

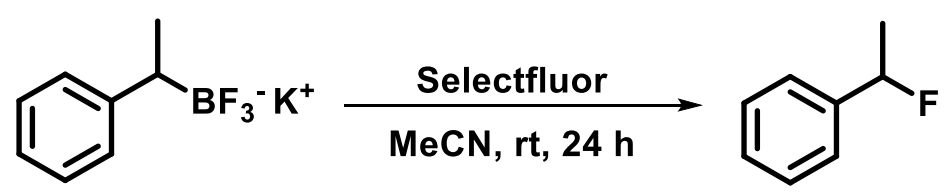

Scheme 3.5 Metal-free electrophilic fluorination of alkyl trifluoroborates

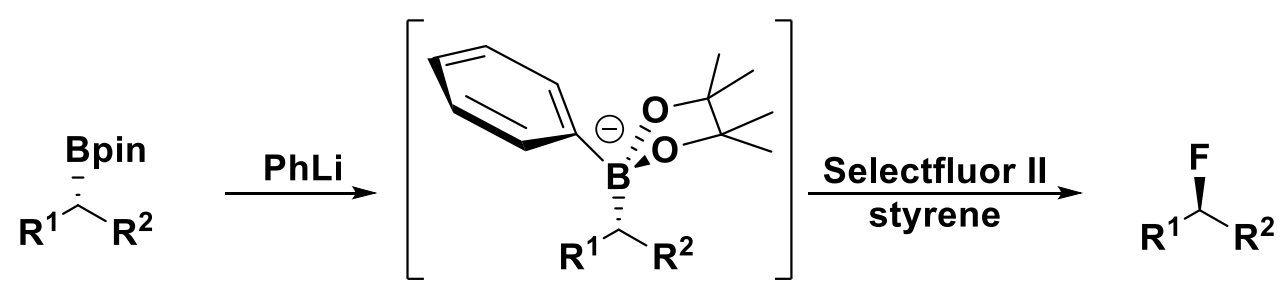

Scheme 3.6 Aggarwal's fluorination of boronate esters

Another method developed for the fluorination of alkylboronates demonstrated the ability to achieve a silver-catalyzed site-specific fluorination pathway. ${ }^{84}$ Primary, secondary, and tertiary alkylboronates reacted with Selectfluor in an acidic aqueous solution afforded alkyl fluorides (Scheme 3.7). Very interestingly, the Li group reported a similar methodology for a decarboxylative fluorination pathway just a few years earlier. ${ }^{85}$ Using Selectfluor as the fluorine source and $\mathrm{AgNO}_{3}$ as the catalyst, carboxylic acids underwent decarboxylative fluorination in aqueous solution to afford site-specific fluorination (Scheme 3.8).
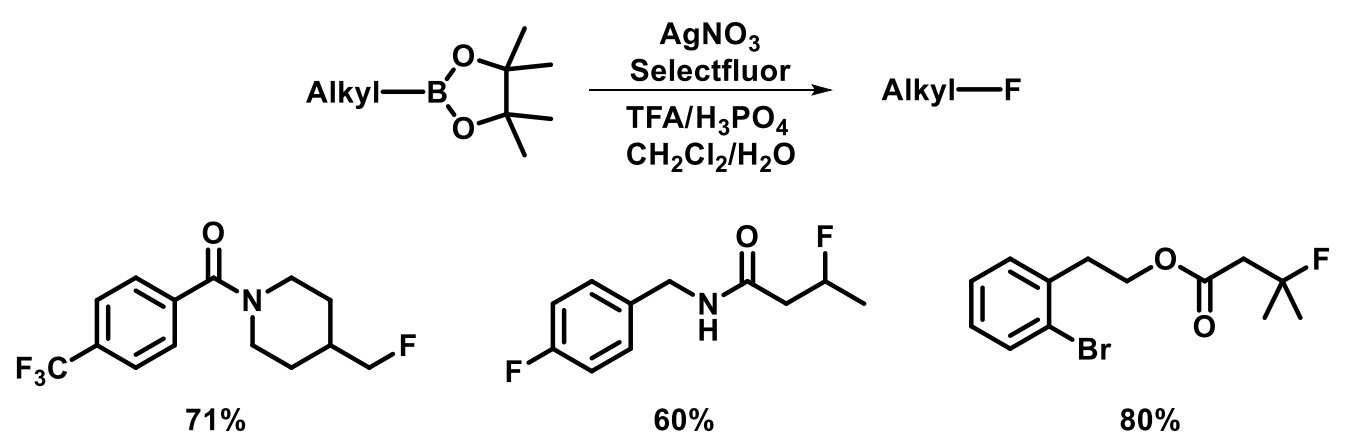

Scheme 3.7 Li's silver-catalyzed fluorination of alkylboronates 


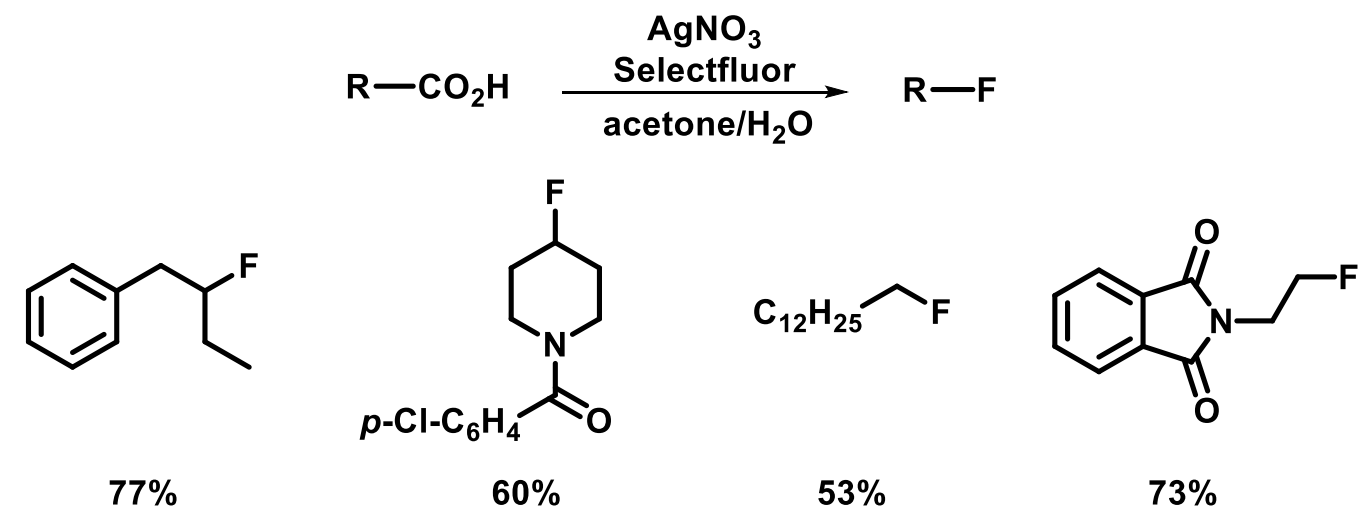

Scheme 3.8 Li's silver-catalyzed decarboxylative fluorination

\subsection{Results}

3.2.1 Optimization for deboronofluorination of boracarboxylated products

Initial efforts to fluorinate our boracarboxylated products involved subjecting the compounds to the Aggarwal fluorination conditions discussed above. The Aggarwal methodology utilizes boronate complexes to achieve fluorination so we choose to use our synthesized difluoroboralactone species as a more nucleophilic boron reagent. The para-methyl difluoroboralactone, $8 \mathrm{c}$, was reacted with Selectfluor in the presence of styrene in acetonitrile (Scheme 3.9). The reaction was then treated with $\mathrm{NaOH}$ and $\mathrm{H}_{2} \mathrm{O}_{2}$ in order to oxidize any leftover boron species. Instead of achieving the desired fluorinated product, $5 \mathrm{c}$, the boron was just oxidized to an alcohol to form the tropic acid derivative. Using more harsh conditions, the reaction was performed at an elevated temperature of $40^{\circ} \mathrm{C}$ and resulted in similar reactivity.

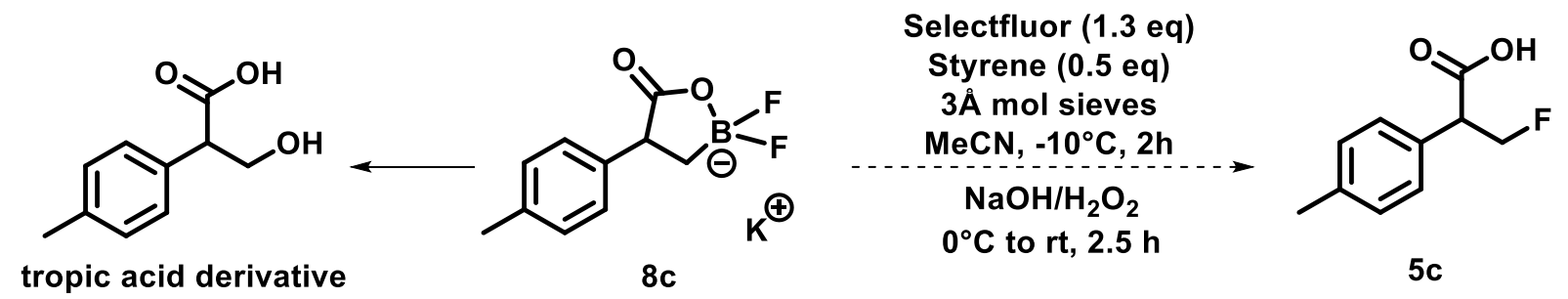

Scheme 3.9 Difluoroboralactone species subjected to Aggarwal fluorination conditions 


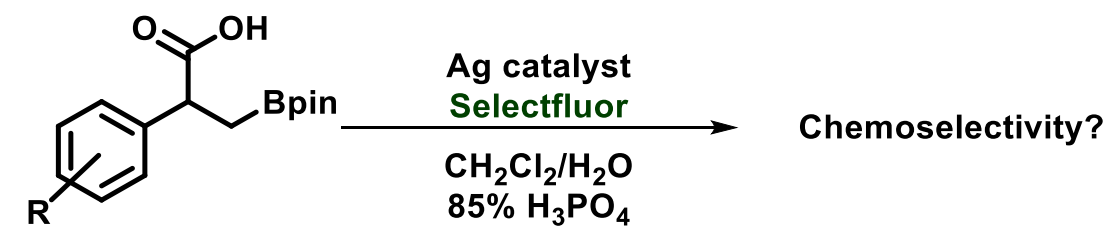

Scheme 3.10 Boracarboxylated products subjected to Li fluorination conditions

Based on the two methodologies by the Li group discussed above, the Popp group wanted to examine the chemoselectivity achieved when subjecting the boracarboxylated products to fluorination conditions (Scheme 3.10). We were interested due to the presence of both the carboxylic acid and boron moiety in these compounds. Both processes by $\mathrm{Li}$ utilize $\mathrm{AgNO}_{3}$ as the catalyst and Selectfluor as the electrophilic fluorination source. The only difference is that the decarboxylative fluorination occurs in neutral aqueous media while deboronofluorination occurs in acidic aqueous solution. While screening with Li's deboronofluorination conditions, we choose to use the tert-butyl boracarboxylated product due to its high yield, ease of purification, and ability to synthesize on a multi-gram scale. This model substrate was subjected to a silver catalyst, Selectfluor as the electrophilic fluorine source, and a biphasic solvent system made up of $\mathrm{CH}_{2} \mathrm{Cl}_{2}$, $\mathrm{H}_{2} \mathrm{O}$, and $\mathrm{H}_{3} \mathrm{PO}_{4}$. The reaction is refluxed to yield a chemoselective deboronofluorination product, $5 b$, as well as a difluorination product, $6 \mathrm{~b}$, resulting from a deborono- and decarboxylative process. It is important to note that the decarboxylative monofluorination with Bpin still present is not an observed by-product of the reaction (Table 3.1).

Similarly to the Li conditions, various silver salts with the addition of trifluoroacetic acid were examined (entries 1-5, Table 3.1). These are all soluble silver (I) salts that we believed could act as an active catalyst. The use of $\mathrm{AgBF}_{4}$ without an increase in yield shows that the $\mathrm{BF}_{4}^{-}$ion is not responsible for any decomposition to a nucleophilic fluoride source (entry 2, Table 3.1). To our delight, the absence of trifluoroacetic acid increased the yield of our desired deboronofluorination product. Without the TFA additive, some additional silver salt screening showed that $\mathrm{AgNO}_{3}$ is the optimal catalyst for this transformation (entries 6-10, Table 3.1). 
Table 3.1 Screening of silver catalysts for deboronofluorination ${ }^{a}$

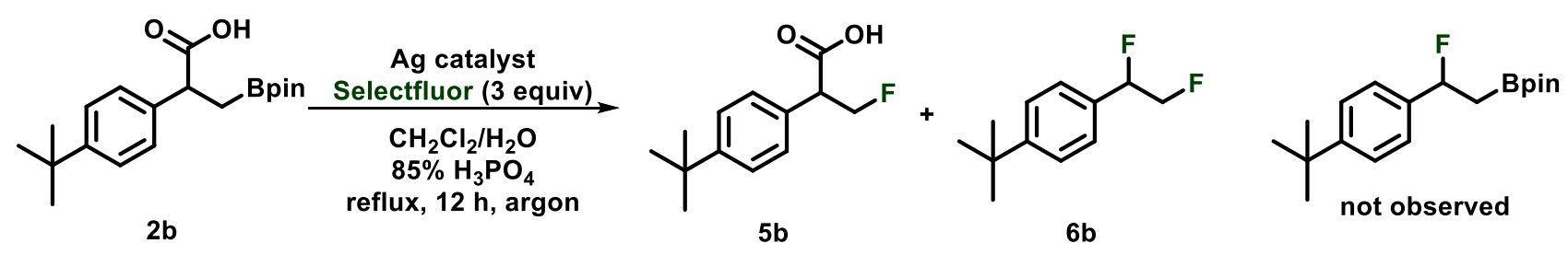

\begin{tabular}{|c|c|c|c|c|}
\hline \multirow[t]{2}{*}{ Entry } & \multirow[t]{2}{*}{ Ag Catalyst/Loading } & \multirow[t]{2}{*}{ Additive } & \multicolumn{2}{|c|}{ Yield $(\%)^{b}$} \\
\hline & & & $5 b$ & $6 b$ \\
\hline 1 & $20 \mathrm{~mol}^{\%} \mathrm{AgNO}_{3}$ & TFA & 58 & 9 \\
\hline 2 & $20 \mathrm{~mol}^{\circ} \mathrm{AgBF}_{4}$ & TFA & 56 & 11 \\
\hline 3 & $20 \mathrm{~mol} \% \mathrm{Ag}_{2} \mathrm{CO}_{3}$ & TFA & 54 & 10 \\
\hline 4 & $20 \mathrm{~mol} \% \mathrm{AgF}$ & TFA & 34 & 5 \\
\hline 5 & $20 \mathrm{~mol} \% \mathrm{Ag}_{2} \mathrm{O}$ & TFA & 33 & $<5$ \\
\hline 6 & $20 \mathrm{~mol} \% \mathrm{AgNO}_{3}$ & & 68 & 7 \\
\hline 7 & $20 \mathrm{~mol}^{\circ} \mathrm{AgBF}_{4}$ & & 63 & 9 \\
\hline 8 & $20 \mathrm{~mol} \% \mathrm{Ag}_{2} \mathrm{CO}_{3}$ & & 54 & 12 \\
\hline 9 & $20 \mathrm{~mol} \%$ AgOAc & & 65 & 5 \\
\hline 10 & $20 \mathrm{~mol} \%$ AgTFA & & 49 & $<5$ \\
\hline
\end{tabular}

Based on the unexpected increased yields obtained from removing trifluoroacetic acid as an additive, we wanted to test if just a catalytic amount of TFA would be useful in this transformation (entry 1, Table 3.2). There seemed to be no change in the yield of 5b so TFA was completely omitted from all future screening and substrate scope investigation. While screening solvent ratios, the absence of $\mathrm{H}_{3} \mathrm{PO}_{4}$ resulted in a lower yield of $5 \mathrm{~b}$ product and a much higher yield of $6 \mathrm{~b}$ (entry 2 , Table 3.2). This result is consistent with a non-acidic solvent condition observed by $\mathrm{Li}$, which favors a decarboxylative fluorination pathway. However, when the volume of $\mathrm{H}_{3} \mathrm{PO}_{4}$ was doubled, the yield of $5 \mathrm{~b}$ was slightly decreased (entry 3 , Table 3.2) so there seems to be an optimal intermediate amount of acid that is necessary for reactivity. The lowering of $\mathrm{AgNO}_{3}$ loading to $10 \mathrm{~mol} \%$ actually resulted in a similar yield of product distribution; however, reaction yields dropped off when lowered to only $5 \mathrm{~mol} \%$ (entries 4 and 5, Table 3.2). It is also observed that the yield of $5 \mathrm{~b}$ significantly decreases when attempting to decrease the Selectfluor from 3 to 1.5 equivalents (entry 6, Table 3.2). When performing the reaction under air, the yield of $5 \mathrm{~b}$ was significantly diminished (entry 7 , Table 3.2 ). This can be attributed to the detriment of 
having an external oxidant other than silver during the reaction. Reducing reaction time to 2 hours showed no change in reactivity, allowing for reaction times to be significantly shortened (entry 8 Table 3.2). Finally, control experiments were performed in the absence of Selectfluor and $\mathrm{AgNO}_{3}$, respectively (entries 9-10, Table 3.2). Both control studies resulted in no yield of monofluorination or difluorination products which signifies the necessity for both Selectfluor and $\mathrm{AgNO}_{3}$ in order to achieve fluorination.

Table 3.2 Screening of reaction conditions for deboronofluorination ${ }^{a}$

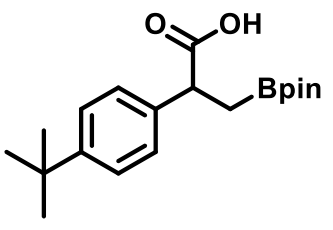

$2 b$

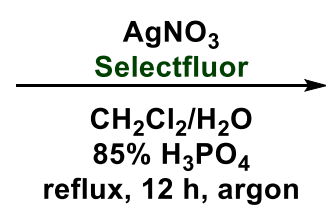

reflux, $12 \mathrm{~h}$, argon

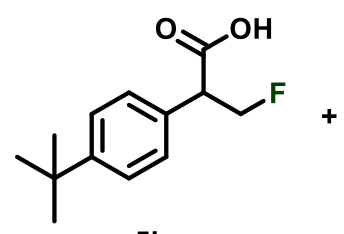

$5 b$<smiles>CC(C)(C)c1ccc(C(F)CF)cc1</smiles>

$6 b$<smiles>CC(C)(C)c1ccc(C(F)CBr)cc1</smiles>

not observed

\begin{tabular}{|c|c|c|c|c|c|}
\hline \multirow[t]{2}{*}{ Entry } & \multirow[t]{2}{*}{ Ag Catalyst/Loading } & \multirow[t]{2}{*}{ Selectfluor (equiv) } & \multirow[t]{2}{*}{ Variation } & \multicolumn{2}{|c|}{ Yield $(\%)^{b}$} \\
\hline & & & & $5 \mathbf{b}$ & $6 b$ \\
\hline 1 & $20 \mathrm{~mol}_{\%} \mathrm{AgNO}_{3}$ & 3 & Catalytic TFA (40 mol\%) & 67 & $<5$ \\
\hline 2 & $20 \mathrm{~mol} \% \mathrm{AgNO}_{3}$ & 3 & No $\mathrm{H}_{3} \mathrm{PO}_{4}$ added & 51 & 18 \\
\hline 3 & $20 \mathrm{~mol} \% \mathrm{AgNO}_{3}$ & 3 & Double $\mathrm{H}_{3} \mathrm{PO}_{4}$ added & 60 & $<5$ \\
\hline 4 & $10 \mathrm{~mol}^{\%} \mathrm{AgNO}_{3}$ & 3 & & 72 & $<5$ \\
\hline 5 & $5 \mathrm{~mol}^{2} \mathrm{AgNO}_{3}$ & 3 & & 58 & $<5$ \\
\hline 6 & $10 \mathrm{~mol} \% \mathrm{AgNO}_{3}$ & 1.5 & & 44 & $<5$ \\
\hline 7 & $10 \mathrm{~mol}_{\%} \mathrm{AgNO}_{3}$ & 3 & Conducted under air & 15 & $<5$ \\
\hline 8 & $10 \mathrm{~mol} \% \mathrm{AgNO}_{3}$ & 3 & Reaction for $\mathbf{2} \mathbf{~ h}$ & 71 & $<5$ \\
\hline 9 & $20 \mathrm{~mol}_{\%} \mathrm{AgNO}_{3}$ & - & & 0 & 0 \\
\hline 10 & - & 3 & & 0 & 0 \\
\hline
\end{tabular}

${ }^{a}$ Boracarboxylated vinyl arene $(0.20 \mathrm{mmol})$ in $\mathrm{CH}_{2} \mathrm{Cl}_{2}(3 \mathrm{~mL}), \mathrm{H}_{2} \mathrm{O}(3.5 \mathrm{~mL})$, and $\mathrm{H}_{3} \mathrm{PO}_{4}(0.1 \mathrm{~mL})^{b}$ Yields were determined by ${ }^{19} \mathrm{~F}$ NMR spectroscopy using fluorobenzene as the internal standard 


\subsubsection{Investigation of substrate scope for deboronofluorination}

Table 3.3 Substrate scope for the deboronofluorination of boracarboxylated products ${ }^{a}$

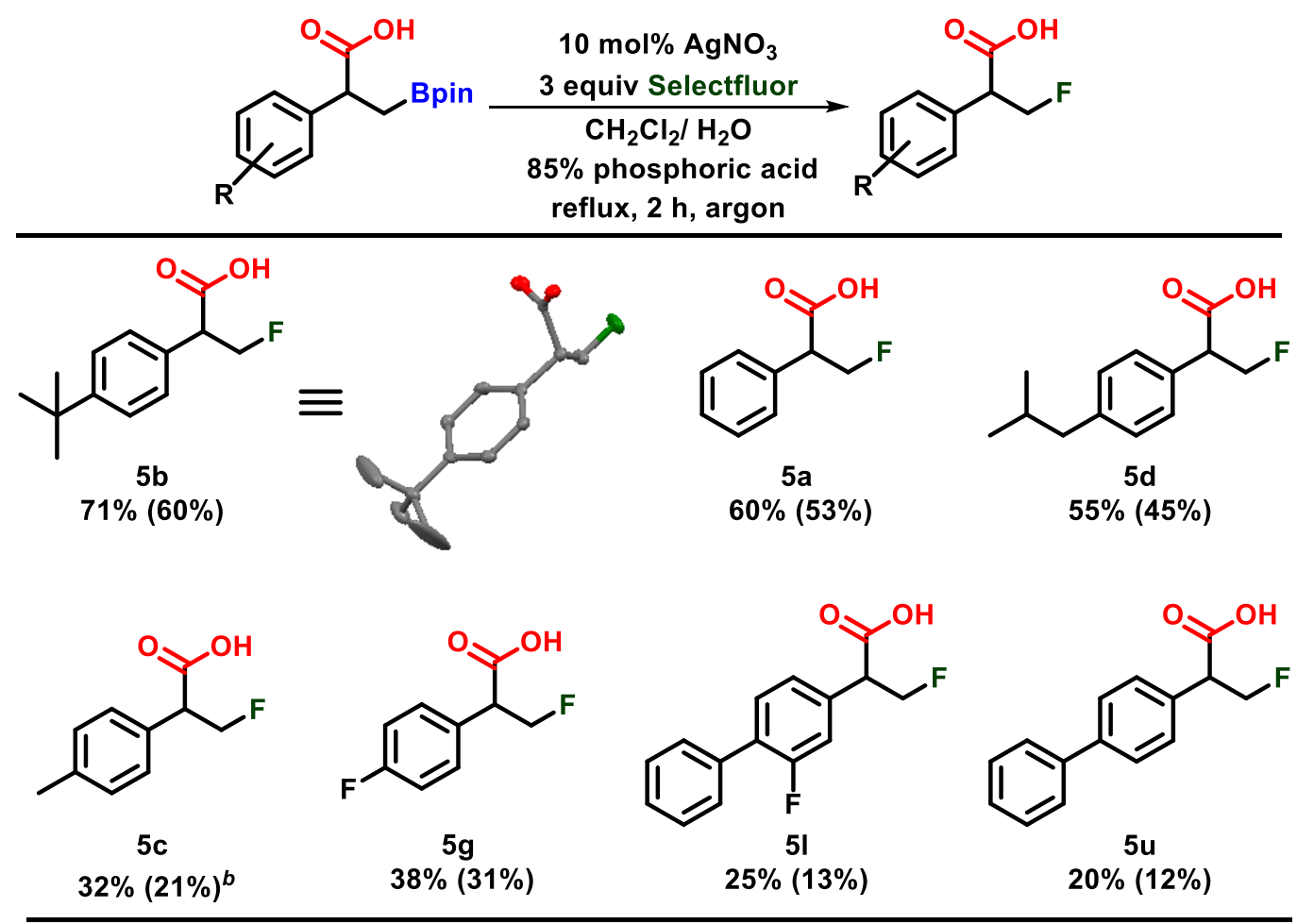

${ }^{a}$ Boracarboxylated vinyl arene $(0.20 \mathrm{mmol})$ in $\mathrm{CH}_{2} \mathrm{Cl}_{2}(3 \mathrm{~mL}), \mathrm{H}_{2} \mathrm{O}(3.5 \mathrm{~mL})$, and $\mathrm{H}_{3} \mathrm{PO}_{4}(0.1 \mathrm{~mL})$. Yields were determined by ${ }^{19} \mathrm{~F}$ NMR spectroscopy using fluorobenzene as the internal standard and isolated yields are reported in parentheses. ${ }^{b}$ Reaction ran for $1 \mathrm{~h}$.

With the optimal conditions at hand, we began to investigate the substrate scope of this fluorination pathway. Electron-neutral and bulky electron-donating groups were tolerated in moderate to good yields (Table 3.3, 5a, 5b, and 5d). Chemoselectivity was confirmed through Xray crystallography of the tert-butyl substrate (5b), shown in Table 3.3 and Appendix I. We were pleased to be able to obtain the novel NSAID fluoro-ibuprofen in a moderate yield (5d). At present, there is only one other synthetic route to access $\beta$-fluoro-ibuprofen. This reported method utilizes an iridium catalyst bearing a phosphoamidite ligand to achieve the regioselective and enantioselective allylic alkylation of fluorobis(phenylsulfonyl)methane. ${ }^{86}$ The sulfonyl functional groups are removed by treatment with magnesium in methanol followed by subsequent rutheniumcatalyzed oxidation (Scheme 3.11). This patented method outlines that these NSAID derivatives 
can have some interesting medicinal chemistry applications. Based on the chemoselectivity that is observed in our catalytic systems, we sought to access this same fluoro-NSAID from a more direct pathway of boracarboxylation and subsequent fluorination of the para-isobutylstyrene. We believe that is an attractive synthesis because it reduces the number of steps to the desired target and moves away from the use of precious metals of iridium and ruthenium.
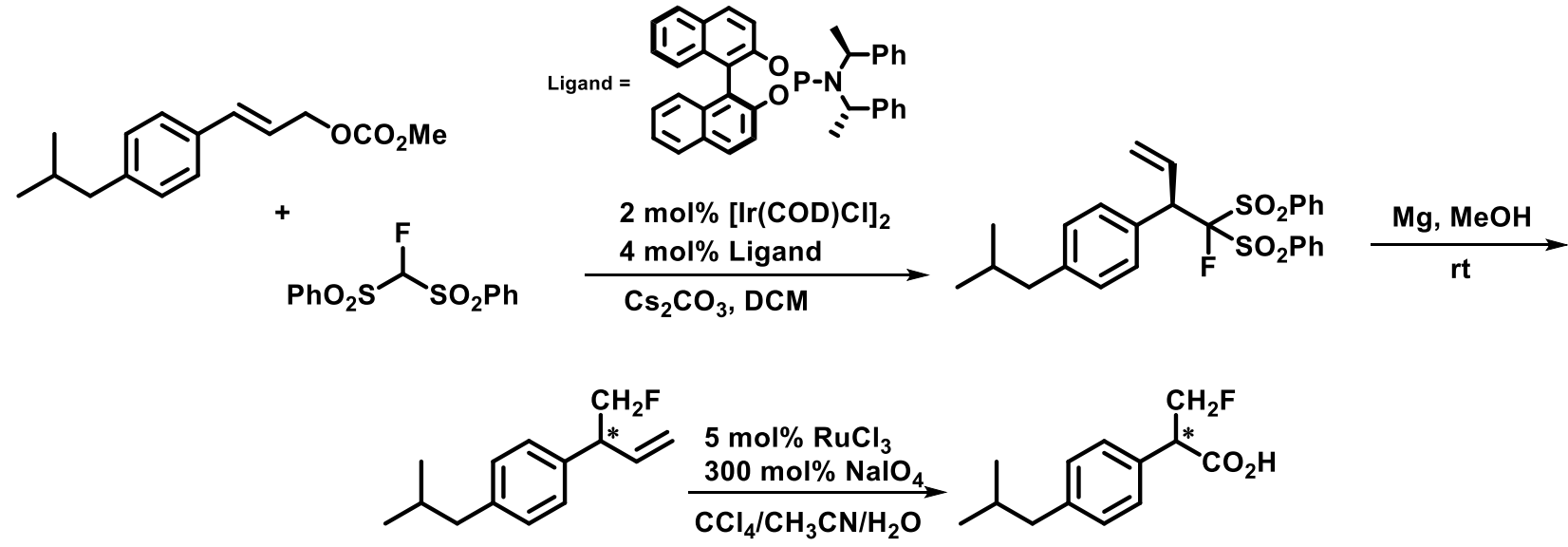

Scheme 3.11 Synthesis of fluorinated ibuprofen (using iridium and ruthenium)

With knowledge of electron-donating substituents achieving chemoselective fluorination reactivity, we sought to subject the para-methyl boracarboxylation product to our conditions. The low yield of $21 \%$ for the para-methyl substrate $(5 \mathrm{c})$ did not reflect the same pattern of reactivity seen with other electron-donating substrates. While screening alternative conditions to optimize reactivity for this substrate, we discovered two other by-products (6c and 7c) that were being formed in relatively equal amounts to our desired deboronofluorination product, shown in Figure 3.4. Time course data revealed that the fluorination of boracarboxylated para-methylstyrene yielded a majority of deboronofluorination product with smaller amounts of the two major byproducts early in the reaction. As the reaction time increases, the deboronofluorination product is consumed by either decarboxylative fluorination or fluorination on the methyl substituent to produce two distinct difluorinated compounds. For this reason, the para-methyl substrate was only reacted one hour in the substrate scope (Table 3.3) before other reactivity was initiated. 


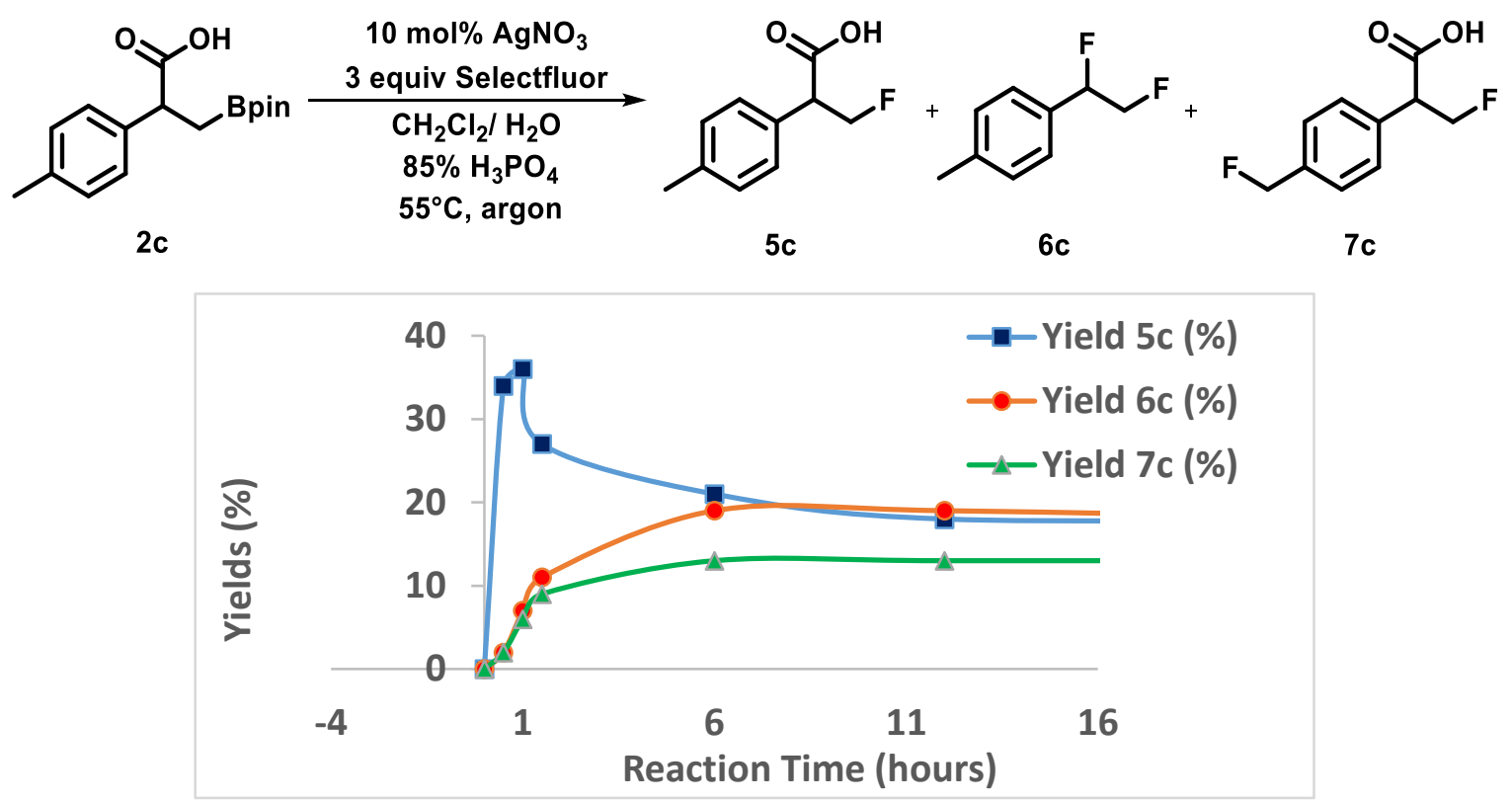

Figure 3.4 Time course for p-Me substrate fluorination

Based on the observation of the two other by-products for the fluorination of the p-methyl substrate, we sought to investigate the optimization of this substrate further (Table 3.4). The boracarboxylated products can be transformed into a difluoroboralactone species by the use of $\mathrm{KHF}_{2}$ in 1:1 THF/water. We hypothesized that this difluoroboralactonate salt could be a more nucleophilic source due to the tetra-coordinate boron center. When subjecting the $\mathrm{p}-\mathrm{Me}$ difluoroboralactone species to our fluorination conditions, there was no improvement in yield (Table 3.4, entry 1). We also tried addition of TFA; however, no increase in yield of $5 \mathrm{c}$ was observed (Table 3.4, entry 2). We attempted to use more harsh conditions by increasing to $80^{\circ} \mathrm{C}$ and $100^{\circ} \mathrm{C}$ in dichloroethane but this did not seem to have any effect on reactivity (Table 3.4, entries 3-4). The last series of experiments that we screened was varying the amount of phosphoric acid. When $\mathrm{H}_{3} \mathrm{PO}_{4}$ was omitted from the reaction, there was a significant shift in reactivity to form more of product $6 \mathrm{c}$ (Table 3.4, entry 5). This makes sense because in the absence of acid, these conditions more resemble a neutral aqueous solution in which decarboxylative fluorination is favorable. The addition of three or even ten times the amount of $\mathrm{H}_{3} \mathrm{PO}_{4}$ did not have a dramatic effect on reactivity (Table 3.4, entries 6-7). Based on these observations, $2 \mathrm{c}$ was run at a shorter reaction time of 1 hour in order to prevent further reactivity to produce $6 \mathrm{c}$ and $7 \mathrm{c}$; however, no other optimization could be achieved to obtain a higher yield. 
Table 3.4 Further screening to attempt to improve p-Me substrate fluorination

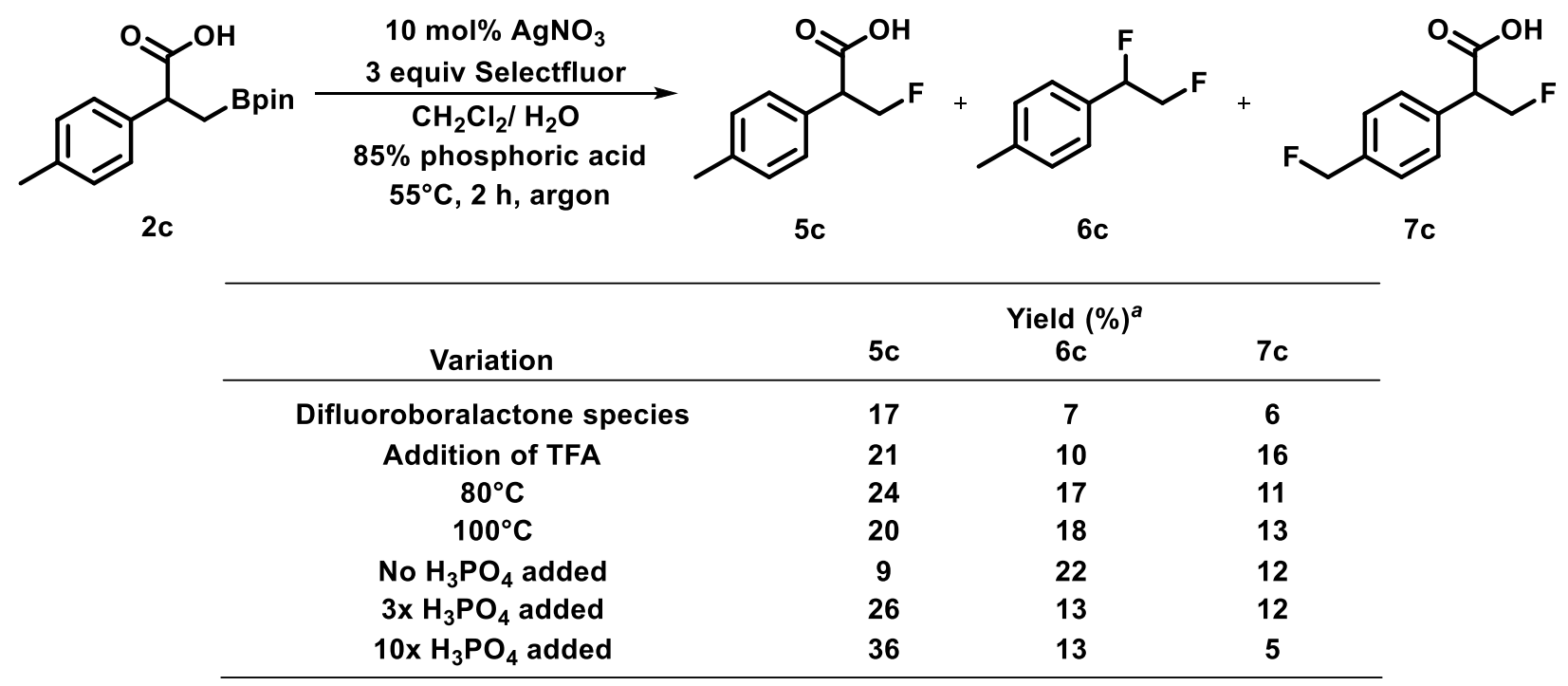

${ }^{a}$ Yields were determined by ${ }^{19} \mathrm{~F}$ NMR spectroscopy using fluorobenzene as the internal standard. At elevated temperature variation, reactions were conducted in 1,2-dichloroethane.

The use of slightly electron-deficient substrates seemed to reduce reactivity, as seen by the para-fluoro (5g), flurbiprofen (51), and biphenyl (5u) derivatives (Table 3.3). These substrates exhibited relatively low yields of about $20-30 \%$ before isolation. Based on NMR analysis, other major products of these three substrates include a relatively high yield of difluorinated species, arising from decarboxylative fluorination and deboronofluorination, which is a common byproduct of all substrates shown above. Other major by-products for these substrates are the formal hydrocarboxylation product, which arises from a protodeboration pathway, as well as other fluorinated aromatic products arising from electrophilic aromatic substitution reactivity. To show an example of this observed reactivity, the ${ }^{19} \mathrm{~F}$ NMR spectrum of the crude reaction mixture for the fluorination of the boracarboxylated flurbiprofen substrate is shown in Figure 3.5. In the region of -116.5 to $-119.5 \mathrm{ppm}$, the spectrum shows a large number $(\sim 7)$ of fluorinated aromatic species arising from electrophilic aromatic substitution. 


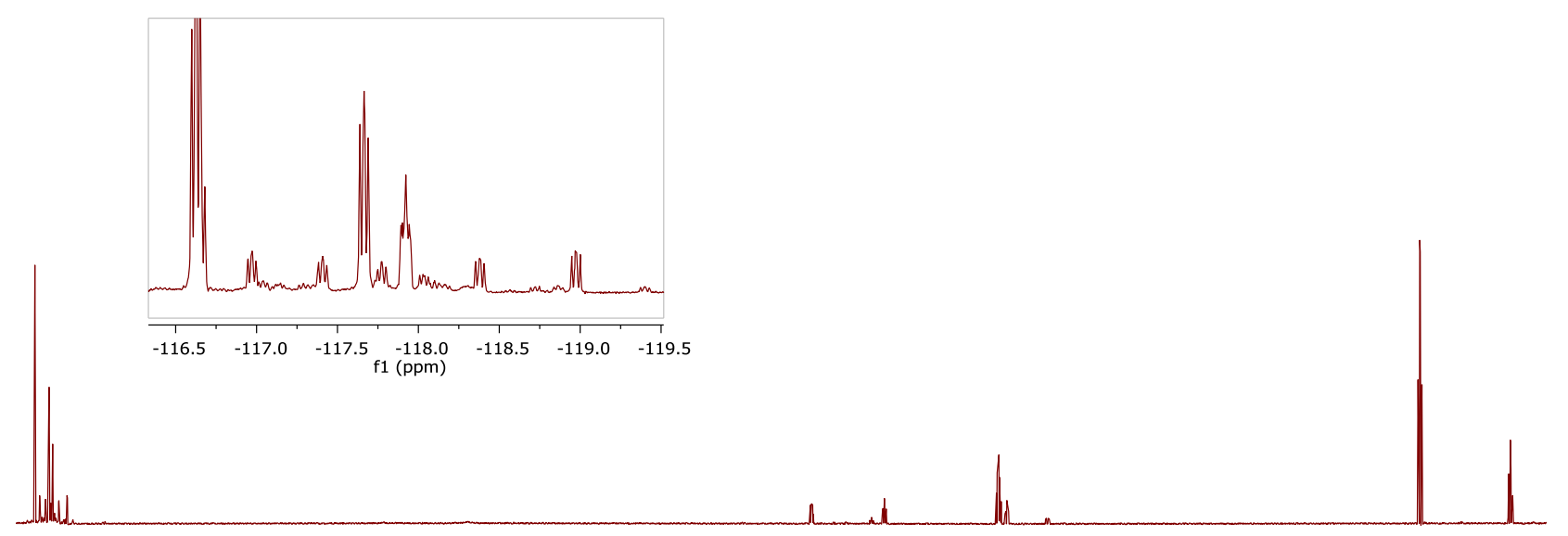

\begin{tabular}{lllllllllllllllllllllllll}
\hline & 15 & -120 & -125 & -130 & -135 & -140 & -145 & -150 & -155 & -160 & -165 & -170 & -175 & -180 & -185 & -190 & -195 & -200 & -205 & -210 & -215 & -220 & -225
\end{tabular}

Figure $3.5{ }^{19} \mathrm{~F}$ NMR spectrum of crude reaction mixture of fluorination of boracarboxylated flurbiprofen

One other particular substrate of interest to fluorinate was the para-trifluoromethyl boracarboxylated product because this would provide access to a highly fluorinated compound. Unfortunately, the electron-withdrawing para-trifluoromethyl fluorination product $(5 \mathrm{~m})$ showed minimal reactivity under deboronofluorination conditions (Table 3.5). This transformation also shows functional group sensitivity. The use of a methoxy substituent ( $5 \mathrm{e}$ and $5 \mathrm{j}$ ) does not tolerate the reaction conditions with or without the use of phosphoric acid. The naphthyl substrate $(5 \mathrm{t})$ also showed very minimal yield for deboronofluorination (Table 3.5). Although some substrates show site selectivity and good yields, we have demonstrated other substrates suffer due to electronics or functional group tolerance. With these substrates, there was still starting material left over along with other many minimal by-products $(<10 \%)$ from electrophilic aromatic substitution chemistry. In these cases, there was no product isolation due to low yields and undesirable by-products. 
Table 3.5 Unsuccessful substrates for the deboronofluorination of boracarboxylated products ${ }^{a}$

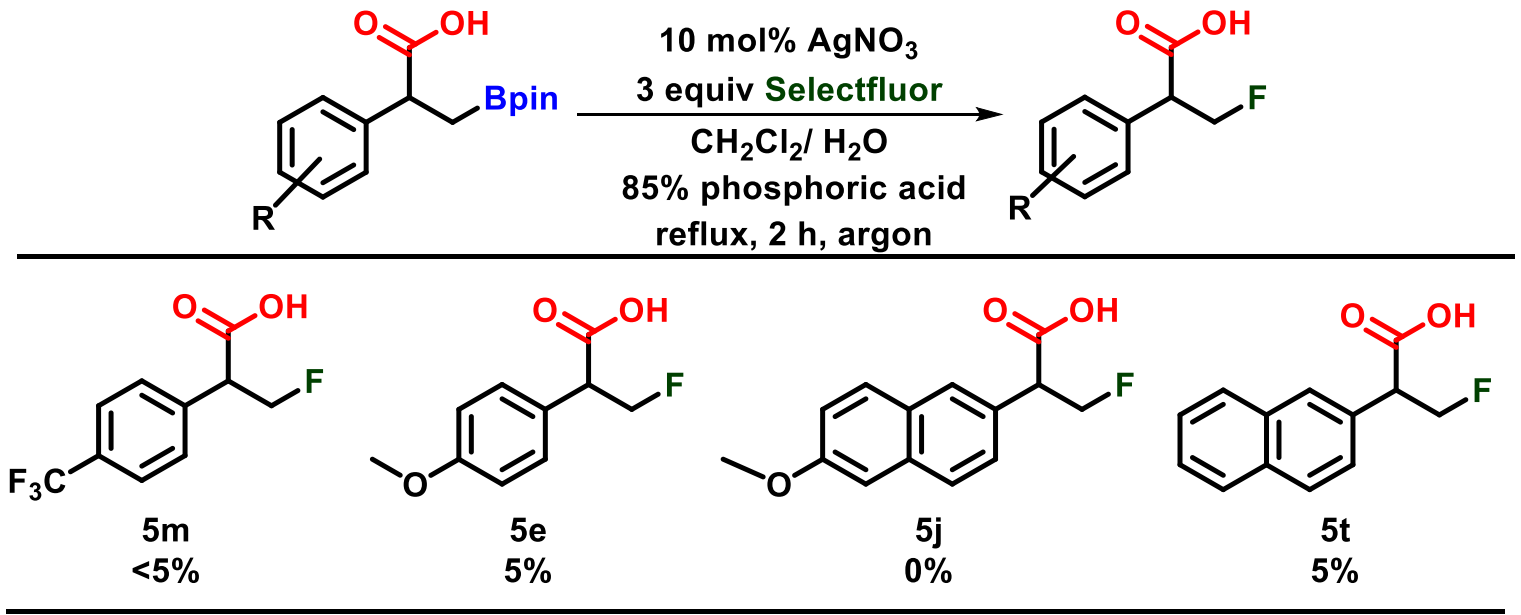

${ }^{a}$ Boracarboxylated vinyl arene $(0.20 \mathrm{mmol})$ in $\mathrm{CH}_{2} \mathrm{Cl}_{2}(3 \mathrm{~mL}), \mathrm{H}_{2} \mathrm{O}(3.5 \mathrm{~mL})$, and $\mathrm{H}_{3} \mathrm{PO}_{4}(0.1 \mathrm{~mL})$.

Yields were determined by ${ }^{19} \mathrm{~F}$ NMR spectroscopy using fluorobenzene as the internal standard.

\subsubsection{Reactivity studies for the fluorination of boracarboxylated products}

The reactivity of the tolyl substrate (2c) being fluorinated on the benzyl substituent initially lead to the idea that this transformation was occurring through a radical pathway. Some initial experiments to probe this hypothesis involve performing reactions with the addition of radical traps. As shown in Table 3.6, the yields of all three major products in the fluorination of $2 \mathrm{c}$ diminished in the presence of either of the two radical trapping agents, (2,2,6,6tetramethylpiperidin-1-yl)oxyl (TEMPO) or butylated hydroxytoluene (BHT). The assumption is that if the pathway does proceed through a radical process, the presence of these stable radicals will slow or stop reactivity. Although there is a possibility of the reaction not being tolerant to TEMPO or BHT, it is good initial evidence that this pathway does involve radicals based on the diminished yields of $5 c, 6 c$, and 7c compared to the control experiment (Table 3.6). 
Table 3.6 Deboronofluorination of tolyl boracarboxylated product in the presence of radical trap reagents ${ }^{a}$

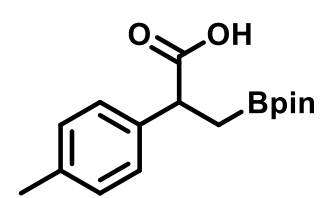

2c

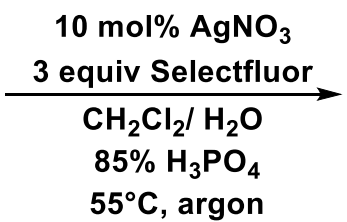

$55^{\circ} \mathrm{C}$, argon

\begin{tabular}{cccc}
\hline & \multicolumn{3}{c}{ Yield (\%) $^{a}$} \\
Variation & $5 \mathrm{c}$ & $6 \mathrm{c}$ & $7 \mathrm{c}$ \\
\hline None & 32 & 6 & 7 \\
$20 \mathrm{~mol}^{2} \mathrm{AgNO}_{3}, 10 \mathrm{~mol} \% \mathrm{TEMPO}$ & 13 & $<5$ & $<5$ \\
$20 \mathrm{~mol}_{\mathrm{AgNO}}, 25 \mathrm{~mol} \% \mathrm{TEMPO}$ & $<5$ & $<5$ & $<5$ \\
$20 \mathrm{~mol}_{3} \mathrm{AgNO}_{3}, 10 \mathrm{~mol} \% \mathrm{BHT}$ & 6 & $<5$ & 5 \\
\hline
\end{tabular}

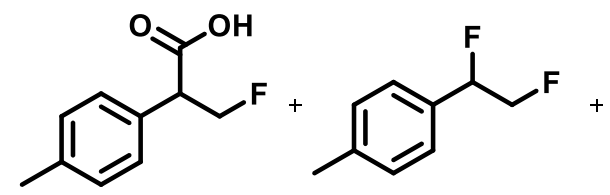

$5 c$

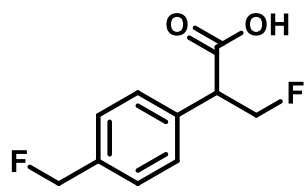

7c

${ }^{a}$ Yields were determined by ${ }^{19} \mathrm{~F}$ NMR spectroscopy using fluorobenzene as the internal standard

Another area of reactivity that was investigated was the ability to apply Li's decarboxylative fluorination conditions to our boracarboxylated products. Revisiting the deboronofluorination screening, we observed that in the absence of $\mathrm{H}_{3} \mathrm{PO}_{4}$ there was a lower amount of deboronofluorinated product (51\%) with a much higher amount of difluorinated product (18\%), which suggests that decarboxylative fluorination is favorable in non-acidic conditions (Scheme 3.12). Based on this observation, 2b was subjected to Li's decarboxylative fluorination conditions. To our surprise, when reacted in the presence of $\mathrm{AgNO}_{3}$ and Selectfluor in an acetone/water media, $2 \mathrm{~b}$ yielded minimal amounts of $5 \mathrm{~b}(7 \%)$ and $6 \mathrm{~b}(5 \%)$ products. Again, there was no evidence of a decarboxylative fluorination in which the Bpin was still intact (Scheme 3.12). Finally, when the isolated deboronofluorination product, 5b, was subjected to subsequent decarboxylative fluorination conditions, the difluorinated product was produced in a moderate yield of $46 \%$ (Scheme 3.12). This series of experiments suggest that the deboronofluorination pathway seems to be the predominant pathway and then some of this product can undergo decarboxylative fluorination to afford the difluorinated product.

The difluorination of vinyl arenes is a transformation that has been known since 1966 when Merritt and co-workers subjected cis-stilbene to $F_{2}$ in order to achieve 1,2-difluoro-1,2diphenylethane. ${ }^{87}$ A similar methodology reacted trans-stilbene with a combination of Selectfluor and HF. pyridine to achieve the same difluorinated product. ${ }^{88}$ The 1,2-difluorination of alkenes has also recently received a lot of attention by the Jacobsen group, in which their catalytic approach 
utilized a nucleophilic fluoride source (HF. pyridine) and an oxidant (mCPBA) in conjunction with an aryl iodide catalyst to access diasteroselective difluorinated vinyl arenes. ${ }^{89,90}$

\section{Revisiting fluorination screening}
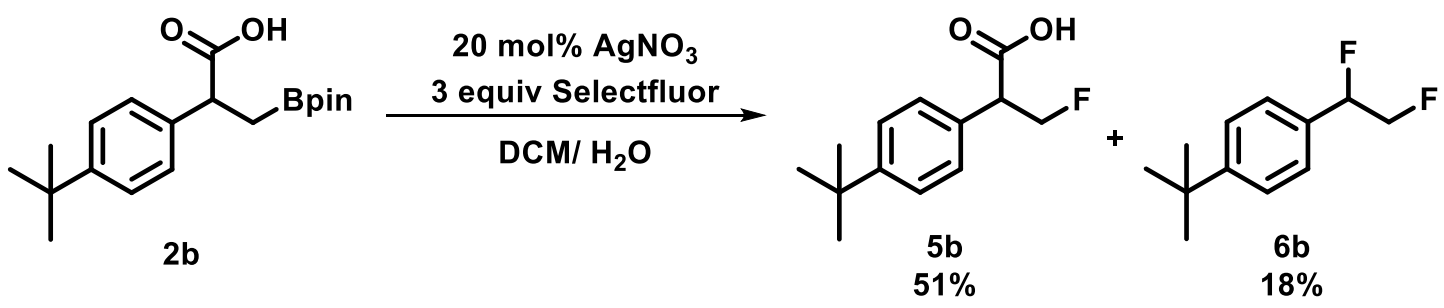

Li's decarboxylative fluorination conditions

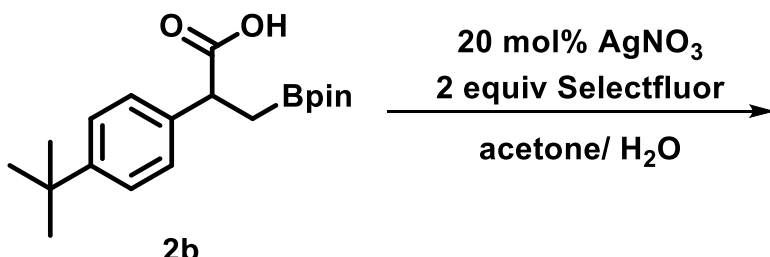

2b

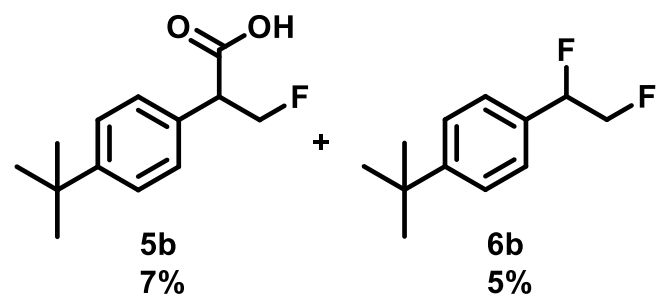

Subsequent decarboxylative fluorination
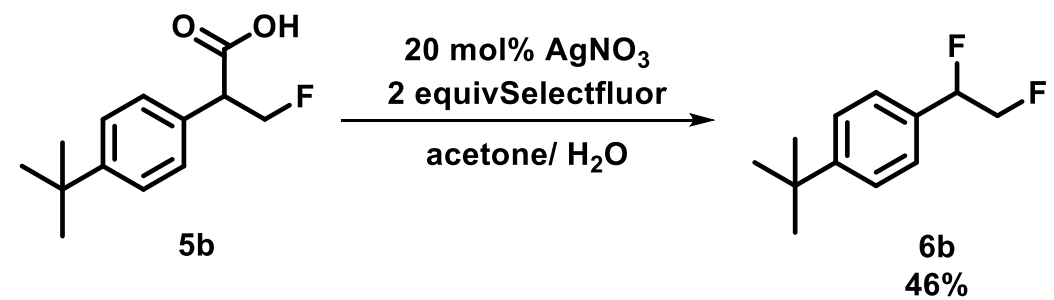

Scheme 3.12 Investigation of the decarboxylative fluorination process

3.2.4 Mechanistic investigation for the fluorination of boracarboxylated products

Because of our substrate scope limitations, we sought to investigate the mechanism further than the reactivity studies discussed above. One plausible route would involve a $S_{E} 2$ pathway, resulting in the inversion of stereochemistry of an enantiopure starting material, similar to the methodology by Aggarwal (Figure 3.6). Another pathway would involve a single electron oxidation of the alkylboronate by a $\mathrm{Ag}(\mathrm{III})-\mathrm{F}$ to yield an alkyl radical, which was previously proposed by the $\mathrm{Li}$ group. If starting with a specific enantiomer, the radical pathway would result in a racemic mixture of products (Figure 3.6). Because the boracarboxylation reaction is not performed asymmetrically at this point, another strategy was employed to investigate the mechanistic pathway. We utilized the trans- $\beta$-methyl styrene substrate, which yields a high 
diastereomeric ratio (>7:1) of boracarboxylated products observed in the ${ }^{1} \mathrm{H}$ NMR analysis (Scheme 3.13 and Figure 3.7). We proposed that if the diastereomeric ratio was maintained after undergoing fluorination, the mechanism was proceeding through an $\mathrm{S}_{\mathrm{E}}$ 2-type pathway. If the diastereomeric ratio was diminished after fluorination, this would suggest a radical pathway.

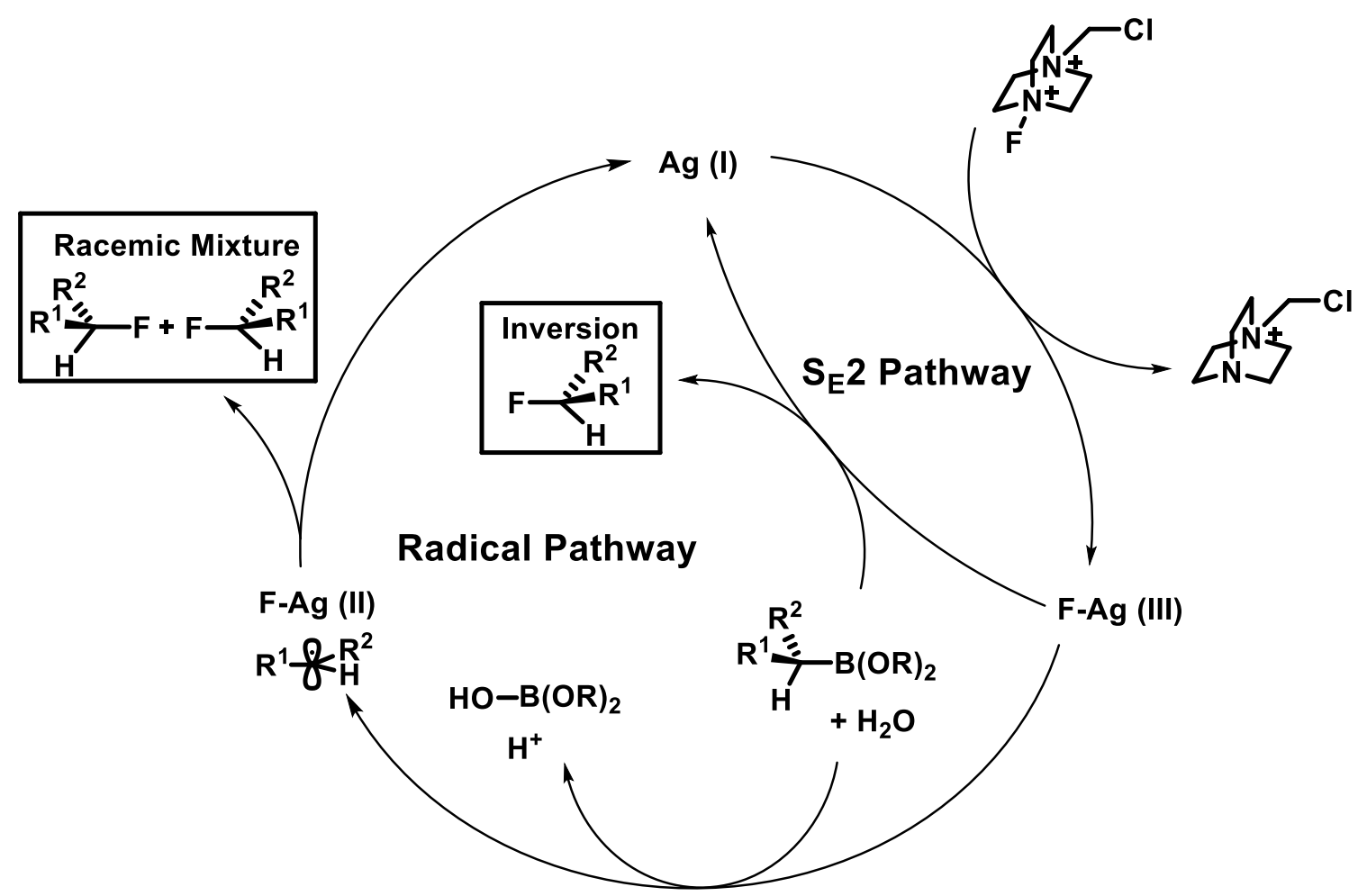

Figure 3.6 Plausible mechanisms for deboronofluorination

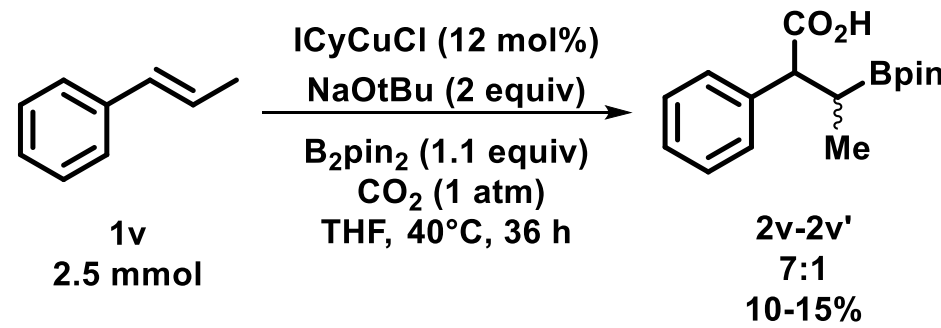

Scheme 3.13 Copper-catalyzed boracarboxylation of trans- $\beta$-methyl styrene 


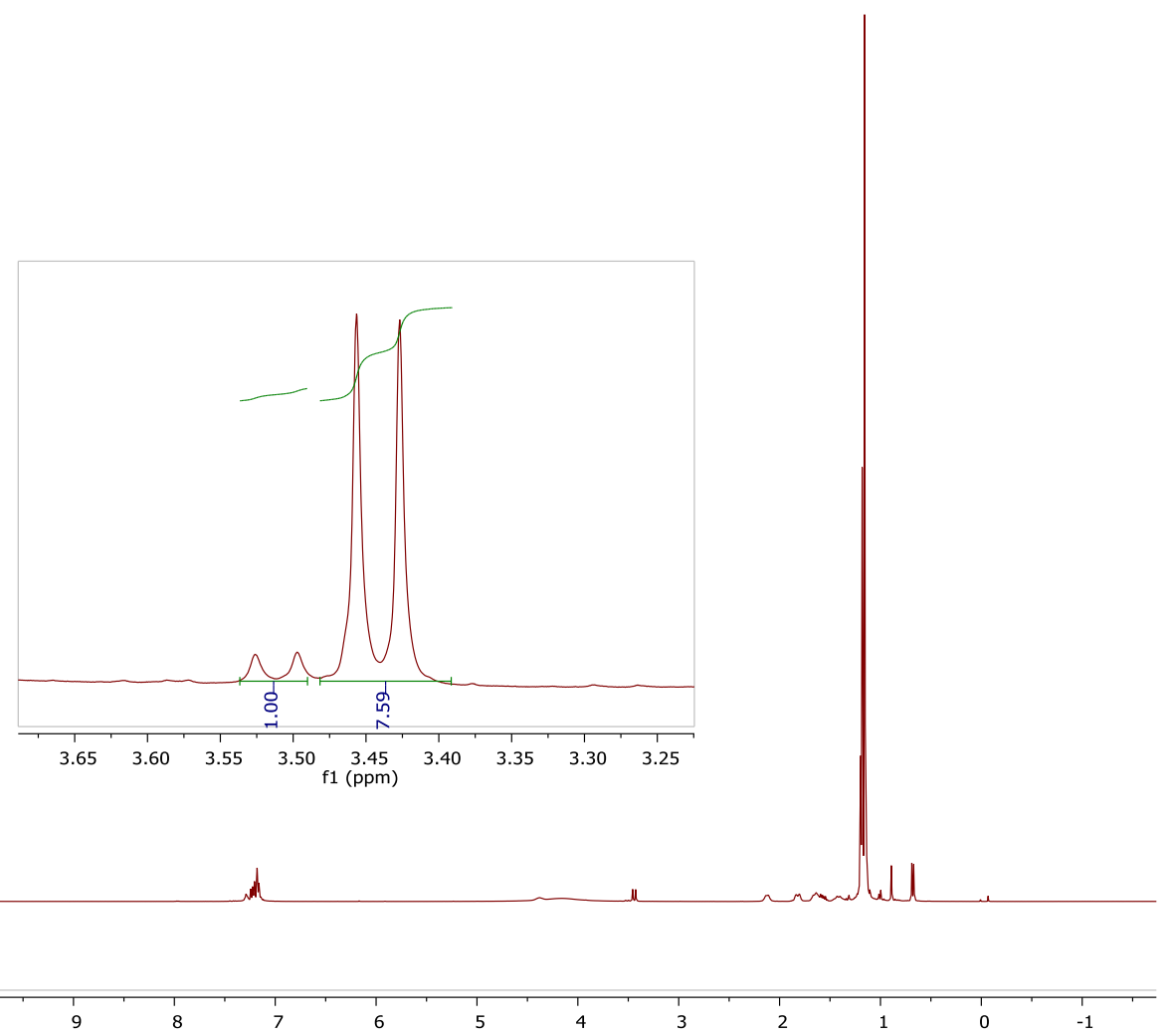

Figure $3.7{ }^{1} \mathrm{H}$ NMR spectrum of boracarboxylation of trans- $\beta$-methyl styrene showing the two diastereomers in a $>7: 1$ ratio

Before the boracarboxylated trans- $\beta$-methyl styrene, $1 \mathrm{v}$, was reacted under fluorination conditions, we first wanted a way to assign the ${ }^{1} \mathrm{H}$ resonances to the corresponding diastereomer. The boracupration occurs in a syn addition so the syn boracarboxylation arises from a stereoretentive insertion of carbon dioxide, while the anti boracarboxylation is the result of a stereoinvertive $\mathrm{S}_{\mathrm{E}} 2$ pathway. Because of the free rotation of the single bonds in the boracarboxylated products, we used $\mathrm{KHF}_{2}$ to form the two difluoroboralactone species and lock all of the atoms into place in the five-membered boralactone ring. The syn diastereomer, $2 \mathrm{v}$, would result in the trans-boralactone, $8 \mathrm{v}$, and the anti diastereomer, $2 \mathrm{v}$, , resulted in the cis-boralactone, $8 v^{\prime}$ (Scheme 3.14). 


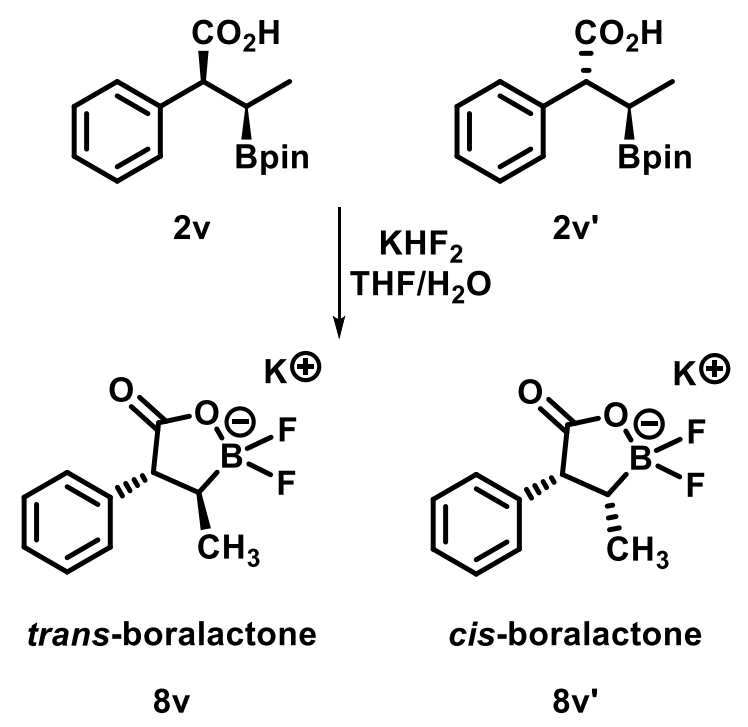

Scheme 3.14 Conversion of the trans- $\beta$-methyl boracarboxylated diastereomers to the difluoroboralactone species

In order to elucidate the stereochemistry, we first sought to use the ${ }^{3} \mathrm{~J}$ coupling constants between the two methine protons in the boralactone. In the ${ }^{1} \mathrm{H}$ NMR of the difluoroboralactones, one benzylic proton resonance at $3.80 \mathrm{ppm}$ showed a ${ }^{3} \mathrm{~J}_{\mathrm{H}-\mathrm{H}}$ coupling constant of $8.5 \mathrm{~Hz}$ (Figure 3.8), which would seem to be consistent with a trans relationship between the two methine protons. Upon further analysis, the benzylic proton resonance at $3.04 \mathrm{ppm}$ corresponding to the other diastereomer showed an even higher ${ }^{3} \mathrm{~J}_{\mathrm{H}-\mathrm{H}}$ coupling constant of $9.7 \mathrm{~Hz}$ (Figure 3.8). Based on the Karplus correlation, these types of 5-membered rings can exhibit relatively large couplings for vicinal cis protons as well as trans protons because they have small dihedral angles. ${ }^{91}$ Based on the large coupling constants of both benzylic protons, we were not able to use this data to match the resonances to the two diastereomers. This resulted in the use of 2D NOESY spectra to determine through-space correlations. The benzylic proton at $3.04 \mathrm{ppm}$ (labeled as $\mathrm{H} 1$ in Figure 3.9) showed a correlation in the NOESY spectrum to the ortho-proton of the aromatic ring and to the protons of the $\mathrm{CH}_{3}$. Based on these correlations, we can assign the benzylic proton at $3.04 \mathrm{ppm}$ to the trans-boralactone, $8 \mathrm{v}$. The cis-boralactone, $8 \mathrm{v}^{\prime}$, is assigned to the benzylic proton at 3.80 ppm, confirmed by the correlation in the NOESY spectrum between $\mathrm{H} 1$ and $\mathrm{H} 2$ (labeled in Figure 3.10). Because more of the trans-boralactone is formed in a 16:1 ratio (Figure 3.8), we can make 
the assumption that more syn boracarboxylated product is formed. Based on this analysis, we know that the syn:anti ratio in the boracarboxylation of trans- $\beta$-methyl styrene is $>7: 1$.

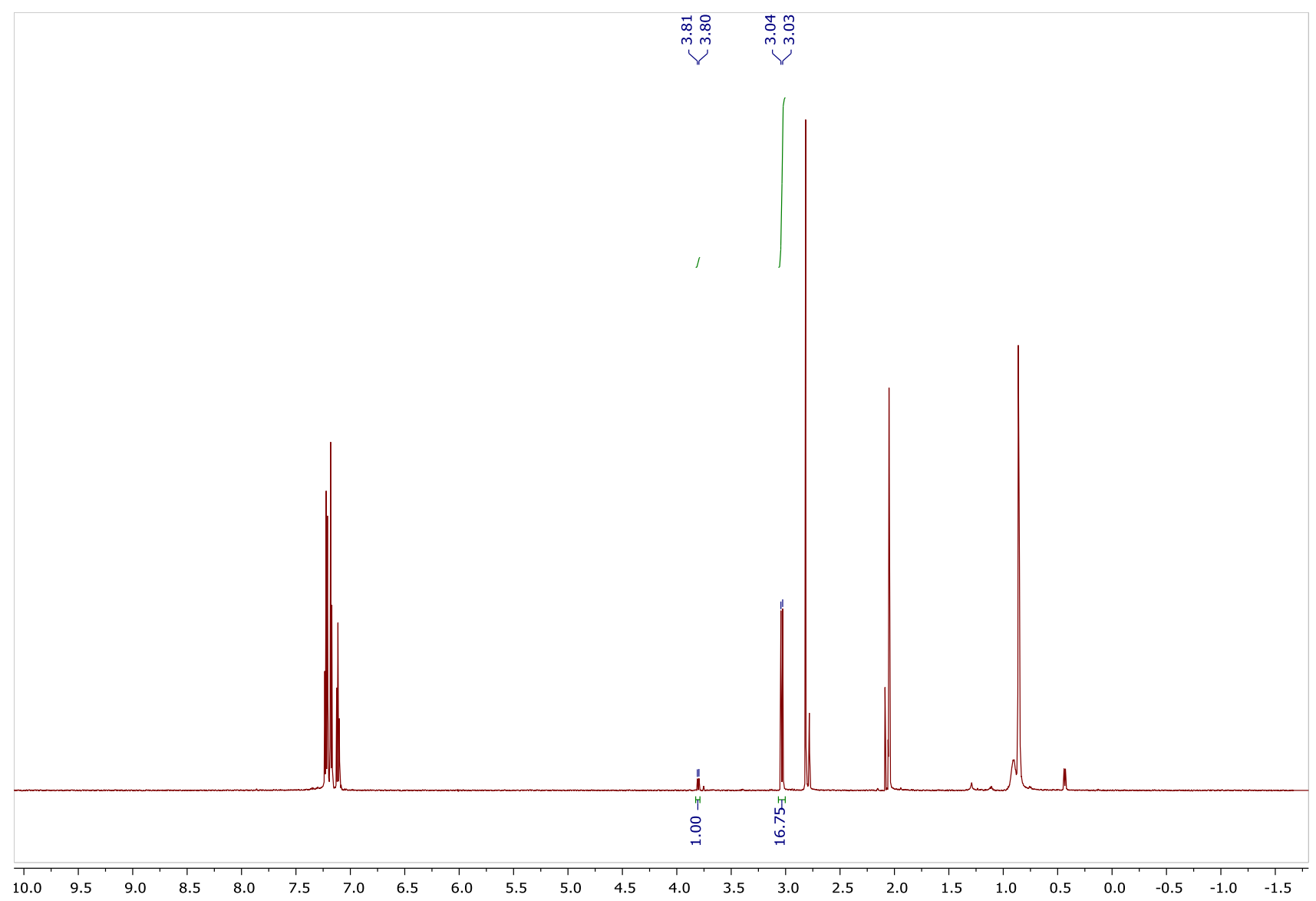

Figure $3.8{ }^{1} \mathrm{H}$ NMR spectrum of the two diastereomers of the trans- $\beta$-methyl difluoroboralactones 


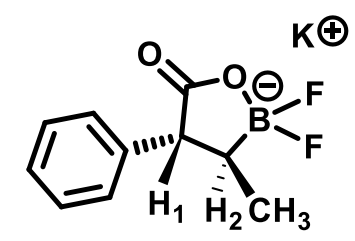

$8 v$
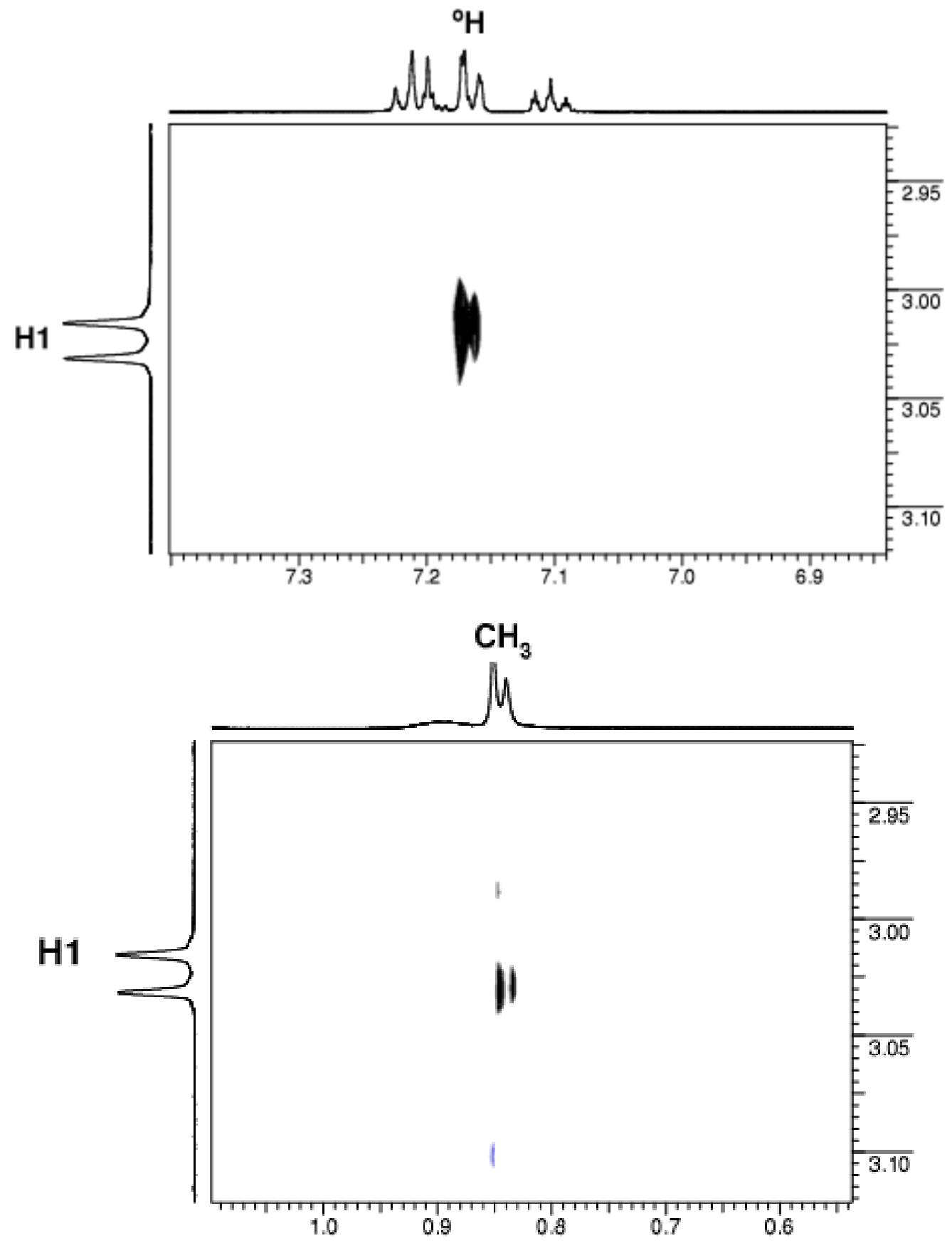

Figure 3.9 Expanded portion of the 2D NOESY spectrum for the trans-boralactone 


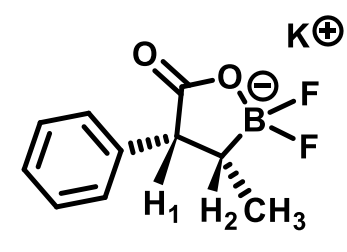

$8 v^{\prime}$

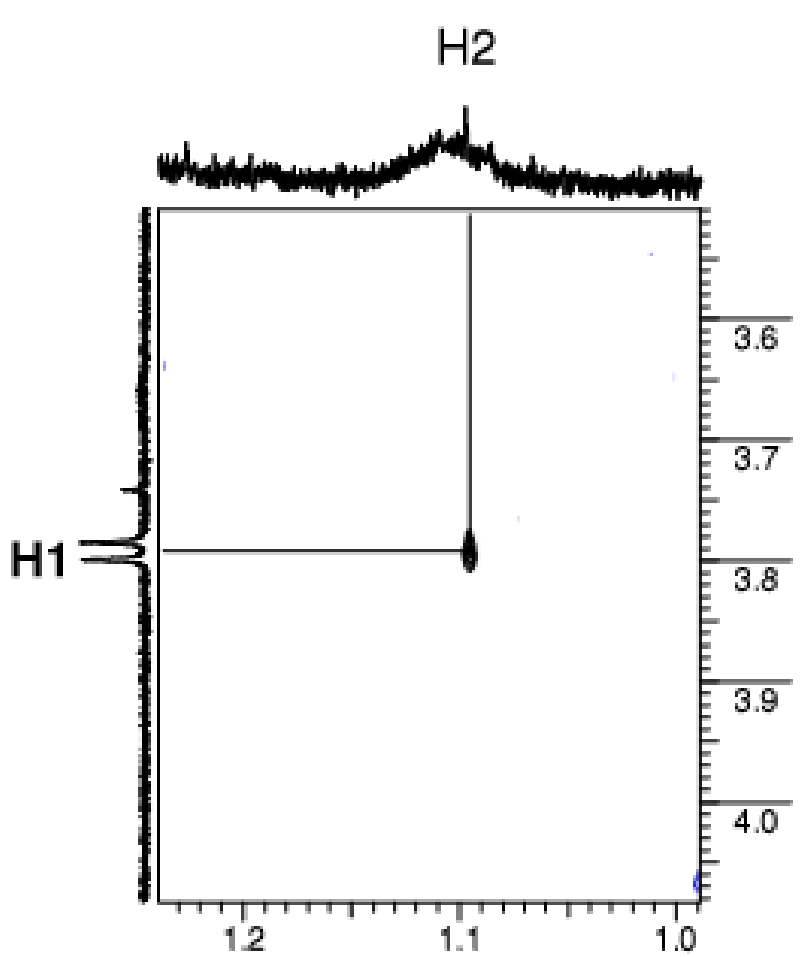

Figure 3.10 Expanded portion of the 2D NOESY spectrum for the cis-boralactone

In order to determine the mechanistic pathway, the boracarboxylated trans- $\beta$-methyl diastereomers, $2 \mathrm{v}-2 \mathrm{v}$, were subjected to the typical deboronofluorination conditions (Scheme 3.15). Fluorination was achieved as shown by Figure 3.11, in which the ${ }^{19} \mathrm{~F}$ NMR shows two distinct fluorine resonances in a doublet of quartet of doublets (dqd) splitting pattern. This splitting arises from the fluorine coupling to the geminal proton, the three methyl protons, and the vicinal proton, respectively. The ${ }^{19} \mathrm{~F}$ NMR integrations show that these two diastereomers are formed in a $<2: 1$ ratio (Scheme 3.15 and Figure 3.11). The diminished diastereomeric ratio suggests a radical pathway for the deboronofluoriantion of boracarboxylated products. This also helps to confirm some of the reactivity observed previously with the fluorination of the methyl substituent in the para-methyl substrate and the diminished reactivity observed when using radical trapping agents such as TEMPO or BHT. 


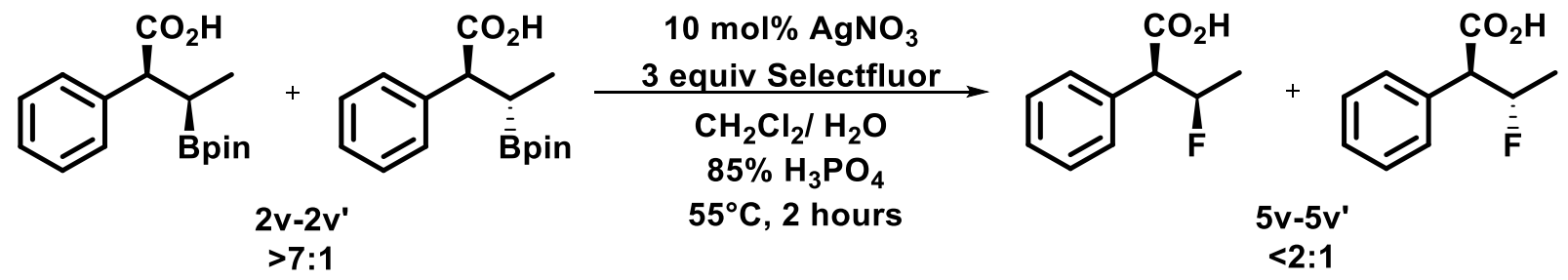

Scheme 3.15 Fluorination of trans- $\beta$-methyl styrene boracarboxylated diastereomers

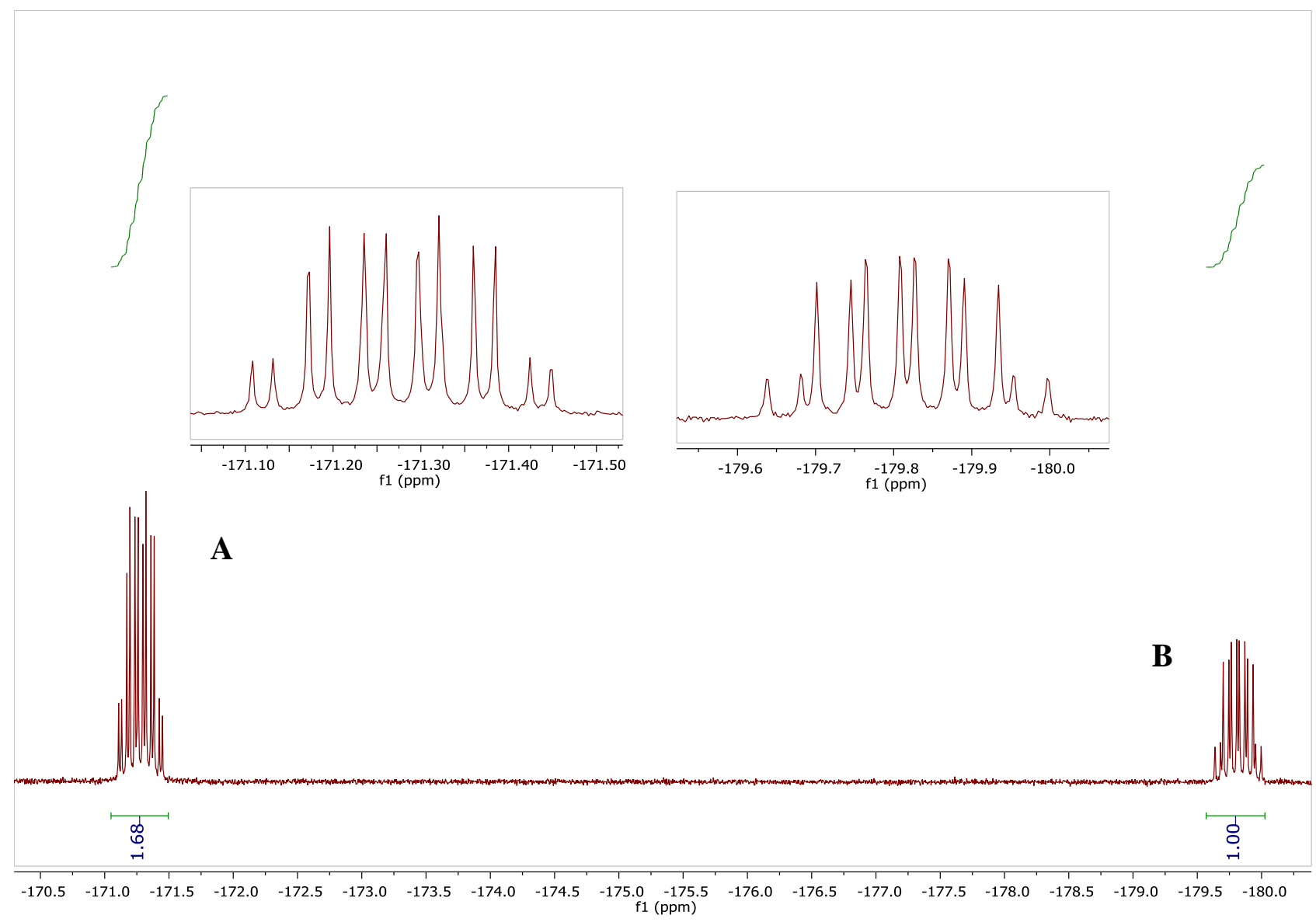

Figure $3.11{ }^{19} \mathrm{~F}$ NMR spectrum for the fluorination of trans- $\beta$-methyl styrene boracarboxylated diastereomers 
Although the ratio of the diastereomers was important for gaining mechanistic insight, we also wanted to assign the fluorine resonances to the corresponding fluorination product. In order to determine which resonance corresponded to the syn or anti diastereomer, we used the ${ }^{19} \mathrm{~F}-{ }^{13} \mathrm{C}$ heteronuclear multiple bond correlation (HMBC) spectra, which shows the ${ }^{2} J_{\mathrm{FC}}$ and ${ }^{3} \mathrm{~J}_{\mathrm{FC}}$ coupling constants. Both fluorine resonances exhibit cross-peaks to the adjacent benzylic carbon and the carbon of the methyl group at $58 \mathrm{ppm}$ and $19 \mathrm{ppm}$, respectively (Figure 3.12). The fluorine resonance (A) at $-171.3 \mathrm{ppm}$ exhibits another cross-peak around $133 \mathrm{ppm}$, which is the coupling to ipso carbon of the phenyl ring. The absence of a cross-peak around $175 \mathrm{ppm}$ indicates a relatively small coupling constant $(<3 \mathrm{~Hz})$ to the carboxylic acid. This signifies that the fluorine and carboxylic acid are in close proximity or in the syn conformation. This means that the fluorine resonance A corresponds to the syn diastereomer, which is formed in a slightly higher amount based on integrations (Figure 3.11).

This is further confirmed by the examining the peak at $-179.8 \mathrm{ppm}(\mathrm{B})$. In the ${ }^{19} \mathrm{~F}_{-}{ }^{13} \mathrm{C}$ $\mathrm{HMBC}$, the resonance shows a cross-peak with the carboxylic acid region of around $175 \mathrm{ppm}$. The presence of the cross-peak indicates that the coupling constant is relatively large so this diastereomer shows an anti-relationship between the carboxylic acid and fluorine. Further, the absence of a cross-peak for the fluorine and ipso carbon of the phenyl means the coupling constant is small due to close proximity. The shifts can also be explained based on the anisotropic effect. When the phenyl ring is placed in a magnetic field, the $\pi$ electrons are induced to circulate, causing an anisotropic magnetic field. In the anti diastereomer, the fluorine is in close proximity to the phenyl ring and is shielded, causing the more upfield signal in the ${ }^{19} \mathrm{~F}$ NMR spectrum. 

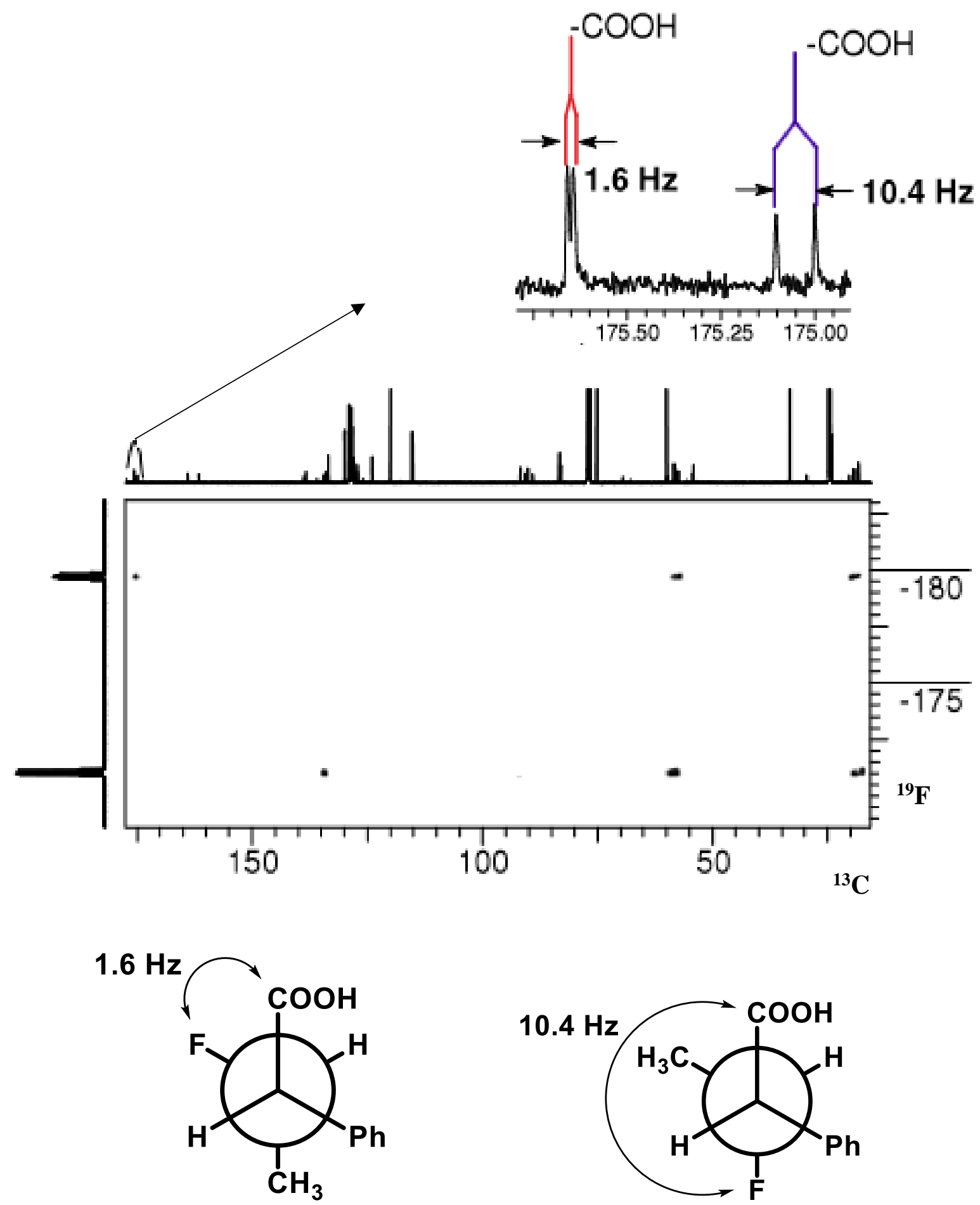

Figure $3.12{ }^{19} \mathrm{~F}_{-}{ }^{13} \mathrm{C}$ HMBC from the fluorination of boracarboxylated trans- $\beta$-methyl styrene 


\subsection{Conclusion}

In this chapter, we have outlined a methodology to achieve the chemoselective deboronofluorination of some boracarboxylated products. Taking advantage of boracarboxylation and subsequent fluorination, we have a direct, efficient synthesis of the $\beta$-fluoro-ibuprofen NSAID derivative. Although chemoselective for some substrates, this method suffers in functional group compatibility due to other reactivity pathways such as electrophilic aromatic substitution. Based on the reactivity that was observed, these limitations were investigated by probing the mechanism. Using a substrate with stereochemical information, we observed diminished diastereomeric ratios when subjected to fluorination conditions, suggesting a radical pathway is occurring in this transformation.

\subsection{Experimental Methods}

\subsubsection{General information}

Dichloromethane and 85\% phosphoric acid were purchased from Fisher and the water was used from the DI tap at WVU for the biphasic solvent system. Deuterated $\mathrm{CDCl}_{3}$ was purchased from Cambridge Isotope Laboratories, Inc. NMR spectra were recorded on either a $400 \mathrm{MHz}$ Agilent or a $400 \mathrm{MHz}$ JEOL NMR spectrometer. ${ }^{1} \mathrm{H}$ NMR experiments were run in $\mathrm{CDCl}_{3}$ using tetramethylsilane as an internal standard and ${ }^{13} \mathrm{C}$ NMR spectra used $\mathrm{CDCl}_{3}$ as a solvent and reference. High-resolution mass spectra were recorded on a Thermo Fisher Scientific Q Exactive Mass Spectrometer dissolving our samples in 1:1 methanol/acetonitrile. All boracarboxylated starting materials were synthesized and isolated with $<5 \%$ impurities of $\mathrm{B}_{2} \mathrm{pin}_{2}$ before subjected to fluorination conditions. The fluorinated compounds were purified by chromatography using SiliaCycle thin-layer chromatography plates and SiliCycle SiliaFlash P60 silica gel.

\subsubsection{Experimental procedures}

For all substrate scope reactions, a 20-mL vial was taped with black electrical tape to avoid any light sensitivity issues. The vial was first charged with a stir bar, boracarboxylated product (0.2 mmol, 1.0 eq.), $\mathrm{AgNO}_{3}(3.4 \mathrm{mg}, 0.02 \mathrm{mmol}, 10 \mathrm{~mol} \%$ ), and Selectfluor (213 mg, $0.6 \mathrm{mmol}$, 3 eq.). To the solids, $3.0 \mathrm{~mL}$ of dichloromethane, $3.5 \mathrm{~mL}$ of deionized water, and $0.1 \mathrm{~mL}$ of $85 \%$ phosphoric acid were added to the reaction vial. A septum cap was secured tightly on the vial and 
taped. The septum cap was punctured with a needle to purge the reaction mixture with argon for 5 minutes with an outlet to a bubbler. The puncture was taped over to prevent any evaporation of solvent. The reactions were stirred at reflux $\left(55^{\circ} \mathrm{C}\right)$ for 2 hours. During screening, reactions were run for 12 hours. In some cases, the reactions were performed with an addition of $0.4 \mathrm{~mL}$ of trifluoroacetic acid, as discussed above in the results. Upon reaction completion, the crude mixture was allowed to cool to room temperature and added to a separatory funnel. The organic layer was extracted with dichloromethane $(15 \mathrm{~mL}$ x 3). The combined organic layers were collected in a 100 $\mathrm{mL}$ round-bottom flask and concentrated under vacuum to give the crude product. Fluorobenzene (0.04 mmol, $20 \mathrm{~mol} \%$ ) was added to the crude mixture as an internal standard and dissolved in $\mathrm{CDCl}_{3}$ to be analyzed by ${ }^{19} \mathrm{~F}$ and ${ }^{1} \mathrm{H}$ NMR. If fluorinated product was present in a reasonable amount, the crude product was isolated by column chromatography or thin-layer chromatography. ${ }^{1} \mathrm{H},{ }^{13} \mathrm{C}$ and ${ }^{19} \mathrm{~F}$ NMR characterization data was carried out on purified compound, along with highresolution mass spectroscopy. During the mechanistic investigation of the fluorination pathway, some 2D NMR techniques such as NOESY were performed to help elucidate the different diastereomers present.

\subsubsection{Characterization of isolated compounds}

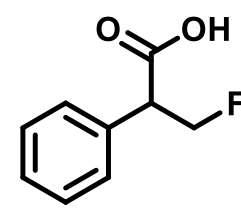

3-fluoro-2-phenyl propionic acid 5a. Purified by thin-layer chromatography eluting with 3:2 hexanes/ethyl acetate $\left(\mathrm{R}_{\mathrm{f}} \sim 0.5\right)$ to afford a clear oil in $53 \%$ yield; ${ }^{1} \mathrm{H}$ NMR $(400 \mathrm{MHz}$, $\left.\mathrm{CDCl}_{3}\right) \delta=7.38-7.25(\mathrm{~m}, 5 \mathrm{H}), 4.93(\mathrm{dt}, \mathrm{J}=46.4,8.9 \mathrm{~Hz}, 1 \mathrm{H}), 4.59$ (ddd, J = 46.4, 9.0, 5.2 Hz, 1H), $4.03(\mathrm{ddd}, \mathrm{J}=13.8,9.0,5.1 \mathrm{~Hz}, 1 \mathrm{H}) ;{ }^{13} \mathrm{C} \mathrm{NMR}\left(101 \mathrm{MHz}, \mathrm{CDCl}_{3}\right) \delta=177.12,133.21(\mathrm{~d}, \mathrm{~J}$ $=8.4 \mathrm{~Hz}), 129.03,128.37,128.26,83.29(\mathrm{~d}, \mathrm{~J}=174.3 \mathrm{~Hz}), 52.13(\mathrm{~d}, \mathrm{~J}=19.1 \mathrm{~Hz}) ;{ }^{19} \mathrm{~F} \mathrm{NMR}(376$ $\left.\mathrm{MHz} \mathrm{CDCl}_{3}\right) \delta=-216.63\left(\mathrm{td}, \mathrm{J}=46.5,13.7 \mathrm{~Hz}\right.$ ); HRMS (ESI) m/z calc. for $\mathrm{C}_{9} \mathrm{H}_{8} \mathrm{FO}_{2}{ }^{-}[\mathrm{M}-\mathrm{H}]^{-}$ 167.0508, found 167.0505 


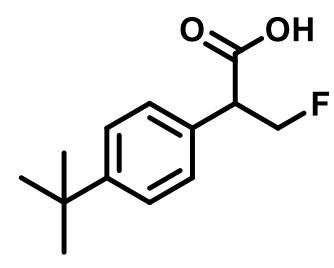

3-fluoro-2-(4-tertbutylphenyl) propionic acid $\mathbf{5 b}$. Purified by silica gel flash chromatography eluting with 3:2 hexanes/ethyl acetate $\left(\mathrm{R}_{\mathrm{f}} \sim 0.5\right)$ to afford a white solid in 60\% yield; ${ }^{1} \mathrm{H}$ NMR (400 MHz, $\left.\mathrm{CDCl}_{3}\right) \delta=7.37(\mathrm{~d}, \mathrm{~J}=8.4 \mathrm{~Hz}, 2 \mathrm{H}), 7.24(\mathrm{~d}, \mathrm{~J}=8.4 \mathrm{~Hz}, 2 \mathrm{H}), 4.94(\mathrm{dt}$, $\mathrm{J}=46.5,9.1 \mathrm{~Hz}, 1 \mathrm{H}), 4.58(\mathrm{ddd}, \mathrm{J}=46.5,9.1,5.3 \mathrm{~Hz}, 1 \mathrm{H}), 4.02(\mathrm{ddd}, \mathrm{J}=13.9,9.1,5.2 \mathrm{~Hz}, 1 \mathrm{H})$, $1.30(\mathrm{~s}, 9 \mathrm{H}) ;{ }^{13} \mathrm{C}$ NMR $\left(101 \mathrm{MHz}, \mathrm{CDCl}_{3}\right) \delta=176.98,151.43,129.82,127.87,125.98,83.26(\mathrm{~d}$, $\mathrm{J}=174.5 \mathrm{~Hz}), 51.52(\mathrm{~d}, \mathrm{~J}=21.2 \mathrm{~Hz}), 34.53,31.21 ;{ }^{19} \mathrm{~F} \mathrm{NMR}\left(376 \mathrm{MHz}, \mathrm{CDCl}_{3}\right) \delta=-216.13(\mathrm{td}$, $\mathrm{J}=46.2,13.3 \mathrm{~Hz}$ ) HRMS (ESI) $\mathrm{m} / \mathrm{z}$ calc. for $\mathrm{C}_{13} \mathrm{H}_{16} \mathrm{FO}_{2}{ }^{-}[\mathrm{M}-\mathrm{H}]^{-} 223.1134$, found 223.1132

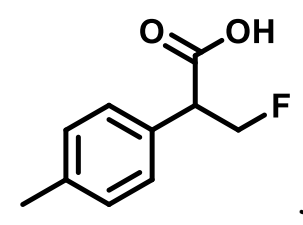

3-fluoro-2-(4-methylphenyl) propionic acid 5c. Purified by thin-layer chromatography eluting with 3:2 hexanes/ethyl acetate $\left(\mathrm{R}_{\mathrm{f}} \sim 0.5\right)$ to afford a white solid in $21 \%$ yield; ${ }^{1} \mathrm{H}$ NMR $\left(400 \mathrm{MHz}, \mathrm{CDCl}_{3}\right) \delta=7.18(\mathrm{~d}, \mathrm{~J}=8.1 \mathrm{~Hz}, 2 \mathrm{H}), 7.14(\mathrm{~d}, \mathrm{~J}=8.1 \mathrm{~Hz}, 2 \mathrm{H}), 4.90(\mathrm{dt}$, $\mathrm{J}=46.5,9.0 \mathrm{~Hz}, 1 \mathrm{H}), 4.55(\mathrm{ddd}, \mathrm{J}=46.5,8.9,5.5 \mathrm{~Hz}, 1 \mathrm{H}), 3.97(\mathrm{ddd}, \mathrm{J}=13.9,8.8,5.5 \mathrm{~Hz}, 1 \mathrm{H})$ $2.32(\mathrm{~s}, 3 \mathrm{H}) ;{ }^{13} \mathrm{C}$ NMR $\left(101 \mathrm{MHz}, \mathrm{CDCl}_{3}\right) \delta=177.07,138.25,130.10(\mathrm{~d}, \mathrm{~J}=8.5 \mathrm{~Hz}), 129.71$, $128.09,83.27(\mathrm{~d}, \mathrm{~J}=174.4 \mathrm{~Hz}), 51.65(\mathrm{~d}, \mathrm{~J}=21.1 \mathrm{~Hz}) 21.06 ;{ }^{19} \mathrm{~F} \mathrm{NMR}\left(376 \mathrm{MHz}, \mathrm{CDCl}_{3}\right) \delta=$ $-216.40\left(\mathrm{td}, \mathrm{J}=46.5,13.6 \mathrm{~Hz}\right.$ ) HRMS (ESI) m/z calc. for $\mathrm{C}_{10} \mathrm{H}_{10} \mathrm{FO}_{2}{ }^{-}[\mathrm{M}-\mathrm{H}]^{-} 181.0659$, found 181.0658

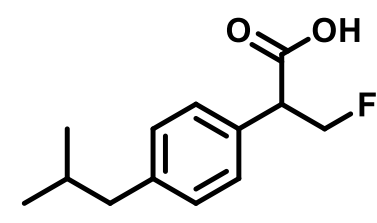

3-fluoro-2-(4-isobutylphenyl) propionic acid $\mathbf{5 d}$. Purified by silica gel flash chromatography eluting with 3:2 hexanes/ethyl acetate $\left(\mathrm{R}_{\mathrm{f}} \sim 0.5\right)$ to afford a white solid in $45 \%$ yield; ${ }^{1} \mathrm{H}$ NMR $\left(400 \mathrm{MHz}, \mathrm{CDCl}_{3}\right) \delta=7.21(\mathrm{~d}, \mathrm{~J}=8.0 \mathrm{~Hz}, 2 \mathrm{H}), 7.12(\mathrm{~d}, \mathrm{~J}=7.9 \mathrm{~Hz}, 2 \mathrm{H}), 4.93(\mathrm{dt}$, $\mathrm{J}=46.5,9.0 \mathrm{~Hz}, 1 \mathrm{H}), 4.57(\mathrm{ddd}, \mathrm{J}=46.4,9.0,5.2 \mathrm{~Hz}, 1 \mathrm{H}), 4.00(\mathrm{ddd}, \mathrm{J}=13.9,9.1,5.3 \mathrm{~Hz}, 1 \mathrm{H})$, $2.45(\mathrm{~d}, \mathrm{~J}=7.2 \mathrm{~Hz}, 2 \mathrm{H}), 1.89-1.79(\mathrm{~m}, 1 \mathrm{H}), 0.89(\mathrm{~d}, \mathrm{~J}=6.5 \mathrm{~Hz}, 6 \mathrm{H}) ;{ }^{13} \mathrm{C} \mathrm{NMR}\left(101 \mathrm{MHz}, \mathrm{CDCl}_{3}\right)$ 
$\delta=177.07,141.99,130.28(\mathrm{~d}, \mathrm{~J}=8.8 \mathrm{~Hz}), 129.73,127.92,83.35(\mathrm{~d}, \mathrm{~J}=174.3 \mathrm{~Hz}), 51.73(\mathrm{~d}, \mathrm{~J}=$ $20.9 \mathrm{~Hz}), 44.99,30.11,22.32 ;{ }^{19} \mathrm{~F} \mathrm{NMR}\left(376 \mathrm{MHz}, \mathrm{CDCl}_{3}\right) \delta=-216.08(\mathrm{td}, \mathrm{J}=46.6,13.6 \mathrm{~Hz})$ HRMS (ESI) $\mathrm{m} / \mathrm{z}$ calc. for $\mathrm{C}_{13} \mathrm{H}_{16} \mathrm{FO}_{2}{ }^{-}[\mathrm{M}-\mathrm{H}]^{-} 223.1134$, found 223.1122

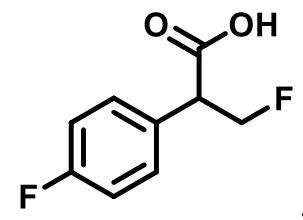

3-fluoro-2-(4-fluorophenyl) propionic acid 5g. Purified by thin-layer chromatography eluting with 4:1 hexanes/ethyl acetate with $4 \%$ acetic acid $\left(\mathrm{R}_{\mathrm{f}} \sim 0.5\right)$ to afford a clear oil in $31 \%$ yield; ${ }^{1} \mathrm{H}$ NMR $\left(400 \mathrm{MHz}, \mathrm{CDCl}_{3}\right) \delta=7.28(\mathrm{dd}, \mathrm{J}=8.4,5.2 \mathrm{~Hz}, 2 \mathrm{H}), 7.03(\mathrm{t}, \mathrm{J}=$ $8.4 \mathrm{~Hz}, 2 \mathrm{H}), 4.88(\mathrm{dt}, \mathrm{J}=46.4,8.8 \mathrm{~Hz}, 1 \mathrm{H}), 4.59$ (ddd, J = 46.3, 9.0, $5.5 \mathrm{~Hz}, 1 \mathrm{H}), 4.00$ (ddd, J = 15.8, 8.8, $5.5 \mathrm{~Hz}, 1 \mathrm{H}) ;{ }^{13} \mathrm{C} \mathrm{NMR}\left(101 \mathrm{MHz}, \mathrm{CDCl}_{3}\right) \delta=176.78,162.66(\mathrm{~d}, \mathrm{~J}=247.6 \mathrm{~Hz}), 129.98$ $(\mathrm{d}, \mathrm{J}=8.3 \mathrm{~Hz}), 128.94(\mathrm{dd}, \mathrm{J}=7.9,3.5 \mathrm{~Hz}), 116.00$ (d, J = 21.7 Hz), $83.12(\mathrm{~d}, \mathrm{~J}=175.3 \mathrm{~Hz}), 51.24$ $(\mathrm{d}, \mathrm{J}=21.7 \mathrm{~Hz}) ;{ }^{19} \mathrm{~F}$ NMR $\left(376 \mathrm{MHz}, \mathrm{CDCl}_{3}\right) \delta=-113.41(\mathrm{ddd}, \mathrm{J}=13.7,8.6,5.2 \mathrm{~Hz}),-217.13$

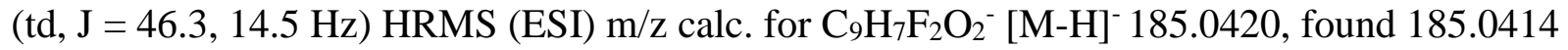

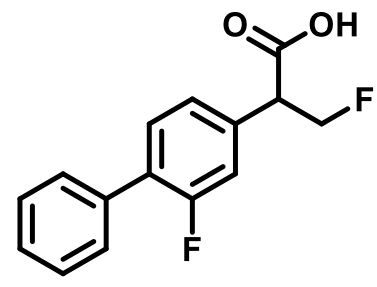

3-fluoro-2-(3-fluorobiphenyl) propionic acid 5l. Purified by thin-layer chromatography eluting with 4:1 hexanes/ethyl acetate with $4 \%$ acetic acid $\left(\mathrm{R}_{\mathrm{f}} \sim 0.4\right)$ to afford a white solid in $13 \%$ yield; ${ }^{1} \mathrm{H}$ NMR $\left(400 \mathrm{MHz}, \mathrm{CDCl}_{3}\right) \delta=7.50(\mathrm{~d}, \mathrm{~J}=7.3 \mathrm{~Hz}, 2 \mathrm{H}), 7.44-7.36(\mathrm{~m}$, 4H), 7.18-7.14 (m, 2H) 4.94 (dt, J = 46.1, 8.5 Hz, 1H), 4.67 (ddd, J = 46.3, 8.8, 5.5 Hz, 1H), 4.06 $(\mathrm{ddd}, \mathrm{J}=13.9,8.0,5.4 \mathrm{~Hz}, 1 \mathrm{H}) ;{ }^{13} \mathrm{C}$ NMR $\left(101 \mathrm{MHz}, \mathrm{CDCl}_{3}\right) \delta=175.88,159.70(\mathrm{~d}, \mathrm{~J}=249.0$ $\mathrm{Hz}), 135.00,134.38$ (d, J = 8.1 Hz), 131.25 (d, J = 3.1 Hz), 129.20 (d, J = 12.8 Hz), 128.90, 128.48, 127.90, 124.36 (d, J = 3.3 Hz), $116.13(\mathrm{~d}, \mathrm{~J}=24.5 \mathrm{~Hz}), 83.01$ (d, J = 175.2 Hz), 51.45 (d, J = 20.9 $\mathrm{Hz}) ;{ }^{19} \mathrm{~F}$ NMR $\left(376 \mathrm{MHz}, \mathrm{CDCl}_{3}\right) \delta=-116.66(\mathrm{t}, \mathrm{J}=9.4 \mathrm{~Hz}),-217.68(\mathrm{td}, \mathrm{J}=46.3,14.4 \mathrm{~Hz})$ HRMS (ESI) m/z calc. for $\mathrm{C}_{15} \mathrm{H}_{11} \mathrm{~F}_{2} \mathrm{O}_{2}^{-}[\mathrm{M}-\mathrm{H}]^{-} 261.0733$, found 261.0734 


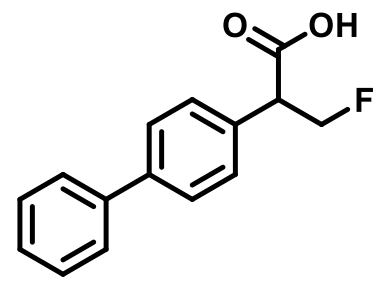

3-fluoro-2-biphenyl propionic acid 5u. Purified by thin-layer chromatography eluting with 4:1 hexanes/ethyl acetate with $4 \%$ acetic acid $\left(\mathrm{R}_{\mathrm{f}} \sim 0.4\right)$ to afford a white solid in $12 \%$ yield; ${ }^{1} \mathrm{H}$ NMR $\left(400 \mathrm{MHz}, \mathrm{CDCl}_{3}\right) \delta=7.58-7.53(\mathrm{~m}, 4 \mathrm{H}), 7.44-7.38(\mathrm{~m}, 4 \mathrm{H})$, $7.34(\mathrm{t}, \mathrm{J}=7.2 \mathrm{~Hz}, 1 \mathrm{H}), 4.97$ (dt, J = 46.2, 8.6 Hz, 1H), 4.65 (ddd, J = 46.2, 9.0, 5.1 Hz, 1H), 4.08 $(\mathrm{ddd}, \mathrm{J}=14.1,8.6,5.8 \mathrm{~Hz}, 1 \mathrm{H}) ;{ }^{13} \mathrm{C} \mathrm{NMR}\left(101 \mathrm{MHz}, \mathrm{CDCl}_{3}\right) \delta=176.38,141.42,140.32,132.10$ (d, J = 8.0 Hz), 128.79, 128.67, 127.75, 127.53, 127.07, 83.23 (d, J = 174.8 Hz), 51.65 (d, J = 21.1 $\left.\mathrm{Hz}) ;{ }^{19} \mathrm{~F} \mathrm{NMR} \mathrm{(376} \mathrm{MHz,} \mathrm{CDCl}_{3}\right) \delta=-216.74(\mathrm{td}, \mathrm{J}=46.4,13.9 \mathrm{~Hz}$ ) HRMS (ESI) m/z calc. for $\mathrm{C}_{15} \mathrm{H}_{12} \mathrm{FO}_{2}^{-}[\mathrm{M}-\mathrm{H}]^{-} 243.0827$, found 243.0825 


\section{Chapter 4: Progress in Suzuki Cross-Coupling of Boracarboxylated Products}

\subsection{Introduction}

Another area of synthetic utility that our group wanted to explore was the cross-coupling of our boracarboxylated products. Similarly to fluorinated compounds, there is a drive to synthesize 2,3-diarylpropionic acids based on their prevalence as biologically active compounds. The synthesized compound DX-9065a exhibited potent and highly selective anti-FXa activity as an anticoagulant bearing both a basic moiety and carboxylic acid functionality (Figure 4.1). ${ }^{92} \mathrm{~A}$ series of 2,3-diphenylpropionic acid derivatives have also shown activity as potent VLA-4 antagonists with good pharmacokinetics and oral bioavailability (Figure 4.1). The integrin very late antigen- 4 is involved in cell adhesion, migration, and activation of leukocytes. ${ }^{93}$

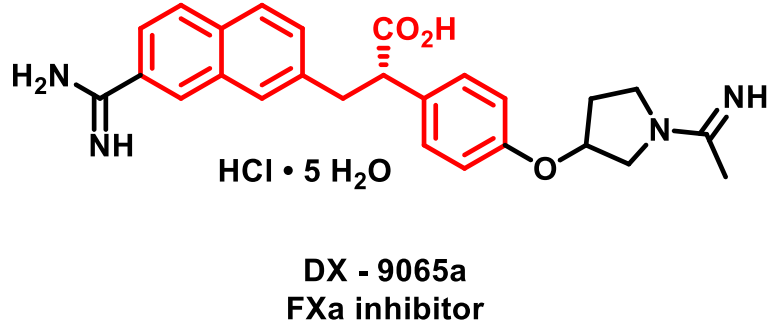

FXa inhibitor

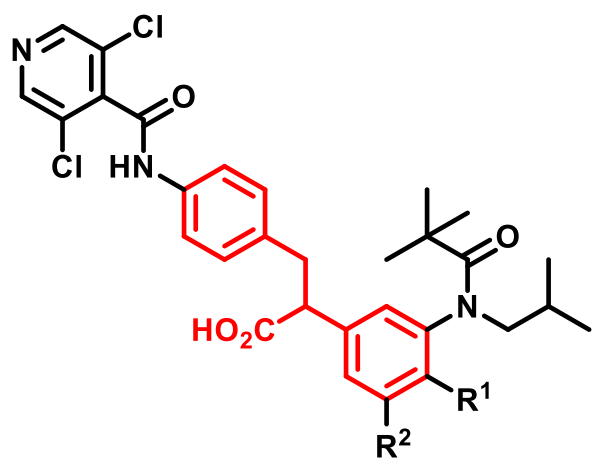

VLA-4 antagonist

Figure 4.1 Biologically active 2,3-diarylpropionic acids

There are a number of synthetic routes to access 2,3-diarylpropionic acid derivatives. A few examples utilizing an alkylation pathway will be described. One method by Miyata demonstrated that the triethylsilylation of a lithium enolate resulted in the formation of a $\mathrm{N}, \mathrm{O}$ ketene acetal. ${ }^{94}$ This could undergo subsequent nucleophilic phenylation with triphenyl aluminum to afford an $\alpha$-phenylated product that can readily be converted into the 2,3-diphenyl propionic acid without racemization by the addition of $4 \mathrm{M} \mathrm{HCl}$ (Scheme 4.1). Another strategy employs the use of a chiral lithium amide to achieve an enantioselective direct alkylation of arylacetic acids. ${ }^{95}$ 
There is also an interesting strategy using $\mathrm{Rh}_{2}(\mathrm{BPCP})_{4}$ that demonstrated the site-selective $\mathrm{C}-\mathrm{H}$ insertion of carbenes into toluene derivatives (Scheme 4.1). ${ }^{96}$

Miyata
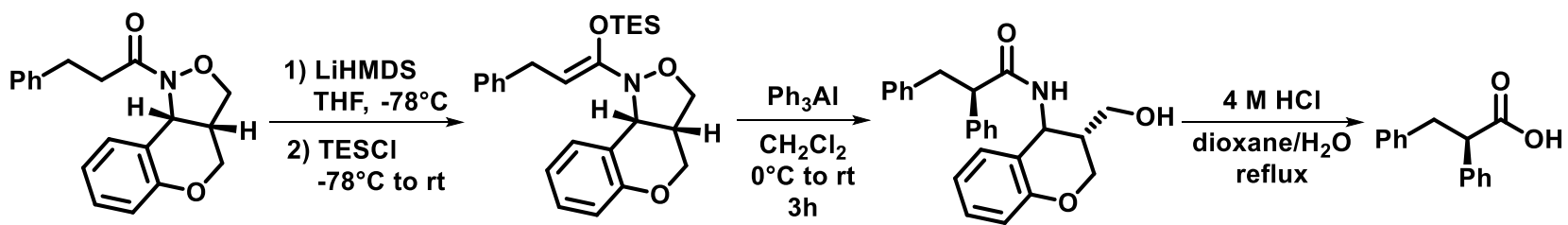

Zakarian
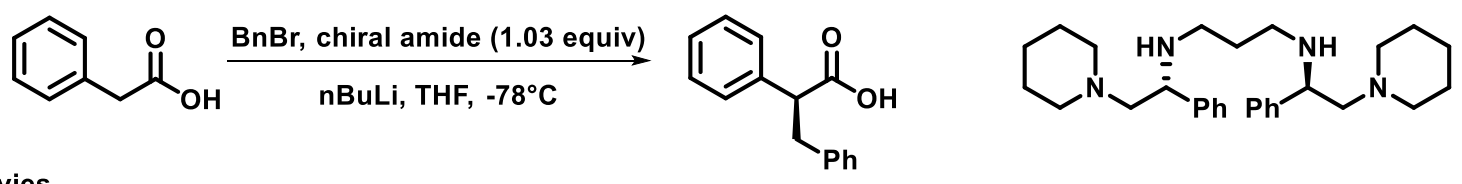

Davies
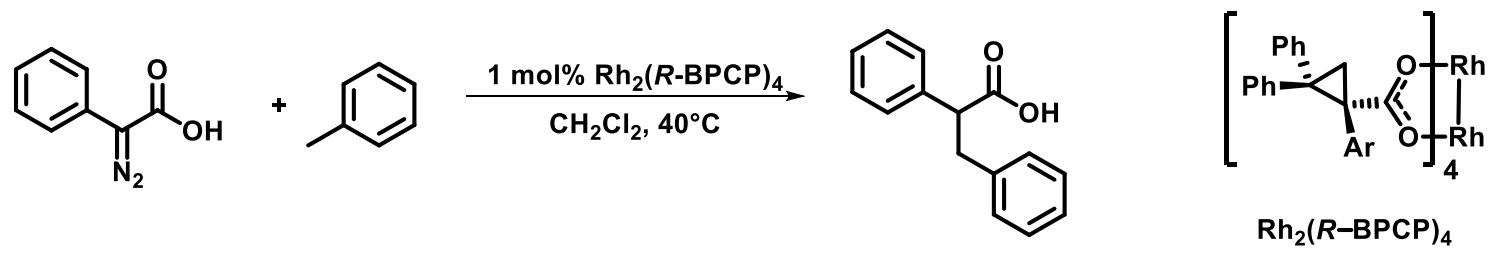

Scheme 4.1 Traditional alkylation approaches to synthesize 2,3-diphenylpropionic acids

One of the major strategies to access these biaryl propionic acid derivatives reported recently is through a formal hydrocarboxylation of stilbenes. One example, previously discussed in Chapter 1, involves Skrydstrup's hydroboration of stilbenes followed by NHC-ligated coppercatalyzed carboxylation. It is important to note that in this strategy stilbenes that have electronically similar aryl rings exhibit a mixture of both the $\alpha$ - and $\beta$-isomers. By employing a stilbene with an electron-deficient and an electron-rich aryl ring, a single regioisomer could be achieved, albeit in a lower yield (Scheme 4.2). A hydrocarboxylation strategy by Martin and coworkers revealed a site-selective hydrocarboxylation of a wide range of unsaturated hydrocarbons using water as the hydride source. ${ }^{97}$ In this report, there was one example of reactivity of an unsymmetrical stilbene. A similar selectivity was observed in this case where the carboxylic acid was installed at the $\alpha$-position of the electron-deficient aryl ring (Scheme 4.3). The final hydrocarboxylation approach is a palladium-catalyzed process in the presence of formic acid and benzoic acid. ${ }^{98}$ When unsymmetrical stilbenes were investigated, an ortho-substituent was added 
to one of the phenyl groups to create steric differentiation while both regioisomers were formed (Scheme 4.4).

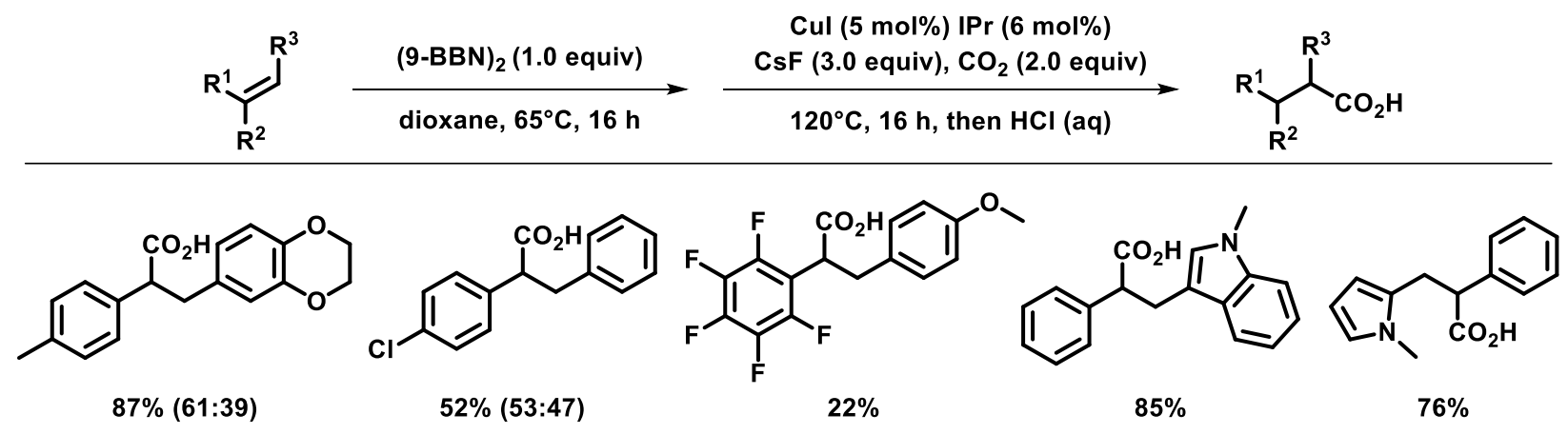

Scheme 4.2 Skrydstrup's hydroboration/carboxylation strategy to access 2,3-diarylpropionic acids

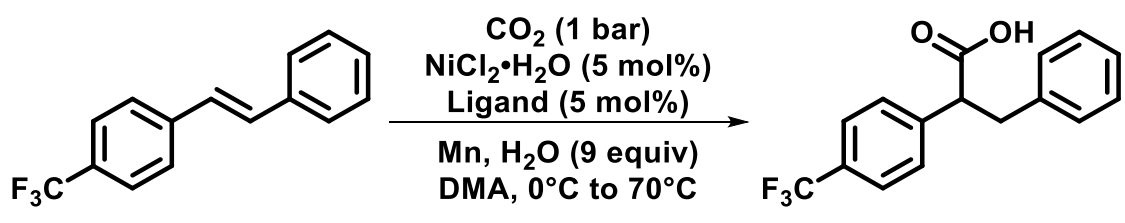<smiles>Cc1cc(C(C)(C)C)cc(-c2cc(C(C)(C)C)ccn2)n1</smiles>

Scheme 4.3 Martin's catalytic hydrocarboxylation

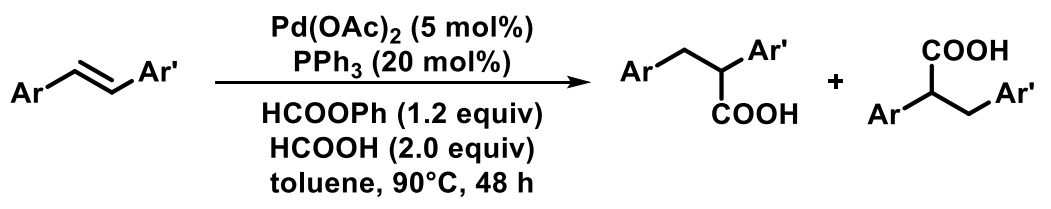<smiles>CCc1ccccc1CC(Cc1ccccc1)c1ccccc1CC(Cc1ccccc1Cl)c1ccc(OC)cc1CC(C(=O)O)c1ccc(C(C(=O)O)C(=O)O)cc1</smiles>

Scheme 4.4 Shi's palladium-catalyzed hydrocarboxylation 
Based on these hydrocarboxylation strategies, it seems that the methodologies commonly employed rely on the electronics or sterics of the aryl rings to determine regioselectivity of the carboxylic acid. Due to our boracarboxylation protocol, we already set the regiochemistry of the acid moiety, affording a unique opportunity to perform cross-coupling to achieve these 2,3-diaryl propionic acids. This Nobel Prize winning reactivity has been established as a versatile and powerful tool to transform a carbon-boron bond into a carbon-carbon bond. Suzuki cross-coupling has proven to be a revolutionary reaction since its discovery in $1979 .{ }^{99,100}$

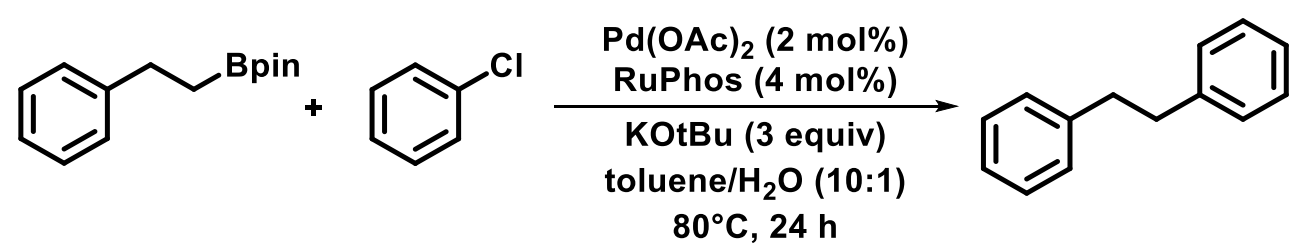

Scheme 4.5 Cross-coupling of an alkylboronate ester

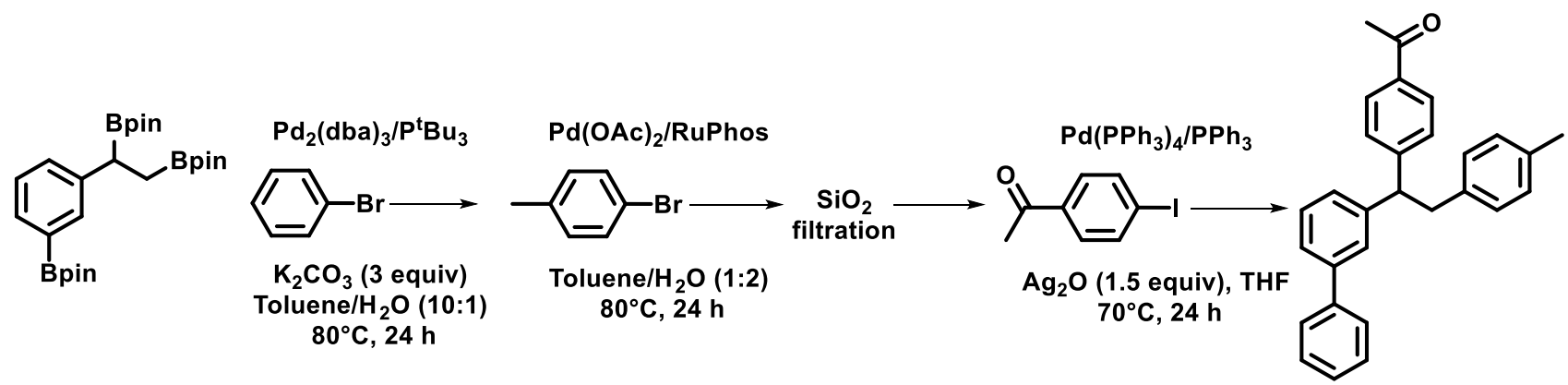

Scheme 4.6 Crudden's orthogonal cross-coupling methodology

We thought this to be a viable route because there are some examples in the literature that demonstrate $\beta$-substituted alkylboronate esters can undergo cross-coupling chemistry. One example shows the linear hydroboration product of styrene could react with chlorobenzene to afford the cross-coupling product through the use of a $\mathrm{Pd}(\mathrm{OAc})_{2} / \mathrm{RuPhos}$ catalyst system (Scheme 4.5). ${ }^{101}$ A sequential cross-coupling of borylated compounds has also been achieved in order to couple a $\beta$-substituted alkylboronate. ${ }^{102}$ One example from Crudden's group demonstrates orthogonal coupling to generate triarylated compounds of pharmaceutical interest. ${ }^{103}$ The initial compound contains three different $\mathrm{C}-\mathrm{B}$ bonds: $\mathrm{B}-\mathrm{C}^{(\mathrm{sp} 2)}$, primary $\mathrm{B}-\mathrm{C}^{(\mathrm{sp} 3)}$, and secondary $\mathrm{B}-\mathrm{C}^{(\mathrm{sp} 3)}$. 
The first coupling was achieved without loss of either of the aliphatic pinacol boronate groups and the second coupling reaction left the benzylic B-C bond intact to produce the triarylated product (Scheme 4.6).

While reviewing the literature, we observed that these benzylic carboxylic acids can be used as a directing group to achieve $\mathrm{C}-\mathrm{H}$ functionalization in the ortho position of arenes. ${ }^{104} \mathrm{In}$ one specific example, $\mathrm{Yu}$ and co-workers reported a methodology to achieve a carboxylatedirected palladium-catalyzed C-H olefination (Scheme 4.7). ${ }^{105} \mathrm{Yu}$ also developed another diverse and high yielding example of the ortho-arylation of enantiomerically pure pivaloyl-protected mandelic acid derivatives (Scheme 4.8). ${ }^{106}$ This methodology does not require the installation and removal of a directing group while achieving monoselectivity. This $\mathrm{C}-\mathrm{H}$ functionalization also occurs with no epimerization of the $\alpha$-chiral centers.
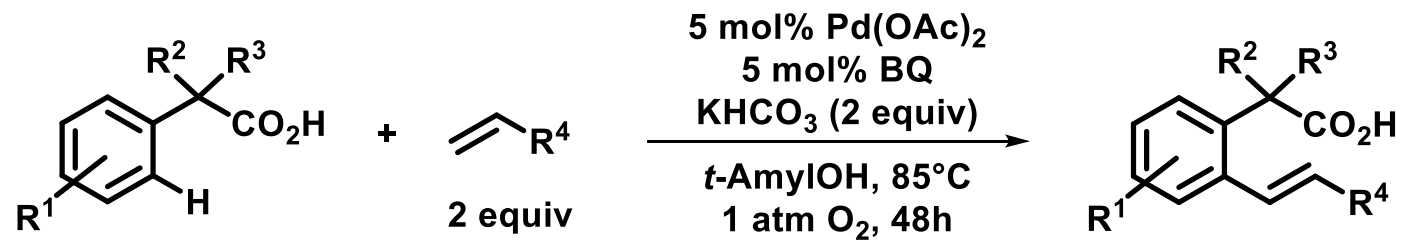

Scheme 4.7 Yu's ortho-olefination strategy using a carboxylic acid directing group

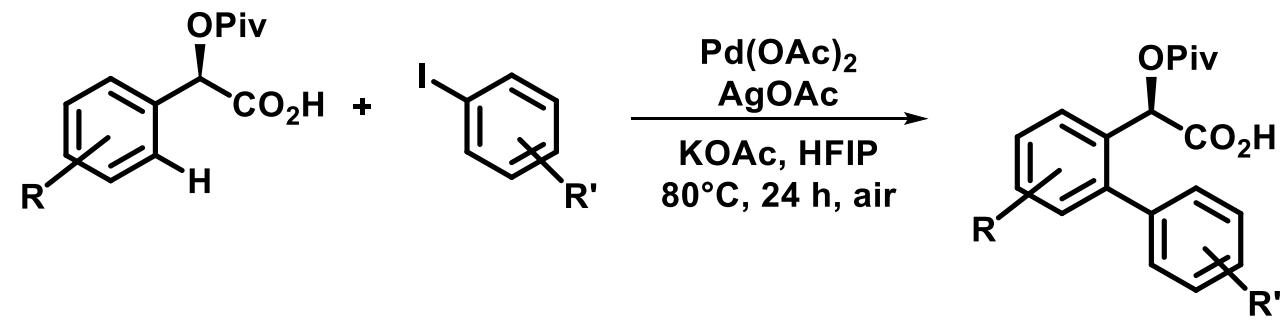

Scheme 4.8 Yu's ortho-arylation methodology using a carboxylic acid directing group 


\subsection{Results}

4.2.1 Optimization for cross-coupling of boracarboxylated products

Based on the reactivity shown in the literature, the Popp group wanted to investigate the ability to perform cross-coupling chemistry on our boracarboxylated products to achieve access to 2,3-diarylpropionic acids through a new strategy. We were also aware of the possibility of activating the ortho-position of the phenyl ring due to the directing group nature of the free carboxylic acid functionality. As in the fluorination project, we investigated the ability to achieve this catalysis using the tert-butyl boracarboxylated product due to its high yield and ease of purification. This boracarboxylated product was coupled with 4-bromobenzotrifluoride. We hoped that the electron-withdrawing nature of the coupling partner would allow for a favorable oxidative addition of the aryl bromide. During initial catalyst screening, two different palladium (0) sources without ligand showed minimal reactivity (Table 4.1, entries 1-2). While $\mathrm{Pd}\left(\mathrm{PPh}_{3}\right)_{4}$ was employed as a catalyst, the optimal solvent mixture was determined to be THF/water and $\mathrm{Cs}_{2} \mathrm{CO}_{3}$ as the optimal base (Table 4.1, entries 3-4). When attempting to switch to a palladium (II) catalyst, reactivity was completely shut down (Table 4.1, entry 5). Next, $\mathrm{Pd}(\mathrm{OAc})_{2}, \mathrm{Pd}\left(\mathrm{PPh}_{3}\right)_{4}$, and $\mathrm{Pd}(\mathrm{dba})_{2}$ were all used as palladium sources in the presence of the Buchwald ligand, XPhos (Table 4.1, entries 6-8). Based on the highest reactivity observed with $\mathrm{Pd}(\mathrm{dba})_{2}$, this source of palladium (0) was used with the RuPhos ligand to achieve a high yield of the 2,3-diarypropionic acid (Table 4.1, entry 9). 
Table 4.1 Screening of catalyst conditions for the cross-coupling of boracarboxylated products ${ }^{a}$

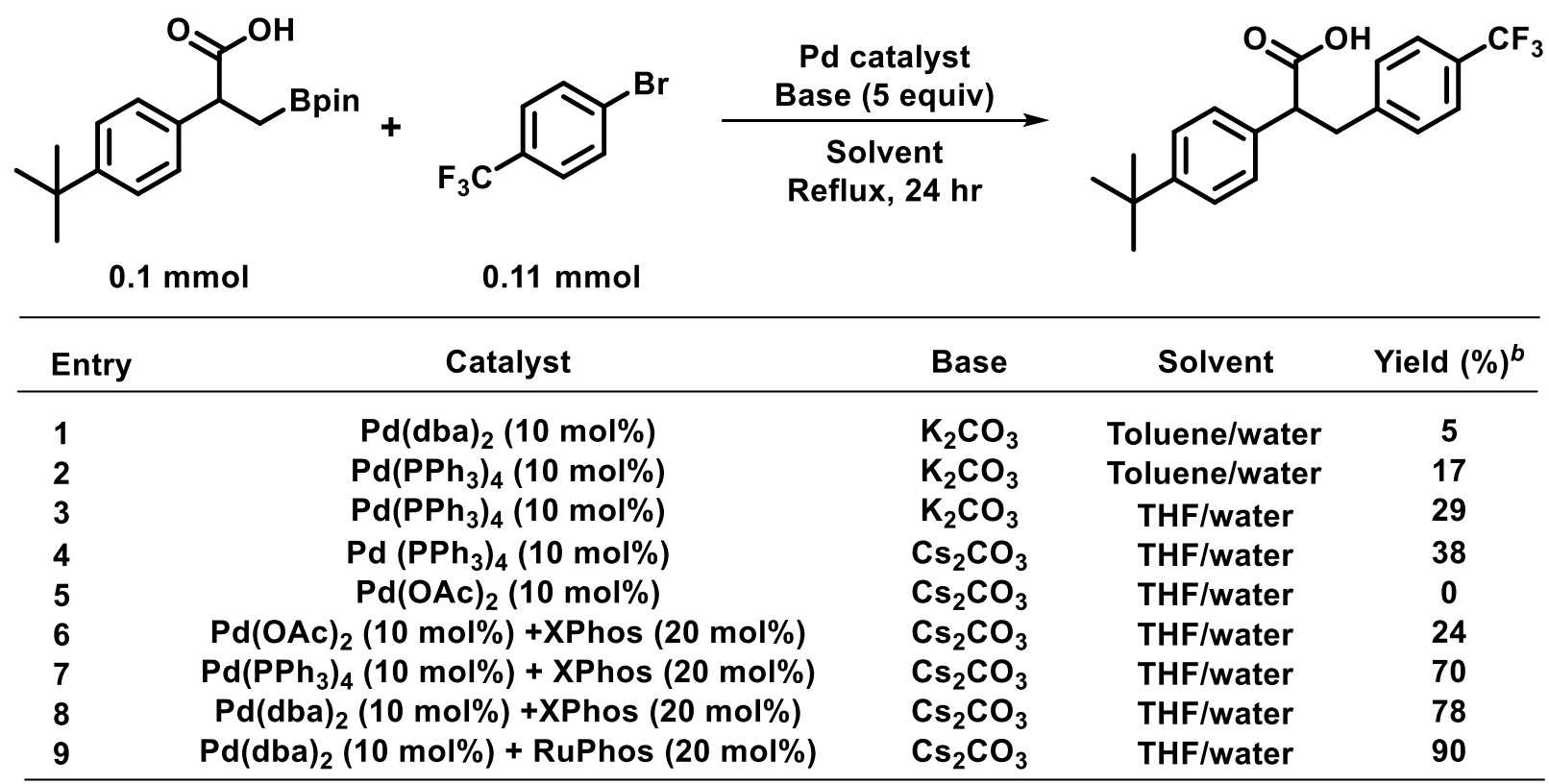

${ }^{a}$ Reactions ran in 10:1 toluene/water or 10:1 THF/water at a concentration of $0.018 \mathrm{M}^{b}$ Yields were determined by ${ }^{1} \mathrm{H}$ NMR spectroscopy using mesitylene as the internal standard

Table 4.2 Screening of reaction conditions for the cross-coupling of boracarboxylated products ${ }^{a}$

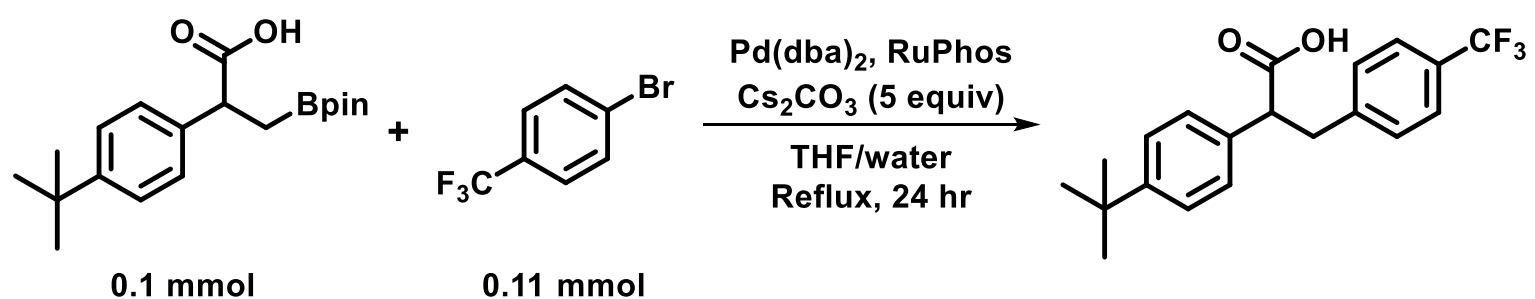

\begin{tabular}{lcccc}
\hline Entry & Pd(dba) & RuPhos & Variation & Yield (\%) $^{b}$ \\
\hline 1 & $10 \mathrm{~mol} \%$ & $20 \mathrm{~mol} \%$ & & 95 \\
2 & $10 \mathrm{~mol} \%$ & $20 \mathrm{~mol} \%$ & 2.5 equiv $\mathrm{Cs}_{2} \mathrm{CO}_{3}$ & 72 \\
3 & $5 \mathrm{~mol} \%$ & $10 \mathrm{~mol} \%$ & & 62 \\
4 & $5 \mathrm{~mol} \%$ & $10 \mathrm{~mol} \%$ & 1.5 equiv aryl bromide & 69 \\
5 & $5 \mathrm{~mol} \%$ & $10 \mathrm{~mol} \%$ & 2 equiv aryl bromide & 68 \\
6 & $5 \mathrm{~mol} \%$ & $10 \mathrm{~mol} \%$ & $48 \mathrm{hr}$ & 88 \\
7 & $5 \mathrm{~mol} \%$ & $5 \mathrm{~mol} \%$ & $48 \mathrm{hr}$ & 77 \\
\hline
\end{tabular}

${ }^{a}$ Reactions ran in 10:1 THF/water at a concentration of $0.045 \mathrm{M}^{b}$ Yields were determined by ${ }^{1} \mathrm{H}$ NMR spectroscopy using mesitylene as the internal standard 
While screening different reaction conditions, we showed that the use of $\operatorname{Pd}(\mathrm{dba})_{2}$ at 10 mol\% and RuPhos at 20 mol\% could achieve a 95\% yield of the cross-coupled product (Table 4.2, entry 1). When attempting to decrease the loading of base by half from 5 to 2.5 equivalents, the reaction yield did drop off by at least a $20 \%$ yield (Table 4.2 , entry 2 ). When attempting to decrease the palladium and ligand loading to $5 \mathrm{~mol} \%$ and $10 \mathrm{~mol} \%$, respectively, there was also a significant decrease in yield (Table 4.2, entry 3). Adding more equivalents of the aryl bromide did not seem to increase the yield much at the lower catalyst loading (Table 4.2, entries 4-5). At these lower catalyst loading reaction conditions, there was still starting material present in the NMR so it was shown that the yield of cross-coupling could be improved by increasing the reaction time to 48 hours (Table 4.2, entry 6). Finally, the $\mathrm{Pd}(\mathrm{dba})_{2}$ and RuPhos were both run at $5 \mathrm{~mol} \%$ in 48 hours to show a good yield of product; however, the reaction seems to proceed better with excess ligand (Table 4.2, entry 7).

Table 4.3 Substrate scope of boracarboxylated products for cross-coupling ${ }^{a}$

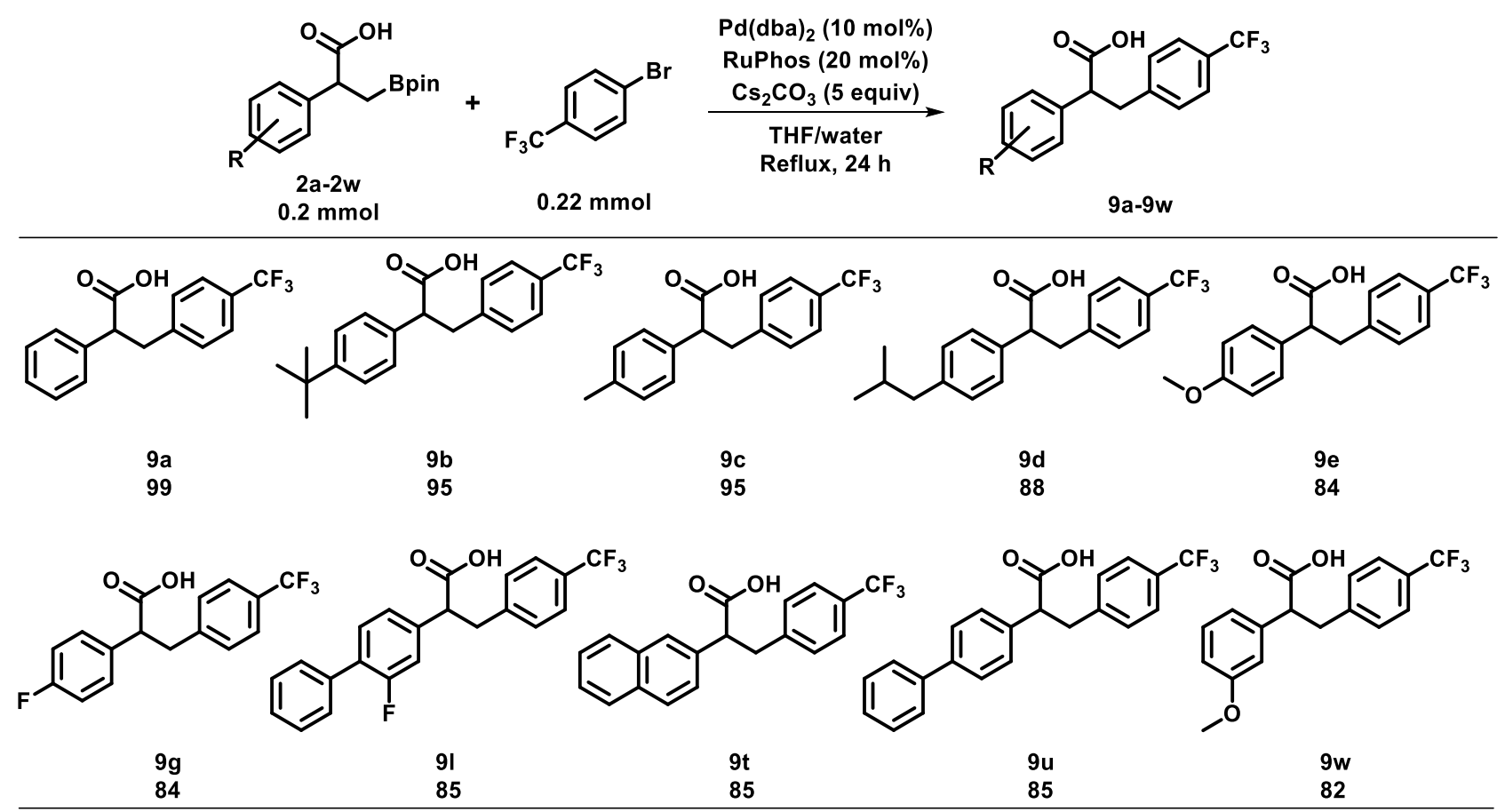

${ }^{a}$ Reactions ran in 10:1 THF $(4.0 \mathrm{~mL}) /$ water $(0.4 \mathrm{~mL})$ at a concentration of $0.045 \mathrm{M}$. Yields were determined by ${ }^{1} \mathrm{H}$ NMR spectroscopy using mesitylene as the internal standard 


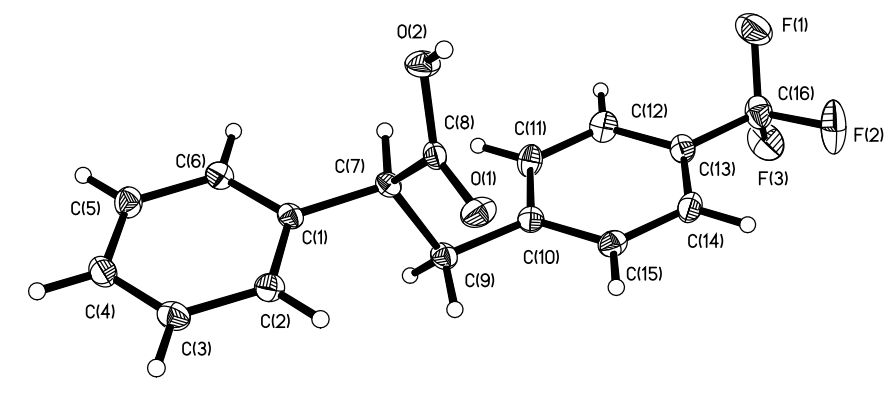

Figure 4.2 X-ray crystal structure of cross-coupling product, 9a

Using the optimized reaction conditions, we first probed the cross-coupling reactivity of some of our boracarboxylated products with 4-bromobenzotrifluoride in the presence of the $\mathrm{Pd}(\mathrm{dba})_{2} / \mathrm{RuPhos}$ catalyst system. We were pleased to demonstrate good yields of the crosscoupled products to afford a number of 2,3-diarylpropionic acid derivatives (Table 4.3). We observed that the boracarboxylated product of styrene underwent cross-coupling in a high yield to access the opposite regioisomer that had previously been shown, in which the carboxylic acid is now situated at the $\alpha$-position of the more electron-rich aryl ring (9a). This product with reversed regioselectivity has been confirmed through crystallographic analysis (Figure 4.2 and Appendix 1). The cross-coupling procedure affords high yields with boracarboxylated products bearing an electron-donating group in the para-position such as tert-butyl, methyl, isobutyl and methoxy (9b, 9c, 9d, and 9e). Cross-coupling is also achieved with the slightly electron-withdrawing para-fluoro boracarboxylated product $(9 \mathrm{~g})$. This method demonstrates the ability to cross-couple to access substrates with extended $\pi$-systems such as fluorbiprofen (9l), naphthyl (9t), and biphenyl (9u). Reactivity could also be achieved in good yield by utilizing the electron-withdrawing metamethoxy boracarboxylated product $(9 \mathrm{w})$.

Next, we wanted to investigate the scope of aryl bromides that would undergo crosscoupling with the tert-butyl boracarboxylated substrate (Table 4.4). The methodology favored the trifluoromethyl and fluoro para-substituted aryl bromides in good yields (9b-10b); however, the 2,4,6-trifluorobromobenzene resulted in a low yield of the cross-coupled product (11b), presumably due to the substitution on both ortho positions. Two other para-substituted electronwithdrawing aryl bromides showed reactivity with tolerance of the nitro and cyano functionalities 
(12b-13b). The strongly donating bromoanisole also demonstrated cross-coupling with the tertbutyl boracarboxylated product (14b). Interestingly, we were also able to use bromostyrene as a coupling in high yield of the coupled product (15b). The alkene functionality allows a point for further synthetic elaboration of this 2,3-diarylpropionic acid. Finally, para-methyl and orthoxylene aryl bromides showed good tolerance to the reaction conditions allowing for methyl substituted derivatives (16b-17b).

Table 4.4 Substrate scope of aryl bromides for cross-coupling ${ }^{a}$
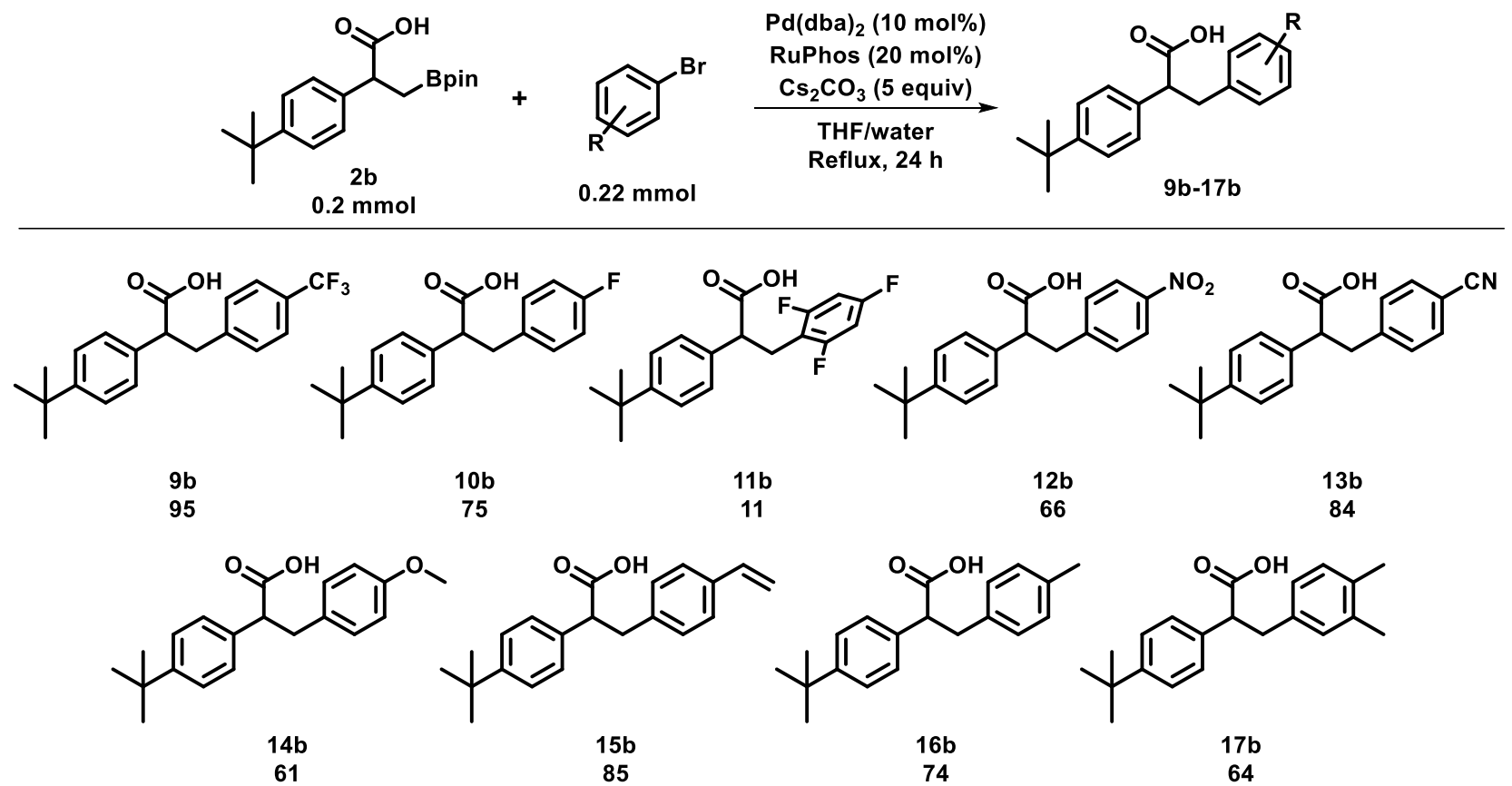

${ }^{a}$ Reactions ran in 10:1 THF $(4.0 \mathrm{~mL}) /$ water $(0.4 \mathrm{~mL})$ at a concentration of $0.045 \mathrm{M}$. Yields were determined by ${ }^{1} \mathrm{H}$ NMR spectroscopy using mesitylene as the internal standard

Another group of substrates that were investigated is the scope of heterocycles that could undergo reactivity (Table 4.5). The 2-bromopyridine showed no reactivity under the optimized conditions (18b) while the 3- and 4-bromopyridine resulted in low yield (19b-20b). The 2- and 3bromofuran, along with the 2-bromothiophene, showed minimal cross-coupled product as well (21b-23b). The yields of cross-coupling significantly increased when employing the benzofuran and benzothiophene variants of the heterocycles. The 5-bromobenzofuran and 5- 
bromobenzothiophene resulted in good yields of cross-coupling (24b-25b). When the 3bromothiphene was screened, the yield did decrease significantly due to the proximity to the heteroatom (26b). Finally, we demonstrated moderate yields of cross-coupling between boracarboxylated tert-butylstyrene and bromo-substituted indoles (27b-28b).

Table 4.5 Substrate scope of heterocycles for cross-coupling ${ }^{a}$

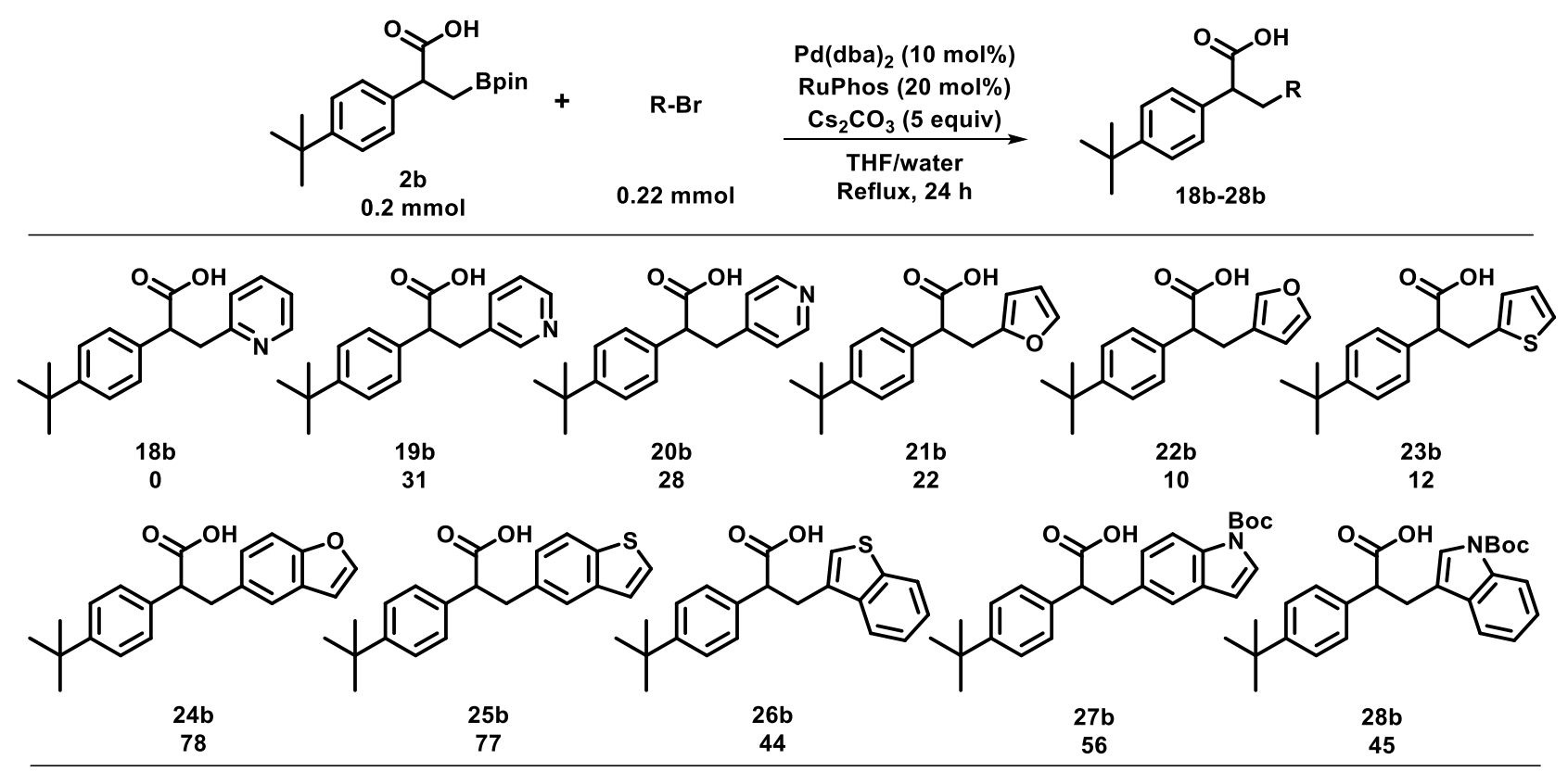

${ }^{a}$ Reactions ran in 10:1 THF $(4.0 \mathrm{~mL}) /$ water $(0.4 \mathrm{~mL})$ at a concentration of $0.045 \mathrm{M}$. Yields were determined by ${ }^{1} \mathrm{H}$ NMR spectroscopy using mesitylene as the internal standard, TBS $=$ to be screened

One more area of investigation was to perform a one-pot boracarboxylation and crosscoupling protocol (Scheme 4.9). The tert-butylstyrene was reacted under regular boracarboxylation conditions to install the $\mathrm{CO}_{2}$ and Bpin moiety. After 24 hours, the crosscoupling catalyst solution of $\operatorname{Pd}(\mathrm{dba})_{2}$ and RuPhos was dissolved in THF and was added to the round-bottom containing the boracarboxylation mixture without any type of workup. The reaction vessel was flushed with argon and allowed to stir for about 5 minutes before the 4bromobenzotrifluoride coupling partner, base, and water were added. This reaction was allowed to reflux for an additional 24 hours. After typical reaction workup, the cross-coupled product was achieved in a moderate yield of $40 \%$. This allows for a protocol in which the boracarboxylated product does not need to be isolated in order to achieve the 2,3-diarylpropionic acid product. 


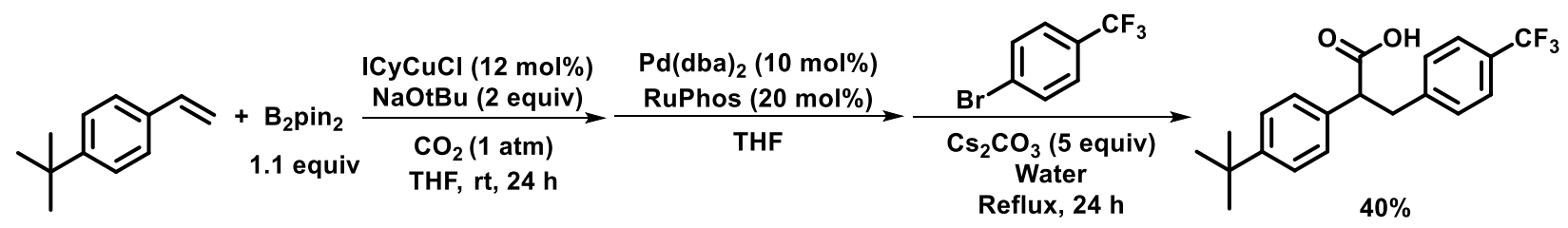

Scheme 4.9 One-pot boracarboxylation/cross-coupling

\subsection{Conclusion}

In this chapter, we have outlined a protocol to derivatize the boron moiety in boracarboxylated products through the versatile reactivity of cross-coupling. We demonstrate the ability to use a new methodology to access a number of 2,3-diarylpropionic acid derivatives. Using our approach, the position of the carboxylic acid is already set through boracarboxylation. This provides the opposite regioisomer observed when compared to the traditional hydrocarboxylation strategies that are commonly employed. This chapter shows the ability to access a number of interesting biaryls products through the use of a variety of different boracarboxylated products, aryl bromides, and heterocycles. We have also shown the ability to perform a one-pot tandem boracarboxylation/cross-coupling strategy to achieve desired product formation without workup of the intermediate boracarboxylated product. More work is still underway to screen additional substrates and carry out isolation of products.

\subsection{Experimental Methods}

\subsubsection{General information}

Dry tetrahydrofuran was used for all experiments from a Glass Contour solvent purification system and the water was used from the DI tap at WVU for the reaction solvent. Deuterated $\mathrm{CDCl}_{3}$ was purchased from Cambridge Isotope Laboratories, Inc. NMR spectra were recorded on either a $400 \mathrm{MHz}$ Agilent or a $400 \mathrm{MHz}$ JEOL NMR spectrometer. ${ }^{1} \mathrm{H}$ NMR experiments were run in $\mathrm{CDCl}_{3}$ using tetramethylsilane as an internal standard and ${ }^{13} \mathrm{C} \mathrm{NMR}$ spectra used $\mathrm{CDCl}_{3}$ as a solvent and reference. All boracarboxylated starting materials were synthesized and isolated with $<5 \%$ impurities of $\mathrm{B}_{2} \mathrm{pin}_{2}$ before subjected to cross-coupling conditions. The 2,3-biaryl propionic 
acid compounds can be isolated by slowly cooling a hot hexanes solution or layering dichloromethane with hexanes in a $-20^{\circ} \mathrm{C}$ freezer.

\subsubsection{Experimental procedures}

For all substrate scope reactions, a $20-\mathrm{mL}$ vial was first charged with a stir bar, $\operatorname{Pd}(\mathrm{dba})_{2}$ (11.6 mg, $0.02 \mathrm{mmol}, 10 \mathrm{~mol} \%$ ), RuPhos (18.6 mg, $0.04 \mathrm{mmol}, 20 \mathrm{~mol} \%$ ) and $4.0 \mathrm{~mL}$ of THF. The vial was swirled to ensure all palladium and ligand was dissolved. Next, boracarboxylated product (0.2 mmol, $1.0 \mathrm{eq}), \mathrm{Cs}_{2} \mathrm{CO}_{3}$ (326 mg, $1.0 \mathrm{mmol}, 5.0$ eq.), aryl bromide (0.22 mmol, 1.1 eq.), and $0.4 \mathrm{~mL}$ of DI water were added to the reaction vial. A septum cap was secured tightly on the vial and taped. The septum cap was punctured with a needle to purge the reaction mixture with argon for 5-10 minutes with an outlet to a bubbler. The puncture was taped over to prevent any evaporation of solvent. The reactions were stirred at reflux $\left(85^{\circ} \mathrm{C}\right)$ for 24 hours. Upon reaction completion, the crude mixture was allowed to cool to room temperature and added to a separatory funnel that contained $1 \mathrm{M} \mathrm{HCl}(10 \mathrm{~mL})$. The organic layer was extracted with dichloromethane (15 $\mathrm{mL}$ x 3). The combined organic layers were collected in a $100 \mathrm{~mL}$ round-bottom flask and concentrated under vacuum to give the crude product. Mesitylene (0.04 mmol, $20 \mathrm{~mol} \%$ ) was added to the crude mixture as an internal standard and dissolved in $\mathrm{CDCl}_{3}$ to be analyzed by ${ }^{1} \mathrm{H}$ NMR. If cross-coupling product was present in a reasonable amount, the crude product was isolated by crystallization techniques. 


\section{References}

${ }^{1}$ Sheldon, R. A.; Chem. Soc. Rev. 2012, 41, 1437-1451.

${ }^{2}$ Centi, G.; Perathoner, S. Catal. Today 2003, 77, 287-297.

${ }^{3}$ Anastas, P. T.; Kirchhoff, M. M.; Williamson, T. C. Appl. Catal., A 2001, 221, 3-13.

${ }^{4}$ Olajire, A. A. J. $\mathrm{CO}_{2}$ Util. 2013, 3-4, 74-92.

${ }^{5}$ Peters, M.; Kohler, B.; Kuckshinrichs, W.; Leitner, W.; Markewitz, P.; Muller, T. E. ChemSusChem 2011, 4, 1216-1240.

${ }^{6}$ Halmann, M. M. Chemical Fixation of Carbon Dioxide: Methods for Recycling $\mathrm{CO}_{2}$ into Useful Products, CRC Press, 1993

${ }^{7}$ Hunt, S. E.; Jones, J. I.; Lindsey, A. S.; Killoh, D. C.; Turner, H. S. J. Chem. Soc. 1958, 31523160 .

${ }^{8}$ Holscher, M.; Gurtler, C.; Keim, W.; Muller, T. E.; Peters, M.; Leitner, W. Z. Naturforsch 2012, 67, 961-975.

${ }^{9}$ Liu, Q.; Wu, L.; Jackstell, R.; Beller, M. Nat. Commun. 2015, 6, 5933-5948.

${ }^{10}$ Sakakura, T.; Kohno, K. Chem. Commun. 2009, 11, 1312-1330.

${ }^{11}$ Yeung, C. S.; Dong, V. M. J. Am. Chem. Soc. 2008, 130, 7826-7827.

${ }^{12}$ Takaya, J. ; Tadami S.; Ukai, K.; Iwasawa, N. Org. Lett. 2008, 10, 2697-2700.

${ }^{13}$ Tran-Vu, H.; Daugulis, O. ACS Catal. 2013, 3, 2417-2420.

${ }^{14}$ Li, S.; Yuan, W.; Ma, S. Angew. Chem., Int. Ed. 2011, 50, 2578-2582.

${ }^{15}$ Fujihara, T.; Xu, T.; Semba, K.; Terao, J.; Tsuji, Y. Angew. Chem., Int. Ed. 2011, 50, 523-527.

${ }^{16}$ Wang, X.; Nakajima, M.; Martin, R. J. Am. Chem. Soc. 2015, 137, 8924-8927.

${ }^{17}$ Green, G. A.; Clin. Cornerstone 2001, 3, 50-59.

${ }^{18}$ Williams, C. M.; Johnson, J. B.; Rovis, T. J. Am. Chem. Soc. 2008, 130, 14936-14937.

${ }^{19}$ Greenhalgh, M. D.; Thomas, S. P. J. Am. Chem. Soc. 2012, 134, 11900-11903.

${ }^{20}$ Shao, P.; Wang, S.; Chen, C.; Xi, C. Org. Lett. 2016, 18, 2050-2053.

${ }^{21}$ Grigg, R. D.; Rigoli, J. W.; Van Hoveln, R.; Neale, S.; Schomaker, J. M. Chem Eur. J. 2012, $18,9391-9396$. 
${ }^{22}$ Juhl, M.; Laursen, S. L. R.; Huang, Y.; Nielsen, D. U.; Daasbjerg, K.; Skrydstrup, T. ACS Catal. 2017, 7, 1392-1396.

${ }^{23}$ Li, S.; Ma, S. Adv. Synth. Catal. 2012, 354, 2387-2394.

${ }^{24}$ Fujihara, T.; Tani, Y.; Semba, K.; Terao, J.; Tsuji, Y. Angew. Chem., Int. Ed. 2012, 51, $11487-$ 11490 .

${ }^{25}$ Zhang, L.; Cheng, J.; Carry, B.; Hou, Z. J. Am. Chem. Soc. 2012, 134, 14314-14317.

${ }^{26}$ Reproduced from original CIF file in Mercury 3.5.1. Hydrogen atoms have been omitted for clarity.

${ }^{27}$ Baker, S. J.; Ding, C. Z.; Akama, T.; Zhang, Y. K.; Hernandez, V.; Xia, Y. Future Med. Chem. 2009, 1, 1275-1288.

${ }^{28}$ Groziak, M. P.; Am. J. Ther. 2001, 8, 321-328.

${ }^{29}$ Hunt, C. D. J. Trace Elem. Med. Biol. 2012, 26, 157-160.

${ }^{30}$ Uluisik, I.; Karakaya, H. C.; Koc, A. J. Trace Elem. Med. Biol. 2018, 45, 156-162.

${ }^{31}$ Semba, K.; Fujihara, T.; Terao, J.; Tsuji, Y. Tetrahedron 2015, 71, 2183-2197.

${ }^{32}$ Laitar, D. S.; Tsui, E. Y.; Sadighi, J. P. Organometallics 2006, 25, 2405-2408.

${ }^{33}$ Dang, L.; Zhao, H.; Lin, Z.; Marder, T. B. Organometallics 2007, 26, 2824-2832.

${ }^{34}$ Mun, S.; Lee, J.; Yun, J. Org. Lett. 2006, 8, 4887-4889.

${ }^{35}$ Takahashi, K.; Ishiyamo, T.; Miyaura, N. Chem. Lett. 2000, 29, 982-983.

${ }^{36}$ Lee, Y.; Hoveyda, A. H. J. Am. Chem. Soc. 2009, 131, 3160-3161.

${ }^{37}$ Hemming, D.; Fritzemeier, R.; Westcott, S. A.; Santos, W. L.; Steel, P. G. Chem. Soc. Rev. 2018, 47, 7477-7494.

${ }^{38}$ Ito, H.; Kosaka, Y.; Nonoyama, K.; Sasaki, Y.; Sawamura, M. Angew. Chem., Int. Ed. 2008, 47, 7424-7427.

${ }^{39}$ Yoshida, H.; Kageyuki, I.; Takaki, K. Org. Lett. 2013, 15, 952-955.

${ }^{40}$ Chen, B.; Cao, P.; Liao, Y.; Wang, M.; Liao, J. Org. Lett. 2018, 20, 1346-1349.

${ }^{41}$ Parra, A.; Amenos, L.; Guisan-Ceinos, M.; Lopez, A.; Garcia Ruano, J. L.; Tortosa, M. J. Am. Chem. Soc. 2014, 136, 15833-15836.

${ }^{42}$ Matsuda, N.; Hirano, K.; Satoh, T.; Miura, M. J. Am. Chem. Soc. 2013, 135, 4934-4937. 
${ }^{43}$ Sakae, R.; Hirano, K.; Miura, M. J. Am. Chem. Soc. 2015, 137, 6460-6463.

${ }^{44}$ Mankad, N. P.; Gray, T. G.; Laitar, D. S.; Sadighi, J. P. Organometallics 2004, 23, 1191-1193.

${ }^{45}$ Ohishi, T.; Zhang, L.; Nishiura, M.; Hou, Z. Angew. Chem., Int. Ed. 2011, 50, 8114-8117.

${ }^{46}$ Butcher, T. W.; McClain, E. J.; Hamilton, T. G.; Perrone, T. M.; Kroner, K. M.; Donohoe, G. C.; Akhmedov, N. G.; Petersen, J. L.; Popp, B. V. Org. Lett. 2016, 18, 6428-6431.

${ }^{47}$ Yatham, V. R.; Shen, Y.; Martin, R. Angew. Chem., Int. Ed. 2017, 56, 10915-10919.

${ }^{48}$ Ye, J. H.; Miao, M.; Huang, H.; Yan, S. S.; Yin, Z. B.; Zhou, W. J.; Yu, D. G. Angew. Chem., Int. Ed. 2017, 56, 15416-15420.

${ }^{49}$ Hou, J.; Ee, A.; Cao, H.; Ong, H. W.; Xu, J. H.; Wu, J. Angew. Chem., Int. Ed. 2018, 57, 1722017224.

${ }^{50}$ Bandar, J. S.; Ascic, E.; Buchwald, S. L. J. Am. Chem. Soc. 2016, 138, 5821-5824.

${ }^{51}$ Ascic, E.; Buchwald, S. L. J. Am. Chem. Soc. 2015, 137, 4666-4669.

${ }^{52}$ Zhu, S.; Buchwald, S. L. J. Am. Chem. Soc. 2014, 136, 15913-15916.

${ }^{53}$ Lipshutz, B. H.; Noson, K.; Chrisman, W.; Lower, A. J. Am. Chem. Soc. 2003, 125, 87798789.

${ }^{54}$ Lipshutz, B. H.; Servesko, J. M. Angew. Chem., Int. Ed. 2003, 42, 4789-4792.

${ }^{55}$ Carry, B.; Zhang, L.; Nishiura, M.; Hou, Z. Angew. Chem., Int. Ed. 2016, 55, 6257-6260.

${ }^{56}$ Tsuda, T.; Sanada, S.; Ueda, K.; Saegusa, T. Inorg. Chem. 1976, 15, 2329-2332.

${ }^{57}$ Tsuda, T.; Chujo, Y.; Saegusa, T. J. Am. Chem. Soc. 1980, 102, 431-433.

${ }^{58}$ Hansch, C.; Leo, A.; Taft, R.W. Chem. Rev. 1991, 91, 165-195.

${ }^{59}$ Miralles, N.; Cid, J.; Cuenca, A. B.; Carbo, J. J.; Fernandez, E. Chem. Commun. 2015, 51, 1693-1696.

${ }^{60}$ Bonet, A.; Pubill-Ulldemolins, C.; Bo, C.; Gulyas, H.; Fernandez, E. Angew. Chem., Int. Ed. 2011, 50, 7158-7161.

${ }^{61}$ Denmark, S. E.; Butler, C. R. Org. Lett. 2006, 8, 63-66.

${ }^{62}$ Santoro, O.; Collado, A.; Slawin, A. M. Z.; Nolan, S. P.; Cazin, C. S. J. Chem Commun. 2013, 49, 10483-10485. 
${ }^{63}$ Gillis, E. P.; Eastman, K. J.; Hill, M. D.; Donnelly, D. J. Meanwell, N. A. J. Med. Chem. 2015, 58, 8315-8359.

${ }^{64}$ Smart, B. E. J. Fluor. Chem. 2001, 109, 3-11.

${ }^{65}$ Hiyama, T. Organofluorine Compounds, Springer-Verlag, 2000; Chapter 5

${ }^{66}$ Chambers, R. D. Fluorine in Organic Chemistry, Blackwell Publishing Ltd, 2004; Chapter 1

${ }^{67}$ Purser, S.; Moore, P. R.; Swallow, S.; Gouverneur, V. Chem. Soc. Rev. 2008, 37, 320-330.

${ }^{68}$ Swallow, S. Prog. Med. Chem. 2015, 54, 65-133.

${ }^{69}$ Muller, K.; Faeh, C.; Diederich, F. Science 2007, 317, 1881-1886.

${ }^{70}$ Wang, J.; Sanchez-Rosello, M.; Acena, J. L.; Pozo, C.; Sorochinsky, A. E.; Fustero, S.; Soloshonok, V. A.; Liu, H. Chem. Rev. 2014, 114, 2432-2506.

${ }^{71}$ Ametamey, S. M.; Honer, M.; Schubiger, P. A. Chem. Rev. 2008, 108, 1501-1516.

${ }^{72}$ O’Hagan, D. Chem. Soc. Rev. 2008, 37, 308-319.

${ }^{73}$ Balz, G.; Schiemann, G. Ber. Deutsch. Chem. Ges. 1927, 60, 1186-1190.

${ }^{74}$ Cresswell, A. J.; Davies, S. G.; Roberts, P. M.; Thomson, J. E. Chem. Rev. 2015, 115, 566-611.

${ }^{75}$ Gottlieb, H. B. J. Am. Chem. Soc. 1936, 58, 532-533.

${ }^{76}$ Adams, D. J.; Clark, J. H. Chem. Soc. Rev. 1999, 28, 225-231.

${ }^{77}$ Liang, T.; Neumann, C. N.; Ritter, T. Angew. Chem., Int. Ed. 2013, 52, 8214-8264.

${ }^{78}$ Hart, J. J.; Syvret, R. G. J. Fluor. Chem. 1999, 100, 157-161.

${ }^{79}$ Banks, R. E.; Mohialdin-Khaffaf, S. N.; Lal, G. S.; Sharif, I.; Syvret, R. G. J. Chem. Soc., Chem. Commun., 1992, 8, 595-596.

${ }^{80}$ Furuya, T.; Ritter, T. Org. Lett. 2009, 11, 2860-2863.

${ }^{81}$ Petasis, N. A.; Yudin, A. K.; Zavialov, I. A.; Prakash, G. K. S.; Olah, G. A. Synlett, 1997, 5, 606-608.

${ }^{82}$ Cazorla, C.; Metay, E.; Andrioletti, B.; Lemaire, M. Tetrahedron Lett. 2009, 50, 3936-3938.

${ }^{83}$ Sandford, C.; Rasappan, R.; Aggarwal, V. K. J. Am. Chem. Soc. 2015, 137, 10100-10103.

${ }^{84}$ Li, Z.; Wang, Z.; Zhu, L.; Tan, X.; Li, C. J. Am. Chem. Soc. 2014, 136, 16439-16443. 
${ }^{85}$ Yin, F.; Wang, Z.; Li, Z.; Li, C. J. Am. Chem. Soc. 2012, 134, 10401-10404.

${ }^{86}$ Liu, W. B.; Zheng, S. C.; He, H.; Zhao, X. M.; Dai, L. X.; You, S. L. Chem. Commun. 2009, 6604-6606.

${ }^{87}$ Merritt, R. F. J. Org. Chem. 1966, 31, 3871-3873.

${ }^{88}$ Lal, G. S. J. Org. Chem. 1993, 58, 2791-2796.

${ }^{89}$ Banik, S. M.; Medley, J. W.; Jacobsen, E. N. J. Am. Chem. Soc. 2016, 138, 5000-5003.

${ }^{90}$ Haj, M. K.; Banik, S. M.; Jacobsen, E. N. Org. Lett. 2019, Article ASAP

${ }^{91}$ Karplus, M. J. Chem. Phys. 1959, 30, 11-15.

${ }_{92}$ Nagahara, T.; Yokoyama, Y.; Inamura, K.; Katakura, S.; Komoriya, S.; Yamaguchi, H.; Hara, T.; Iwamoto, M. J. Med. Chem. 1994, 37, 1200-1207.

${ }^{93}$ Hoshina, Y.; Ikegami, S.; Okuyama, A.; Fukui, H.; Inoguchi, K.; Maruyama, T.; Fujimoto, K.; Matsumura, Y.; Aoyama, A.; Harada, T.; Tanaka, H.; Nakamura, T. Bioorg. Med. Chem. Lett. 2005, 15, 217-220.

${ }^{94}$ Takeda, N.; Futaki, E.; Kobori, Y.; Ueda, M.; Miyata, O. Angew. Chem., Int. Ed. 2017, 56, 16342-16346.

${ }^{95}$ Stivala, C.; Zakarian, A. J. Am. Chem. Soc. 2011, 133, 11936-11939.

${ }^{96}$ Davies, H. M. L.; Morton, D. Chem. Soc. Rev. 2011, 40, 1857-1869.

${ }^{97}$ Gaydou, M.; Moragas, T.; Julia-Hernandez, F.; Martin, R. J. Am. Chem. Soc. 2017, 139, 1216112164.

${ }^{98}$ Dai, J.; Ren, W.; Li, J.; Shi, Y. Org. Chem. Front. 2018, 5, 561-565.

${ }^{99}$ Miyaura, N.; Yamada, K.; Suzuki, A. Tetrahedron, 1979, 20, 3437-3440.

${ }^{100}$ Miyaura, N.; Suzuki, A. J. Chem. Soc., Chem. Commun. 1979, 19, 866-867.

${ }^{101}$ Yang, K.; Song, Q. Green Chem. 2016, 18, 932-936.

${ }^{102}$ Chen, B.; Cao, P.; Yin, X.; Liao, Y.; Jiang, L.; Ye, J.; Wang, M.; Liao, J. ACS Catal. 2017, 7, 2425-2429.

${ }^{103}$ Crudden, C. M.; Ziebenhaus, C.; Rygus, J. P. G.; Ghozati, K.; Unsworth, P. J.; Nambo, M.; Voth, S.; Hutchinson, M.; Laberge, V. S.; Maekawa, Y.; Imao, D. Nat. Commun. 2016, 7, 1106511071. 
${ }^{104}$ Satoh, T.; Miura, M. Synthesis, 2010, 20, 3395-3409.

${ }^{105}$ Wang, D. H.; Engle, K. M.; Shi. B. F.; Yu, J. Q. Science, 2010, 327, 315-319.

${ }^{106}$ Dastbaravardeh, N.; Toba, T.; Farmer, M. E.; Yu, J. Q. J. Am. Chem. Soc. 2015, 137, 98779884. 
Appendix I: X-Ray Crystallography 


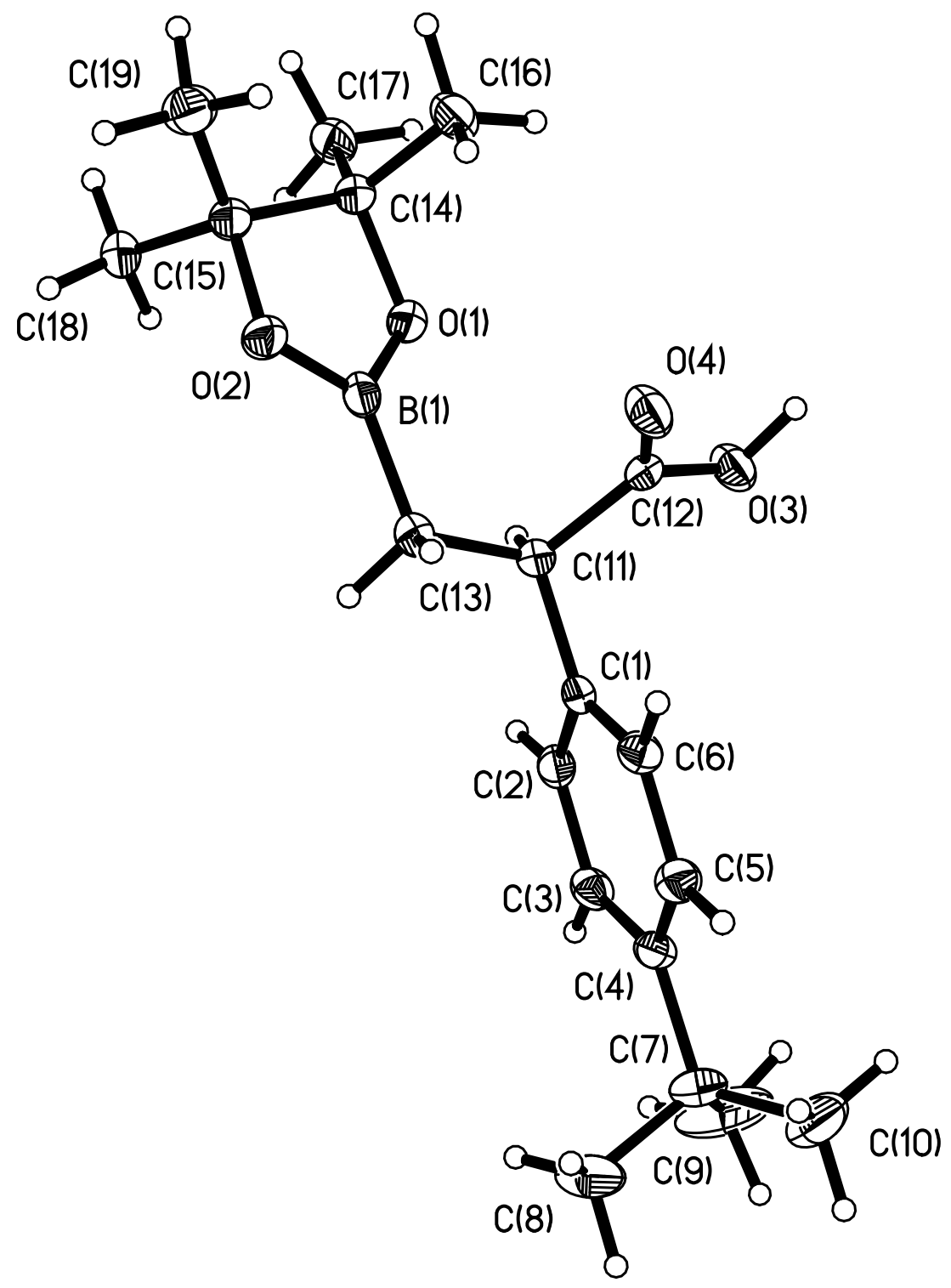

Figure 1. Perspective view of the molecular structure of the $\mathrm{C}_{19} \mathrm{H}_{29} \mathrm{BO}_{4}$ with the atom labeling scheme for the non-hydrogen atoms. The thermal ellipsoids are scaled to enclose $50 \%$ probability. 


\section{Description of the X-ray Structural Analysis of $\mathrm{C}_{19} \mathrm{H}_{29} \mathrm{BO}_{4}$}

A colorless crystal of $\mathrm{C}_{19} \mathrm{H}_{29} \mathrm{BO}_{4}$ was covered in a polybutene oil (Sigma-Aldrich) and placed on the end of a MiTeGen loop. The sample was cooled to $100 \mathrm{~K}$ with an Oxford Cryostream 700 system and optically aligned on a Bruker AXS D8 Venture fixed-chi X-ray diffractometer

equipped with a Triumph monochromator, a Mo K $\alpha$ radiation source $(\lambda=0.71073 \AA)$, and a PHOTON 100 CMOS detector. Two sets of 12 frames each were collected using the omega scan method with a $10 \mathrm{~s}$ exposure time. Integration of these frames followed by reflection indexing and least-squares refinement produced a crystal orientation matrix for the monoclinic crystal lattice that was used for the structural analysis.

Data collection consisted of the measurement of a total of 186 frames in one run using omega scans with the detector held at $5.00 \mathrm{~cm}$ from the crystal. Frame scan parameters are summarized in Table 1 below:

Table 1. Data collection details for $\mathrm{C}_{19} \mathrm{H}_{29} \mathrm{BO}_{4}$.

\begin{tabular}{|c|c|c|c|c|c|c|c|}
\hline Run & $2 \theta$ & $\omega$ & $\varphi$ & $\chi$ & Scan Width $\left(^{\circ}\right)$ & Frames & $\begin{array}{c}\text { Exposure } \\
\text { Time }(\mathrm{sec})\end{array}$ \\
\hline 1 & 12.11 & -170.89 & -245.11 & 54.79 & 1.00 & 186 & 30.00 \\
\hline
\end{tabular}

The APEX2 software program (version 2014.1-1) ${ }^{1}$ was used for diffractometer control, preliminary frame scans, indexing, orientation matrix calculations, least-squares refinement of cell parameters, and the data collection. The frames were integrated with the Bruker SAINT software package using a narrow-frame algorithm. The integration of the data using a monoclinic unit cell yielded a total of 9820 reflections to a maximum $\theta$ angle of $27.53^{\circ}(0.77 \AA$ resolution $)$, of which 4463 were independent (average redundancy 2.200 , completeness $=99.0 \%, \mathrm{R}_{\text {int }}=2.05 \%, \mathrm{R}_{\text {sig }}=$ 
$3.38 \%)$ and $3341(74.86 \%)$ were greater than $2 \sigma\left(\mathrm{F}^{2}\right)$. The final cell constants of $\underline{a}=10.8565(7)$ $\AA, \underline{b}=16.1793(11) \AA, \underline{c}=12.2433(9) \AA, \beta=114.1484(19)^{\circ}$, volume $=1962.3(2) \AA^{3}$, are based upon the refinement of the XYZ-centroids of 5314 reflections above $20 \sigma$ (I) with $6.218^{\circ}<2 \theta<$ 54.98 ${ }^{\circ}$. Data were corrected for absorption effects using the multi-scan method (SADABS). The ratio of minimum to maximum apparent transmission was 0.850 . The calculated minimum and maximum transmission coefficients (based on crystal size) are 0.958 and 0.978 .

The structure was solved by direct methods and difference Fourier analysis using the programs provided by SHELXL-2014. ${ }^{2}$ Idealized positions for the hydrogen atoms were included as fixed contributions using a riding model with isotropic temperature factors set at 1.2 (methine, methylene, and aromatic hydrogens) or 1.5 (methyl hydrogens) times that of the adjacent carbon atom. The positions of the methyl hydrogen atoms were optimized by a rigid rotating group refinement with idealized angles. The fractional coordinates and isotropic thermal parameter of the hydrogen atom bound to oxygen atom $\mathrm{O}(3)$ were refined. Full-matrix least-squares refinement, based upon the minimization of $\Sigma \mathrm{w}_{\mathrm{i}}\left|\mathrm{F}_{\mathrm{o}}{ }^{2}-\mathrm{F}_{\mathrm{c}}{ }^{2}\right|^{2}$, with weighting $\mathrm{w}_{\mathrm{i}}^{-1}=\left[\sigma^{2}\left(\mathrm{~F}_{\mathrm{o}}{ }^{2}\right)+(0.0796 \mathrm{P})^{2}+\right.$ $1.4928 \mathrm{P}]$, where $\mathrm{P}=\left(\operatorname{Max}\left(\mathrm{F}_{\mathrm{o}}{ }^{2}, 0\right)+2 \mathrm{~F}_{\mathrm{c}}{ }^{2}\right) / 3{ }^{2}$ The final anisotropic full-matrix least-squares refinement on $\mathrm{F}^{2}$ with 228 variables converged at $\mathrm{R} 1=5.99 \%$, for the 3341 observed data and $\mathrm{wR} 2=16.99 \%$ for all data. The goodness-of-fit was $1.043{ }^{3}$

A correction for secondary extinction was not applied. The largest peak in the final difference electron density synthesis was $0.479 \mathrm{e}^{-/} \AA^{3}$ and the largest hole was $-0.277 \mathrm{e}^{-} / \AA^{3}$ with an RMS deviation of $0.063 \mathrm{e}^{-} / \AA^{3}$. The linear absorption coefficient, atomic scattering factors, and anomalous dispersion corrections were calculated from values found in the International Tables of X-ray Crystallography. ${ }^{4}$ 


\section{References}

1. APEX2 is a Bruker AXS crystallographic software package for single crystal data collection, reduction and preparation.

2. Sheldrick, G. M., SHELXL-2014, Crystallographic software package, Bruker AXS, Inc., Madison, Wisconsin, USA.

3. $\mathrm{R}_{1}=\sum\left(|| \mathrm{F}_{\mathrm{o}}|-| \mathrm{F}_{\mathrm{c}} \mid\right) / \sum\left|\mathrm{F}_{\mathrm{o}}\right|, \mathrm{wR}_{2}=\left[\sum\left[\mathrm{w}\left(\mathrm{F}_{\mathrm{o}}^{2}-\mathrm{F}_{\mathrm{c}}{ }^{2}\right)^{2}\right] / \sum\left[\mathrm{w}\left(\mathrm{F}_{\mathrm{o}}{ }^{2}\right)^{2}\right]\right]^{1 / 2}, \mathrm{R}_{\text {int. }}=\sum \mid \mathrm{F}_{\mathrm{o}}{ }^{2}-\left.\mathrm{F}_{\mathrm{o}}{ }^{2}($ mean $)\right|^{2} /$

$\sum\left[\mathrm{F}_{\mathrm{o}}{ }^{2}\right]$, and GOF $=\left[\Sigma\left[\mathrm{w}\left(\mathrm{F}_{\mathrm{o}}{ }^{2}-\mathrm{F}_{\mathrm{c}}{ }^{2}\right)^{2}\right] /(\mathrm{n}-\mathrm{p})\right]^{1 / 2}$, where $\mathrm{n}$ is the number of reflections and $\mathrm{p}$ is the total number of parameters which were varied during the last refinement cycle.

4. International Tables for X-ray Crystallography (1974). Vol. IV, p. 55. Birmingham: Kynoch Press. (Present distributor, D. Reidel, Dordrecht.). 
Table 2. Crystal data for $\mathrm{C}_{19} \mathrm{H}_{29} \mathrm{BO}_{4}$.

$\begin{array}{lll}\text { Identification code } & \mathrm{bp} 38 \mathrm{cms} & \\ \text { Empirical formula } & \mathrm{C}_{19} \mathrm{H}_{29} \mathrm{BO}_{4} & \\ \text { Emp. formula weight } & 332.23 \mathrm{~g} / \mathrm{mol} & \\ \text { Temperature } & 100(2) \mathrm{K} & \\ \text { Wavelength } & 0.71073 \AA & \\ \text { Crystal size } & 0.296 \times 0.376 \times 0.572 \mathrm{~mm} \\ \text { Crystal system } & \text { monoclinic } & \\ \text { Space group } & \mathrm{P} 2{ }_{1} / \mathrm{c}(\mathrm{No} .14) & \\ \text { Unit cell dimensions } & \mathrm{a}=10.8565(7) \AA & \alpha=90^{\circ} \\ & \mathrm{b}=16.1793(11) \AA & \beta=114.1484(19)^{\circ} \\ & \mathrm{c}=12.2433(9) \AA & \gamma=90^{\circ} \\ \text { Volume } & 1962.3(2) \AA^{3} & \\ \text { Z } & 4 \\ \text { Density (calculated) } & 1.125 \mathrm{~g} / \mathrm{cm}^{3} & \\ \text { Absorption coefficient } & 0.076 \mathrm{~mm}^{-1} & \\ \text { F(000) } & 720\end{array}$

Table 3. Data collection and structure refinement for $\mathrm{C}_{19} \mathrm{H}_{29} \mathrm{BO}_{4}$.

$\begin{array}{ll}\text { Theta range } & 3.11 \text { to } 27.53^{\circ} \\ \text { Index ranges } & -14 \leq \mathrm{h} \leq 14,-20 \leq \mathrm{k} \leq 20,-10 \leq 1 \leq 15 \\ \text { Reflections } & 9820 \\ \text { Independent reflections } & 4463[\mathrm{R}(\mathrm{int})=0.0205] \\ \begin{array}{l}\text { Coverage of independent } \\ \text { reflections }\end{array}\end{array}$

Absorption correction multi-scan

Max. and min. transmission 0.978 and 0.958

Refinement method Full-matrix least-squares on $\mathrm{F}^{2}$

Refinement program SHELXL-2014 (Sheldrick, 2014)

Data / restraints / parameters 4463 / 0 / 228

Goodness-of-fit on $\mathrm{F}^{2} \quad 1.043$

Final R indices $\quad 3341$ data; $\mathrm{I}>2 \sigma(\mathrm{I}) \quad \mathrm{R} 1=0.0599, \mathrm{wR} 2=0.1513$

all data $\quad \mathrm{R} 1=0.0828, \mathrm{wR} 2=0.1699$

Largest diff. peak and hole 0.479 and $-0.277 \mathrm{e}^{-} / \AA^{3}$ 
Table 4. Atomic coordinates and equivalent isotropic atomic displacement parameters $\left(\AA^{2}\right)$ for $\mathrm{C}_{19} \mathrm{H}_{29} \mathrm{BO}_{4}$. $\mathrm{U}(\mathrm{eq})$ is defined as one third of the trace of the orthogonalized $\mathrm{U}_{\mathrm{ij}}$ tensor.

\begin{tabular}{|c|c|c|c|c|}
\hline & $\mathrm{x} / \mathrm{a}$ & $y / b$ & $\mathrm{z} / \mathrm{c}$ & $\mathrm{U}(\mathrm{eq})$ \\
\hline $\mathrm{O} 1$ & $0.18336(13)$ & $0.09621(8)$ & $0.34778(12)$ & $0.0234(3)$ \\
\hline $\mathrm{O} 2$ & $0.40152(13)$ & $0.13201(8)$ & $0.38822(12)$ & $0.0252(3)$ \\
\hline $\mathrm{O} 3$ & $0.99378(13)$ & $0.93161(9)$ & $0.11436(13)$ & $0.0284(3)$ \\
\hline $\mathrm{O} 4$ & $0.15940(13)$ & $0.00541(9)$ & $0.09922(12)$ & $0.0289(3)$ \\
\hline $\mathrm{C} 1$ & $0.23327(17)$ & $0.83529(11)$ & $0.27292(15)$ & $0.0196(4)$ \\
\hline $\mathrm{C} 2$ & $0.21550(18)$ & $0.78024(12)$ & $0.35184(16)$ & $0.0214(4)$ \\
\hline $\mathrm{C} 3$ & $0.24182(18)$ & $0.69629(12)$ & $0.34807(16)$ & $0.0229(4)$ \\
\hline $\mathrm{C} 4$ & $0.28541(18)$ & $0.66417(11)$ & $0.26432(16)$ & $0.0219(4)$ \\
\hline $\mathrm{C} 5$ & $0.30608(19)$ & $0.72053(12)$ & $0.18685(17)$ & $0.0238(4)$ \\
\hline C6 & $0.28030(19)$ & $0.80403(11)$ & $0.19114(16)$ & $0.0230(4)$ \\
\hline $\mathrm{C} 7$ & $0.3113(2)$ & $0.57146(12)$ & $0.2584(2)$ & $0.0306(5)$ \\
\hline $\mathrm{C} 8$ & $0.4596(3)$ & $0.55401(15)$ & $0.3425(2)$ & $0.0494(7)$ \\
\hline C9 & $0.2196(3)$ & $0.52022(15)$ & $0.2981(3)$ & $0.0661(10)$ \\
\hline $\mathrm{C} 10$ & $0.2926(3)$ & $0.54568(15)$ & $0.1326(2)$ & $0.0525(7)$ \\
\hline C11 & $0.20590(18)$ & $0.92702(11)$ & $0.27983(16)$ & $0.0206(4)$ \\
\hline $\mathrm{C} 12$ & $0.11863(18)$ & $0.95931(11)$ & $0.15551(16)$ & $0.0208(4)$ \\
\hline C13 & $0.33550(18)$ & $0.97769(11)$ & $0.33882(17)$ & $0.0230(4)$ \\
\hline C14 & $0.18679(18)$ & $0.18683(11)$ & $0.35048(16)$ & $0.0225(4)$ \\
\hline $\mathrm{C} 15$ & $0.34081(18)$ & $0.20477(11)$ & $0.41902(17)$ & $0.0228(4)$ \\
\hline $\mathrm{C} 16$ & $0.1314(2)$ & $0.21481(13)$ & $0.22075(17)$ & $0.0286(4)$ \\
\hline $\mathrm{C} 17$ & $0.0991(2)$ & $0.21740(13)$ & $0.41262(19)$ & $0.0284(4)$ \\
\hline C18 & $0.3878(2)$ & $0.20432(12)$ & $0.55435(17)$ & $0.0280(4)$ \\
\hline C19 & $0.3900(2)$ & $0.28159(12)$ & $0.37939(19)$ & $0.0305(5)$ \\
\hline B1 & $0.3076(2)$ & $0.07076(13)$ & $0.35792(18)$ & $0.0227(4)$ \\
\hline
\end{tabular}


Table 5. Interatomic distances ( $\mathrm{A})$ for $\mathrm{C}_{19} \mathrm{H}_{29} \mathrm{BO}_{4}$.

$\begin{array}{llll}\text { O1-B1 } & 1.366(2) & \text { O1-C14 } & 1.467(2) \\ \text { O2-B1 } & 1.360(2) & \text { O2-C15 } & 1.472(2) \\ \text { O3-C12 } & 1.317(2) & \text { O4-C12 } & 1.215(2) \\ \text { C1-C2 } & 1.384(3) & \text { C1-C6 } & 1.392(3) \\ \text { C1-C11 } & 1.523(2) & \text { C2-C3 } & 1.393(3) \\ \text { C3-C4 } & 1.394(3) & \text { C4-C5 } & 1.398(3) \\ \text { C4-C7 } & 1.533(3) & \text { C5-C6 } & 1.385(3) \\ \text { C7-C9 } & 1.519(3) & \text { C7-C10 } & 1.528(3) \\ \text { C7-C8 } & 1.541(3) & \text { C11-C12 } & 1.519(2) \\ \text { C11-C13 } & 1.530(2) & \text { C13-B1 } & 1.572(3) \\ \text { C14-C16 } & 1.519(3) & \text { C14-C17 } & 1.524(3) \\ \text { C14-C15 } & 1.561(3) & \text { C15-C19 } & 1.509(3) \\ \text { C15-C18 } & 1.521(3) & & \end{array}$

Table 6. Bond angles $\left({ }^{\circ}\right)$ for $\mathrm{C}_{19} \mathrm{H}_{29} \mathrm{BO}_{4}$.

$\begin{array}{llll}\text { B1-O1-C14 } & 106.51(14) & \text { B1-O2-C15 } & 106.75(14) \\ \text { C2-C1-C6 } & 117.71(17) & \text { C2-C1-C11 } & 120.15(16) \\ \text { C6-C1-C11 } & 122.11(16) & \text { C1-C2-C3 } & 121.02(17) \\ \text { C2-C3-C4 } & 121.61(17) & \text { C3-C4-C5 } & 116.93(17) \\ \text { C3-C4-C7 } & 121.54(17) & \text { C5-C4-C7 } & 121.52(17) \\ \text { C6-C5-C4 } & 121.29(18) & \text { C5-C6-C1 } & 121.40(17) \\ \text { C9-C7-C10 } & 109.8(2) & \text { C9-C7-C4 } & 111.25(18) \\ \text { C10-C7-C4 } & 111.30(17) & \text { C9-C7-C8 } & 109.2(2) \\ \text { C10-C7-C8 } & 107.1(2) & \text { C4-C7-C8 } & 108.02(17) \\ \text { C12-C11-C1 } & 109.60(14) & \text { C12-C11-C13 } & 111.39(15) \\ \text { C1-C11-C13 } & 112.69(15) & \text { O4-C12-O3 } & 123.29(16) \\ \text { O4-C12-C11 } & 123.83(16) & \text { O3-C12-C11 } & 112.88(16) \\ \text { C11-C13-B1 } & 112.78(15) & \text { O1-C14-C16 } & 106.19(14) \\ \text { O1-C14-C17 } & 108.69(15) & \text { C16-C14-C17 } & 111.36(16) \\ \text { O1-C14-C15 } & 102.11(13) & \text { C16-C14-C15 } & 112.68(16) \\ \text { C17-C14-C15 } & 114.94(15) & \text { O2-C15-C19 } & 108.80(15) \\ \text { O2-C15-C18 } & 106.83(15) & \text { C19-C15-C18 } & 110.44(16) \\ \text { O2-C15-C14 } & 101.94(13) & \text { C19-C15-C14 } & 114.98(15) \\ \text { C18-C15-C14 } & 113.12(16) & \text { O2-B1-O1 } & 114.04(17) \\ \text { O2-B1-C13 } & 124.71(17) & \text { O1-B1-C13 } & 121.23(17)\end{array}$


Table 7. Anisotropic atomic displacement parameters $\left(\AA^{2}\right)$ for $\mathrm{C}_{19} \mathrm{H}_{29} \mathrm{BO}_{4}$. The anisotropic atomic displacement factor exponent takes the form: $-2 \pi^{2}\left[h^{2} a^{* 2} U_{11}+\right.$ $\left.\ldots+2 \mathrm{~h} \mathrm{k} \mathrm{a}^{*} \mathrm{~b}^{*} \mathrm{U}_{12}\right]$.

$\begin{array}{ccccccc} & \mathrm{U}_{11} & \mathrm{U}_{22} & \mathrm{U}_{33} & \mathrm{U}_{23} & \mathrm{U}_{13} & \mathrm{U}_{12} \\ \mathrm{O} 1 & 0.0206(6) & 0.0205(6) & 0.0247(7) & -0.0031(5) & 0.0050(5) & 0.0000(5) \\ \mathrm{O} 2 & 0.0215(7) & 0.0209(7) & 0.0300(7) & -0.0045(5) & 0.0073(6) & 0.0021(5) \\ \mathrm{O} 3 & 0.0204(7) & 0.0287(7) & 0.0280(7) & 0.0067(6) & 0.0017(6) & -0.0017(5) \\ \text { O4 } & 0.0212(7) & 0.0324(8) & 0.0261(7) & 0.0064(6) & 0.0024(5) & -0.0022(6) \\ \text { C1 } & 0.0167(8) & 0.0177(8) & 0.0177(8) & -0.0008(6) & 0.0003(6) & 0.0005(6) \\ \text { C2 } & 0.0196(8) & 0.0237(9) & 0.0184(8) & -0.0011(7) & 0.0053(7) & -0.0004(7) \\ \text { C3 } & 0.0225(9) & 0.0220(9) & 0.0213(9) & 0.0060(7) & 0.0062(7) & -0.0004(7) \\ \text { C4 } & 0.0191(8) & 0.0178(8) & 0.0245(9) & 0.0020(7) & 0.0046(7) & 0.0019(7) \\ \text { C5 } & 0.0253(9) & 0.0228(9) & 0.0233(9) & -0.0002(7) & 0.0101(8) & 0.0019(7) \\ \text { C6 } & 0.0263(9) & 0.0199(9) & 0.0201(9) & 0.0041(7) & 0.0067(7) & 0.0003(7) \\ \text { C7 } & 0.0373(11) & 0.0166(9) & 0.0393(12) & 0.0026(8) & 0.0170(9) & 0.0051(8) \\ \text { C8 } & 0.0547(16) & 0.0347(13) & 0.0543(16) & 0.0040(11) & 0.0179(13) & 0.0217(12) \\ \text { C9 } & 0.082(2) & 0.0187(11) & 0.128(3) & 0.0060(14) & 0.074(2) & -0.0010(12) \\ \text { C10 } & 0.080(2) & 0.0255(11) & 0.0439(14) & -0.0071(10) & 0.0173(13) & 0.0053(12) \\ \text { C11 } & 0.0212(9) & 0.0174(8) & 0.0193(8) & -0.0014(7) & 0.0045(7) & 0.0023(7) \\ \text { C12 } & 0.0216(9) & 0.0143(8) & 0.0218(9) & -0.0035(7) & 0.0041(7) & 0.0015(7) \\ \text { C13 } & 0.0194(9) & 0.0232(9) & 0.0217(9) & -0.0018(7) & 0.0038(7) & 0.0014(7) \\ \text { C14 } & 0.0218(9) & 0.0188(9) & 0.0228(9) & -0.0018(7) & 0.0049(7) & 0.0026(7) \\ \text { C15 } & 0.0208(9) & 0.0204(9) & 0.0242(9) & -0.0031(7) & 0.0060(7) & 0.0032(7) \\ \text { C16 } & 0.0258(10) & 0.0320(10) & 0.0231(9) & 0.0033(8) & 0.0050(8) & 0.0073(8) \\ \text { C17 } & 0.0221(9) & 0.0297(10) & 0.0301(10) & -0.0009(8) & 0.0075(8) & 0.0045(8) \\ \text { C18 } & 0.0259(10) & 0.0260(10) & 0.0238(10) & -0.0039(8) & 0.0017(8) & 0.0011(8) \\ \text { C19 } & 0.0301(10) & 0.0251(10) & 0.0362(11) & 0.0006(8) & 0.0134(9) & -0.0002(8) \\ \text { B1 } & 0.0200(10) & 0.0253(10) & 0.0177(9) & -0.0026(8) & 0.0026(8) & 0.0017(8)\end{array}$


Table 8. Hydrogen atom coordinates and isotropic atomic displacement parameters $\left(\AA^{2}\right)$ for $\mathrm{C}_{19} \mathrm{H}_{29} \mathrm{BO}_{4}$.

$\begin{array}{ccccc} & \mathrm{x} / \mathrm{a} & \mathrm{y} / \mathrm{b} & \mathrm{z} / \mathrm{c} & \mathrm{U}(\mathrm{eq}) \\ \text { H3O } & -0.057(3) & 0.9568(17) & 0.040(3) & 0.051(8) \\ \text { H2 } & 0.1849 & 0.8000 & 0.4095 & 0.026 \\ \text { H3 } & 0.2298 & 0.6600 & 0.4039 & 0.027 \\ \text { H5 } & 0.3384 & 0.7012 & 0.1302 & 0.029 \\ \text { H6 } & 0.2950 & 0.8407 & 0.1371 & 0.028 \\ \text { H8A } & 0.4755 & 0.5701 & 0.4243 & 0.074 \\ \text { H8B } & 0.5191 & 0.5859 & 0.3160 & 0.074 \\ \text { H8C } & 0.4783 & 0.4949 & 0.3405 & 0.074 \\ \text { H9A } & 0.1255 & 0.5366 & 0.2520 & 0.099 \\ \text { H9B } & 0.2438 & 0.5295 & 0.3835 & 0.099 \\ \text { H9C } & 0.2305 & 0.4615 & 0.2843 & 0.099 \\ \text { H10A } & 0.3078 & 0.4861 & 0.1311 & 0.079 \\ \text { H10B } & 0.3574 & 0.5755 & 0.1102 & 0.079 \\ \text { H10C } & 0.2005 & 0.5590 & 0.0757 & 0.079 \\ \text { H11 } & 0.1533 & 0.9331 & 0.3300 & 0.025 \\ \text { H13A } & 0.3868 & 0.9751 & 0.2882 & 0.028 \\ \text { H13B } & 0.3921 & 0.9528 & 0.4173 & 0.028 \\ \text { H16A } & 0.1919 & 1.1964 & 0.1843 & 0.043 \\ \text { H16B } & 0.1249 & 1.2752 & 0.2173 & 0.043 \\ \text { H16C } & 0.0416 & 1.1909 & 0.1770 & 0.043 \\ \text { H17A } & 0.0045 & 1.2038 & 0.3635 & 0.043 \\ \text { H17B } & 0.1089 & 1.2774 & 0.4234 & 0.043 \\ \text { H17C } & 0.1276 & 1.1906 & 0.4909 & 0.043 \\ \text { H18A } & 0.3523 & 1.1552 & 0.5784 & 0.042 \\ \text { H18B } & 0.3547 & 1.2541 & 0.5793 & 0.042 \\ \text { H18C } & 0.4867 & 1.2034 & 0.5925 & 0.042 \\ \text { H19A } & 0.4869 & 1.2884 & 0.4276 & 0.046 \\ \text { H19B } & 0.3414 & 1.3298 & 0.3900 & 0.046 \\ \text { H19C } & 0.3735 & 1.2764 & 0.2948 & 0.046\end{array}$




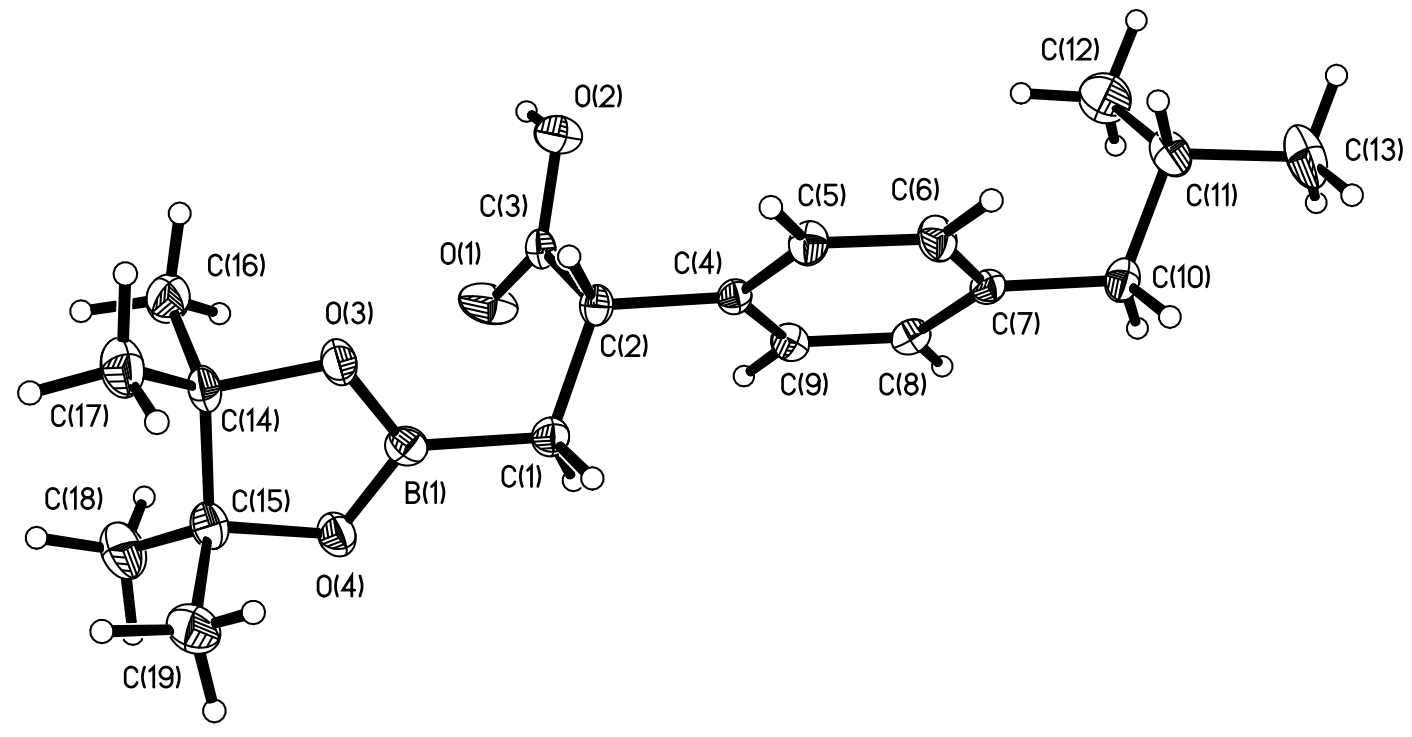

Figure 1. Perspective view of the molecular structure of $\mathrm{C}_{19} \mathrm{H}_{29} \mathrm{BO}_{4}$ with the atom labeling scheme for the non-hydrogen atoms. The thermal ellipsoids are scaled to enclose 50\% probability. 


\section{Description of the X-ray Structural Analysis of $\mathrm{C}_{19} \mathrm{H}_{29} \mathrm{BO}_{4} \cdot \mathrm{HOCMe}_{2} \mathrm{CMe}_{2} \mathrm{OH}$}

A colorless crystal of $\mathrm{C}_{19} \mathrm{H}_{29} \mathrm{BO}_{4} \cdot \mathrm{HOCMe}{ }_{2} \mathrm{CMe}_{2} \mathrm{OH}$ was covered in a polybutene oil (SigmaAldrich) and placed on the end of a MiTeGen loop. The sample was cooled to $100 \mathrm{~K}$ with an Oxford Cryostream 700 system and optically aligned on a Bruker AXS D8 Venture fixed-chi Xray diffractometer equipped with a Triumph monochromator, a Mo K $\alpha$ radiation source $(\lambda=$ $0.71073 \AA$ ), and a PHOTON 100 CMOS detector. Three sets of 12 frames each were collected using the omega scan method with a $10 \mathrm{~s}$ exposure time. Integration of these frames followed by reflection indexing and least-squares refinement produced a crystal orientation matrix for the triclinic crystal lattice that was used for the structural analysis.

Data collection consisted of the measurement of a total of 276 frames in three runs using omega scans with the detector held at $5.00 \mathrm{~cm}$ from the crystal. Frame scan parameters are summarized in Table 1 below:

Table 1. Data collection details for $\mathrm{C}_{19} \mathrm{H}_{29} \mathrm{BO}_{4} \cdot \mathrm{HOCMe}_{2} \mathrm{CMe}_{2} \mathrm{OH}$.

\begin{tabular}{|c|c|c|c|c|c|c|c|}
\hline Run & $2 \theta$ & $\omega$ & $\varphi$ & $\chi$ & Scan Width $\left(^{\circ}\right)$ & Frames & $\begin{array}{c}\text { Exposure } \\
\text { Time (sec) }\end{array}$ \\
\hline 1 & 16.35 & -165.34 & 0.00 & 54.74 & 2.00 & 92 & 40.00 \\
\hline 2 & 16.35 & -165.34 & -105.00 & 54.74 & 2.00 & 92 & 40.00 \\
\hline 3 & 16.35 & -165.34 & 153.00 & 54.74 & 2.00 & 92 & 40.00 \\
\hline
\end{tabular}

The APEX3 software program (version 2016.9-0) ${ }^{1}$ was used for diffractometer control, preliminary frame scans, indexing, orientation matrix calculations, least-squares refinement of cell parameters, and the data collection. The frames were integrated with the Bruker SAINT software package using a narrow-frame algorithm. The integration of the data using a triclinic unit cell yielded a total of 19008 reflections to a maximum $\theta$ angle of $27.50^{\circ}$ ( $0.77 \AA$ A resolution), of which 6132 were independent (average redundancy 3.100, completeness $=99.6 \%, \mathrm{R}_{\mathrm{int}}=3.40 \%, \mathrm{R}_{\mathrm{sig}}=$ 
$4.01 \%)$ and $4563(74.41 \%)$ were greater than $2 \sigma\left(\mathrm{F}^{2}\right)$. The final cell constants of $\underline{a}=10.0852(5)$ $\AA, \underline{b}=11.7620(6) \AA ⿻ 上 丨=12.1027(6) \AA, \alpha=79.7176(13)^{\circ}, \beta=82.3089(13)^{\circ}, \gamma=72.4206(13)^{\circ}$, volume $=1341.73(12) \AA^{3}$, are based upon the refinement of the XYZ-centroids of 9961 reflections above $20 \sigma(\mathrm{I})$ with $6.363^{\circ}<2 \theta<60.11^{\circ}$. Data were corrected for absorption effects using the multi-scan method (SADABS). The ratio of minimum to maximum apparent transmission was 0.881. The calculated minimum and maximum transmission coefficients (based on crystal size) are 0.969 and 0.984 .

The structure was solved by direct methods and difference Fourier analysis using the programs provided by SHELXL-2014/7. ${ }^{2}$ The crystallographic asymmetric unit contains a molecule of $\mathrm{C}_{19} \mathrm{H}_{29} \mathrm{BO}_{4}$ and a molecule of $\mathrm{HOCMe}_{2} \mathrm{CMe}_{2} \mathrm{OH}$. Idealized positions for the hydrogen atoms bound to carbon atoms were included as fixed contributions using a riding model with isotropic temperature factors set at 1.2 (methine, methylene, and aromatic hydrogens) or 1.5 (methyl hydrogens) times that of the adjacent carbon atom. The fractional coordinates of the two hydroxyl hydrogens of $\mathrm{HOCMe}_{2} \mathrm{CMe}_{2} \mathrm{OH}$ were refined, whereas the position of the hydrogen of the carboxylic group was idealized using a rigid rotating refinement of the $\mathrm{O}-\mathrm{H}$ bond orientation. The isotropic temperature factor for the hydrogen atoms bound to $\mathrm{O}$ were set at 1.5 times that of the adjacent oxygen atom. Full-matrix least-squares refinement, based upon the minimization of $\sum \mathrm{W}_{\mathrm{i}}\left|\mathrm{F}_{\mathrm{o}}{ }^{2}-\mathrm{F}_{\mathrm{c}}{ }^{2}\right|^{2}$, with weighting $\mathrm{w}_{\mathrm{i}}^{-1}=\left[\sigma^{2}\left(\mathrm{~F}_{\mathrm{o}}{ }^{2}\right)+(0.0537 \mathrm{P})^{2}+0.6234 \mathrm{P}\right]$, where $\mathrm{P}=\left(\operatorname{Max}\left(\mathrm{F}_{\mathrm{o}}^{2}, 0\right)\right.$ $\left.+2 \mathrm{~F}_{\mathrm{c}}{ }^{2}\right) / 3 .^{2}$ The final anisotropic full-matrix least-squares refinement on $\mathrm{F}^{2}$ with 306 variables converged at $\mathrm{R} 1=4.99 \%$, for the 4563 observed data with $\mathrm{I}>2 \sigma(\mathrm{I})$ and $\mathrm{wR} 2=12.69 \%$ for all data. The goodness-of-fit was $1.047 .{ }^{3}$

A correction for secondary extinction was not applied. The largest peak in the final difference electron density synthesis was $0.604 \mathrm{e}^{-} / \AA^{3}$ and the largest hole was $-0.278 \mathrm{e}^{-} / \AA^{3}$ with an RMS 
deviation of $0.050 \mathrm{e}^{-} / \AA^{3}$. The linear absorption coefficient, atomic scattering factors, and anomalous dispersion corrections were calculated from values found in the International Tables of X-ray Crystallography. ${ }^{4}$

\section{References}

1. APEX3 is a Bruker AXS crystallographic software package for single crystal data collection, reduction and preparation.

2. Sheldrick, G. M., SHELXL-2014, Crystallographic software package, Bruker AXS, Inc., Madison, Wisconsin, USA.

3. $\mathrm{R}_{1}=\sum\left(|| \mathrm{F}_{\mathrm{o}}|-| \mathrm{F}_{\mathrm{c}} \|\right) / \sum\left|\mathrm{F}_{\mathrm{o}}\right|, \mathrm{wR}_{2}=\left[\sum\left[\mathrm{w}\left(\mathrm{F}_{\mathrm{o}}^{2}-\mathrm{F}_{\mathrm{c}}^{2}\right)^{2}\right] / \sum\left[\mathrm{w}\left(\mathrm{F}_{\mathrm{o}}^{2}\right)^{2}\right]\right]^{1 / 2}, \mathrm{R}_{\text {int. }}=\sum \mid \mathrm{F}_{\mathrm{o}}^{2}-\left.\mathrm{F}_{\mathrm{o}}^{2}($ mean $)\right|^{2 /}$ $\sum\left[\mathrm{F}_{\mathrm{o}}^{2}\right]$, and GOF $=\left[\sum\left[\mathrm{w}\left(\mathrm{F}_{\mathrm{o}}{ }^{2}-\mathrm{F}_{\mathrm{c}}{ }^{2}\right)^{2}\right] /(\mathrm{n}-\mathrm{p})\right]^{1 / 2}$, where $\mathrm{n}$ is the number of reflections and $\mathrm{p}$ is the total number of parameters which were varied during the last refinement cycle.

4. International Tables for X-ray Crystallography (1974). Vol. IV, p. 55. Birmingham: Kynoch Press. (Present distributor, D. Reidel, Dordrecht.). 
Table 2. Crystal data for $\mathrm{C}_{19} \mathrm{H}_{29} \mathrm{BO}_{4} \cdot \mathrm{HOCMe}_{2} \mathrm{CMe}_{2} \mathrm{OH}$.

\begin{tabular}{|c|c|c|}
\hline Identification code & \multicolumn{2}{|l|}{$\mathrm{bp} 45 \mathrm{cms}$} \\
\hline Chemical formula & \multicolumn{2}{|l|}{$\mathrm{C}_{25} \mathrm{H}_{43} \mathrm{BO}_{6}$} \\
\hline Formula weight & \multicolumn{2}{|l|}{$450.40 \mathrm{~g} / \mathrm{mol}$} \\
\hline Temperature & \multicolumn{2}{|l|}{$100(2) \mathrm{K}$} \\
\hline Wavelength & \multicolumn{2}{|l|}{$0.71073 \AA$} \\
\hline Crystal size & \multicolumn{2}{|c|}{$0.204 \times 0.293 \times 0.418 \mathrm{~mm}$} \\
\hline Crystal system & \multicolumn{2}{|l|}{ triclinic } \\
\hline Space group & \multicolumn{2}{|l|}{$\mathrm{P}(-1)($ No. 2) } \\
\hline \multirow[t]{3}{*}{ Unit cell } & $\mathrm{a}=10.0852(5) \AA$ & $\alpha=79.7176(13)^{\circ}$ \\
\hline & $\mathrm{b}=11.7620(6) \AA$ & $\beta=82.3089(13)^{\circ}$ \\
\hline & $c=12.1027(6) \AA$ & $\gamma=72.4206(13)^{\circ}$ \\
\hline
\end{tabular}

Volume, $\AA^{3}$

1341.73(12)

$\mathrm{Z} 2$

Density (calc) $\quad 1.115 \mathrm{~g} / \mathrm{cm}^{3}$

Absorption

coefficient

$0.077 \mathrm{~mm}^{-1}$

$\mathrm{F}(000)$

492

Table 3. Data collection and structure refinement for $\mathrm{C}_{19} \mathrm{H}_{29} \mathrm{BO}_{4} \cdot \mathrm{HOCMe} 2 \mathrm{CMe}_{2} \mathrm{OH}$.

\begin{tabular}{|c|c|}
\hline Theta range & 3.18 to $27.50^{\circ}$ \\
\hline Index ranges & $-13 \leq \mathrm{h} \leq 13,-15 \leq \mathrm{k} \leq 15,-15 \leq 1 \leq 15$ \\
\hline Reflections & 19008 \\
\hline Independent reflections & $6132[\mathrm{R}($ int $)=0.0340]$ \\
\hline Coverage & $99.6 \%$ \\
\hline Absorption correction & multi-scan \\
\hline Max. and min. trans. & 0.984 and 0.969 \\
\hline Refinement method & Full-matrix least-squares on $\mathrm{F}^{2}$ \\
\hline Refinement program & SHELXL-2014/7 (Sheldrick, 2014) \\
\hline $\begin{array}{l}\text { Data / restraints } \\
\text { parameters }\end{array}$ & 6132 / 0 / 306 \\
\hline Goodness-of-fit on $\mathrm{F}^{2}$ & 1.047 \\
\hline \multirow[t]{2}{*}{ Final $\mathrm{R}$ indices } & data; $\mathrm{R} 1=0.0499, \mathrm{wR} 2=0.1158$ \\
\hline & $\mathrm{R} 1=0.0723, \mathrm{wR} 2=0.1269$ \\
\hline
\end{tabular}


Table 4. Atomic coordinates and equivalent isotropic atomic displacement parameters $\left(\AA^{2}\right)$ for $\mathrm{C}_{19} \mathrm{H}_{29} \mathrm{BO}_{4} \cdot \mathrm{HOCMe} \mathrm{CMe}_{2} \mathrm{OH}$. U(eq) is defined as one third of the trace of the orthogonalized $\mathrm{U}_{\mathrm{ij}}$ tensor.

\begin{tabular}{|c|c|c|c|c|}
\hline & $\mathrm{x} / \mathrm{a}$ & $y / b$ & $\mathrm{z} / \mathrm{c}$ & $\mathrm{U}(\mathrm{eq})$ \\
\hline $\mathrm{O} 1$ & $0.10098(15)$ & $0.90234(11)$ & $0.27689(10)$ & $0.0340(3)$ \\
\hline $\mathrm{O} 2$ & $0.06278(12)$ & $0.72758(10)$ & $0.26900(9)$ & $0.0238(3)$ \\
\hline $\mathrm{O} 3$ & $0.45517(11)$ & $0.74780(10)$ & $0.32700(9)$ & $0.0222(3)$ \\
\hline $\mathrm{O} 4$ & $0.40940(11)$ & $0.94152(10)$ & $0.36042(9)$ & $0.0232(3)$ \\
\hline $\mathrm{O} 5$ & $0.07548(13)$ & $0.94870(9)$ & $0.88290(9)$ & $0.0216(3)$ \\
\hline O6 & $0.95256(11)$ & $0.82842(10)$ & $0.07709(8)$ & $0.0172(2)$ \\
\hline $\mathrm{C} 1$ & $0.24454(16)$ & $0.81822(14)$ & $0.46718(13)$ & $0.0195(3)$ \\
\hline $\mathrm{C} 2$ & $0.16836(15)$ & $0.73973(13)$ & $0.42827(12)$ & $0.0165(3)$ \\
\hline C3 & $0.10737(15)$ & $0.79947(13)$ & $0.31706(12)$ & $0.0164(3)$ \\
\hline $\mathrm{C} 4$ & $0.05418(15)$ & $0.71170(13)$ & $0.51495(12)$ & $0.0153(3)$ \\
\hline C5 & $0.06797(16)$ & $0.59598(13)$ & $0.57209(13)$ & $0.0198(3)$ \\
\hline C6 & $0.96549(17)$ & $0.57125(14)$ & $0.65335(13)$ & $0.0214(3)$ \\
\hline $\mathrm{C} 7$ & $0.84509(15)$ & $0.66204(14)$ & $0.67907(12)$ & $0.0167(3)$ \\
\hline $\mathrm{C} 8$ & $0.83161(16)$ & $0.77774(14)$ & $0.62127(12)$ & $0.0173(3)$ \\
\hline C9 & $0.93454(16)$ & $0.80244(13)$ & $0.54096(12)$ & $0.0178(3)$ \\
\hline $\mathrm{C} 10$ & $0.73244(16)$ & $0.63464(14)$ & $0.76632(13)$ & $0.0211(3)$ \\
\hline $\mathrm{C} 11$ & $0.65398(16)$ & $0.55485(14)$ & $0.73254(15)$ & $0.0241(4)$ \\
\hline $\mathrm{C} 12$ & $0.5846(2)$ & $0.61036(19)$ & $0.62431(17)$ & $0.0367(4)$ \\
\hline $\mathrm{C} 13$ & $0.5467(2)$ & $0.52952(17)$ & $0.82794(18)$ & $0.0376(5)$ \\
\hline $\mathrm{C} 14$ & $0.55074(16)$ & $0.79979(14)$ & $0.24650(13)$ & $0.0211(3)$ \\
\hline $\mathrm{C} 15$ & $0.54578(16)$ & $0.91462(14)$ & $0.29588(14)$ & $0.0216(3)$ \\
\hline $\mathrm{C} 16$ & $0.48860(19)$ & $0.82810(18)$ & $0.13345(14)$ & $0.0311(4)$ \\
\hline $\mathrm{C} 17$ & $0.69239(18)$ & $0.70767(16)$ & $0.24116(16)$ & $0.0306(4)$ \\
\hline $\mathrm{C} 18$ & $0.5513(2)$ & $0.02350(16)$ & $0.20869(16)$ & $0.0331(4)$ \\
\hline C19 & $0.65353(19)$ & $0.89309(18)$ & $0.37909(16)$ & $0.0336(4)$ \\
\hline $\mathrm{C} 20$ & $0.23094(17)$ & $0.77868(16)$ & $0.97729(15)$ & $0.0259(4)$ \\
\hline $\mathrm{C} 21$ & $0.10793(17)$ & $0.81926(13)$ & $0.90403(13)$ & $0.0198(3)$ \\
\hline $\mathrm{C} 22$ & $0.14814(18)$ & $0.77114(15)$ & $0.79168(13)$ & $0.0255(4)$ \\
\hline $\mathrm{C} 23$ & $0.97790(16)$ & $0.78606(14)$ & $0.96858(13)$ & $0.0193(3)$ \\
\hline $\mathrm{C} 24$ & $0.0012(2)$ & $0.65019(15)$ & $0.99590(15)$ & $0.0296(4)$ \\
\hline $\mathrm{C} 25$ & $0.84776(17)$ & $0.84498(16)$ & $0.90474(14)$ & $0.0249(4)$ \\
\hline B1 & $0.37068(18)$ & $0.83812(16)$ & $0.38257(15)$ & $0.0192(4)$ \\
\hline
\end{tabular}


Table 5. Interatomic distances $(\AA)$ for $\mathrm{C}_{19} \mathrm{H}_{29} \mathrm{BO}_{4} \cdot \mathrm{HOCMe}_{2} \mathrm{CMe}_{2} \mathrm{OH}$.

$\begin{array}{llll}\text { O1-C3 } & 1.2065(18) & \mathrm{O} 2-\mathrm{C} 3 & 1.3156(18) \\ \text { O3-B1 } & 1.365(2) & \mathrm{O} 3-\mathrm{C} 14 & 1.4643(18) \\ \text { O4-B1 } & 1.359(2) & \mathrm{O} 4-\mathrm{C} 15 & 1.4627(19) \\ \text { O5-C21 } & 1.4398(18) & \mathrm{O} 6-\mathrm{C} 23 & 1.4508(18) \\ \mathrm{C} 1-\mathrm{C} 2 & 1.531(2) & \mathrm{C} 1-\mathrm{B} 1 & 1.571(2) \\ \mathrm{C} 2-\mathrm{C} 3 & 1.519(2) & \mathrm{C} 2-\mathrm{C} 4 & 1.522(2) \\ \mathrm{C} 4-\mathrm{C} 5 & 1.388(2) & \mathrm{C} 4-\mathrm{C} 9 & 1.391(2) \\ \mathrm{C} 5-\mathrm{C} 6 & 1.388(2) & \mathrm{C} 6-\mathrm{C} 7 & 1.395(2) \\ \mathrm{C} 7-\mathrm{C} 8 & 1.390(2) & \mathrm{C} 7-\mathrm{C} 10 & 1.513(2) \\ \mathrm{C} 8-\mathrm{C} 9 & 1.385(2) & \mathrm{C} 10-\mathrm{C} 11 & 1.532(2) \\ \mathrm{C} 11-\mathrm{C} 12 & 1.515(3) & \mathrm{C} 11-\mathrm{C} 13 & 1.526(2) \\ \mathrm{C} 14-\mathrm{C} 17 & 1.511(2) & \mathrm{C} 14-\mathrm{C} 16 & 1.522(2) \\ \mathrm{C} 14-\mathrm{C} 15 & 1.557(2) & \mathrm{C} 15-\mathrm{C} 19 & 1.515(2) \\ \mathrm{C} 15-\mathrm{C} 18 & 1.517(2) & \mathrm{C} 20-\mathrm{C} 21 & 1.529(2) \\ \mathrm{C} 21-\mathrm{C} 22 & 1.524(2) & \mathrm{C} 21-\mathrm{C} 23 & 1.552(2) \\ \mathrm{C} 23-\mathrm{C} 24 & 1.524(2) & \mathrm{C} 23-\mathrm{C} 25 & 1.527(2)\end{array}$


Table 6. Bond angles ( ${ }^{\circ}$ ) for $\mathrm{C}_{19} \mathrm{H}_{29} \mathrm{BO}_{4} \cdot \mathrm{HOCMe}_{2} \mathrm{CMe}_{2} \mathrm{OH}$.

$\begin{array}{llll}\text { B1-O3-C14 } & 107.13(12) & \text { B1-O4-C15 } & 107.12(12) \\ \text { C2-C1-B1 } & 113.16(13) & \text { C3-C2-C4 } & 109.89(12) \\ \text { C3-C2-C1 } & 110.28(12) & \text { C4-C2-C1 } & 113.03(12) \\ \text { O1-C3-O2 } & 123.55(14) & \text { O1-C3-C2 } & 123.29(14) \\ \text { O2-C3-C2 } & 113.16(12) & \text { C5-C4-C9 } & 118.22(13) \\ \text { C5-C4-C2 } & 121.09(13) & \text { C9-C4-C2 } & 120.67(13) \\ \text { C4-C5-C6 } & 121.01(14) & \text { C5-C6-C7 } & 120.82(14) \\ \text { C8-C7-C6 } & 117.91(14) & \text { C8-C7-C10 } & 121.29(13) \\ \text { C6-C7-C10 } & 120.79(14) & \text { C9-C8-C7 } & 121.18(14) \\ \text { C8-C9-C4 } & 120.85(14) & \text { C7-C10-C11 } & 114.63(13) \\ \text { C12-C11-C13 } & 110.61(15) & \text { C12-C11-C10 } & 111.96(14) \\ \text { C13-C11-C10 } & 110.19(14) & \text { O3-C14-C17 } & 108.78(13) \\ \text { O3-C14-C16 } & 105.93(12) & \text { C17-C14-C16 } & 110.73(14) \\ \text { O3-C14-C15 } & 102.50(12) & \text { C17-C14-C15 } & 114.91(14) \\ \text { C16-C14-C15 } & 113.18(14) & \text { O4-C15-C19 } & 106.50(13) \\ \text { O4-C15-C18 } & 108.49(13) & \text { C19-C15-C18 } & 109.79(14) \\ \text { O4-C15-C14 } & 102.79(12) & \text { C19-C15-C14 } & 113.71(14) \\ \text { C18-C15-C14 } & 114.88(14) & \text { O5-C21-C22 } & 108.67(12) \\ \text { O5-C21-C20 } & 104.74(13) & \text { C22-C21-C20 } & 111.51(14) \\ \text { O5-C21-C23 } & 107.95(12) & \text { C22-C21-C23 } & 112.36(13) \\ \text { C20-C21-C23 } & 111.23(13) & \text { O6-C23-C24 } & 105.16(12) \\ \text { O6-C23-C25 } & 108.30(12) & \text { C24-C23-C25 } & 110.36(14) \\ \text { O6-C23-C21 } & 108.65(12) & \text { C24-C23-C21 } & 112.36(13) \\ \text { C25-C23-C21 } & 111.70(13) & \text { O4-B1-O3 } & 113.93(14) \\ \text { O4-B1-C1 } & 124.81(14) & \text { O3-B1-C1 } & 121.22(14)\end{array}$


Table 7. Anisotropic atomic displacement parameters $\left(\AA^{2}\right)$ for $\mathrm{C}_{19} \mathrm{H}_{29} \mathrm{BO}_{4} \cdot \mathrm{HOCMe} \mathrm{CMe}_{2} \mathrm{OH}$. The anisotropic atomic displacement factor exponent takes the form: $-2 \pi^{2}\left[\mathrm{~h}^{2} \mathrm{a}^{* 2} \mathrm{U}_{11}+\ldots+2 \mathrm{~h} \mathrm{k} \mathrm{a}{ }^{*} \mathrm{~b}^{*} \mathrm{U}_{12}\right]$.

\begin{tabular}{|c|c|c|c|c|c|c|}
\hline & $\mathrm{U}_{11}$ & $\mathrm{U}_{22}$ & $\mathrm{U}_{33}$ & $\mathrm{U}_{23}$ & $\mathrm{U}_{13}$ & $\mathrm{U}_{12}$ \\
\hline $\mathrm{O} 1$ & $0.0580(9)$ & $0.0211(6)$ & $0.0286(7)$ & $0.0089(5)$ & $-0.0203(6)$ & $-0.0197(6)$ \\
\hline $\mathrm{O} 2$ & $0.0360(7)$ & $0.0189(6)$ & $.0184(6)$ & $.0033(4)$ & $-0.0113(5)$ & $-0.0107(5)$ \\
\hline $\mathrm{O} 3$ & $0.0195(6)$ & $0.0221(6)$ & $0.0251(6)$ & $-0.0028(5)$ & $0.0042(5)$ & $-0.0091(5)$ \\
\hline $\mathrm{O} 4$ & $0.0184(6)$ & $0.0246(6)$ & $0.0274(6)$ & $-0.0047(5)$ & $0.0014(5)$ & $-0.0082(5)$ \\
\hline $\mathrm{O} 5$ & $0.0345(7)$ & $0.0136(5)$ & $0.0168(5)$ & $0.0010(4)$ & $-0.0052(5)$ & $-0.0073(5)$ \\
\hline O6 & $0.0260(6)$ & $0.0137(5)$ & $0.0123(5)$ & $-0.0016(4)$ & 0.000 & $-0.0073(5)$ \\
\hline $\mathrm{C} 1$ & $0.0183(8)$ & $0.0244(8)$ & $0.0171(7)$ & $-0.0034(6)$ & $-0.0015(6)$ & $-0.0075(6)$ \\
\hline $\mathrm{C} 2$ & $0.0155(7)$ & $0.0175(7)$ & $0.0146(7)$ & $0.0007(6)$ & $-0.0009(6)$ & $-0.0037(6)$ \\
\hline $\mathrm{C} 3$ & $0.0151(7)$ & $0.0185(7)$ & $0.0148(7)$ & $0.0009(6)$ & $0.0003(6)$ & $-0.0059(6)$ \\
\hline $\mathrm{C} 4$ & $0.0153(7)$ & $0.0189(7)$ & $0.0122(7)$ & $-0.0009(6)$ & $-0.0030(6)$ & $-0.0057(6)$ \\
\hline $\mathrm{C} 5$ & $0.0192(8)$ & $0.0153(7)$ & $0.0213(8)$ & $-0.0022(6)$ & & $-0.0012(6)$ \\
\hline C6 & $0.0248(8)$ & $0.0143(7)$ & $0.0223(8)$ & $0.0021(6)$ & $0.0004(7)$ & $-0.0051(6)$ \\
\hline $\mathrm{C} 7$ & $0.0172(7)$ & $0.0199(8)$ & $0.0141(7)$ & $-0.0033(6)$ & $-0.0016(6)$ & $-0.0065(6)$ \\
\hline $\mathrm{C} 8$ & $0.0160(7)$ & $0.0180(7)$ & $0.0167(7)$ & $-0.0039(6)$ & $-0.0037(6)$ & $-0.0011(6)$ \\
\hline $\mathrm{C} 9$ & $0.0199(8)$ & $0.0153(7)$ & $0.0173(7)$ & $0.0021(6)$ & $-0.0057(6)$ & $-0.0047(6)$ \\
\hline G & $0.0213(8)$ & $0.0216(8)$ & $0.0181(7)$ & $-0.0023(6)$ & $0.0030(6)$ & $-0.0051(6)$ \\
\hline 1 & $0.0183(8)$ & $0.0172(8)$ & $0.0345(9)$ & $-0.0036(7)$ & $0.0036(7)$ & $41(6)$ \\
\hline $\mathrm{C} 12$ & $0.0292(10)$ & $0.0471(12)$ & $0.0385(11)$ & $-0.0073(9)$ & $-0.0069(8)$ & $-0.0155(9)$ \\
\hline C13 & $0.0275(10)$ & $0.0311(10)$ & $0.0490(12)$ & $0.0042(9)$ & $0.0075(9)$ & $-0.0109(8)$ \\
\hline C14 & $0.0190(8)$ & $0.0248(8)$ & $0.0198(8)$ & $0.0003(6)$ & $0.0025(6)$ & $-0.0105(6)$ \\
\hline $\mathrm{C} 15$ & $0.0156(7)$ & $0.0230(8)$ & $0.0248(8)$ & $-0.0010(7)$ & $-0.0007(6)$ & $-0.0052(6)$ \\
\hline C16 & $0.0284(9)$ & $0.0451(11)$ & $0.0234(9)$ & $76(8)$ & 0.000 & $2(8)$ \\
\hline $\mathrm{C} 17$ & $0.0225(9)$ & $0.0276(9)$ & $0.0380(10)$ & $-0.0032(8)$ & $0.0060(8)$ & $-0.0063(7)$ \\
\hline C18 & $0.0297(10)$ & $0.0267(9)$ & $0.0410(11)$ & $0.0020(8)$ & $0.0009(8)$ & $-0.0109(8)$ \\
\hline C19 & $0.0263(9)$ & $0.0459(11)$ & $0.0338(10)$ & $-0.0067(9)$ & $-0.0079(8)$ & $-0.0152(8)$ \\
\hline $\mathrm{C} 20$ & $0.0196(8)$ & $0.0271(9)$ & $0.0306(9)$ & $0.0007(7)$ & $-0.0080(7)$ & $-0.0064(7)$ \\
\hline $\mathrm{C} 21$ & $0.0249(8)$ & $0.0150(7)$ & $0.0187(7)$ & $-0.0015(6)$ & $-0.0019(6)$ & $-0.0051(6)$ \\
\hline $\mathrm{C} 22$ & $0.0316(9)$ & $0.0264(9)$ & $0.0195(8)$ & $-0.0079(7)$ & $0.0050(7)$ & $-0.0102(7)$ \\
\hline $\mathrm{C} 23$ & $0.0238(8)$ & $0.0184(8)$ & $0.0168(7)$ & $-0.0049(6)$ & $-0.0007(6)$ & $-0.0069(6)$ \\
\hline $\mathrm{C} 24$ & $0.0392(10)$ & $0.0192(8)$ & $0.0322(9)$ & $-0.0069(7)$ & $0.0081(8)$ & $-0.0139(7)$ \\
\hline $\mathrm{C} 25$ & $0.0200(8)$ & $0.0328(9)$ & $0.0236(8)$ & $-0.0050(7)$ & $-0.0047(7)$ & $-0.0087(7)$ \\
\hline B1 & $0.0156(8)$ & $0.0229(9)$ & $0.0196(8)$ & $-0.0024(7)$ & $-0.0066(7)$ & $-0.0043(7)$ \\
\hline
\end{tabular}


Table 8. Hydrogen atom coordinates and isotropic atomic displacement parameters $\left(\AA^{2}\right)$ for $\mathrm{C}_{19} \mathrm{H}_{29} \mathrm{BO}_{4} \cdot \mathrm{HOCMe}_{2} \mathrm{CMe}_{2} \mathrm{OH}$.

\begin{tabular}{|c|c|c|c|c|}
\hline & $\mathrm{x} / \mathrm{a}$ & $y / b$ & $\mathrm{z} / \mathrm{c}$ & $\mathrm{U}(\mathrm{eq})$ \\
\hline $\mathrm{H} 2$ & 0.0310 & 0.7644 & 0.2077 & 0.036 \\
\hline $\mathrm{H} 5 \mathrm{~A}$ & $0.016(2)$ & $0.9742(18)$ & $0.8391(18)$ & 0.032 \\
\hline H6A & $-0.0566(19)$ & $0.8991(18)$ & $1.0671(16)$ & 0.026 \\
\hline $\mathrm{H} 1 \mathrm{~A}$ & 0.2793 & 0.7797 & 0.5415 & 0.023 \\
\hline H1B & 0.1774 & 0.8976 & 0.4769 & 0.023 \\
\hline $\mathrm{H} 2 \mathrm{~A}$ & 0.2386 & 0.6615 & 0.4154 & 0.02 \\
\hline H5 & 0.1488 & 0.5327 & 0.5553 & 0.024 \\
\hline H6 & -0.0225 & 0.4915 & 0.6919 & 0.026 \\
\hline H8 & -0.2497 & 0.8410 & 0.6372 & 0.021 \\
\hline H9 & -0.0767 & 0.8824 & 0.5031 & 0.021 \\
\hline $\mathrm{H} 10 \mathrm{~A}$ & -0.3358 & 0.7117 & 0.7818 & 0.025 \\
\hline H10B & -0.2245 & 0.5944 & 0.8372 & 0.025 \\
\hline H11 & -0.2767 & 0.4762 & 0.7198 & 0.029 \\
\hline $\mathrm{H} 12 \mathrm{~A}$ & -0.4833 & 0.6882 & 0.6345 & 0.055 \\
\hline H12B & -0.4634 & 0.5563 & 0.6051 & 0.055 \\
\hline $\mathrm{H} 12 \mathrm{C}$ & -0.3445 & 0.6225 & 0.5633 & 0.055 \\
\hline H13A & -0.5246 & 0.6051 & 0.8400 & 0.056 \\
\hline H13B & -0.4066 & 0.4939 & 0.8972 & 0.056 \\
\hline $\mathrm{H} 13 \mathrm{C}$ & -0.4975 & 0.4733 & 0.8079 & 0.056 \\
\hline H16A & 0.4802 & 0.7539 & 0.1127 & 0.047 \\
\hline H16B & 0.5496 & 0.8621 & 0.0757 & 0.047 \\
\hline $\mathrm{H} 16 \mathrm{C}$ & 0.3961 & 0.8865 & 0.1391 & 0.047 \\
\hline H17A & 0.7242 & 0.6815 & 0.3171 & 0.046 \\
\hline H17B & 0.7592 & 0.7437 & 0.1922 & 0.046 \\
\hline $\mathrm{H} 17 \mathrm{C}$ & 0.6856 & 0.6380 & 0.2107 & 0.046 \\
\hline H18A & 0.4717 & 1.0454 & 0.1630 & 0.05 \\
\hline H18B & 0.6384 & 1.0041 & 0.1599 & 0.05 \\
\hline $\mathrm{H} 18 \mathrm{C}$ & 0.5475 & 1.0914 & 0.2468 & 0.05 \\
\hline H19A & 0.6334 & 0.9638 & 0.4176 & 0.05 \\
\hline H19B & 0.7467 & 0.8794 & 0.3388 & 0.05 \\
\hline H19C & 0.6503 & 0.8221 & 0.4347 & 0.05 \\
\hline $\mathrm{H} 20 \mathrm{~A}$ & 0.3106 & 0.8026 & 0.9352 & 0.039 \\
\hline H20B & 0.2568 & 0.6908 & 0.9978 & 0.039 \\
\hline $\mathrm{H} 20 \mathrm{C}$ & 0.2042 & 0.8166 & 1.0459 & 0.039 \\
\hline
\end{tabular}




$\begin{array}{lllll}\text { H22A } & 0.0678 & 0.7999 & 0.7463 & 0.038 \\ \text { H22B } & 0.1769 & 0.6828 & 0.8052 & 0.038 \\ \text { H22C } & 0.2256 & 0.7997 & 0.7513 & 0.038 \\ \text { H24A } & 0.0841 & 0.6138 & 1.0379 & 0.044 \\ \text { H24B } & 0.0149 & 0.6159 & 0.9257 & 0.044 \\ \text { H24C } & -0.0805 & 0.6335 & 1.0417 & 0.044 \\ \text { H25A } & -0.2317 & 0.8210 & 0.9472 & 0.037 \\ \text { H25B } & -0.1362 & 0.8189 & 0.8303 & 0.037 \\ \text { H25C } & -0.1724 & 0.9329 & 0.8957 & 0.037\end{array}$




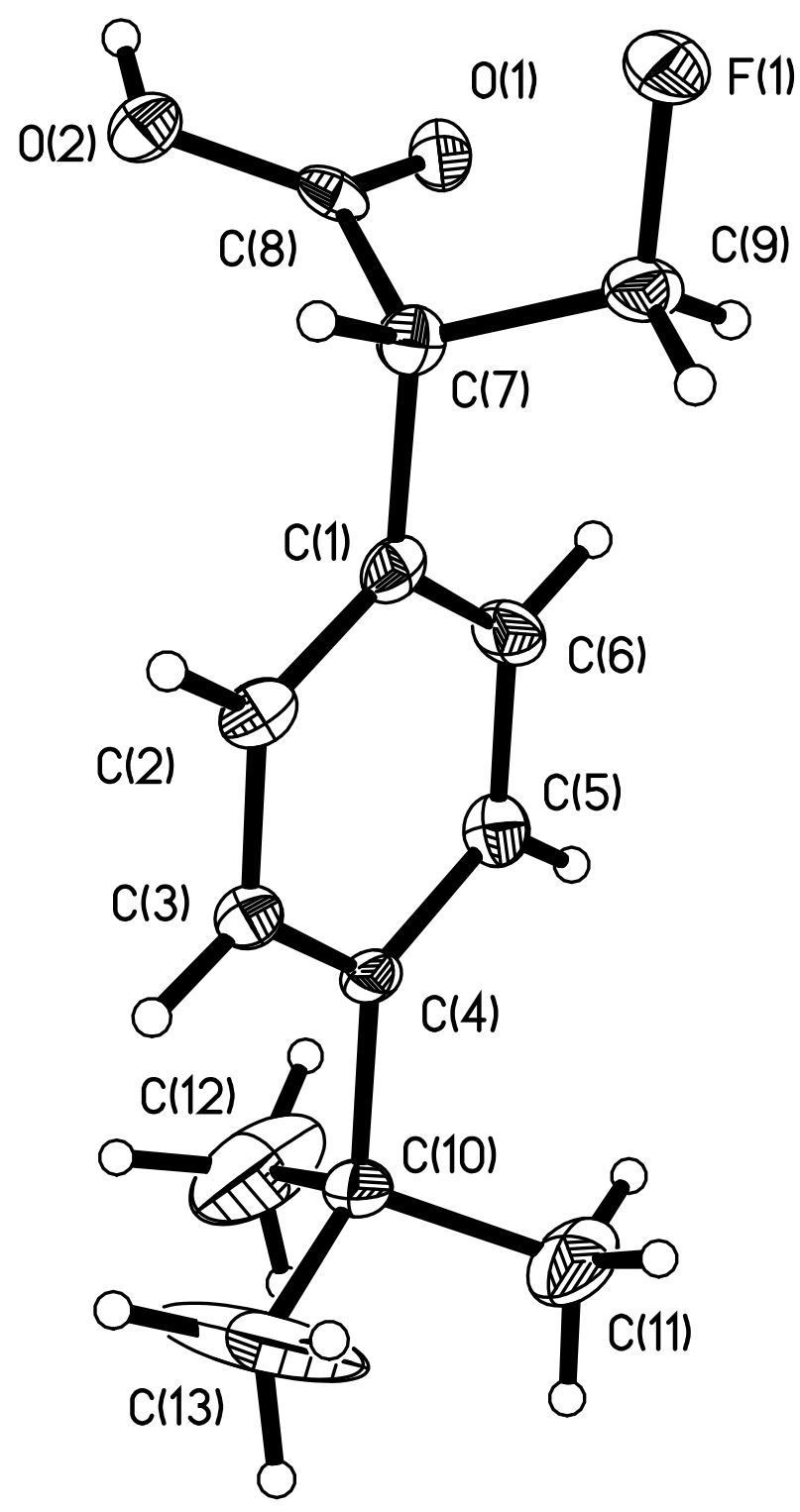

Figure 1. Perspective view of the molecular structure of the $\mathrm{C}_{13} \mathrm{H}_{17} \mathrm{O}_{2} \mathrm{~F}$ with the atom labeling scheme for the non-hydrogen atoms. The thermal ellipsoids are scaled to enclose $50 \%$ probability. 


\section{Description of the X-ray Structural Analysis of $\mathrm{C}_{13} \mathrm{H}_{17} \mathrm{O}_{2} \mathrm{~F}$}

A colorless crystal of $\mathrm{C}_{13} \mathrm{H}_{17} \mathrm{O}_{2} \mathrm{~F}$ was covered in a polybutene oil (Sigma-Aldrich) and placed on the end of a MiTeGen loop. The sample was cooled to $100 \mathrm{~K}$ with an Oxford Cryostream 700 system and optically aligned on a Bruker AXS D8 Venture fixed-chi X-ray diffractometer

equipped with a Triumph monochromator, a Mo K $\alpha$ radiation source $(\lambda=0.71073 \AA)$, and a PHOTON 100 CMOS detector. Three sets of 12 frames each were collected using the omega scan method with a $10 \mathrm{~s}$ exposure time. Integration of these frames followed by reflection indexing and least-squares refinement produced a crystal orientation matrix for the monoclinic crystal lattice that was used for the structural analysis.

Data collection consisted of the measurement of a total of 368 frames in three runs using omega scans with the detector held at $5.00 \mathrm{~cm}$ from the crystal. Frame scan parameters are summarized in Table 1 below:

Table 1. Data collection details for $\mathrm{C}_{13} \mathrm{H}_{17} \mathrm{O}_{2} \mathrm{~F}$.

\begin{tabular}{|c|c|c|c|c|c|c|c|}
\hline Run & $2 \theta$ & $\omega$ & $\varphi$ & $\chi$ & Scan Width $\left(^{\circ}\right)$ & Frames & $\begin{array}{c}\text { Exposure } \\
\text { Time }(\mathrm{sec})\end{array}$ \\
\hline 1 & 21.65 & -160.04 & -156.00 & 54.74 & 2.00 & 92 & 15.00 \\
\hline 2 & 21.65 & -160.04 & 0.00 & 54.74 & 2.00 & 92 & 15.00 \\
\hline 3 & 21.65 & -160.04 & 102.00 & 54.74 & 2.00 & 92 & 15.00 \\
\hline 4 & 21.65 & -160.04 & 153.00 & 54.74 & 2.00 & 92 & 15.00 \\
\hline
\end{tabular}

The APEX3 software program (version 2016.9-0) ${ }^{1}$ was used for diffractometer control, preliminary frame scans, indexing, orientation matrix calculations, least-squares refinement of cell parameters, and the data collection. The frames were integrated with the Bruker SAINT software package using a narrow-frame algorithm. The integration of the data using a monoclinic unit cell yielded a total of 17861 reflections to a maximum $\theta$ angle of $26.00^{\circ}(0.81 \AA$ resolution $)$, of which 2345 were independent (average redundancy 7.617, completeness $=100.0 \%, \mathrm{R}_{\text {int }}=3.67 \%, \mathrm{R}_{\text {sig }}=$ 
$2.18 \%)$ and $2071(88.32 \%)$ were greater than $2 \sigma\left(\mathrm{F}^{2}\right)$. The final cell constants of $\underline{a}=15.9977(12)$ $\AA, \underline{b}=5.8881(3) \AA, \underline{c}=14.1730(8) \AA, \beta=116.2710(15)^{\circ}$, volume $=1197.15(13) \AA^{3}$, are based upon the refinement of the XYZ-centroids of 9982 reflections above $20 \sigma(\mathrm{I})$ with $5.749^{\circ}<2 \theta<$ $64.73^{\circ}$. Data were corrected for absorption effects using the multi-scan method (SADABS). The ratio of minimum to maximum apparent transmission was 0.876 . The calculated minimum and maximum transmission coefficients (based on crystal size) are 0.941 and 0.991.

The structure was solved by direct methods and difference Fourier analysis using the programs provided by SHELXL-2014/7. ${ }^{2}$ Idealized positions for the hydrogen atoms were included as fixed contributions using a riding model with isotropic temperature factors set at 1.2 (methine, methylene, and aromatic hydrogens) or 1.5 (methyl and hydroxylic hydrogens) times that of the adjacent carbon atom. The t-butyl substituent is disordered. The disorder was refined using a two-site model with the site occupancy ration of 60:40. The elongated thermal ellipsoid for $\mathrm{C}(13)$ of the major site led to an A Alert when CheckCIF was run. The positions of the methyl hydrogen atoms and the hydroxylic hydrogen bound to oxygen atom $\mathrm{O}(2)$ were optimized by a rigid rotating group refinement with idealized angles. Full-matrix least-squares refinement, based upon the minimization of $\Sigma \mathrm{w}_{\mathrm{i}}\left|\mathrm{F}_{\mathrm{o}}{ }^{2}-\mathrm{F}_{\mathrm{c}}{ }^{2}\right|^{2}$, with weighting $\mathrm{w}_{\mathrm{i}}^{-1}=\left[\sigma^{2}\left(\mathrm{~F}_{\mathrm{o}}{ }^{2}\right)+(0.0318 \mathrm{P})^{2}+4.9862\right.$ $\mathrm{P}]$, where $\mathrm{P}=\left(\operatorname{Max}\left(\mathrm{F}_{\mathrm{o}}{ }^{2}, 0\right)+2 \mathrm{~F}_{\mathrm{c}}{ }^{2}\right) / 3$. $^{2}$ The final anisotropic full-matrix least-squares refinement on $\mathrm{F}^{2}$ with 180 variables converged at $\mathrm{R} 1=7.95 \%$, for the 2071 observed data and $\mathrm{wR} 2=20.36 \%$ for all data. The goodness-of-fit was $1.206 .^{3}$

A correction for secondary extinction was not applied. The largest peak in the final difference electron density synthesis was $0.567 \mathrm{e}^{-} / \AA^{3}$ and the largest hole was $-0.328 \mathrm{e}^{-} / \AA^{3}$ with an RMS deviation of $0.082 \mathrm{e}^{-} / \AA^{3}$. The linear absorption coefficient, atomic scattering factors, and 
anomalous dispersion corrections were calculated from values found in the International Tables of X-ray Crystallography. ${ }^{4}$

\section{References}

1. APEX3 is a Bruker AXS crystallographic software package for single crystal data collection, reduction and preparation.

2. Sheldrick, G. M., SHELXL-2014, Crystallographic software package, Bruker AXS, Inc., Madison, Wisconsin, USA.

3. $\mathrm{R}_{1}=\sum\left(\| \mathrm{F}_{\mathrm{o}}|-| \mathrm{F}_{\mathrm{c}} \mid\right) / \sum\left|\mathrm{F}_{\mathrm{o}}\right|, \mathrm{wR}_{2}=\left[\sum\left[\mathrm{w}\left(\mathrm{F}_{\mathrm{o}}{ }^{2}-\mathrm{F}_{\mathrm{c}}{ }^{2}\right)^{2}\right] / \sum\left[\mathrm{w}\left(\mathrm{F}_{\mathrm{o}}{ }^{2}\right)^{2}\right]\right]^{1 / 2}, \mathrm{R}_{\text {int. }}=\sum\left|\mathrm{F}_{\mathrm{o}}^{2}-\mathrm{F}_{\mathrm{o}}^{2}(\mathrm{mean})\right|^{2 /}$

$\sum\left[\mathrm{F}_{\mathrm{o}}{ }^{2}\right]$, and GOF $=\left[\sum\left[\mathrm{w}\left(\mathrm{F}_{\mathrm{o}}{ }^{2}-\mathrm{F}_{\mathrm{c}}{ }^{2}\right)^{2}\right] /(\mathrm{n}-\mathrm{p})\right]^{1 / 2}$, where $\mathrm{n}$ is the number of reflections and $\mathrm{p}$ is the total number of parameters which were varied during the last refinement cycle.

4. International Tables for X-ray Crystallography (1974). Vol. IV, p. 55. Birmingham: Kynoch Press. (Present distributor, D. Reidel, Dordrecht.). 
Table 2. Crystal data for $\mathrm{C}_{13} \mathrm{H}_{17} \mathrm{O}_{2} \mathrm{~F}$.

$\begin{array}{lll}\text { Identification code } & \mathrm{bp} 42 \mathrm{cms} \\ \text { Empirical formula } & \mathrm{C}_{13} \mathrm{H}_{17} \mathrm{FO}_{2} & \\ \text { Emp. formula weight } & 224.26 \mathrm{~g} / \mathrm{mol} & \\ \text { Temperature } & 100(2) \mathrm{K} \\ \text { Wavelength } & 0.71073 \AA \\ \text { Crystal size } & 0.100 \times 0.604 \times 0.668 \mathrm{~mm} \\ \text { Crystal system } & \text { monoclinic } & \\ \text { Space group } & \mathrm{P} 21 / \mathrm{c}(\mathrm{No} .14) & \\ \text { Unit cell dimensions } & \mathrm{a}=15.9977(12) \AA \quad \alpha=90^{\circ} \\ & \mathrm{b}=5.8881(3) \AA & \beta=116.2710(15)^{\circ} \\ & \mathrm{c}=14.1730(8) \AA & \gamma=90^{\circ} \\ \text { Volume } & 1197.15(13) \AA^{3} & \\ \text { Z } & 4 \\ \text { Density (calculated) } & 1.244 \mathrm{~g} / \mathrm{cm}^{3} & \\ \text { Absorption coefficient } & 0.092 \mathrm{~mm}^{-1} & \\ \text { F(000) } & 480\end{array}$

Table 3. Data collection and structure refinement for $\mathrm{C}_{13} \mathrm{H}_{17} \mathrm{O}_{2} \mathrm{~F}$.

$\begin{array}{ll}\text { Theta range } & 2.84 \text { to } 26.00^{\circ} \\ \text { Index ranges } & -19 \leq \mathrm{h} \leq 19,-7 \leq \mathrm{k} \leq 7,-17 \leq 1 \leq 17 \\ \text { Reflections } & 17861 \\ \begin{array}{l}\text { Independent reflections } \\ \text { Coverage of independent }\end{array} & 2345[\mathrm{R}(\mathrm{int})=0.0367] \\ \text { reflections } & 100.0 \%\end{array}$

Absorption correction multi-scan

Max. and min. transmission 0.991 and 0.941

Refinement method Full-matrix least-squares on $\mathrm{F}^{2}$

Refinement program SHELXL-2014/7 (Sheldrick, 2014)

Data / restraints / parameters 2345 / 0 / 180

Goodness-of-fit on $\mathrm{F}^{2} \quad 1.206$

Final R indices $\quad 2071$ data; $\mathrm{I}>2 \sigma(\mathrm{I}) \quad \mathrm{R} 1=0.0795, \mathrm{wR} 2=0.2000$

all data $\quad \mathrm{R} 1=0.0873, \mathrm{wR} 2=0.2036$

Largest diff. peak and hole 0.567 and $-0.328 \mathrm{e}^{-} / \AA^{3}$ 
Table 4. Atomic coordinates and equivalent isotropic atomic displacement parameters $\left(\AA^{2}\right)$ for $\mathrm{C}_{13} \mathrm{H}_{17} \mathrm{O}_{2} \mathrm{~F}$. U(eq) is defined as one third of the trace of the orthogonalized $\mathrm{U}_{\mathrm{ij}}$ tensor.

$\begin{array}{lcccc} & \mathrm{x} / \mathrm{a} & \mathrm{y} / \mathrm{b} & \mathrm{z} / \mathrm{c} & \mathrm{U}(\mathrm{eq}) \\ \mathrm{F} 1 & 0.42100(16) & 0.8555(4) & 0.0677(2) & 0.0325(6) \\ \mathrm{O} 1 & 0.40342(17) & 0.3514(5) & 0.9785(2) & 0.0239(6) \\ \mathrm{O} 2 & 0.52793(17) & 0.4187(5) & 0.13078(19) & 0.0209(6) \\ \mathrm{C} 1 & 0.3351(2) & 0.3655(6) & 0.1539(3) & 0.0175(7) \\ \mathrm{C} 2 & 0.3519(2) & 0.4364(6) & 0.2531(3) & 0.0198(8) \\ \mathrm{C} 3 & 0.2873(2) & 0.5696(6) & 0.2679(3) & 0.0202(8) \\ \mathrm{C} 4 & 0.2035(2) & 0.6354(6) & 0.1848(3) & 0.0179(7) \\ \mathrm{C} 5 & 0.1879(3) & 0.5659(6) & 0.0841(3) & 0.0209(8) \\ \mathrm{C} 6 & 0.2533(3) & 0.4322(7) & 0.0689(3) & 0.0226(8) \\ \mathrm{C} 7 & 0.4052(2) & 0.2115(6) & 0.1386(3) & 0.0189(7) \\ \mathrm{C} 8 & 0.4470(2) & 0.3346(6) & 0.0748(3) & 0.0167(7) \\ \mathrm{C} 9 & 0.3585(3) & 0.9926(6) & 0.0859(3) & 0.0257(9) \\ \mathrm{C} 10 & 0.1330(3) & 0.7806(7) & 0.2035(3) & 0.0228(8) \\ \mathrm{C} 11 & 0.0342(5) & 0.6789(18) & 0.1377(8) & 0.043(3) \\ \text { C12 } & 0.1334(10) & 0.0134(17) & 0.1625(18) & 0.089(7) \\ \text { C13 } & 0.1506(12) & 0.775(5) & 0.3158(10) & 0.139(11) \\ \text { C11' } & 0.0444(8) & 0.828(3) & 0.1072(11) & 0.052(6) \\ \text { C12' } & 0.1777(9) & 0.0154(18) & 0.2487(12) & 0.030(3) \\ \text { C13' } & 0.1130(11) & 0.672(2) & 0.2890(14) & 0.042(5) \\ & & & & \end{array}$


Table 5. Interatomic distances ( $\mathrm{A})$ for $\mathrm{C}_{13} \mathrm{H}_{17} \mathrm{O}_{2} \mathrm{~F}$.

$\begin{array}{llll}\text { F1-C9 } & 1.395(4) & \text { O1-C8 } & 1.231(4) \\ \text { O2-C8 } & 1.281(4) & \text { C1-C2 } & 1.375(5) \\ \text { C1-C6 } & 1.386(5) & \text { C1-C7 } & 1.530(5) \\ \text { C2-C3 } & 1.384(5) & \text { C3-C4 } & 1.392(5) \\ \text { C4-C5 } & 1.396(5) & \text { C4-C10 } & 1.528(5) \\ \text { C5-C6 } & 1.401(5) & \text { C7-C9 } & 1.511(5) \\ \text { C7-C8 } & 1.526(5) & \text { C10-C13 } & 1.490(14) \\ \text { C10-C12 } & 1.490(13) & \text { C10-C11' } & 1.495(12) \\ \text { C10-C13' } & 1.524(13) & \text { C10-C11 } & 1.556(9) \\ \text { C10-C12' } & 1.558(12) & & \end{array}$

Table 6. Bond angles $\left({ }^{\circ}\right)$ for $\mathrm{C}_{13} \mathrm{H}_{17} \mathrm{O}_{2} \mathrm{~F}$.

$\begin{array}{llll}\text { C2-C1-C6 } & 119.0(3) & \text { C2-C1-C7 } & 120.1(3) \\ \text { C6-C1-C7 } & 120.9(3) & \text { C1-C2-C3 } & 120.4(3) \\ \text { C2-C3-C4 } & 122.2(3) & \text { C3-C4-C5 } & 116.9(3) \\ \text { C3-C4-C10 } & 121.1(3) & \text { C5-C4-C10 } & 121.9(3) \\ \text { C4-C5-C6 } & 120.9(3) & \text { C1-C6-C5 } & 120.5(3) \\ \text { C9-C7-C8 } & 111.3(3) & \text { C9-C7-C1 } & 110.1(3) \\ \text { C8-C7-C1 } & 110.1(3) & \text { O1-C8-O2 } & 125.2(3) \\ \text { O1-C8-C7 } & 120.9(3) & \text { O2-C8-C7 } & 113.8(3) \\ \text { F1-C9-C7 } & 110.3(3) & \text { C13-C10-C12 } & 113.9(12) \\ \text { C11'-C10-C13' } & 110.8(9) & \text { C13-C10-C4 } & 111.6(7) \\ \text { C12-C10-C4 } & 108.4(5) & \text { C11'-C10-C4 } & 114.8(5) \\ \text { C13'-C10-C4 } & 109.6(6) & \text { C13-C10-C11 } & 107.0(10) \\ \text { C12-C10-C11 } & 107.4(7) & \text { C4-C10-C11 } & 108.2(4) \\ \text { C11'-C10-C12' } & 106.7(9) & \text { C13'-C10-C12' } & 105.2(8) \\ \text { C4-C10-C12' } & 109.2(5) & & \end{array}$


Table 7. Anisotropic atomic displacement parameters $\left(\AA^{2}\right)$ for $\mathrm{C}_{13} \mathrm{H}_{17} \mathrm{O}_{2} \mathrm{~F}$. The anisotropic atomic displacement factor exponent takes the form: $-2 \pi^{2}\left[h^{2} a^{* 2} U_{11}+\ldots\right.$ $\left.+2 \mathrm{~h} \mathrm{k} \mathrm{a}^{*} \mathrm{~b}^{*} \mathrm{U}_{12}\right]$.

$\begin{array}{ccccccc} & \mathrm{U}_{11} & \mathrm{U}_{22} & \mathrm{U}_{33} & \mathrm{U}_{23} & \mathrm{U}_{13} & \mathrm{U}_{12} \\ \mathrm{~F} 1 & 0.0311(12) & 0.0174(11) & 0.0551(16) & -0.0079(11) & 0.0245(12) & 0.0017(10) \\ \mathrm{O} 1 & 0.0242(13) & 0.0253(14) & 0.0239(14) & -0.0068(11) & 0.0123(11) & -0.0071(11) \\ \text { O2 } & 0.0192(13) & 0.0235(14) & 0.0222(13) & 0.0029(11) & 0.0111(11) & -0.0014(11) \\ \text { C1 } & 0.0170(17) & 0.0135(16) & 0.0238(18) & 0.0035(14) & 0.0106(14) & -0.0020(14) \\ \text { C2 } & 0.0180(17) & 0.0208(18) & 0.0219(18) & 0.0065(15) & 0.0099(15) & 0.0019(15) \\ \text { C3 } & 0.0210(18) & 0.0214(18) & 0.0216(18) & -0.0017(15) & 0.0126(15) & -0.0036(15) \\ \text { C4 } & 0.0193(17) & 0.0149(17) & 0.0257(18) & -0.0028(14) & 0.0156(15) & -0.0041(14) \\ \text { C5 } & 0.0201(17) & 0.0203(18) & 0.0190(17) & 0.0013(15) & 0.0058(14) & 0.0009(15) \\ \text { C6 } & 0.029(2) & 0.026(2) & 0.0179(17) & -0.0026(15) & 0.0145(16) & -0.0026(16) \\ \text { C7 } & 0.0205(17) & 0.0170(17) & 0.0202(17) & 0.0016(14) & 0.0100(14) & -0.0008(15) \\ \text { C8 } & 0.0251(18) & 0.0097(16) & 0.0188(17) & 0.0004(13) & 0.0129(15) & 0.0049(14) \\ \text { C9 } & 0.030(2) & 0.0155(18) & 0.043(2) & -0.0031(17) & 0.0256(19) & -0.0017(16) \\ \text { C10 } & 0.0202(18) & 0.0229(19) & 0.029(2) & -0.0053(16) & 0.0146(16) & -0.0001(15) \\ \text { C11 } & 0.025(4) & 0.035(5) & 0.074(6) & -0.005(5) & 0.025(4) & 0.003(4) \\ \text { C12 } & 0.072(9) & 0.026(5) & 0.21(2) & -0.011(8) & 0.095(13) & -0.002(5) \\ \text { C13 } & 0.076(11) & 0.30(3) & 0.036(6) & -0.029(12) & 0.021(7) & 0.092(15) \\ \text { C11' } & 0.022(6) & 0.071(13) & 0.048(8) & -0.021(8) & 0.003(5) & 0.029(7) \\ \text { C12' } & 0.033(6) & 0.014(5) & 0.063(8) & -0.004(5) & 0.038(6) & -0.001(5) \\ \text { C13' } & 0.060(11) & 0.027(6) & 0.078(13) & 0.022(7) & 0.066(10) & 0.017(6)\end{array}$


Table 8. Hydrogen atom coordinates and isotropic atomic displacement parameters $\left(\AA^{2}\right)$ for $\mathrm{C}_{13} \mathrm{H}_{17} \mathrm{O}_{2} \mathrm{~F}$.

\begin{tabular}{|c|c|c|c|c|}
\hline & $\mathrm{x} / \mathrm{a}$ & $y / b$ & $\mathrm{z} / \mathrm{c}$ & $\mathrm{U}(\mathrm{eq})$ \\
\hline $\mathrm{H} 2$ & 0.5507 & 0.4663 & 0.0913 & 0.031 \\
\hline $\mathrm{H} 2 \mathrm{~A}$ & 0.4081 & 0.3937 & 0.3119 & 0.024 \\
\hline $\mathrm{H} 3$ & 0.3007 & 0.6177 & 0.3371 & 0.024 \\
\hline H5 & 0.1321 & 0.6099 & 0.0251 & 0.025 \\
\hline H6 & 0.2416 & 0.3867 & -0.0001 & 0.027 \\
\hline H7 & 0.4566 & 0.1745 & 0.2093 & 0.023 \\
\hline H9A & 0.3361 & -0.0891 & 0.1314 & 0.031 \\
\hline H9B & 0.3040 & 0.0269 & 0.0183 & 0.031 \\
\hline H11A & -0.0112 & 0.7607 & 0.1538 & 0.065 \\
\hline H11B & 0.0343 & 0.5179 & 0.1553 & 0.065 \\
\hline $\mathrm{H} 11 \mathrm{C}$ & 0.0174 & 0.6941 & 0.0626 & 0.065 \\
\hline $\mathrm{H} 12 \mathrm{~A}$ & 0.1881 & 1.0965 & 0.2127 & 0.134 \\
\hline H12B & 0.0766 & 1.0938 & 0.1532 & 0.134 \\
\hline $\mathrm{H} 12 \mathrm{C}$ & 0.1358 & 1.0031 & 0.0947 & 0.134 \\
\hline H13A & 0.2085 & 0.8562 & 0.3589 & 0.209 \\
\hline H13B & 0.1562 & 0.6167 & 0.3395 & 0.209 \\
\hline H13C & 0.0986 & 0.8476 & 0.3229 & 0.209 \\
\hline H11D & 0.0584 & 0.9104 & 0.0559 & 0.078 \\
\hline $\mathrm{H} 11 \mathrm{E}$ & 0.0031 & 0.9193 & 0.1263 & 0.078 \\
\hline $\mathrm{H} 11 \mathrm{~F}$ & 0.0137 & 0.6837 & 0.0763 & 0.078 \\
\hline H12D & 0.2340 & 0.9929 & 0.3148 & 0.046 \\
\hline $\mathrm{H} 12 \mathrm{E}$ & 0.1330 & 1.1083 & 0.2617 & 0.046 \\
\hline $\mathrm{H} 12 \mathrm{~F}$ & 0.1940 & 1.0928 & 0.1979 & 0.046 \\
\hline H13D & 0.0839 & 0.5236 & 0.2651 & 0.063 \\
\hline H13E & 0.0708 & 0.7704 & 0.3039 & 0.063 \\
\hline $\mathrm{H} 13 \mathrm{~F}$ & 0.1715 & 0.6538 & 0.3531 & 0.063 \\
\hline
\end{tabular}




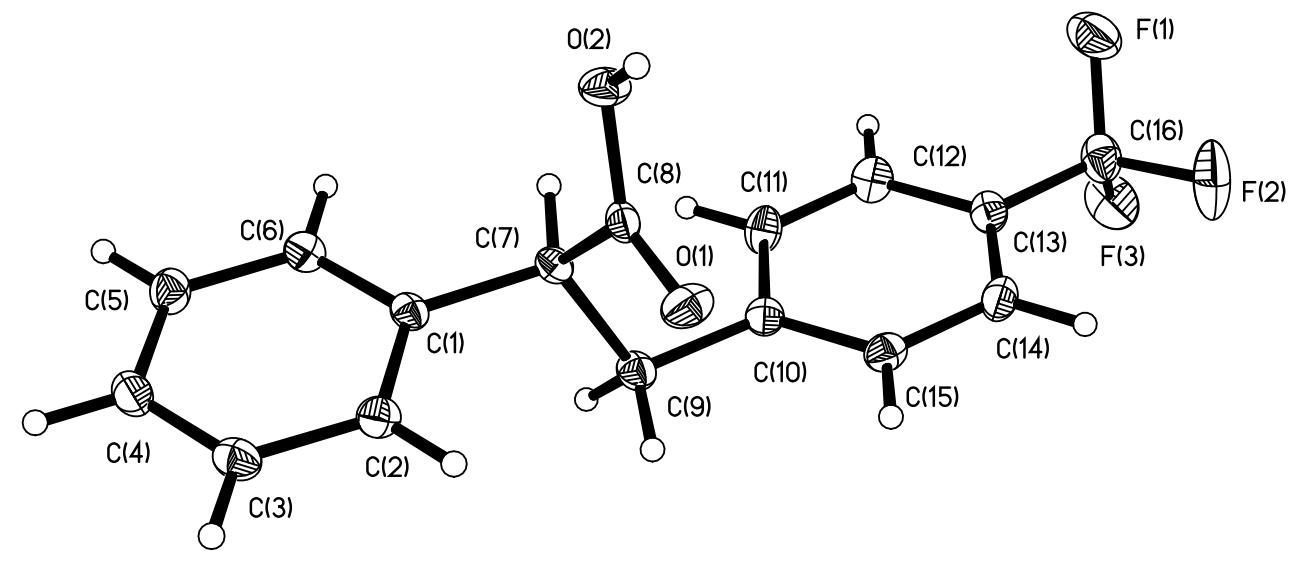

Figure 1. Perspective view of the molecular structure of $\mathrm{C}_{16} \mathrm{H}_{13} \mathrm{~F}_{3} \mathrm{O}_{2}$ with the atom labeling scheme provided for the non-hydrogen atoms. The thermal ellipsoids are scaled to enclose 50\% probability. 


\section{Description of the X-ray Structural Analysis of $\mathrm{C}_{16} \mathrm{H}_{13} \mathrm{~F}_{3} \mathrm{O}_{2}$}

A colorless crystalline fragment of $\mathrm{C}_{16} \mathrm{H}_{13} \mathrm{~F}_{3} \mathrm{O}_{2}$ was covered in polybutene oil (Sigma-Aldrich) and placed on the end of a MiTeGen loop. The sample was cooled to $100 \mathrm{~K}$ with an Oxford Cryostream 700 system and optically aligned on a Bruker AXS D8 Venture fixed-chi X-ray diffractometer

equipped with a Triumph monochromator, a Mo Ka radiation source $(\lambda=0.71073 \AA)$, and a PHOTON 100 CMOS detector. Three sets of 12 frames each were collected using the omega scan method with a 10 second exposure time. Integration of these frames followed by reflection indexing and least-squares refinement produced a crystal orientation matrix for the monoclinic crystal lattice that was used for the structural analysis.

Data collection consisted of the measurement of a total of 246 frames in two runs using omega scans with the detector held at $5.00 \mathrm{~cm}$ from the crystal. Frame scan parameters are summarized in Table 1 below:

Table 1. Data collection details for $\mathrm{C}_{16} \mathrm{H}_{13} \mathrm{~F}_{3} \mathrm{O}_{2}$.

\begin{tabular}{|c|c|c|c|c|c|c|c|}
\hline Run & $2 \theta$ & $\omega$ & $\varphi$ & $\chi$ & Scan Width $\left(^{\circ}\right)$ & Frames & $\begin{array}{c}\text { Exposure } \\
\text { Time }(\mathrm{sec})\end{array}$ \\
\hline 1 & 22.76 & -159.43 & 167.28 & 54.78 & 1.50 & 123 & 15.00 \\
\hline 2 & 22.76 & -159.43 & 51.97 & 54.78 & 1.50 & 123 & 15.00 \\
\hline
\end{tabular}

The APEX3 software program (version 2016.9-0) ${ }^{1}$ was used for diffractometer control, preliminary frame scans, indexing, orientation matrix calculations, least-squares refinement of cell parameters, and the data collection. The frames were integrated with the Bruker SAINT software package using a narrow-frame algorithm. The integration of the data using a monoclinic unit cell yielded a total of 13411 reflections to a maximum $\theta$ angle of $30.00^{\circ}(0.71 \AA$ A resolution), of which 3940 were independent (average redundancy 3.404 , completeness $=99.8 \%, R_{\text {int }}=2.82 \%, R_{\text {sig }}=$ $2.68 \%)$ and $3246(82.39 \%)$ were greater than $2 \sigma\left(\mathrm{F}^{2}\right)$. The final cell constants of $\underline{a}=15.5902(7)$ 
$\AA, \underline{b}=5.5765(3) \AA, \underline{c}=16.7923(8) \AA, \beta=111.6230(10)^{\circ}$, volume $=1357.17(12) \AA^{3}$, are based upon the refinement of the XYZ-centroids of 8082 reflections above $20 \sigma(\mathrm{I})$ with $6.780^{\circ}<2 \theta<$ $65.07^{\circ}$. Data were corrected for absorption effects using the multi-scan method (SADABS). The calculated minimum and maximum transmission coefficients (based on the crystal dimensions) are

0.945 and 0.955 .

The structure was solved by the intrinsic phasing method and difference Fourier analysis using the programs provided by SHELXL-2014/7. ${ }^{2}$ The crystallographic asymmetric unit contains a molecule of $\mathrm{C}_{16} \mathrm{H}_{13} \mathrm{~F}_{3} \mathrm{O}_{2}$. Idealized positions for the hydrogen atoms were included as fixed contributions using a riding model with isotropic temperature factors set at 1.2 times that of the adjacent carbon atom and 1.5 times that of the adjacent oxygen atom. Full-matrix least-squares refinement, based upon the minimization of $\Sigma \mathrm{w}_{\mathrm{i}}\left|\mathrm{F}_{\mathrm{o}}{ }^{2}-\mathrm{F}_{\mathrm{c}}{ }^{2}\right|^{2}$, with weighting $\mathrm{w}_{\mathrm{i}}{ }^{-1}=\left[\sigma^{2}\left(\mathrm{~F}_{\mathrm{o}}{ }^{2}\right)+\right.$ $\left.(0.0490 \mathrm{P})^{2}+0.5915 \mathrm{P}\right]$, where $\mathrm{P}=\left(\operatorname{Max}\left(\mathrm{F}_{\mathrm{o}}^{2}, 0\right)+2 \mathrm{~F}_{\mathrm{c}}{ }^{2}\right) / 3 .^{2}$ The final full-matrix least-squares refinement on $\mathrm{F}^{2}$ with 191 variables converged at $\mathrm{R} 1=4.55 \%$ for the 3246 observed data with $\mathrm{I}>2 \sigma(\mathrm{I})$ and at $\mathrm{wR} 2=12.21 \%$ for all data. The goodness-of-fit was $1.168 .^{3}$

A correction for secondary extinction was not applied. The largest peak in the final difference electron density synthesis was $0.426 \mathrm{e}^{-} / \AA^{3}$ and the largest hole was $-0.433 \mathrm{e}^{-} / \AA^{3}$ and the RMS deviation was $0.055 \mathrm{e}^{-} / \AA^{3}$. The linear absorption coefficient, atomic scattering factors, and anomalous dispersion corrections were calculated from values found in the International Tables of X-ray Crystallography. ${ }^{4}$ 


\section{References}

1. APEX3 is a Bruker AXS crystallographic software package for single crystal data collection, reduction and preparation.

2. Sheldrick, G. M., SHELXL-2014, Crystallographic software package, Bruker AXS, Inc., Madison, Wisconsin, USA.

3. $\mathrm{R}_{1}=\sum\left(|| \mathrm{F}_{\mathrm{o}}|-| \mathrm{F}_{\mathrm{c}} \mid\right) / \sum\left|\mathrm{F}_{\mathrm{o}}\right|, \mathrm{wR}_{2}=\left[\sum\left[\mathrm{w}\left(\mathrm{F}_{\mathrm{o}}^{2}-\mathrm{F}_{\mathrm{c}}^{2}\right)^{2}\right] / \sum\left[\mathrm{w}\left(\mathrm{F}_{\mathrm{o}}{ }^{2}\right)^{2}\right]\right]^{1 / 2}, \mathrm{R}_{\mathrm{int}}=\sum\left|\mathrm{F}_{\mathrm{o}}^{2}-\mathrm{F}_{\mathrm{o}}^{2}(\mathrm{mean})\right|^{2 /}$

$\sum\left[\mathrm{F}_{\mathrm{o}}^{2}\right]$, and GOF $=\left[\Sigma\left[\mathrm{w}\left(\mathrm{F}_{\mathrm{o}}^{2}-\mathrm{F}_{\mathrm{c}}^{2}\right)^{2}\right] /(\mathrm{n}-\mathrm{p})\right]^{1 / 2}$, where $\mathrm{n}$ is the number of reflections and $\mathrm{p}$ is the total number of parameters which were varied during the last refinement cycle.

4. International Tables for X-ray Crystallography (1974). Vol. IV, p. 55. Birmingham: Kynoch Press. (Present distributor, D. Reidel, Dordrecht.). 
Table 2. Crystal data for $\mathrm{C}_{16} \mathrm{H}_{13} \mathrm{~F}_{3} \mathrm{O}_{2}$.

\begin{tabular}{|c|c|c|}
\hline Ident. code & \multicolumn{2}{|l|}{ bp58cms } \\
\hline Emp. formula & \multicolumn{2}{|l|}{$\mathrm{C}_{16} \mathrm{H}_{13} \mathrm{~F}_{3} \mathrm{O}_{2}$} \\
\hline Emp. form. wgt. & \multicolumn{2}{|l|}{$294.26 \mathrm{~g} / \mathrm{mol}$} \\
\hline Temperature & \multicolumn{2}{|l|}{$100(2) \mathrm{K}$} \\
\hline Wavelength & \multicolumn{2}{|l|}{$0.71073 \AA$} \\
\hline Crystal size & \multicolumn{2}{|c|}{$0.386 \times 0.392 \times 0.472 \mathrm{~mm}$} \\
\hline Crystal system & \multicolumn{2}{|l|}{ monoclinic } \\
\hline Space group & \multicolumn{2}{|l|}{$\mathrm{P} 2{ }_{1} / \mathrm{c}$ (No. 14) } \\
\hline \multirow[t]{3}{*}{ Unit cell } & $a=15.5902(7) \AA$ & $\alpha=90^{\circ}$ \\
\hline & $\mathrm{b}=5.5765(3) \AA$ & $\beta=111.623(1)^{\circ}$ \\
\hline & $c=16.7923(8) \AA$ & $\gamma=90^{\circ}$ \\
\hline Volume, $\AA^{3}$ & $1357.17(12)$ & \\
\hline $\mathrm{Z}$ & 4 & \\
\hline Density (calc) & $1.440 \mathrm{~g} / \mathrm{cm}^{3}$ & \\
\hline Abs. coefficient & $0.121 \mathrm{~mm}^{-1}$ & \\
\hline $\mathrm{F}(000)$ & 608 & \\
\hline
\end{tabular}

Table 3. Data collection and structure refinement for $\mathrm{C}_{16} \mathrm{H}_{13} \mathrm{~F}_{3} \mathrm{O}_{2}$.

Theta range

Index ranges

Reflections

Independent refls

Coverage

Abs. correction

Max. and min. trans.

Refinement method

Refinement program

Data / restrs / parms

GOF on $\mathrm{F}^{2}$

Final $\mathrm{R}$ indices

Largest diff. peak and hole

$$
\begin{aligned}
& 3.05 \text { to } 30.00^{\circ} \\
& -21 \leq \mathrm{h} \leq 21,-7 \leq \mathrm{k} \leq 7,-23 \leq 1 \leq 22 \\
& 13411 \\
& 3940[\mathrm{R}(\mathrm{int})=0.0282] \\
& 99.8 \% \\
& \text { multi-scan } \\
& 0.955 \text { and } 0.945 \\
& \text { Full-matrix least-squares on } \mathrm{F}^{2} \\
& \text { SHELXL-2014/7 (Sheldrick, } 2014) \\
& 3940 / 0 / 191 \\
& 1.168 \\
& 3246 \\
& \text { data; R1 }=0.0455, \mathrm{wR} 2=0.1140 \\
& \mathrm{I}>2 \sigma(\mathrm{I}) \\
& \text { all data } \mathrm{R} 1=0.0577, \mathrm{wR} 2=0.1221 \\
& 0.426 \text { and }-0.433 \mathrm{e}^{-} / \AA^{3}
\end{aligned}
$$


Table 4. Atomic coordinates and equivalent isotropic atomic displacement parameters $\left(\AA^{2}\right)$ for $\mathrm{C}_{16} \mathrm{H}_{13} \mathrm{~F}_{3} \mathrm{O}_{2}$. $\mathrm{U}(\mathrm{eq})$ is defined as one third of the trace of the orthogonalized $\mathrm{U}_{\mathrm{ij}}$ tensor.

$\begin{array}{lcccc} & \mathrm{x} / \mathrm{a} & \mathrm{y} / \mathrm{b} & \mathrm{z} / \mathrm{c} & \mathrm{U}(\mathrm{eq}) \\ \mathrm{F} 1 & 0.59145(7) & 0.85365(19) & 0.11784(6) & 0.0375(3) \\ \mathrm{F} 2 & 0.61047(8) & 0.4941(2) & 0.08358(6) & 0.0439(3) \\ \mathrm{F} 3 & 0.48410(6) & 0.5980(2) & 0.09870(6) & 0.0346(2) \\ \text { O1 } & 0.91178(7) & 0.34207(18) & 0.49950(6) & 0.0214(2) \\ \text { O2 } & 0.92811(7) & 0.73902(17) & 0.51549(6) & 0.0204(2) \\ \text { C1 } & 0.83690(8) & 0.5333(2) & 0.63848(8) & 0.0140(2) \\ \text { C2 } & 0.88675(9) & 0.3305(2) & 0.67867(8) & 0.0173(2) \\ \text { C3 } & 0.91888(9) & 0.3097(2) & 0.76727(9) & 0.0195(3) \\ \text { C4 } & 0.90035(9) & 0.4883(3) & 0.81644(8) & 0.0197(3) \\ \text { C5 } & 0.85030(9) & 0.6889(3) & 0.77684(8) & 0.0196(3) \\ \text { C6 } & 0.81927(9) & 0.7118(2) & 0.68828(8) & 0.0169(2) \\ \text { C7 } & 0.80279(8) & 0.5637(2) & 0.54162(8) & 0.0143(2) \\ \text { C8 } & 0.88559(8) & 0.5361(2) & 0.51541(7) & 0.0147(2) \\ \text { C9 } & 0.72576(9) & 0.3854(2) & 0.49297(8) & 0.0169(2) \\ \text { C10 } & 0.68605(8) & 0.4404(2) & 0.39816(8) & 0.0161(2) \\ \text { C11 } & 0.63100(9) & 0.6433(3) & 0.36892(8) & 0.0204(3) \\ \text { C12 } & 0.59605(9) & 0.7027(3) & 0.28262(9) & 0.0214(3) \\ \text { C13 } & 0.61620(9) & 0.5568(2) & 0.22436(8) & 0.0182(3) \\ \text { C14 } & 0.67018(9) & 0.3535(3) & 0.25223(8) & 0.0198(3) \\ \text { C15 } & 0.70512(9) & 0.2968(2) & 0.33901(8) & 0.0182(3) \\ \text { C16 } & 0.57620(10) & 0.6235(3) & 0.13171(9) & 0.0242(3)\end{array}$


Table 5. Interatomic distances ( $\AA$ ) for $\mathrm{C}_{16} \mathrm{H}_{13} \mathrm{~F}_{3} \mathrm{O}_{2}$.

$\begin{array}{llll}\text { F1-C16 } & 1.3410(19) & \text { F2-C16 } & 1.3333(17) \\ \text { F3-C16 } & 1.3425(16) & \text { O1-C8 } & 1.2205(16) \\ \text { O2-C8 } & 1.3111(16) & \text { C1-C6 } & 1.3912(17) \\ \text { C1-C2 } & 1.3968(17) & \text { C1-C7 } & 1.5230(16) \\ \text { C2-C3 } & 1.3888(18) & \text { C3-C4 } & 1.3900(19) \\ \text { C4-C5 } & 1.3857(19) & \text { C5-C6 } & 1.3898(18) \\ \text { C7-C8 } & 1.5173(17) & \text { C7-C9 } & 1.5412(17) \\ \text { C9-C10 } & 1.5118(17) & \text { C10-C15 } & 1.3904(18) \\ \text { C10-C11 } & 1.3954(19) & \text { C11-C12 } & 1.3874(19) \\ \text { C12-C13 } & 1.3945(19) & \text { C13-C14 } & 1.386(2) \\ \text { C13-C16 } & 1.4944(19) & \text { C14-C15 } & 1.3911(19)\end{array}$


Table 6. Bond angles $\left(^{\circ}\right)$ for $\mathrm{C}_{16} \mathrm{H}_{13} \mathrm{~F}_{3} \mathrm{O}_{2}$.

$\begin{array}{llll}\text { C6-C1-C2 } & 119.13(11) & \text { C6-C1-C7 } & 119.58(11) \\ \text { C2-C1-C7 } & 121.29(11) & \text { C3-C2-C1 } & 120.13(12) \\ \text { C2-C3-C4 } & 120.31(12) & \text { C5-C4-C3 } & 119.78(12) \\ \text { C4-C5-C6 } & 120.01(12) & \text { C5-C6-C1 } & 120.63(12) \\ \text { C8-C7-C1 } & 107.39(10) & \text { C8-C7-C9 } & 111.15(10) \\ \text { C1-C7-C9 } & 113.04(10) & \text { O1-C8-O2 } & 123.75(11) \\ \text { O1-C8-C7 } & 122.85(11) & \text { O2-C8-C7 } & 113.33(11) \\ \text { C10-C9-C7 } & 111.35(10) & \text { C15-C10-C11 } & 118.75(12) \\ \text { C15-C10-C9 } & 121.54(12) & \text { C11-C10-C9 } & 119.68(11) \\ \text { C12-C11-C10 } & 121.01(12) & \text { C11-C12-C13 } & 119.34(13) \\ \text { C14-C13-C12 } & 120.40(12) & \text { C14-C13-C16 } & 121.58(12) \\ \text { C12-C13-C16 } & 118.01(13) & \text { C13-C14-C15 } & 119.60(12) \\ \text { C10-C15-C14 } & 120.89(12) & \text { F2-C16-F1 } & 106.04(12) \\ \text { F2-C16-F3 } & 107.39(12) & \text { F1-C16-F3 } & 105.12(13) \\ \text { F2-C16-C13 } & 112.93(13) & \text { F1-C16-C13 } & 112.74(12) \\ \text { F3-C16-C13 } & 112.08(11) & & \end{array}$


Table 7. Anisotropic atomic displacement parameters $\left(\AA^{2}\right)$ for $\mathrm{C}_{16} \mathrm{H}_{13} \mathrm{~F}_{3} \mathrm{O}_{2}$. The anisotropic atomic displacement factor exponent takes the form: $-2 \pi^{2}\left[h^{2} a^{* 2} U_{11}+\ldots+2\right.$ $\left.\mathrm{h} \mathrm{k} \mathrm{a}{ }^{*} \mathrm{~b}^{*} \mathrm{U}_{12}\right]$.

$\begin{array}{lcccccc} & \mathrm{U}_{11} & \mathrm{U}_{22} & \mathrm{U}_{33} & \mathrm{U}_{23} & \mathrm{U}_{13} & \mathrm{U}_{12} \\ \text { F1 } & 0.0430(6) & 0.0401(6) & 0.0244(5) & 0.0068(4) & 0.0065(4) & -0.0138(5) \\ \text { F2 } & 0.0475(6) & 0.0648(8) & 0.0179(4) & -0.0072(5) & 0.0101(4) & 0.0142(6) \\ \text { F3 } & 0.0189(4) & 0.0519(6) & 0.0249(5) & 0.0041(4) & -0.0016(3) & -0.0090(4) \\ \text { O1 } & 0.0212(5) & 0.0178(5) & 0.0304(5) & -0.0051(4) & 0.0158(4) & -0.0038(4) \\ \text { O2 } & 0.0214(5) & 0.0167(5) & 0.0281(5) & -0.0004(4) & 0.0150(4) & -0.0032(4) \\ \text { C1 } & 0.0119(5) & 0.0168(6) & 0.0145(5) & 0.0012(4) & 0.0062(4) & -0.0016(4) \\ \text { C2 } & 0.0180(6) & 0.0162(6) & 0.0192(6) & 0.0002(5) & 0.0087(5) & 0.0008(5) \\ \text { C3 } & 0.0191(6) & 0.0180(6) & 0.0203(6) & 0.0044(5) & 0.0058(5) & 0.0016(5) \\ \text { C4 } & 0.0202(6) & 0.0228(6) & 0.0154(6) & 0.0022(5) & 0.0058(5) & -0.0020(5) \\ \text { C5 } & 0.0214(6) & 0.0214(6) & 0.0182(6) & -0.0023(5) & 0.0097(5) & -0.0001(5) \\ \text { C6 } & 0.0167(6) & 0.0171(6) & 0.0181(6) & 0.0013(5) & 0.0079(5) & 0.0019(5) \\ \text { C7 } & 0.0141(5) & 0.0155(5) & 0.0146(5) & 0.0015(4) & 0.0068(4) & 0.0003(4) \\ \text { C8 } & 0.0147(5) & 0.0187(6) & 0.0104(5) & 0.0000(4) & 0.0043(4) & -0.0022(4) \\ \text { C9 } & 0.0153(5) & 0.0196(6) & 0.0163(6) & 0.0007(5) & 0.0062(4) & -0.0029(5) \\ \text { C10 } & 0.0130(5) & 0.0190(6) & 0.0171(6) & -0.0018(4) & 0.0064(4) & -0.0039(4) \\ \text { C11 } & 0.0186(6) & 0.0241(7) & 0.0187(6) & -0.0041(5) & 0.0070(5) & 0.0030(5) \\ \text { C12 } & 0.0179(6) & 0.0241(7) & 0.0209(6) & -0.0011(5) & 0.0056(5) & 0.0030(5) \\ \text { C13 } & 0.0139(5) & 0.0245(7) & 0.0156(6) & -0.0024(5) & 0.0047(4) & -0.0048(5) \\ \text { C14 } & 0.0201(6) & 0.0224(6) & 0.0188(6) & -0.0066(5) & 0.0093(5) & -0.0044(5) \\ \text { C15 } & 0.0177(6) & 0.0162(6) & 0.0215(6) & -0.0017(5) & 0.0082(5) & -0.0017(5) \\ \text { C16 } & 0.0200(6) & 0.0331(8) & 0.0180(6) & -0.0025(5) & 0.0054(5) & -0.0037(6)\end{array}$


Table 8. Hydrogen atom coordinates and isotropic atomic displacement parameters $\left(\AA^{2}\right)$ for $\mathrm{C}_{16} \mathrm{H}_{13} \mathrm{~F}_{3} \mathrm{O}_{2}$.

$\begin{array}{crrrc} & \mathrm{x} / \mathrm{a} & \mathrm{y} / \mathrm{b} & \mathrm{z} / \mathrm{c} & \mathrm{U}(\mathrm{eq}) \\ \mathrm{H} 2 & 0.9775 & 0.7115 & 0.5078 & 0.031 \\ \mathrm{H} 2 \mathrm{~A} & 0.8987 & 0.2066 & 0.6453 & 0.021 \\ \text { H3 } & 0.9537 & 0.1728 & 0.7944 & 0.023 \\ \text { H4 } & 0.9219 & 0.4728 & 0.8770 & 0.024 \\ \text { H5 } & 0.8372 & 0.8107 & 0.8102 & 0.024 \\ \text { H6 } & 0.7857 & 0.8507 & 0.6615 & 0.02 \\ \text { H7 } & 0.7781 & 0.7302 & 0.5271 & 0.017 \\ \text { H9A } & 0.7510 & 0.2204 & 0.5018 & 0.02 \\ \text { H9B } & 0.6761 & 0.3934 & 0.5163 & 0.02 \\ \text { H11 } & 0.6172 & 0.7422 & 0.4087 & 0.025 \\ \text { H12 } & 0.5588 & 0.8414 & 0.2634 & 0.026 \\ \text { H14 } & 0.6832 & 0.2535 & 0.2123 & 0.024 \\ \text { H15 } & 0.7425 & 0.1582 & 0.3581 & 0.022\end{array}$


Appendix II: NMR Characterization 
Figure A2.1: 3-boronic acid pinacol ester-2-phenyl propionic acid (2a) - ${ }^{1} \mathrm{H}$ NMR

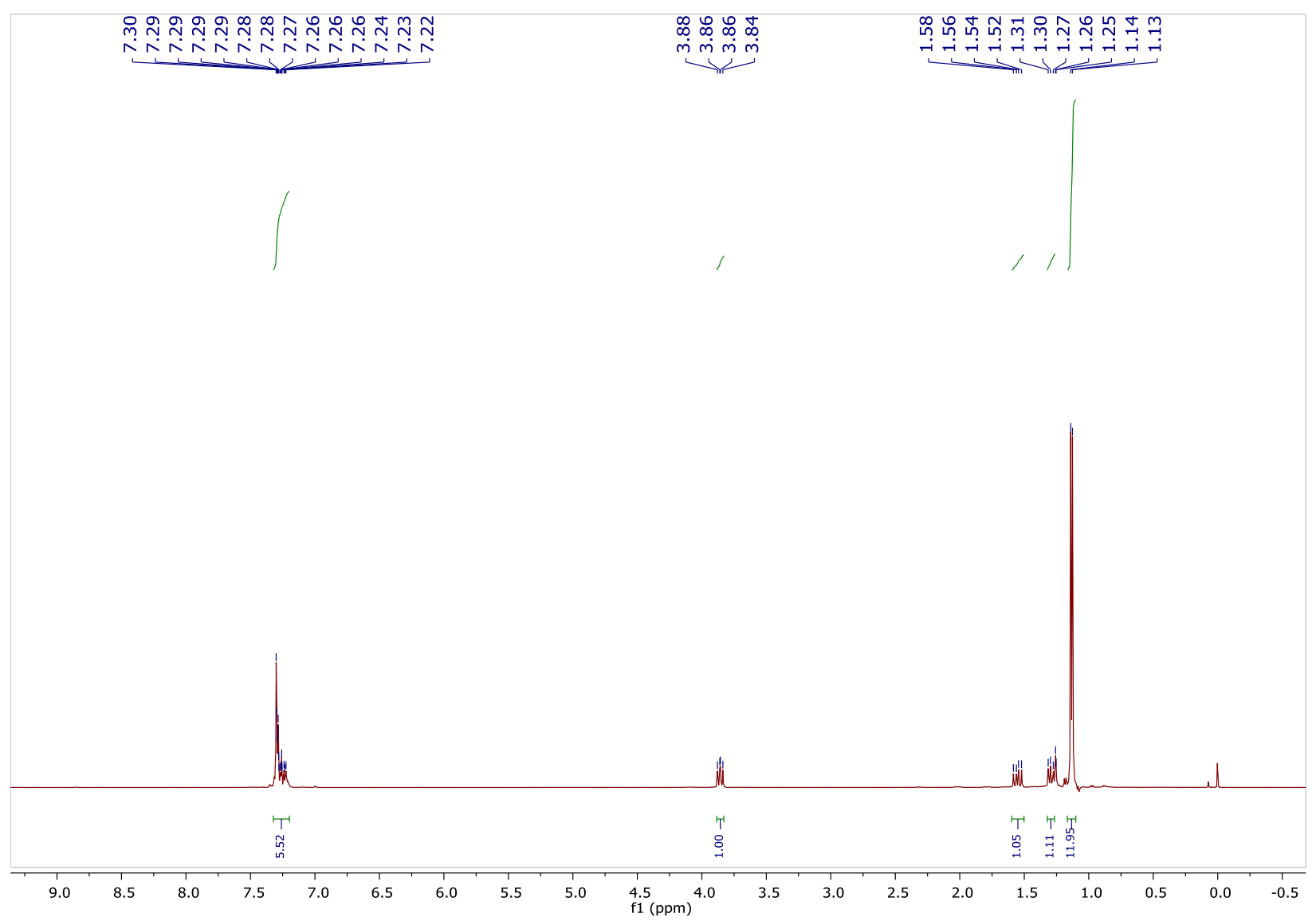


Figure A2.2: 3-boronic acid pinacol ester-2-phenyl propionic acid (2a) $-{ }^{13} \mathrm{C}$ NMR

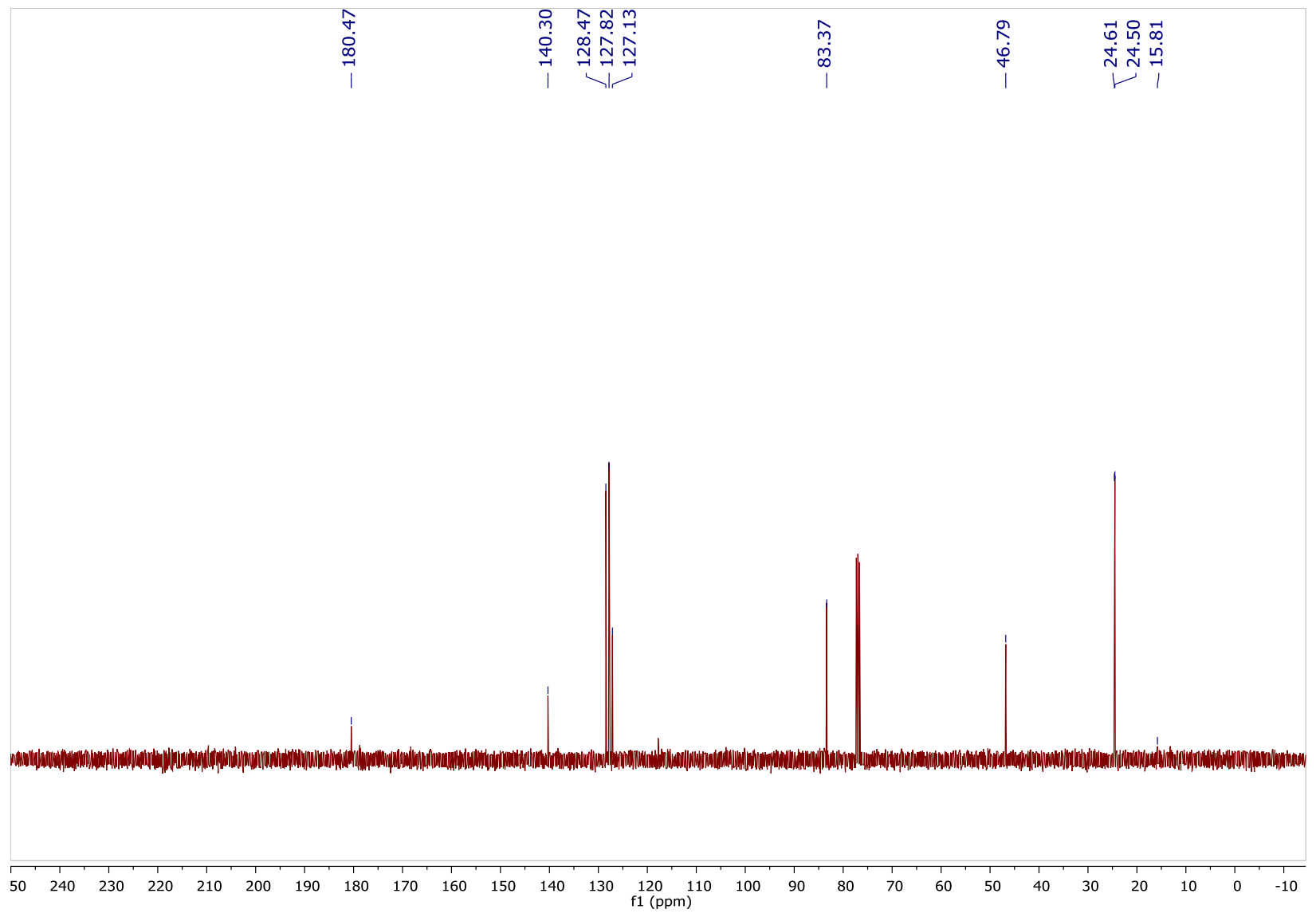


Figure A2.3: 3-boronic acid pinacol ester-2-phenyl propionic acid (2a) - ${ }^{11} \mathrm{~B}$ NMR

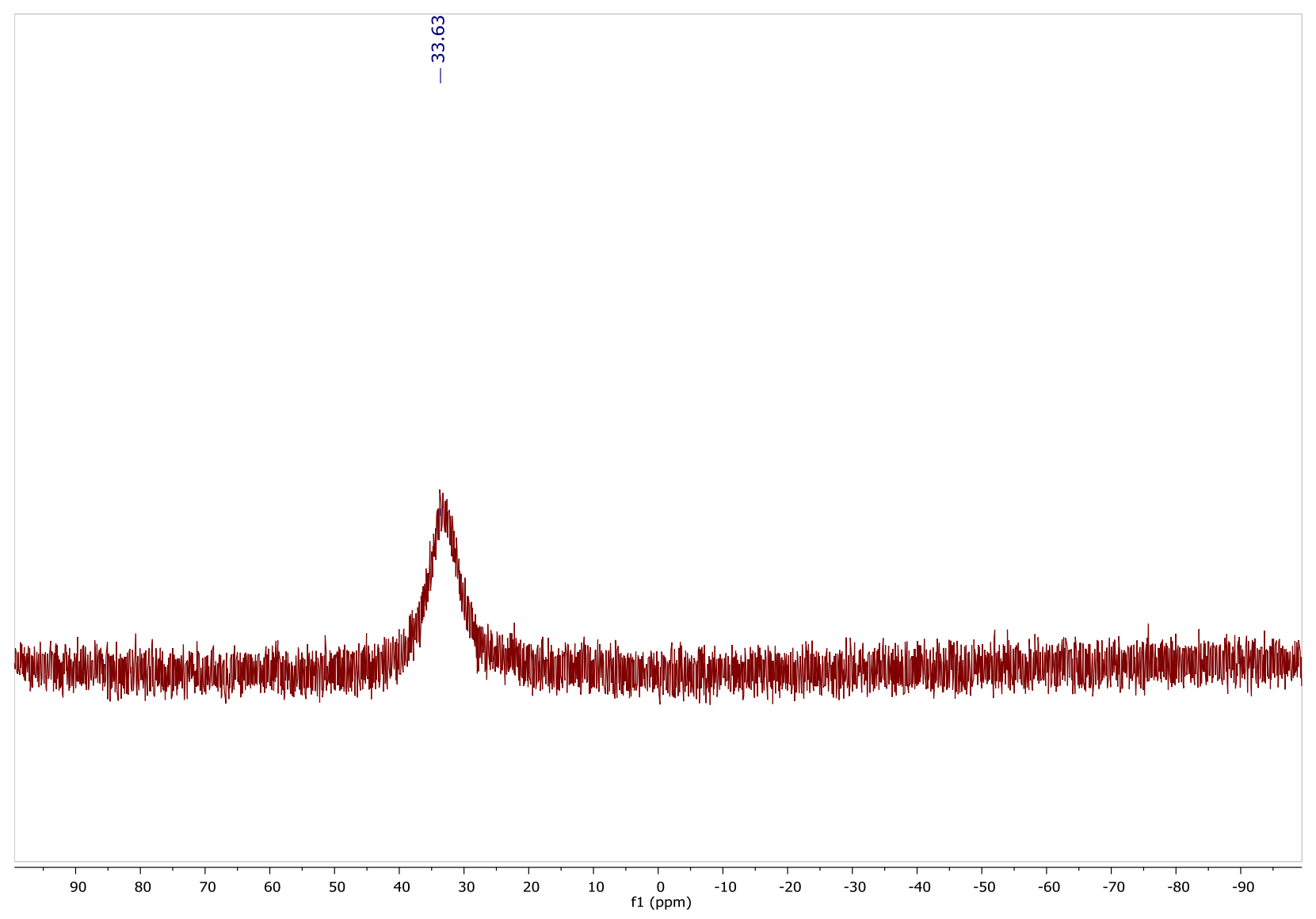


Figure A2.4: 3-boronic acid pinacol ester-2-(4-tertbuylphenyl) propionic acid (2b) - ${ }^{1} \mathrm{H}$ NMR

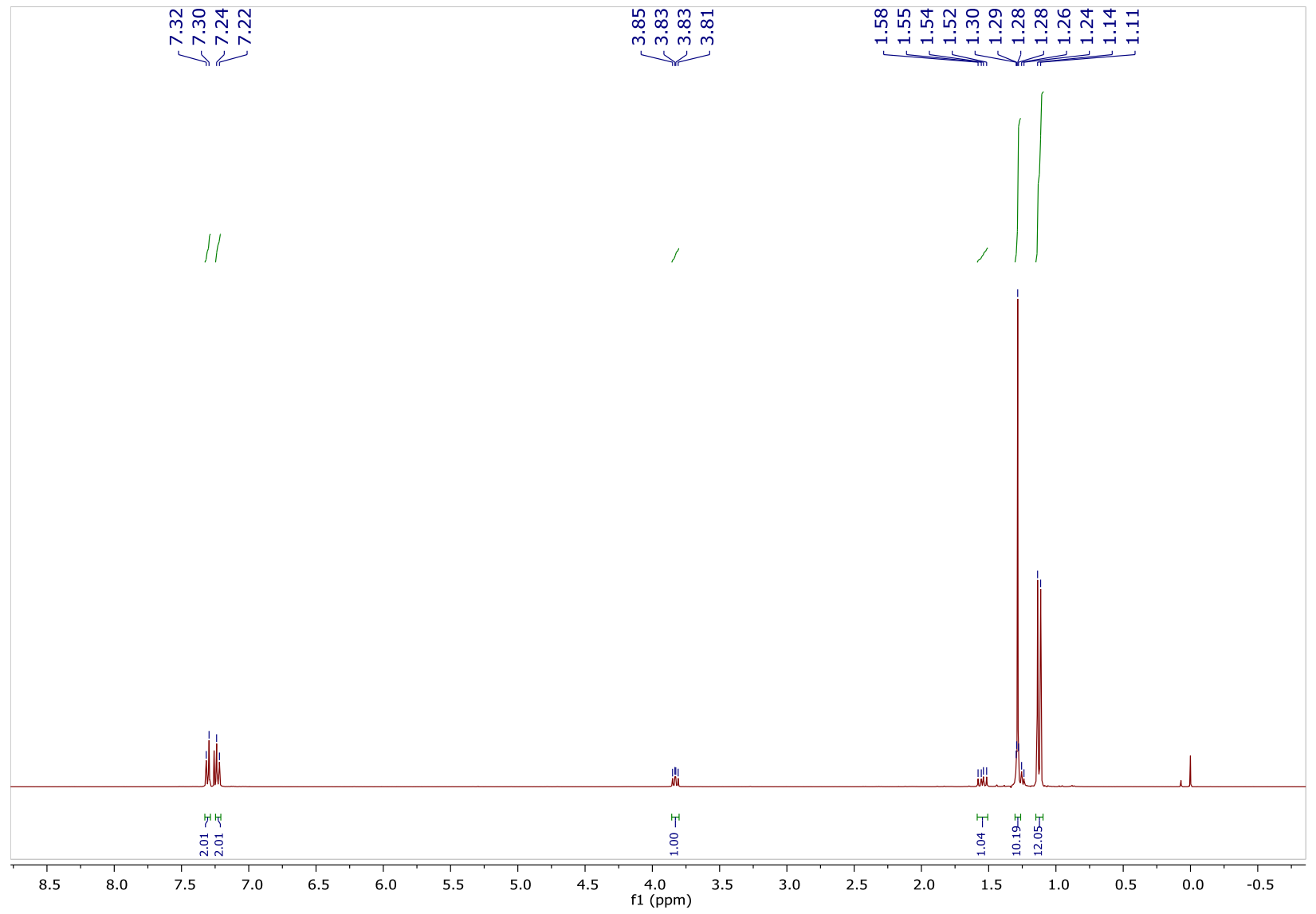


Figure A2.5: 3-boronic acid pinacol ester-2-(4-tertbuylphenyl) propionic acid (2b) - ${ }^{13} \mathrm{C}$ NMR

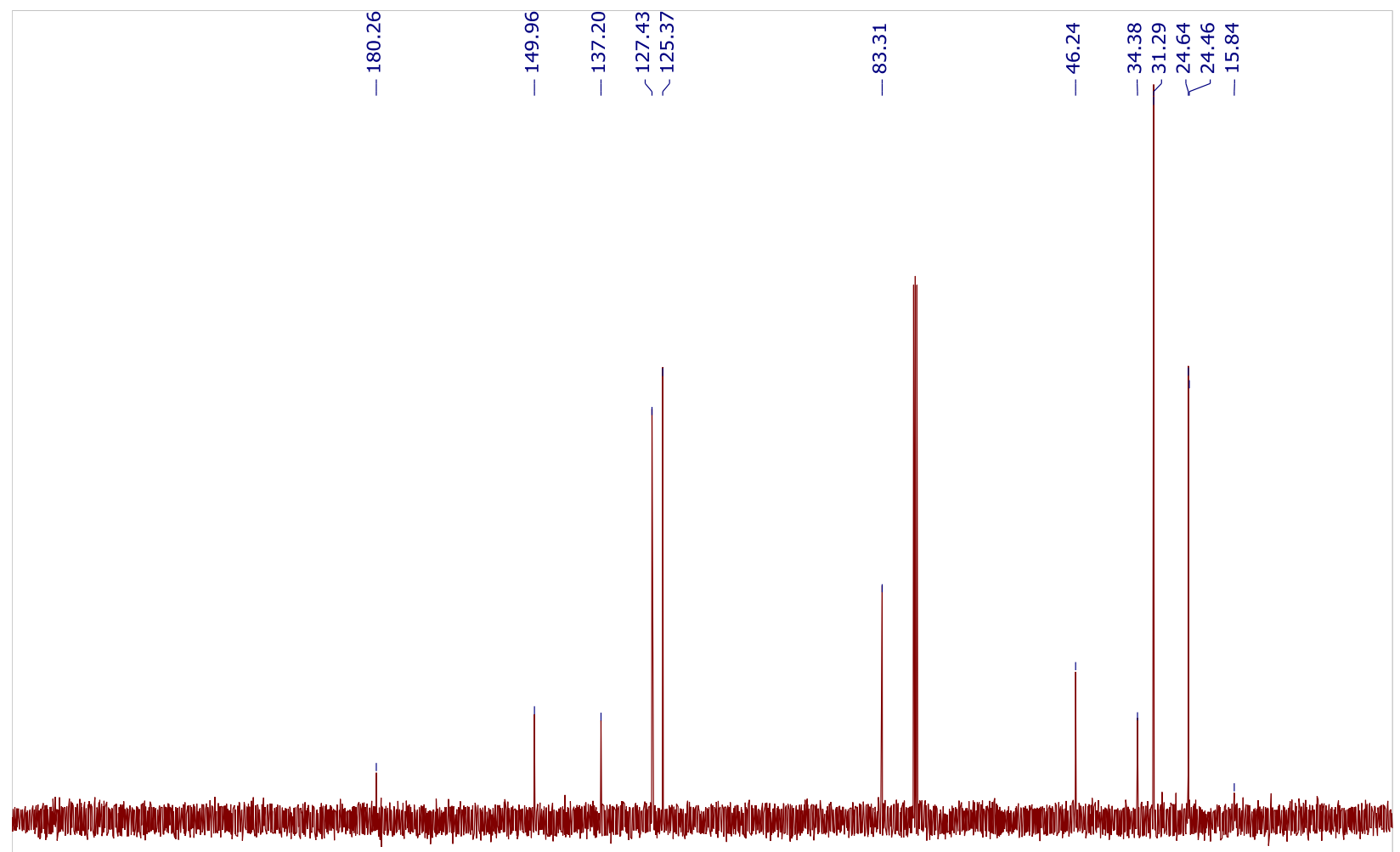

$\begin{array}{lllllllllllllllllllllllllll}50 & 240 & 230 & 220 & 210 & 200 & 190 & 180 & 170 & 160 & 150 & 140 & 130 & 120 & 110 & 100 & 90 & 80 & 70 & 60 & 50 & 40 & 30 & 20 & 10 & 0 & -10\end{array}$ 
Figure A2.6: 3-boronic acid pinacol ester-2-(4-tertbuylphenyl) propionic acid (2b) - ${ }^{11} \mathrm{~B}$ NMR

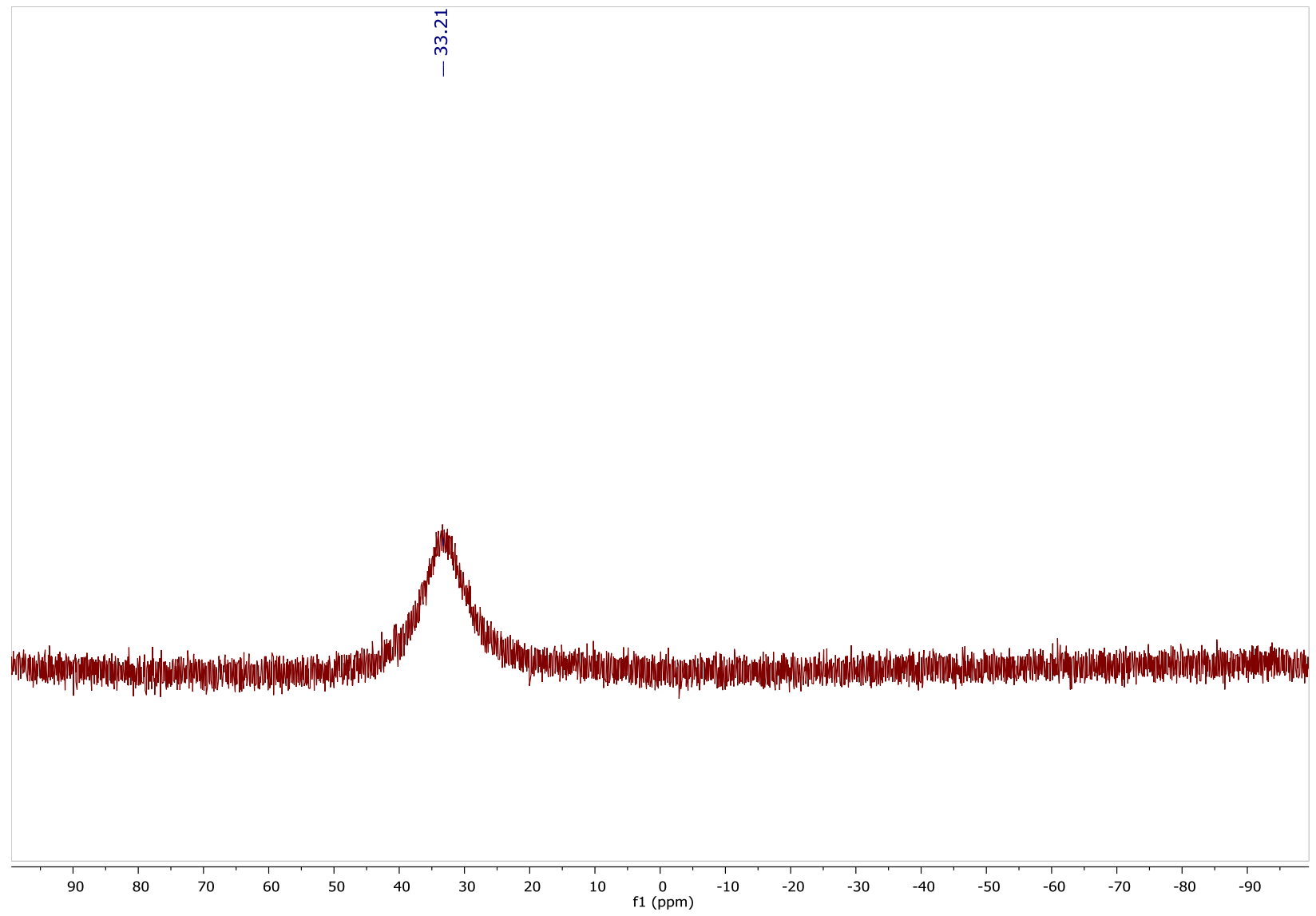


Figure A2.7: 3-boronic acid pinacol ester-2-(4-methylphenyl) propionic acid (2c) - ${ }^{1} \mathrm{H}$ NMR

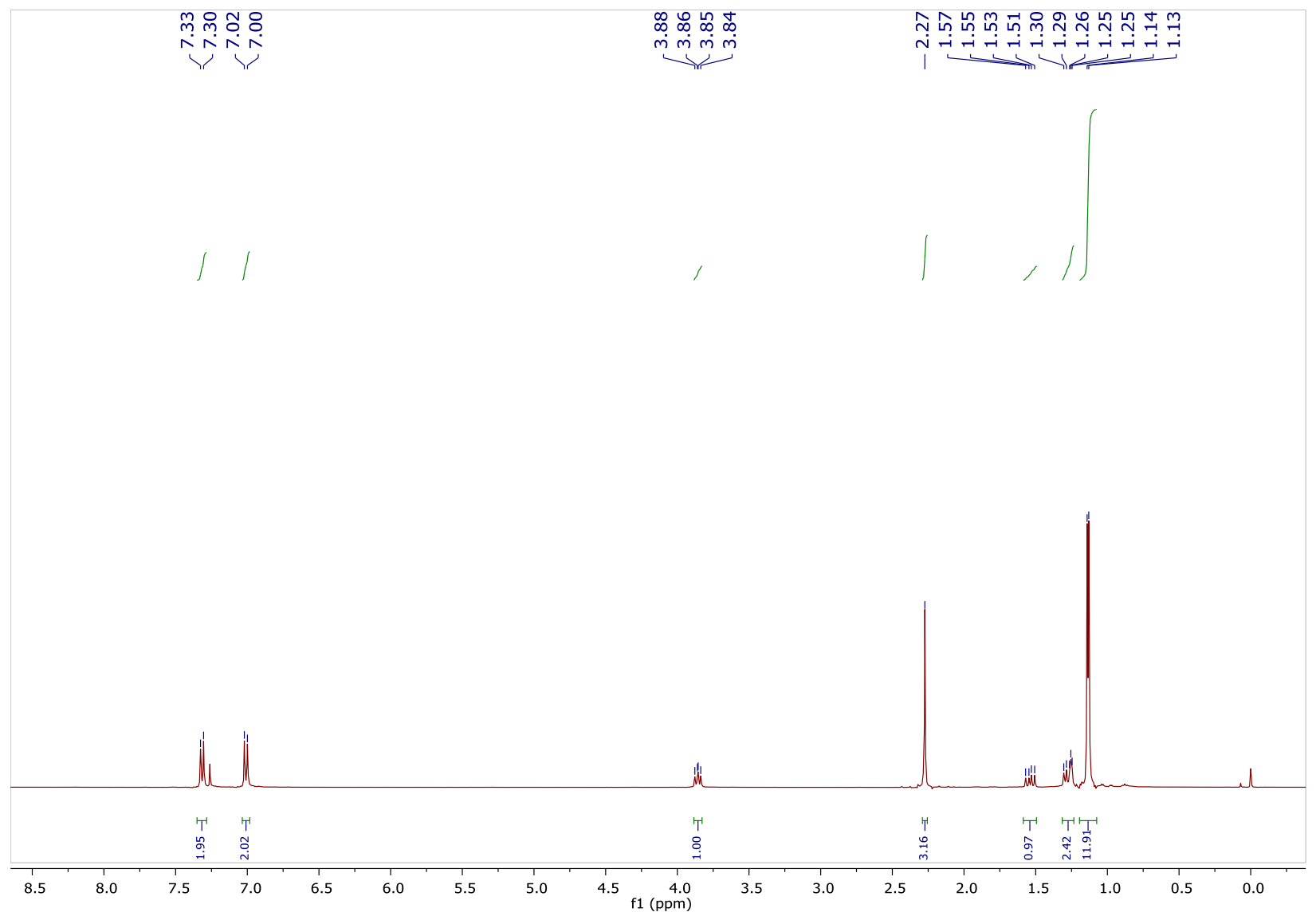


Figure A2.8: 3-boronic acid pinacol ester-2-(4-methylphenyl) propionic acid (2c) $-{ }^{13} \mathrm{C}$ NMR

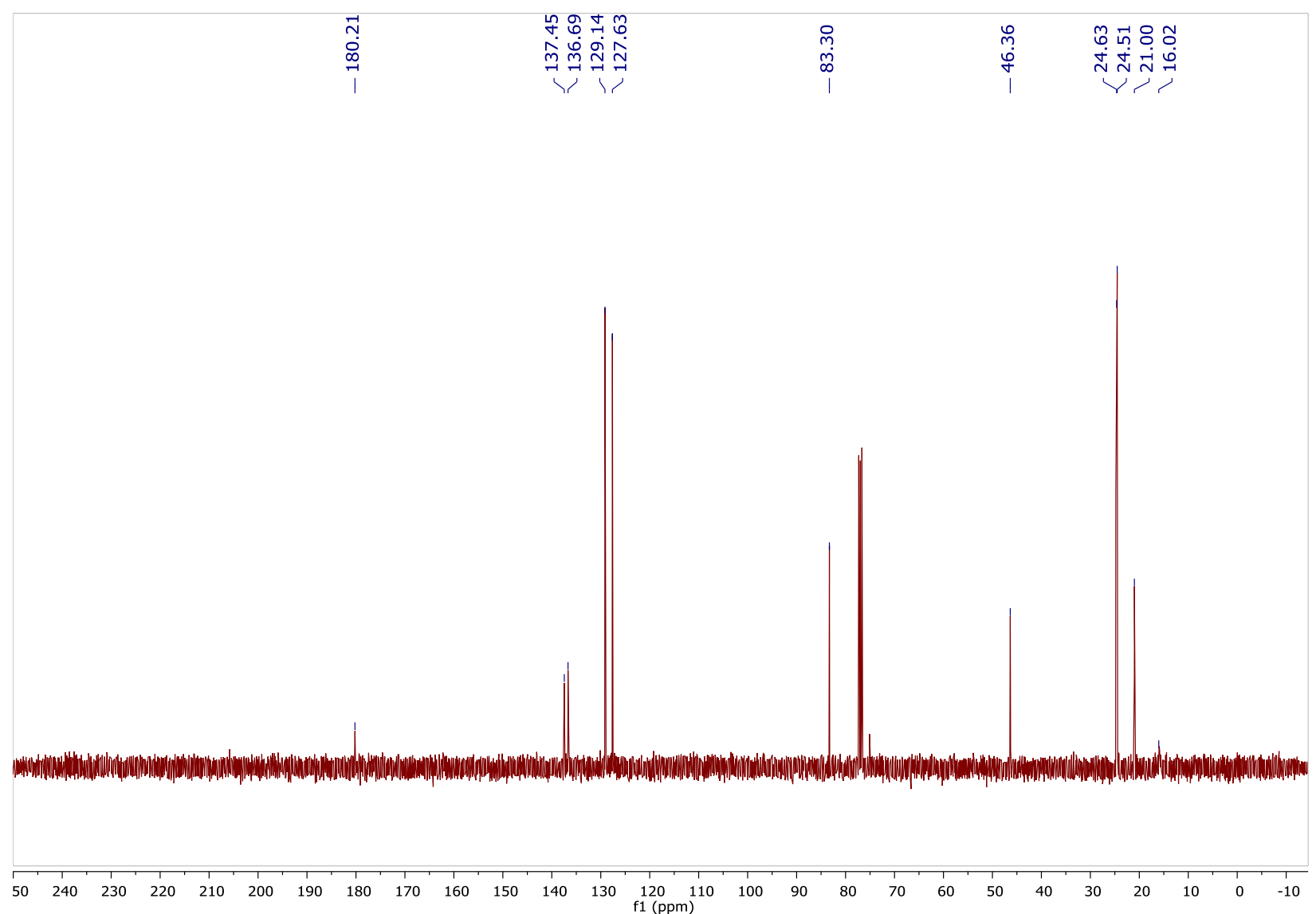


Figure A2.9: 3-boronic acid pinacol ester-2-(4-methylphenyl) propionic acid (2c) - ${ }^{11} \mathrm{~B}$ NMR

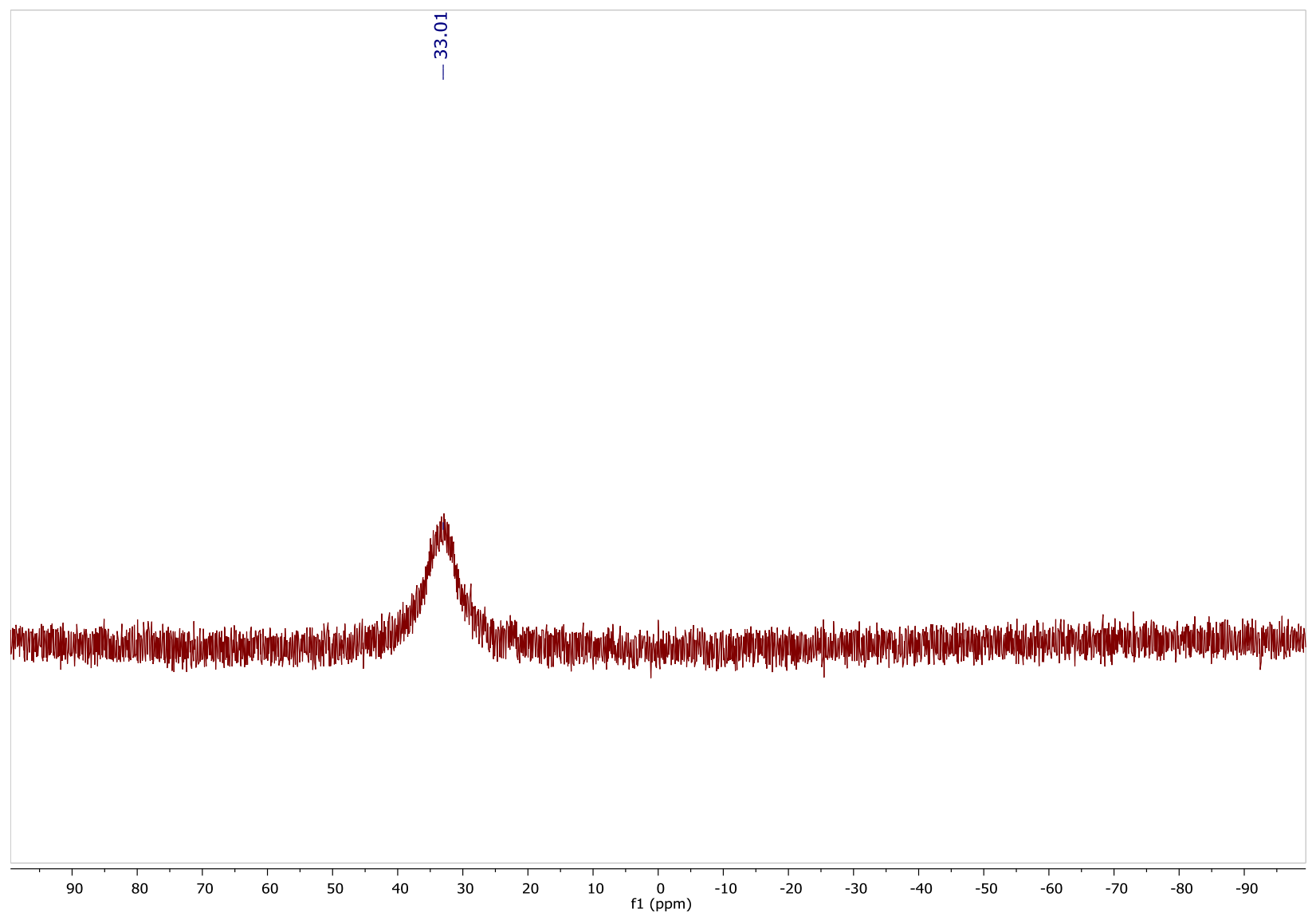


Figure A2.10: 3-boronic acid pinacol ester-2-(4-isobutylphenyl) propionic acid (2d) - ${ }^{1} \mathrm{H}$ NMR

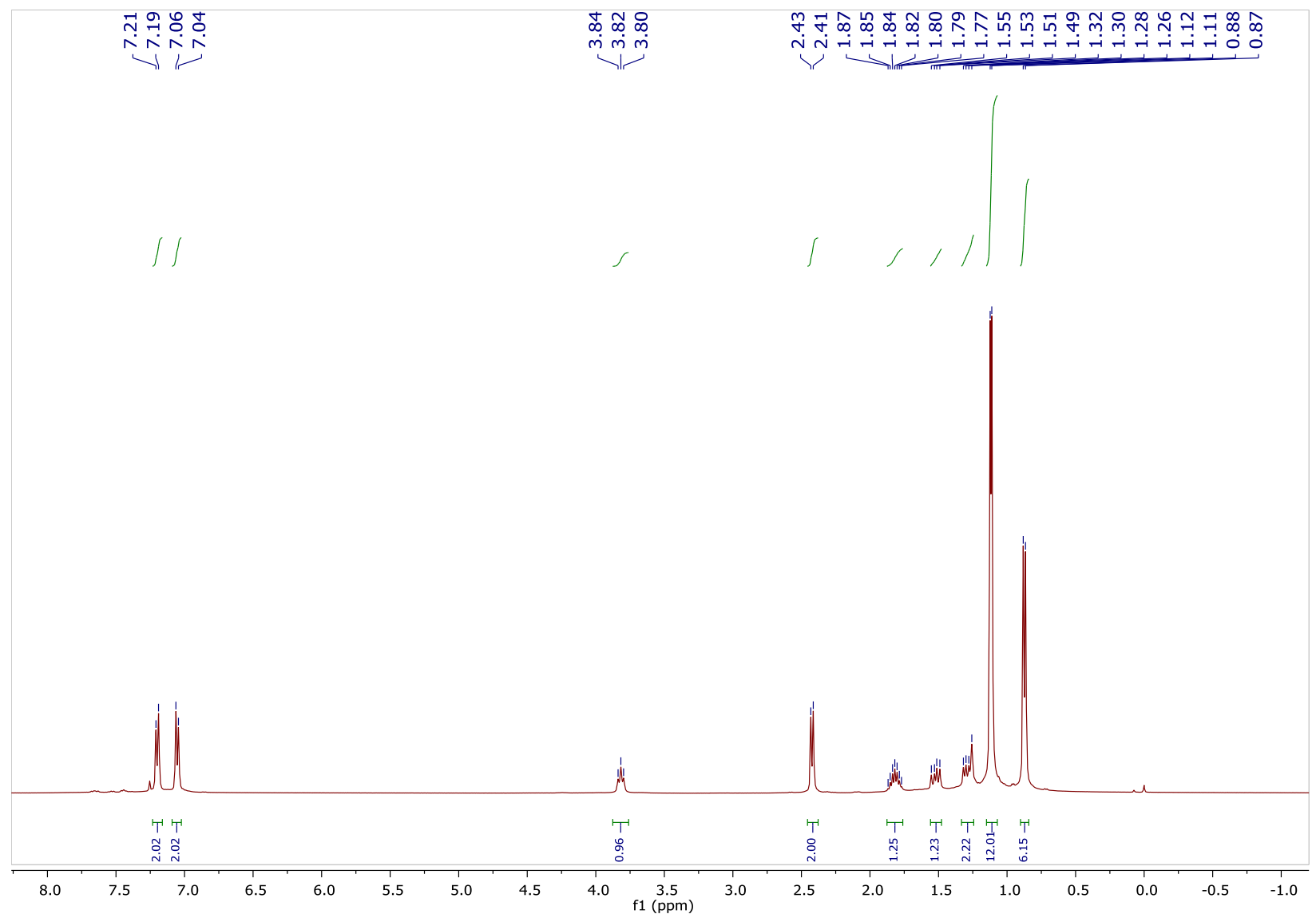


Figure A2.11: 3-boronic acid pinacol ester-2-(4-isobutylphenyl) propionic acid (2d) - ${ }^{13} \mathrm{C}$ NMR

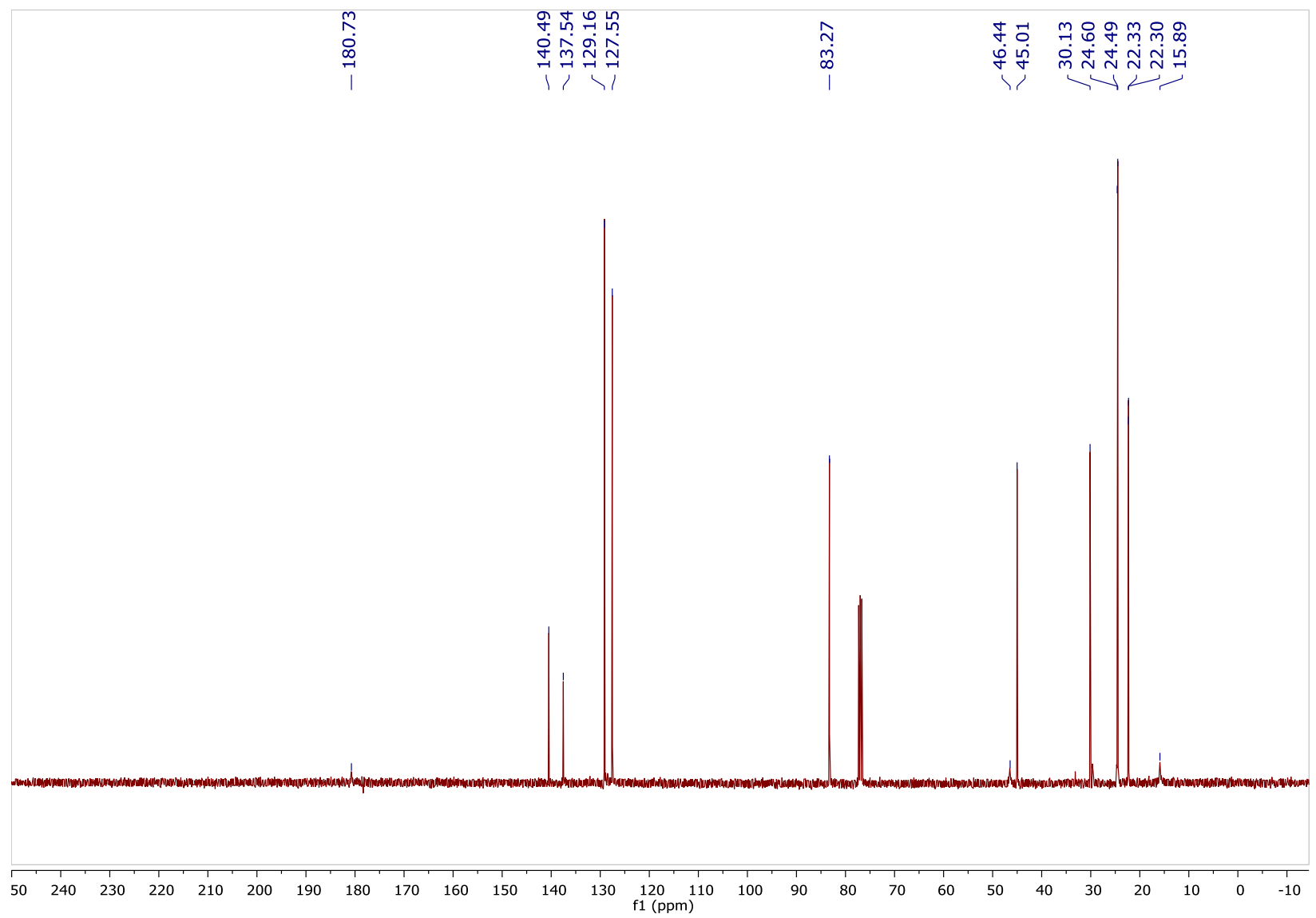


Figure A2.12: 3-boronic acid pinacol ester-2-(4-isobutylphenyl) propionic acid (2d) - ${ }^{11} \mathrm{~B}$ NMR

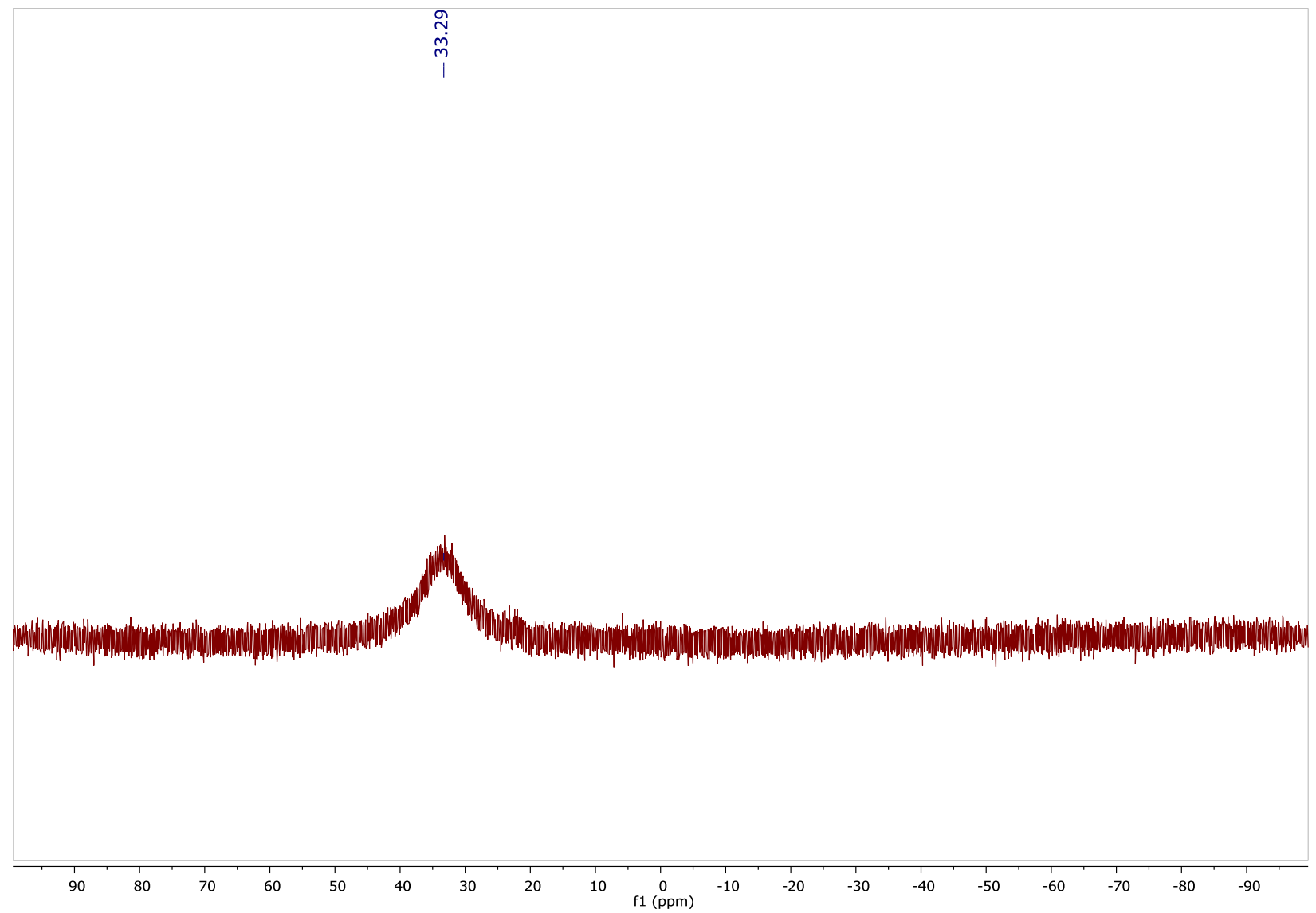


Figure A2.13: 3-boronic acid pinacol ester-2-(4-methoxyphenyl) propionic acid (2e) - ${ }^{1} \mathrm{H}$ NMR

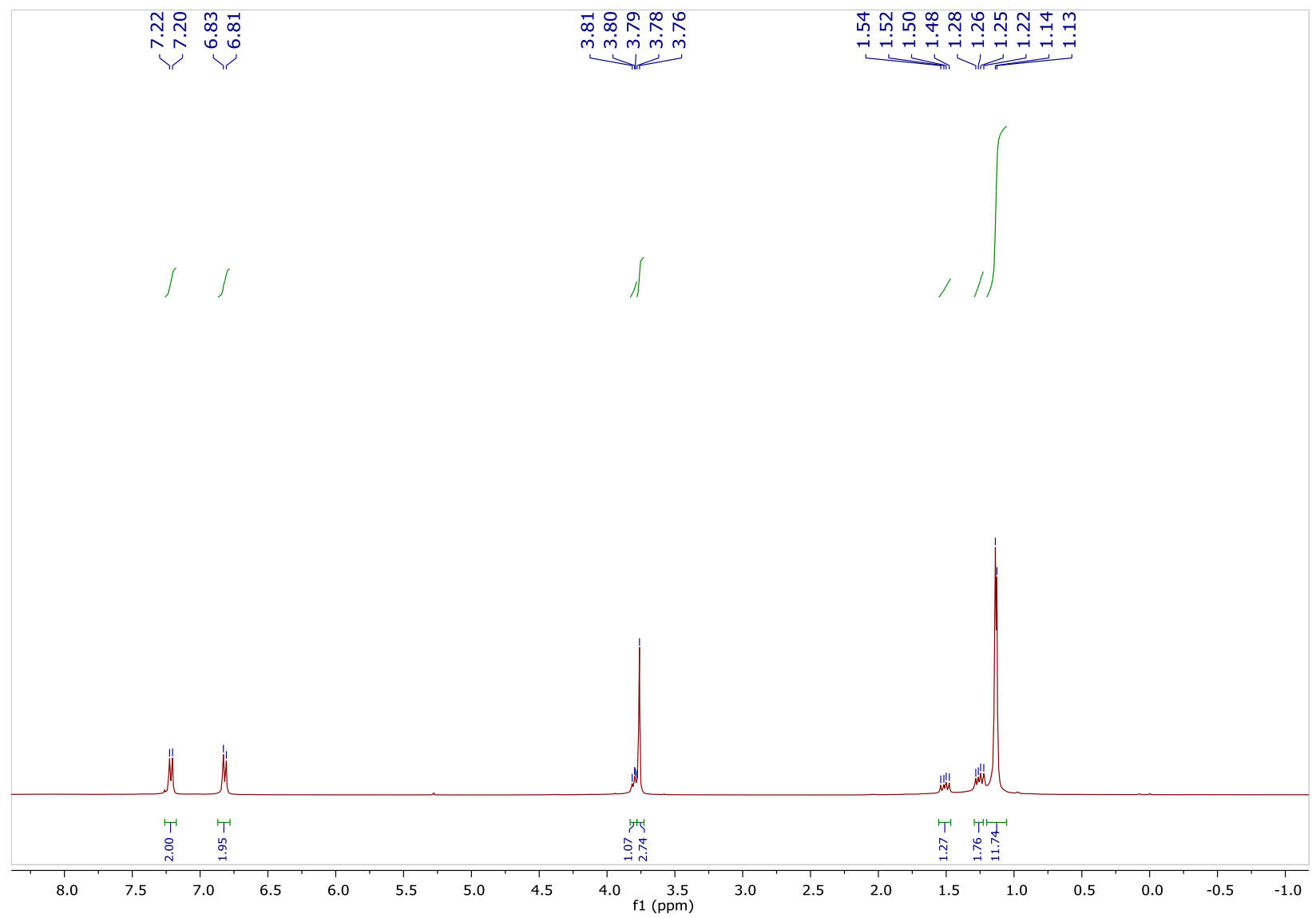


Figure A2.14: 3-boronic acid pinacol ester-2-(4-methoxyphenyl) propionic acid (2e) - ${ }^{13} \mathrm{C}$ NMR

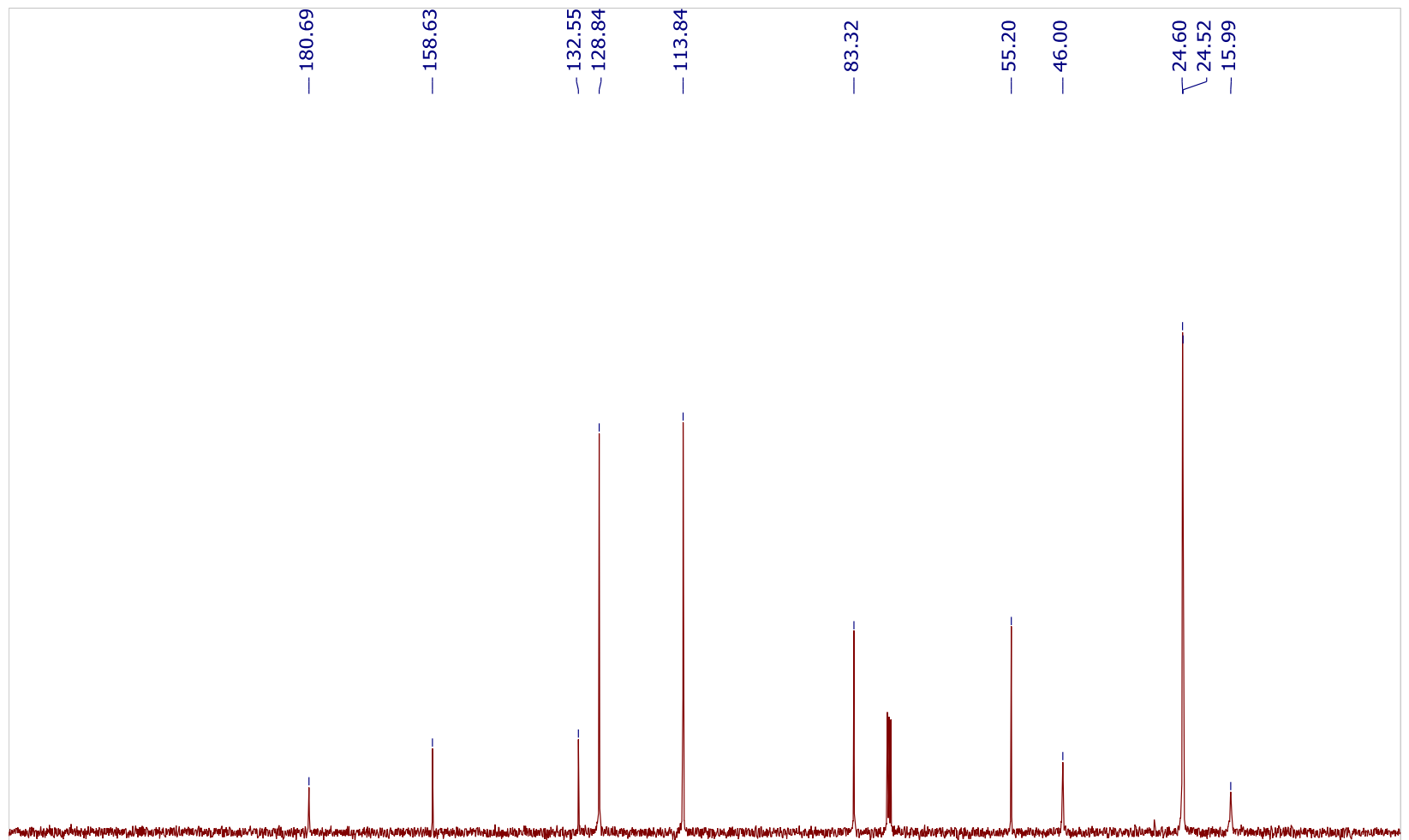

$\begin{array}{llllllllllllllllllllllllll}230 & 220 & 210 & 200 & 190 & 180 & 170 & 160 & 150 & 140 & 130 & 120 & 110 & 100 & 90 & 80 & 70 & 60 & 50 & 40 & 30 & 20 & 10 & 0 & -10\end{array}$ 
Figure A2.15: 3-boronic acid pinacol ester-2-(4-methoxyphenyl) propionic acid (2e) - ${ }^{11} \mathrm{~B}$ NMR

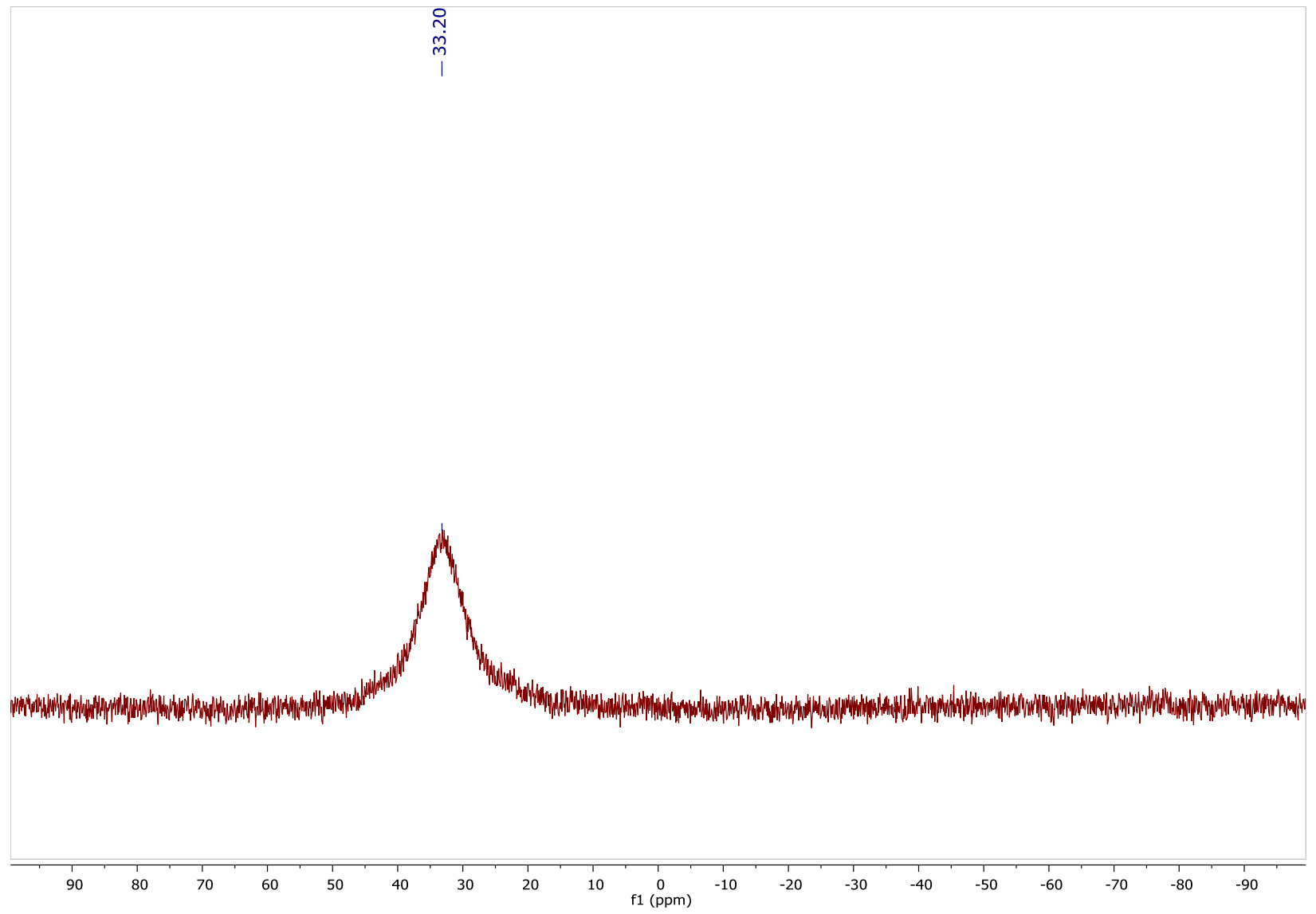


Figure A2.16: 3-boronic acid pinacol ester-2-(4-N(methyl)acetamide phenyl) propionic acid (2f) ${ }^{1} \mathrm{H}$ NMR

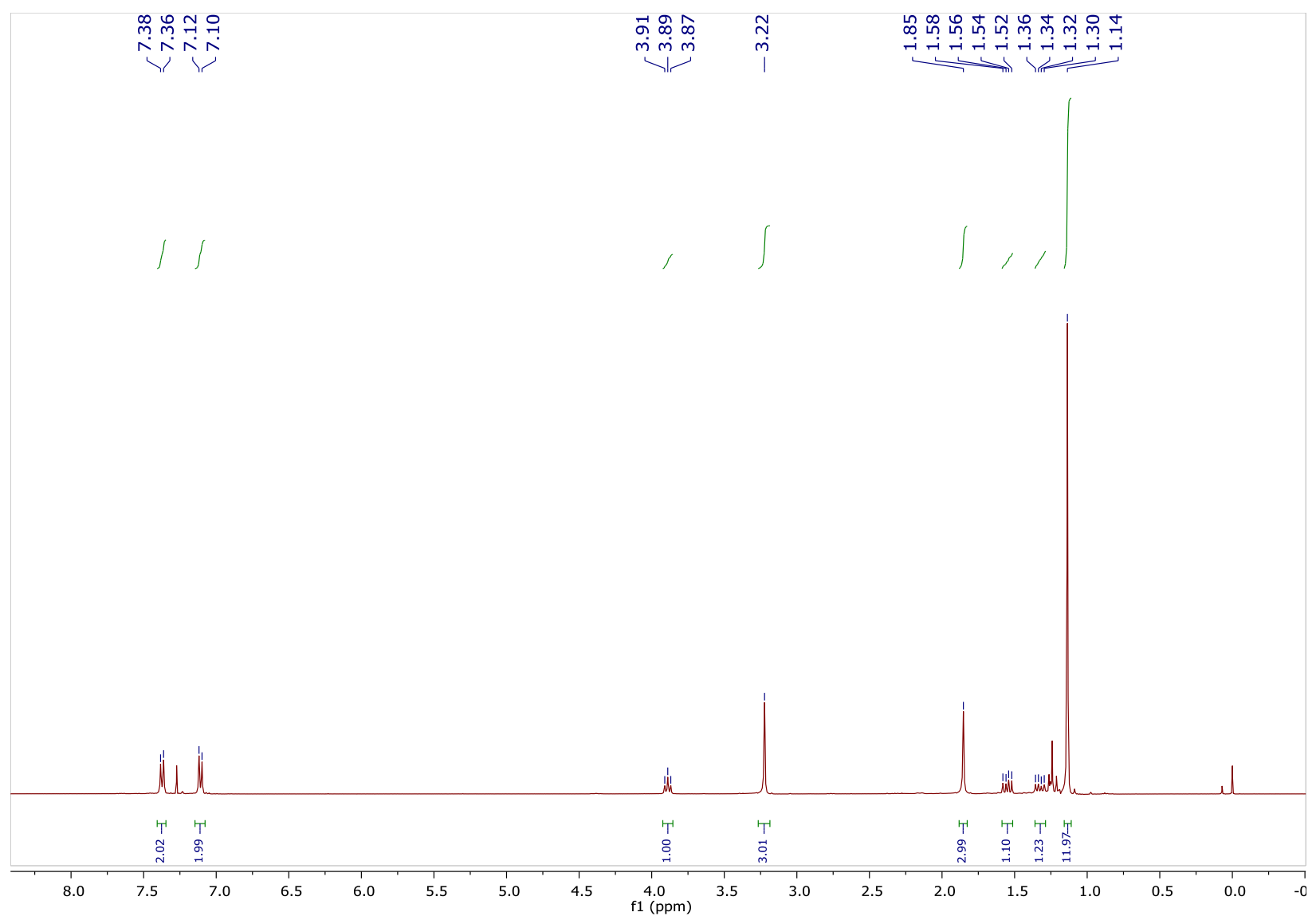


Figure A2.17: 3-boronic acid pinacol ester-2-(4-N(methyl)acetamide phenyl) propionic acid (2f) ${ }^{13} \mathrm{C}$ NMR

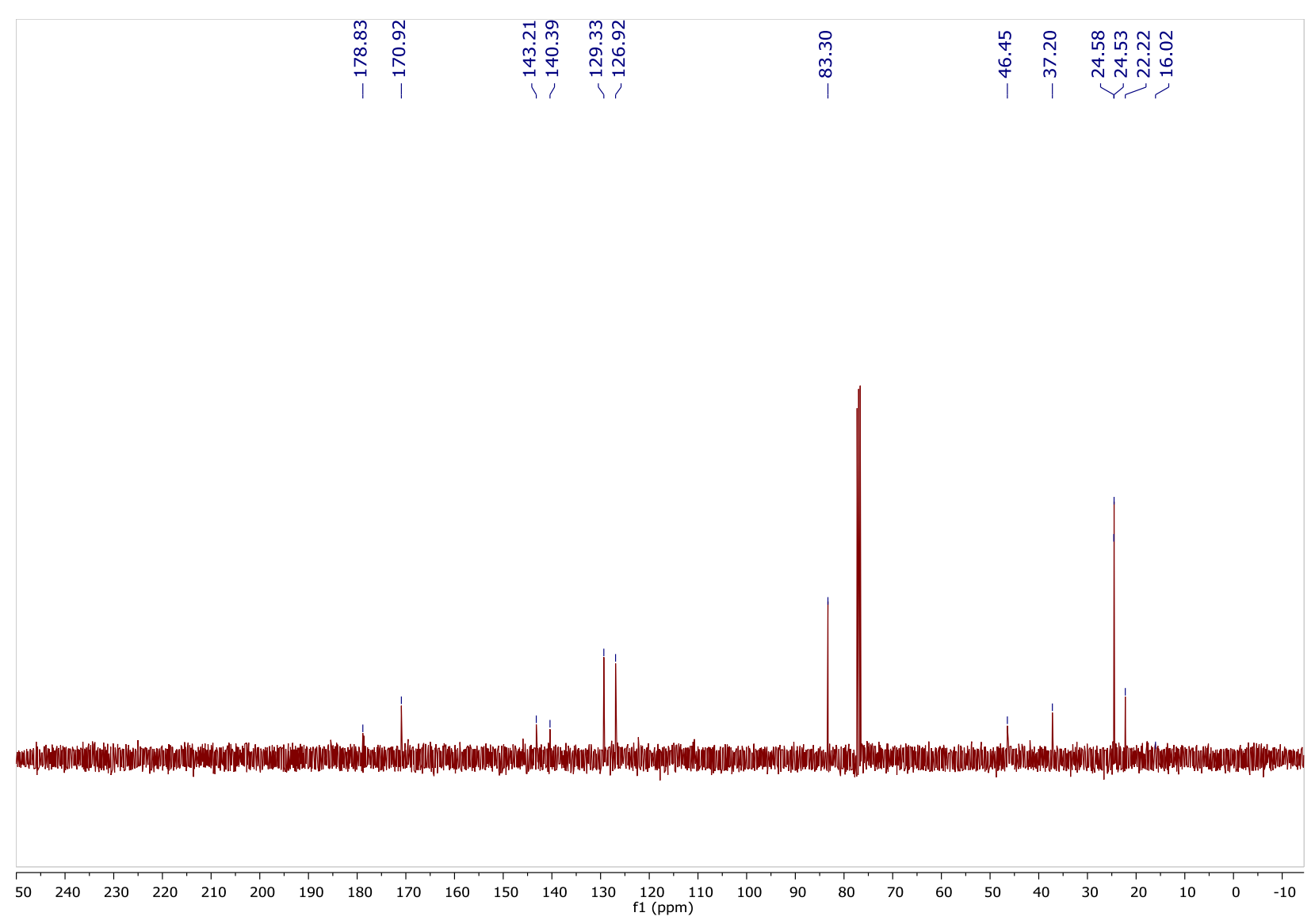


Figure A2.18: 3-boronic acid pinacol ester-2-(4-N(methyl)acetamide phenyl) propionic acid (2f) ${ }^{11} \mathrm{~B}$ NMR

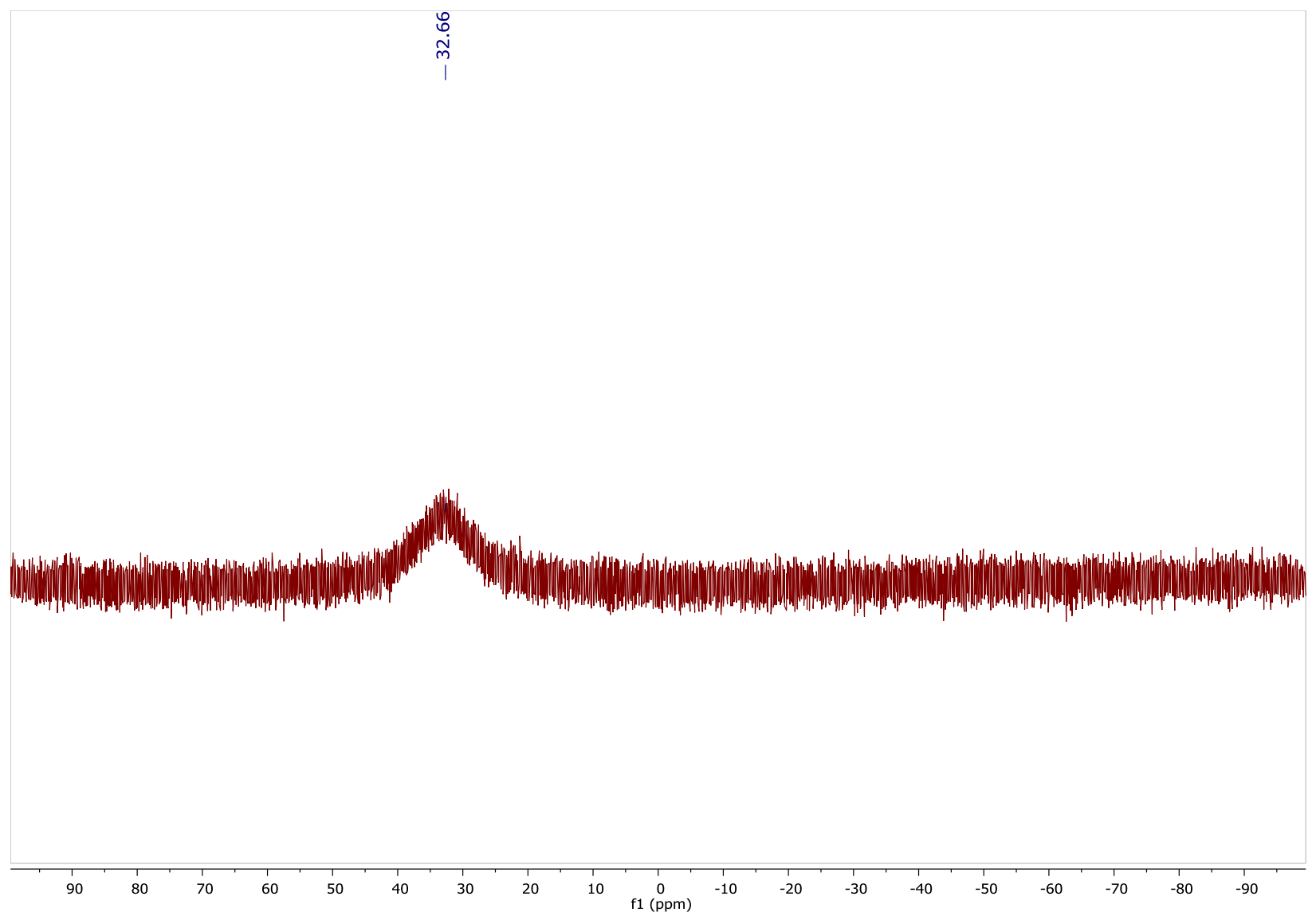


Figure A2.19: 3-boronic acid pinacol ester-2-(4-fluorophenyl) propionic acid $(2 \mathrm{~g})-{ }^{1} \mathrm{H}$ NMR

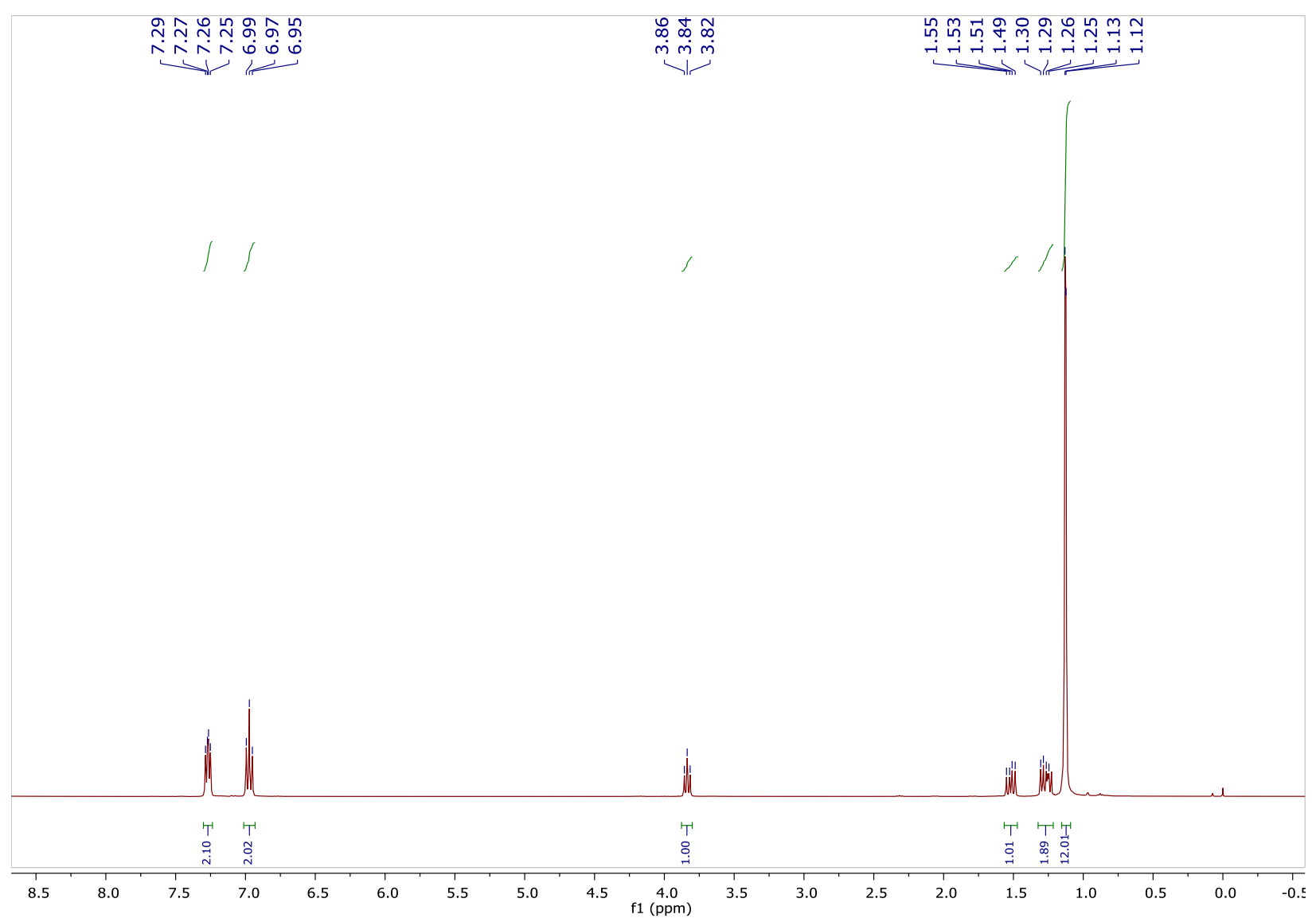


Figure A2.20: 3-boronic acid pinacol ester-2-(4-fluorophenyl) propionic acid (2g) - ${ }^{13} \mathrm{C}$ NMR

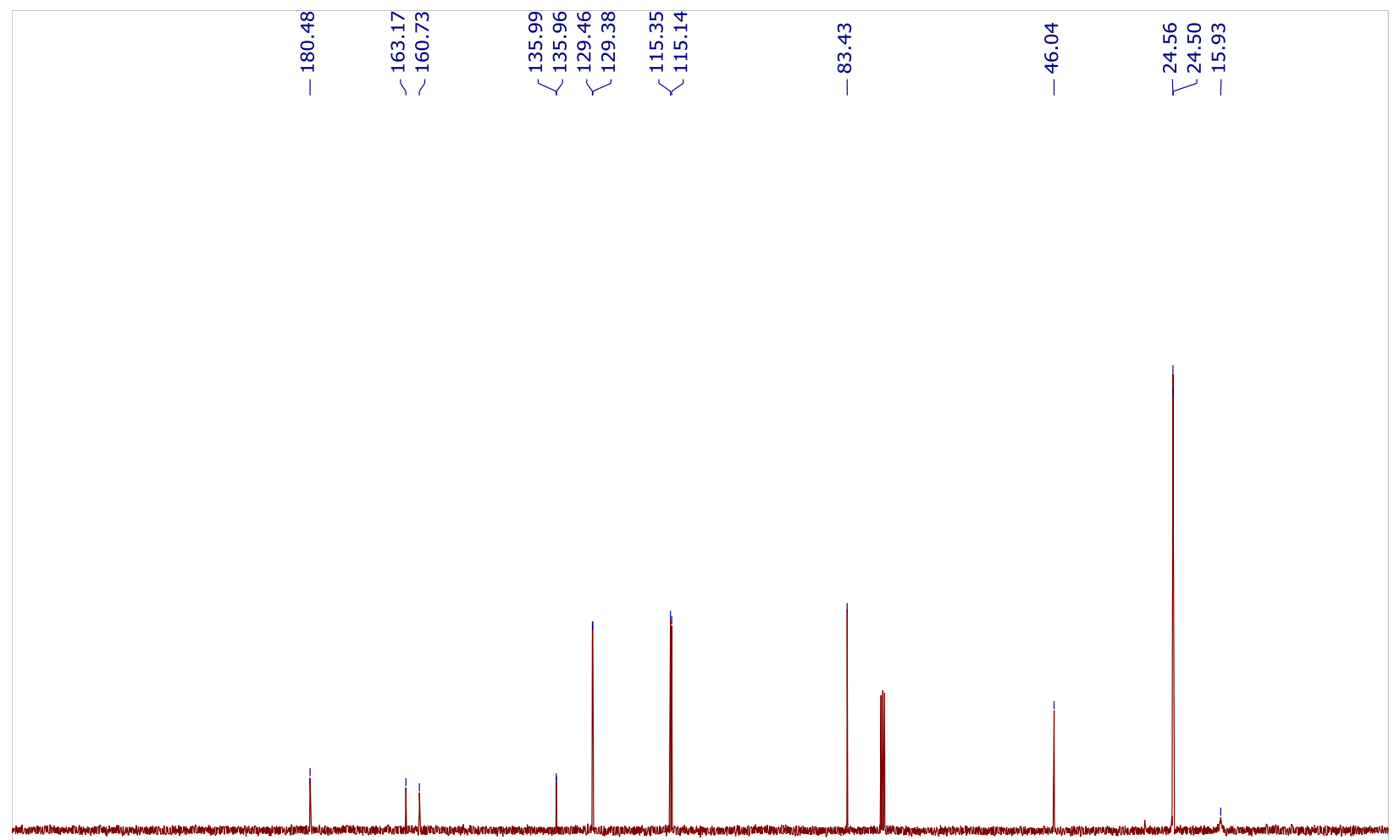

$\begin{array}{llllllllllllllllllllllllllll}230 & 220 & 210 & 200 & 190 & 180 & 170 & 160 & 150 & 140 & 130 & 120 & 110 & 100 & 90 & 80 & 70 & 60 & 50 & 40 & 30 & 20 & 10 & 0 & -10\end{array}$ 
Figure A2.21: 3-boronic acid pinacol ester-2-(4-fluorophenyl) propionic acid (2g) - ${ }^{11} \mathrm{~B}$ NMR

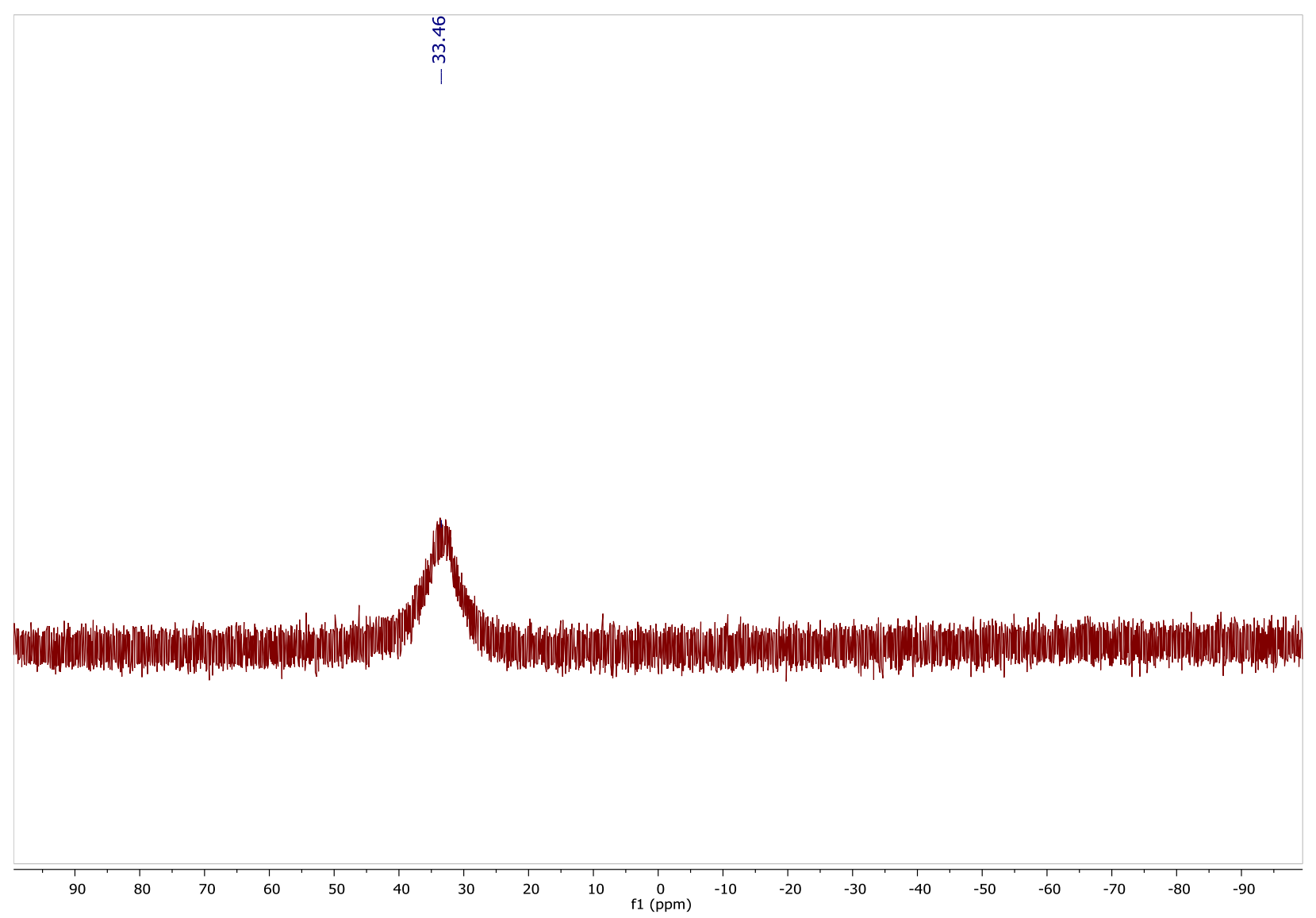


Figure A2.22: 3-boronic acid pinacol ester-2-(4-fluorophenyl) propionic acid (2g) - ${ }^{19} \mathrm{~F} \mathrm{NMR}$

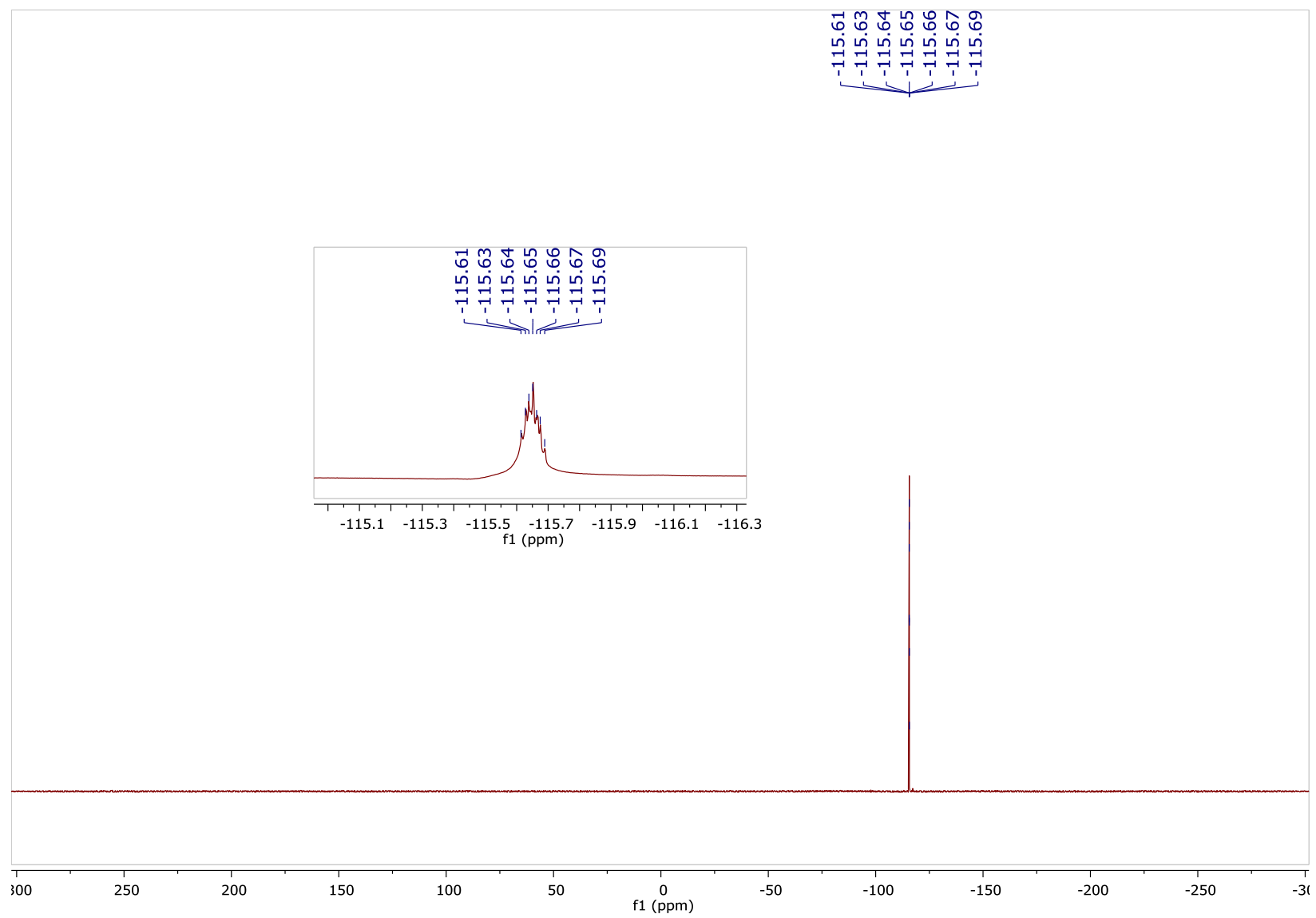


Figure A2.23: 3-boronic acid pinacol ester-2-(3-fluorophenyl) propionic acid (2h) - ${ }^{1} \mathrm{H}$ NMR

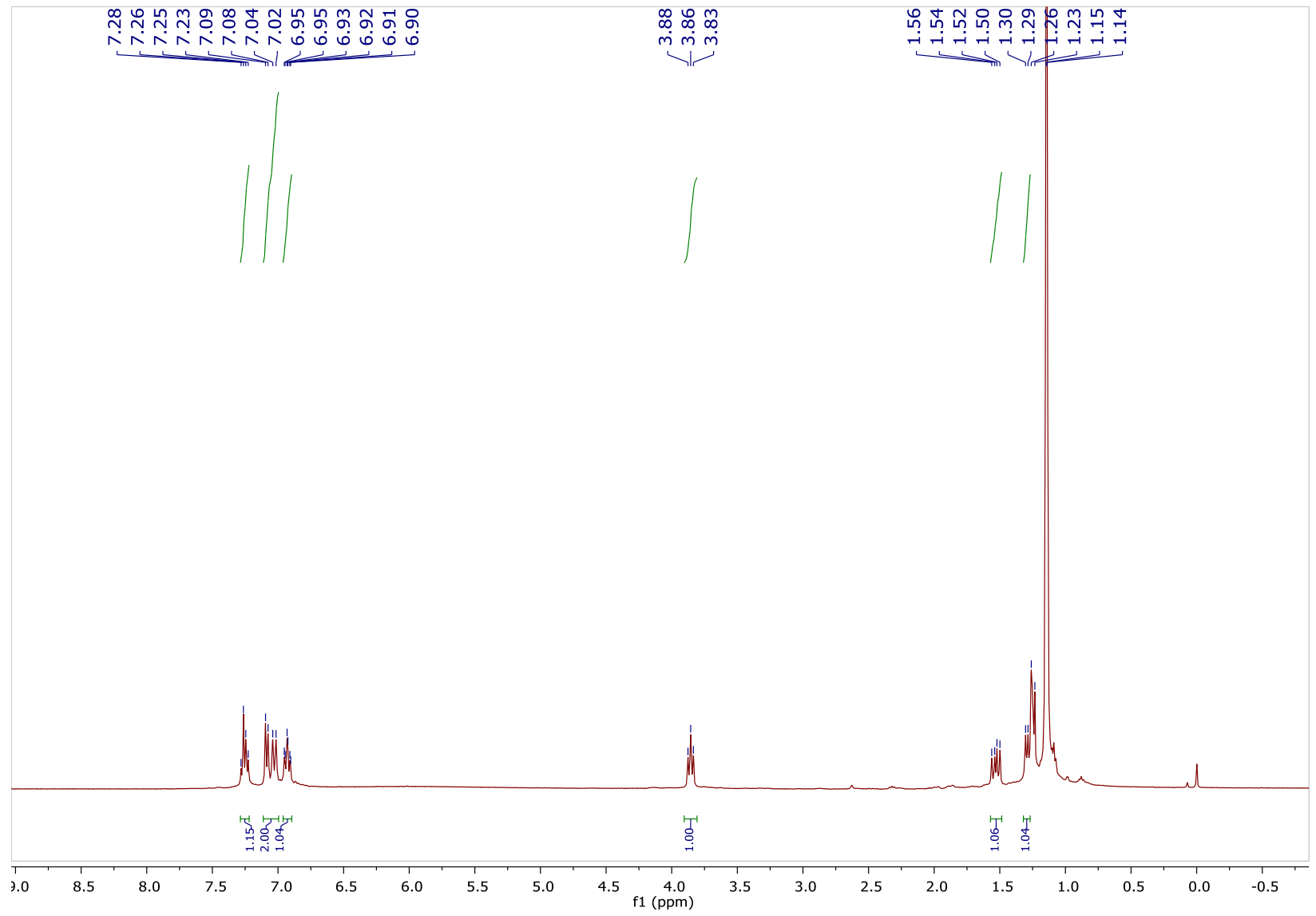


Figure A2.24: 3-boronic acid pinacol ester-2-(3-fluorophenyl) propionic acid (2h) - ${ }^{13} \mathrm{C}$ NMR

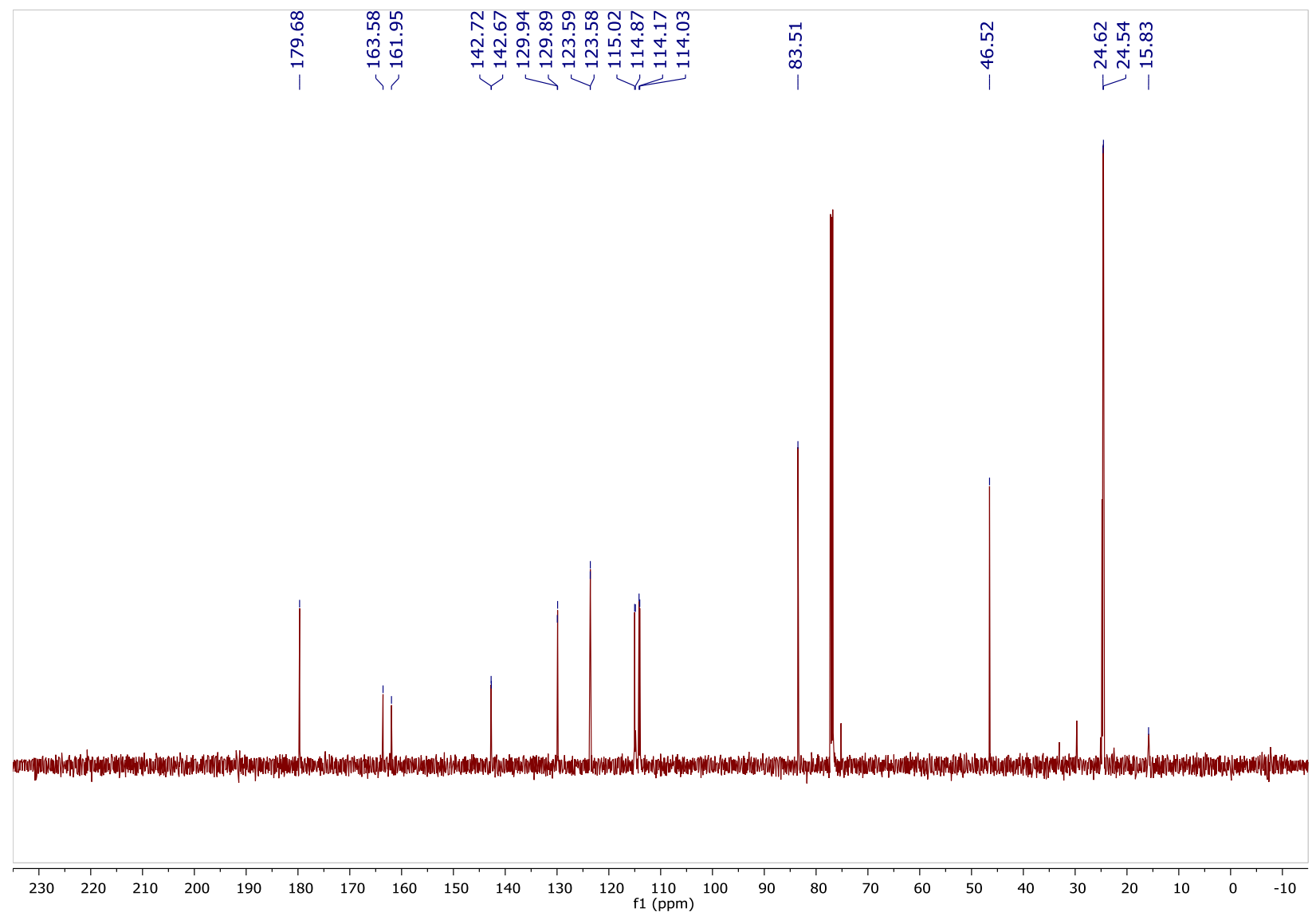


Figure A2.25: 3-boronic acid pinacol ester-2-(3-fluorophenyl) propionic acid (2h) - ${ }^{11} \mathrm{~B}$ NMR

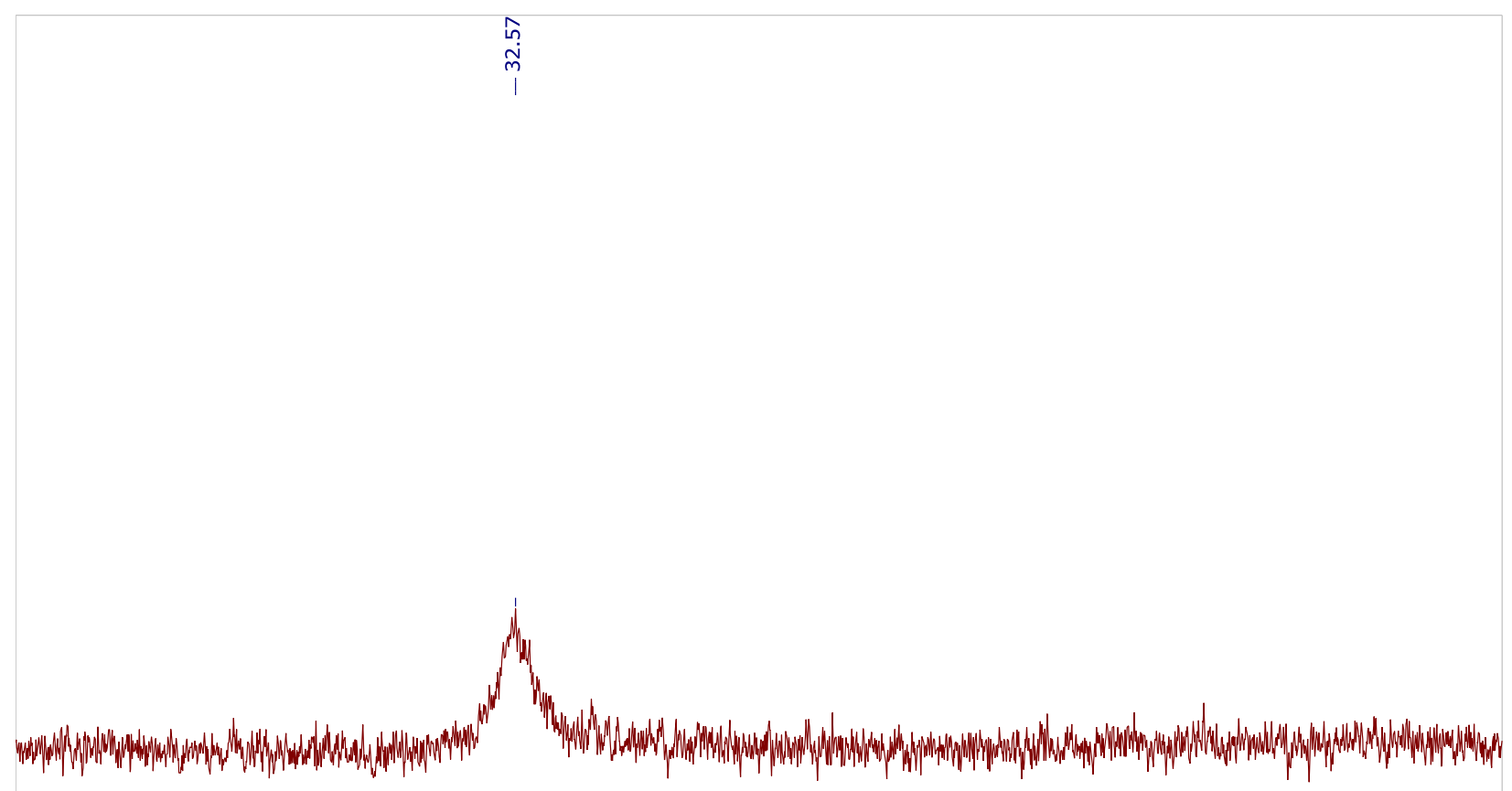

\begin{tabular}{|c|c|c|c|c|c|c|c|c|c|c|c|c|c|c|c|c|c|c|}
\hline 1 & 1 & 1 & 1 & 1 & 1 & 1 & 1 & 1 & T & 1 & 1 & 1 & 1 & 1 & 1 & 1 & 1 & 1 \\
\hline 90 & 80 & 70 & 60 & 50 & 40 & 30 & 20 & 10 & $\begin{array}{c}0 \\
\mathrm{f} 1(\mathrm{ppm})\end{array}$ & -10 & -20 & -30 & -40 & -50 & -60 & -70 & -80 & -90 \\
\hline
\end{tabular}


Figure A2.26: 3-boronic acid pinacol ester-2-(3-fluorophenyl) propionic acid (2h) $-{ }^{19} \mathrm{~F} \mathrm{NMR}$
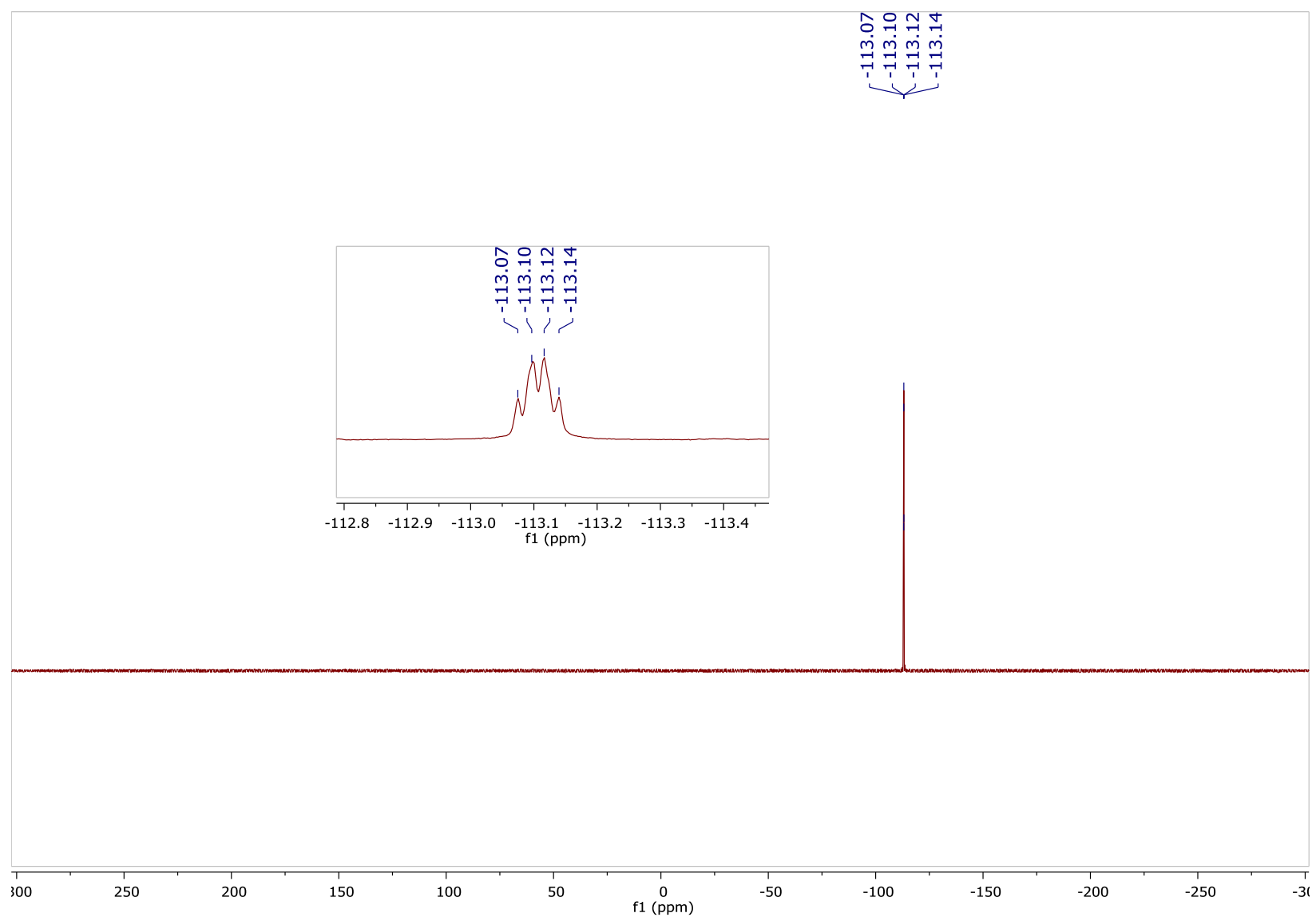
Figure A2.27: 3-boronic acid pinacol ester-2-(2-fluorophenyl) propionic acid (2i) - ${ }^{1} \mathrm{H}$ NMR

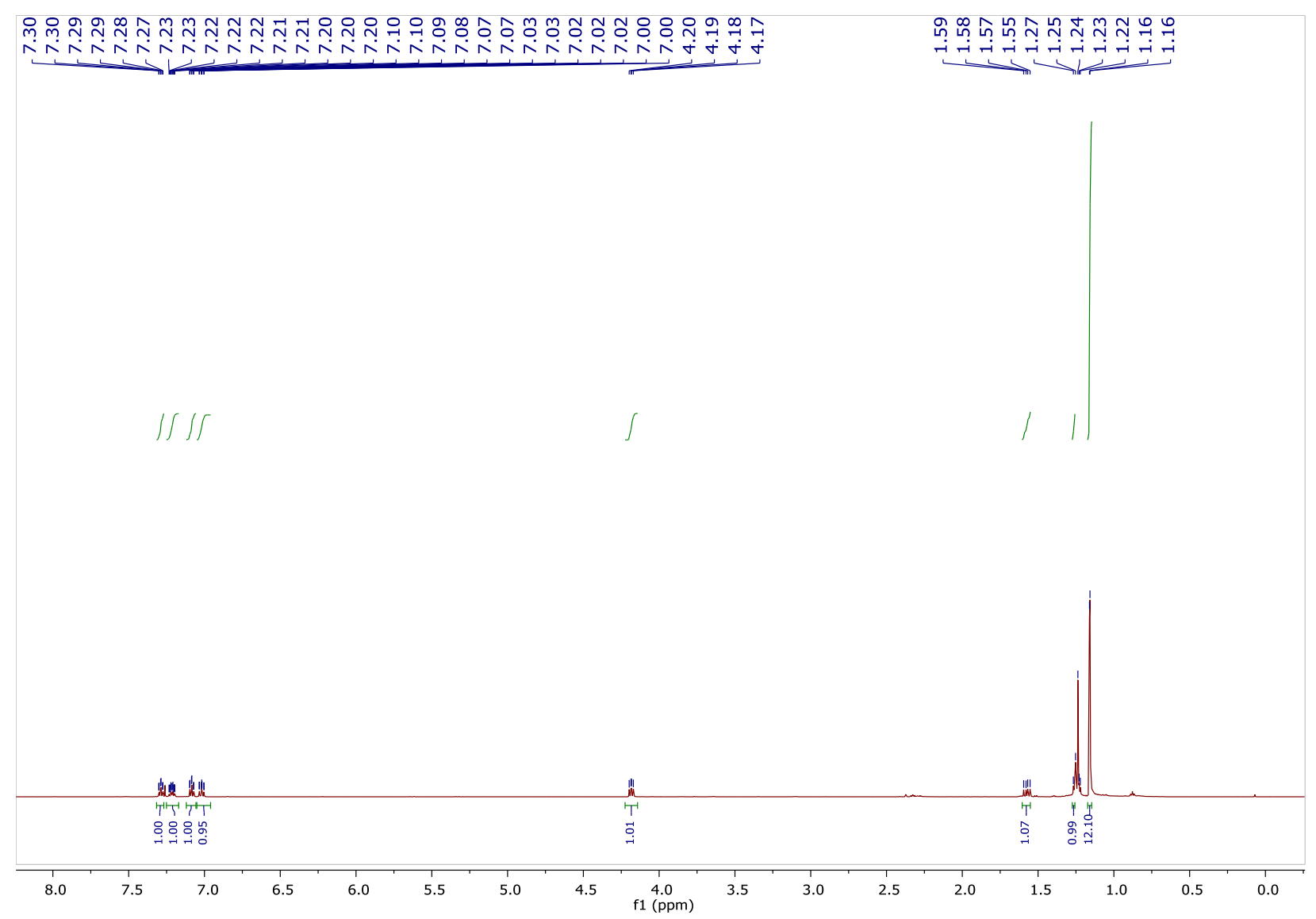


Figure A2.28: 3-boronic acid pinacol ester-2-(2-fluorophenyl) propionic acid (2i) $-{ }^{13} \mathrm{C}$ NMR

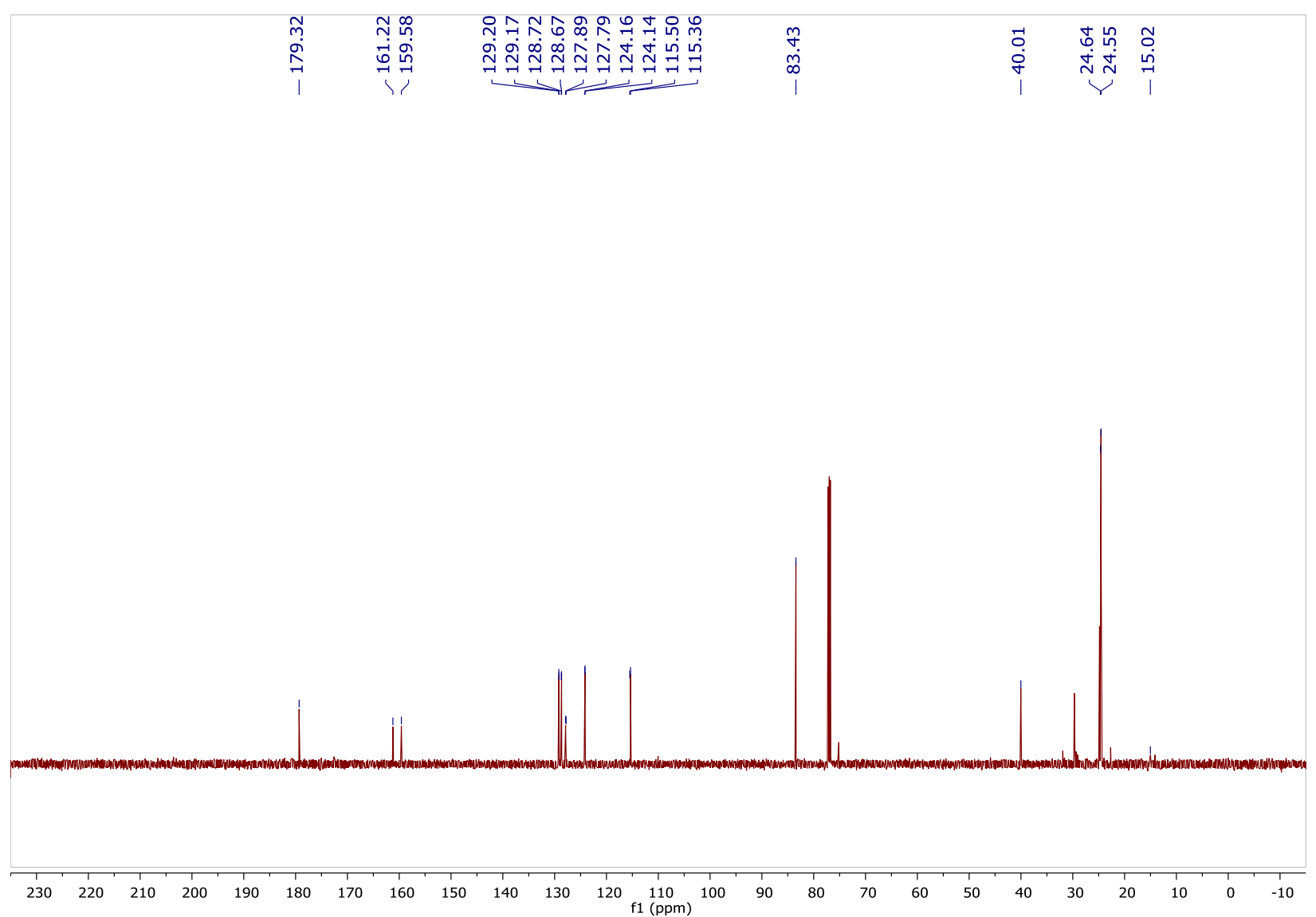


Figure A2.29: 3-boronic acid pinacol ester-2-(2-fluorophenyl) propionic acid (2i) - ${ }^{11} \mathrm{~B}$ NMR

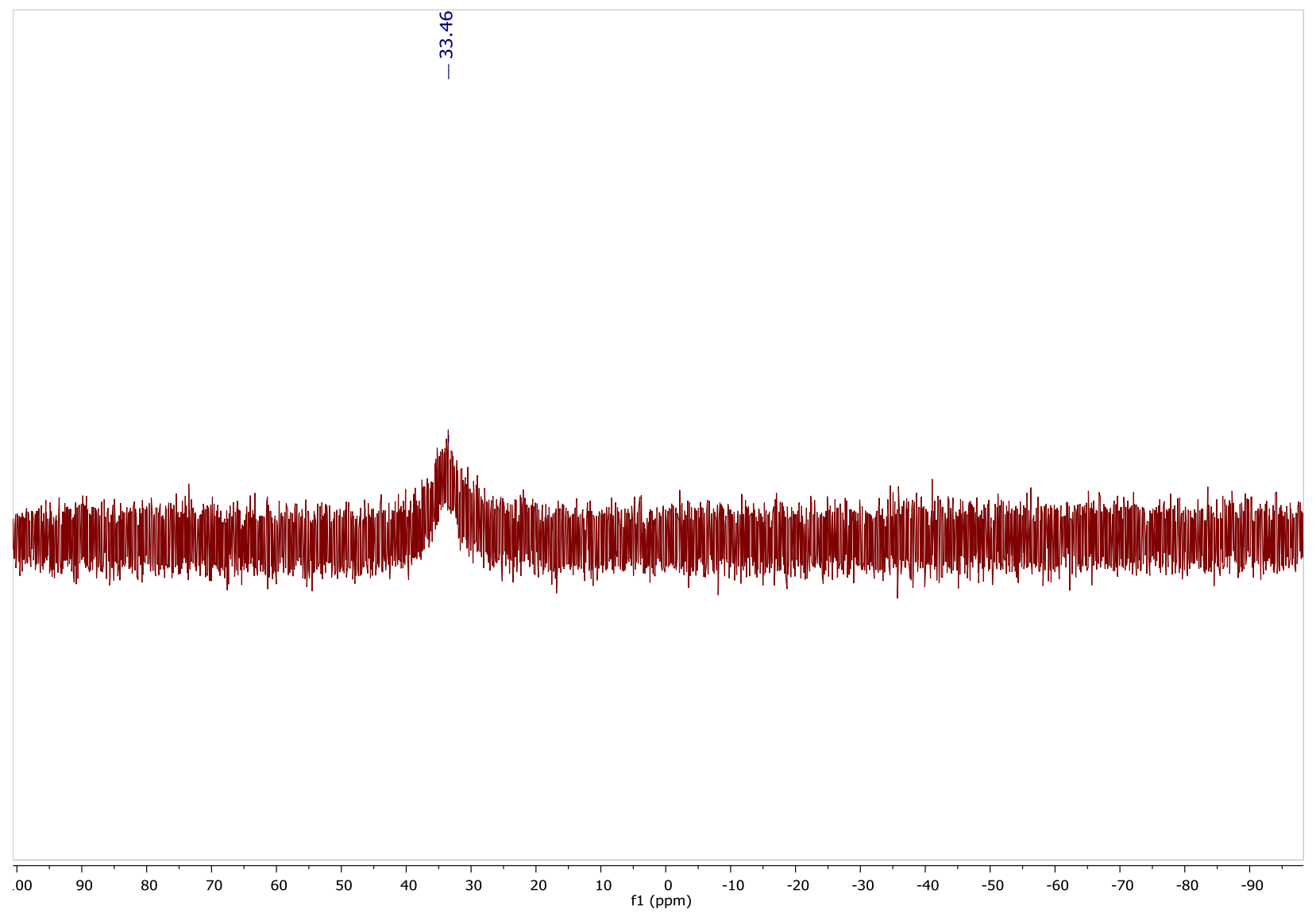


Figure A2.30: 3-boronic acid pinacol ester-2-(2-fluorophenyl) propionic acid (2i) $-{ }^{19} \mathrm{~F} \mathrm{NMR}$

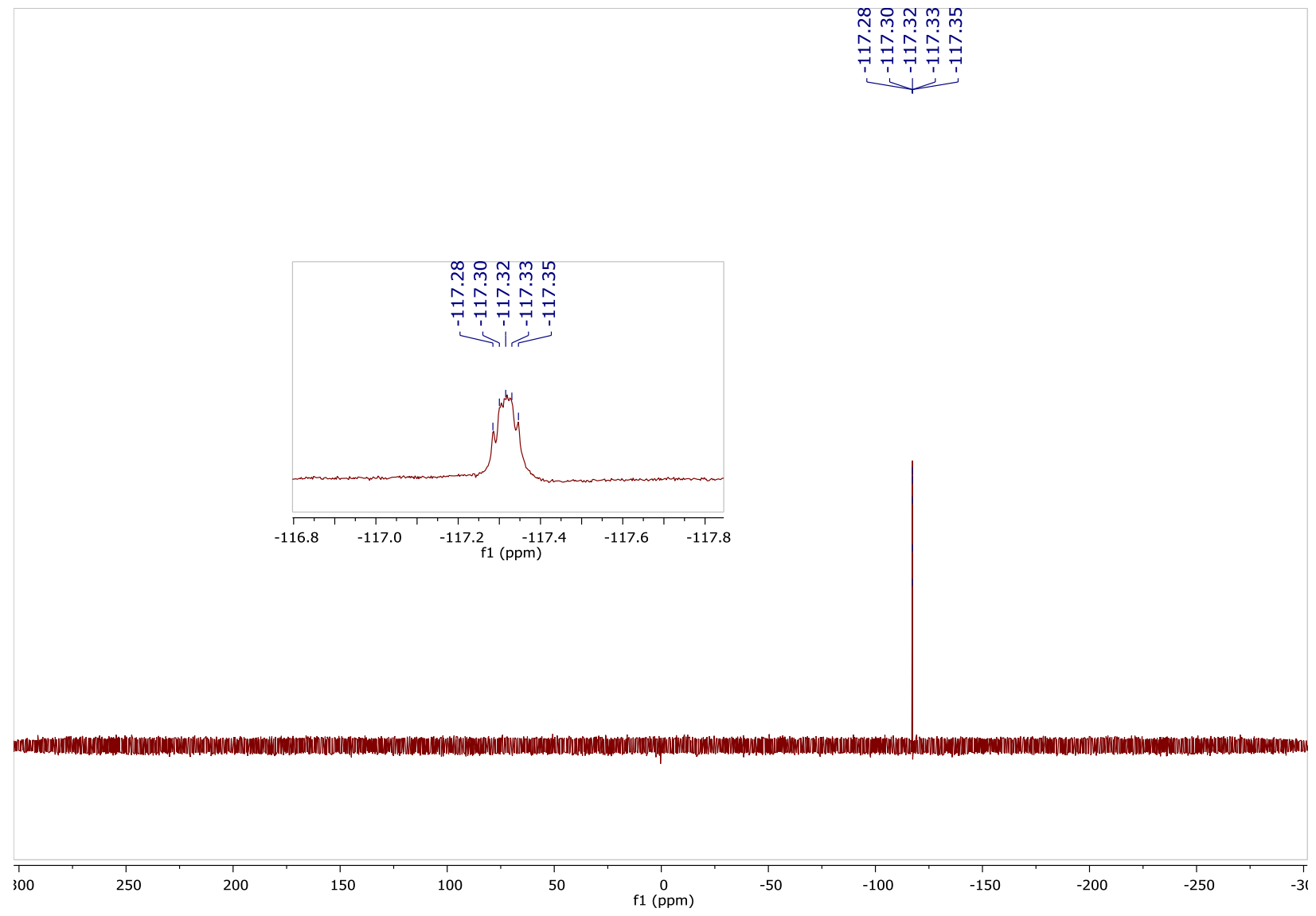


Figure A2.31: 3-boronic acid pinacol ester-2-(6-methoxynaphthalene) propionic acid (2j) ${ }^{1} \mathrm{H}$ NMR

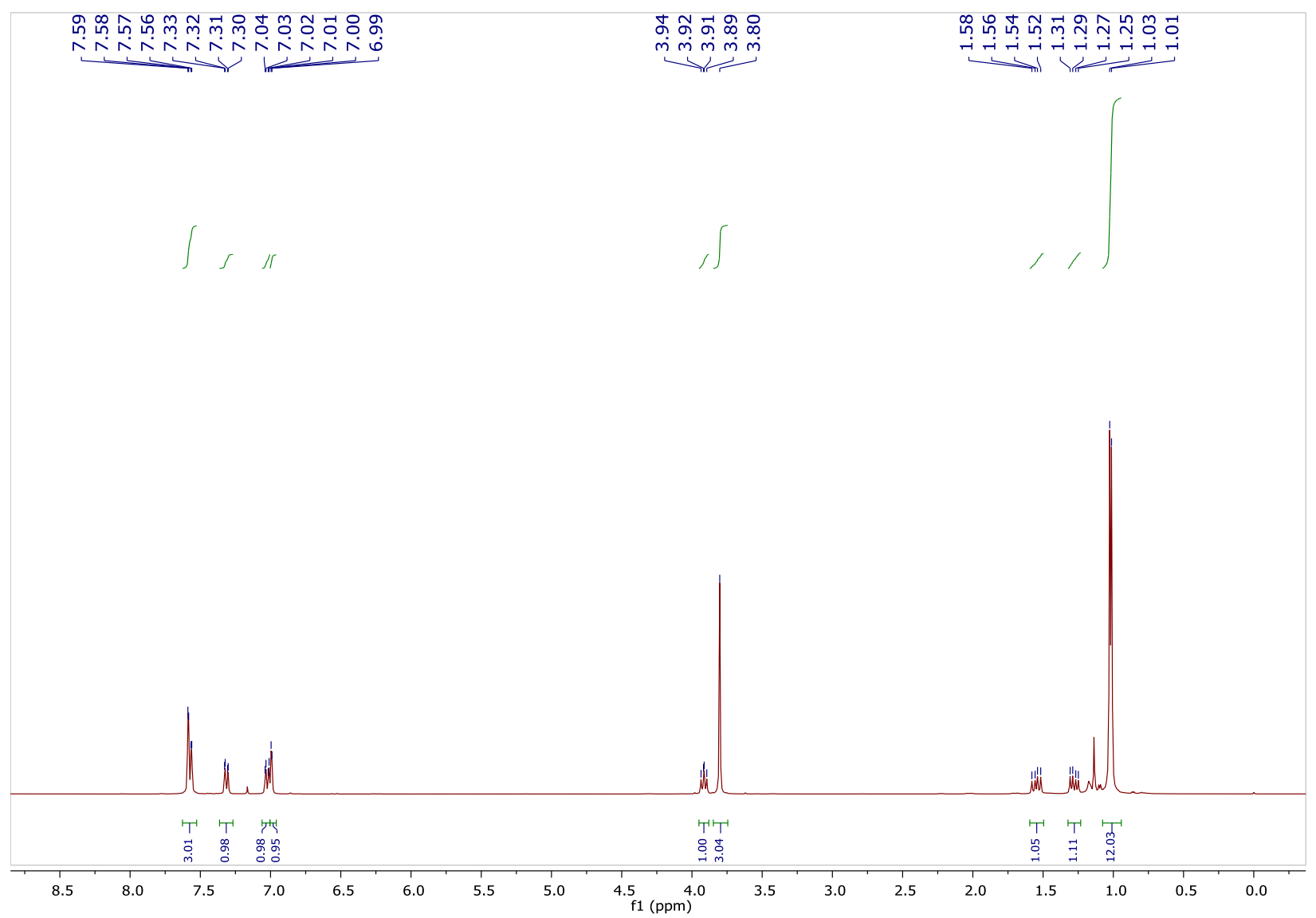


Figure A2.32: 3-boronic acid pinacol ester-2-(6-methoxynaphthalene) propionic acid (2j) ${ }^{13} \mathrm{C}$ NMR

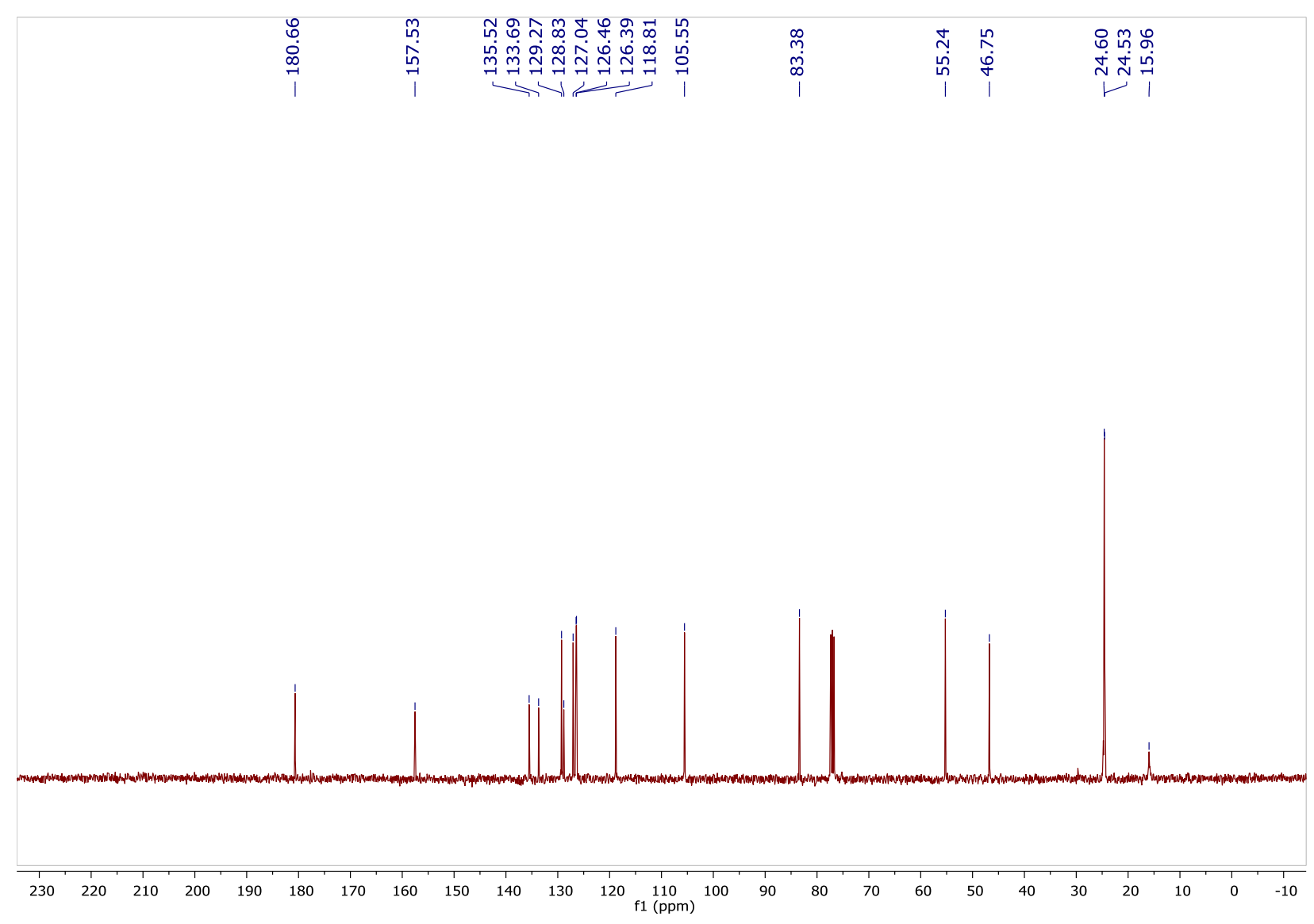


Figure A2.33: 3-boronic acid pinacol ester-2-(6-methoxynaphthalene) propionic acid (2j) ${ }^{11} \mathrm{~B}$ NMR

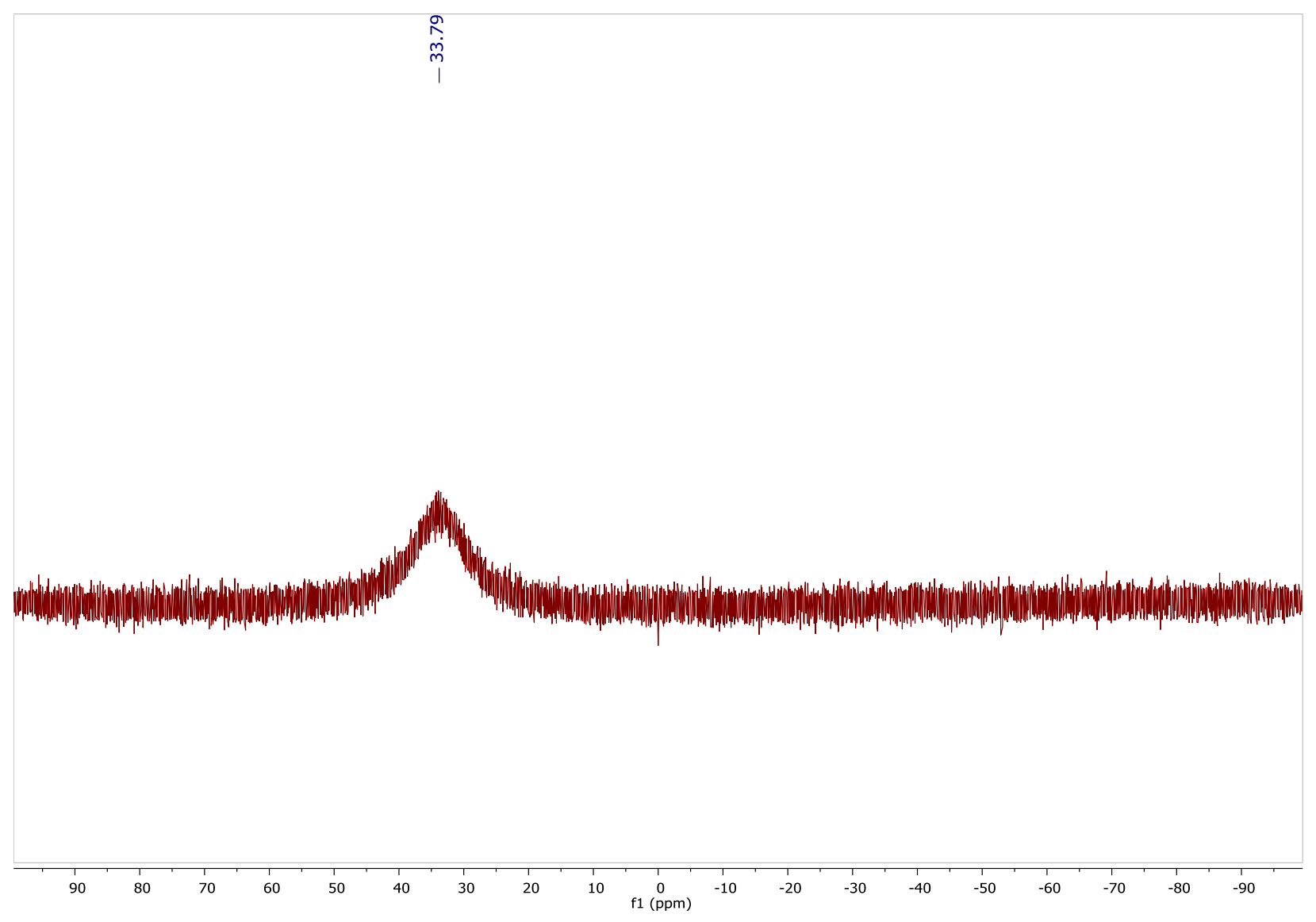


Figure A2.34: 3-boronic acid pinacol ester-2-(3-phenoxyphenyl) propionic acid (2k) - ${ }^{1} \mathrm{H}$ NMR

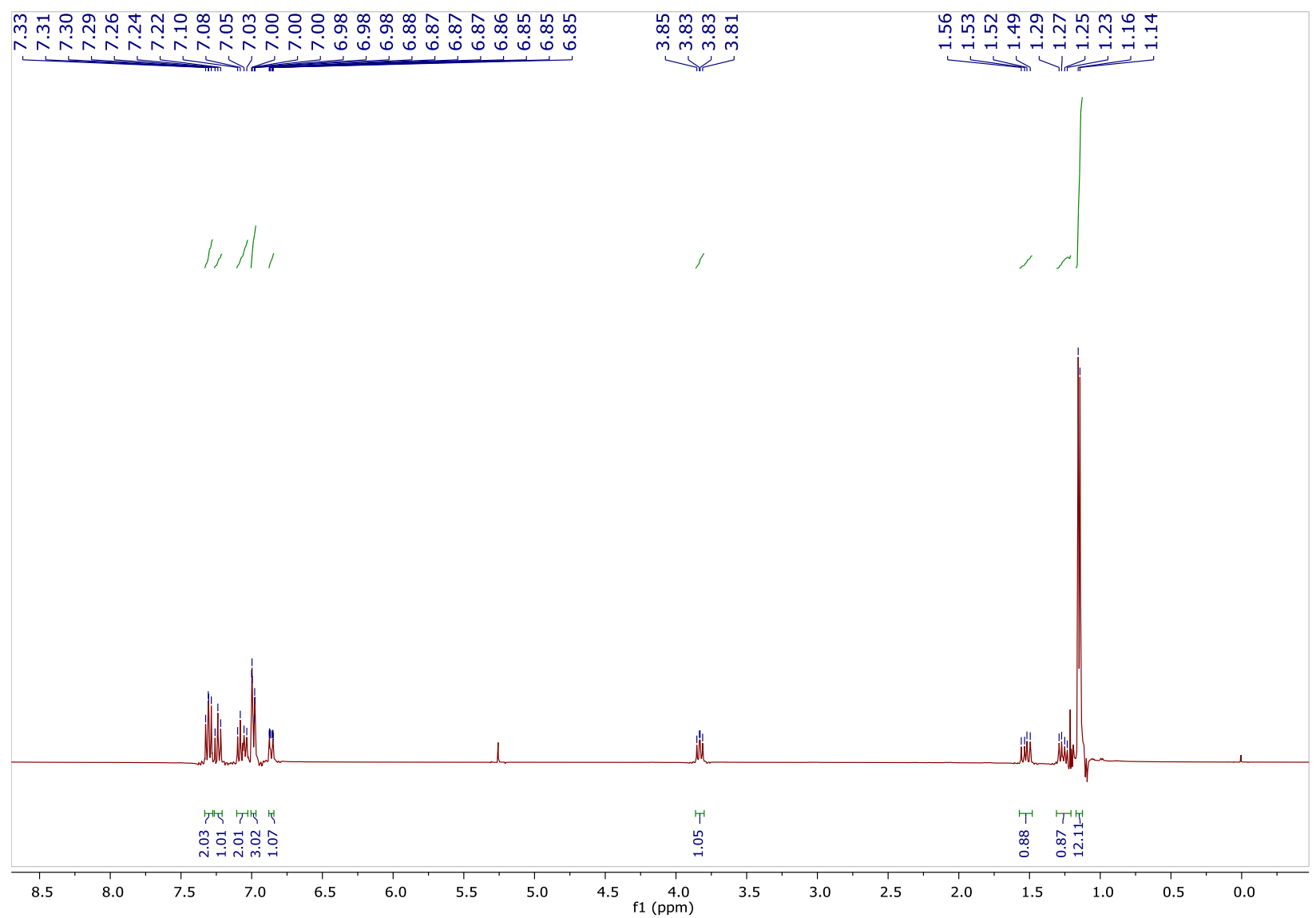


Figure A2.35: 3-boronic acid pinacol ester-2-(3-phenoxyphenyl) propionic acid (2k) - ${ }^{13} \mathrm{C}$ NMR
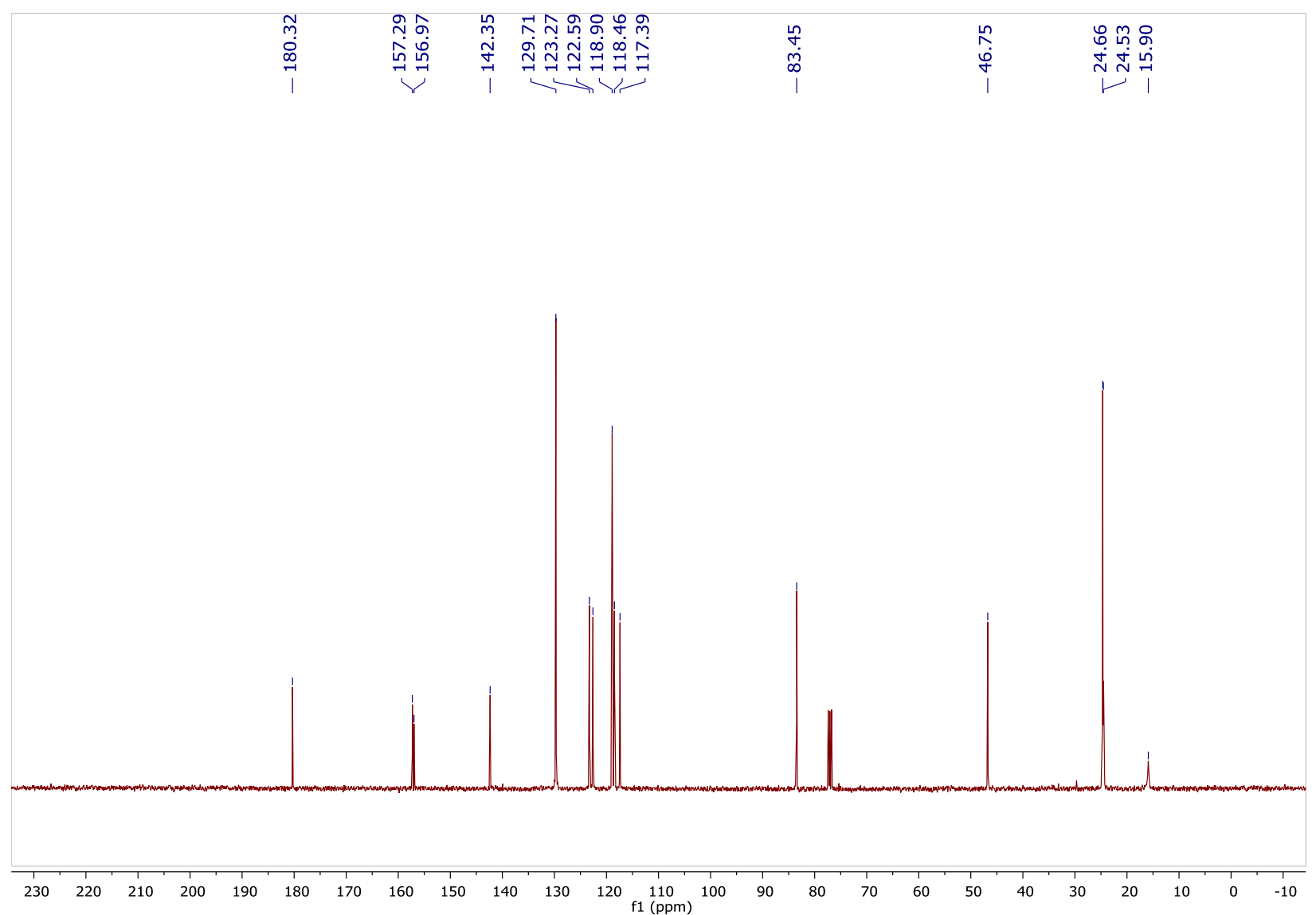
Figure A2.36 3-boronic acid pinacol ester-2-(3-phenoxyphenyl) propionic acid (2k) - ${ }^{11} \mathrm{~B}$ NMR

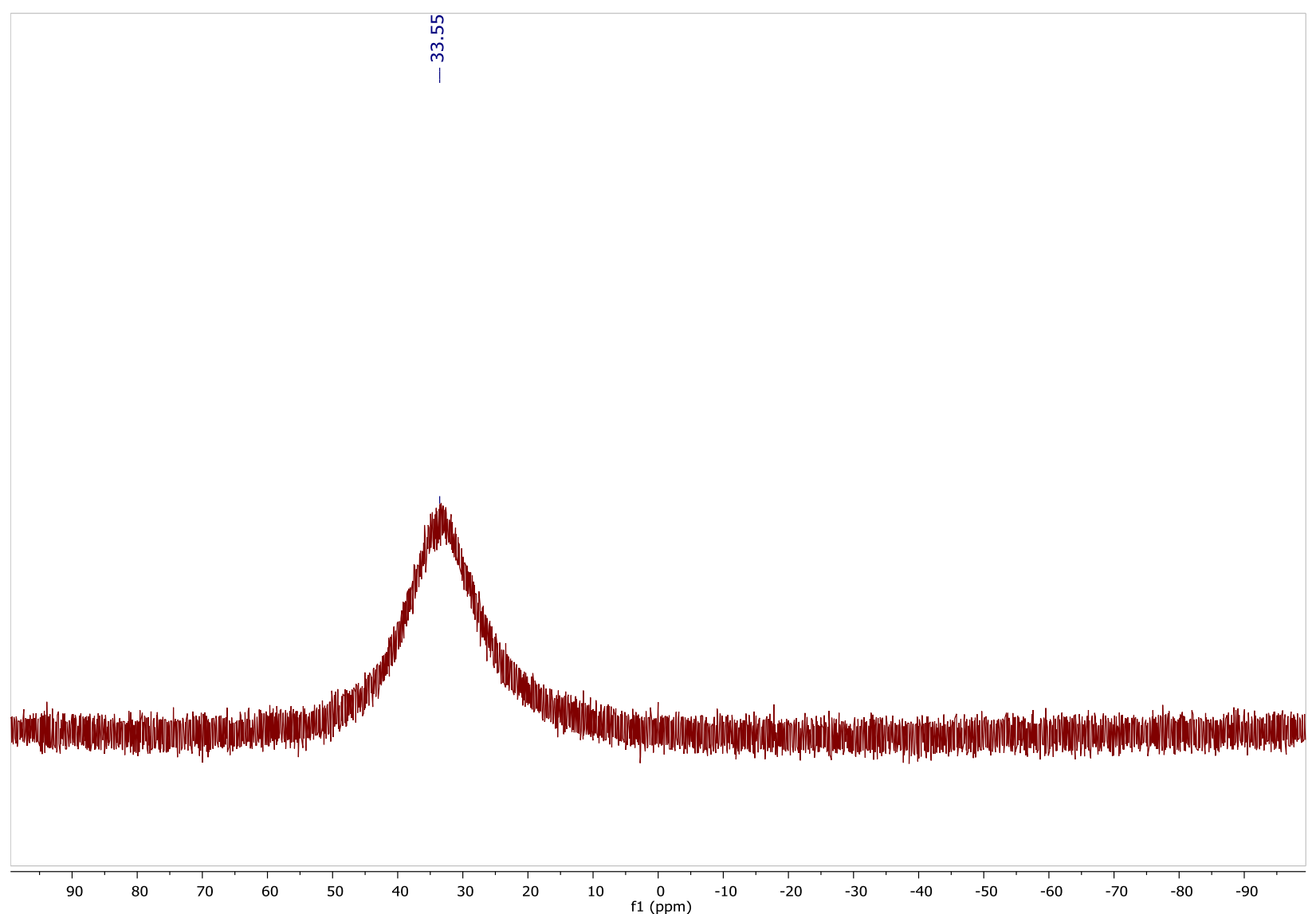


Figure A2.37 3-boronic acid pinacol ester-2-(3-fluorobiphenyl) propionic acid (2l) - ${ }^{1} \mathrm{H}$ NMR

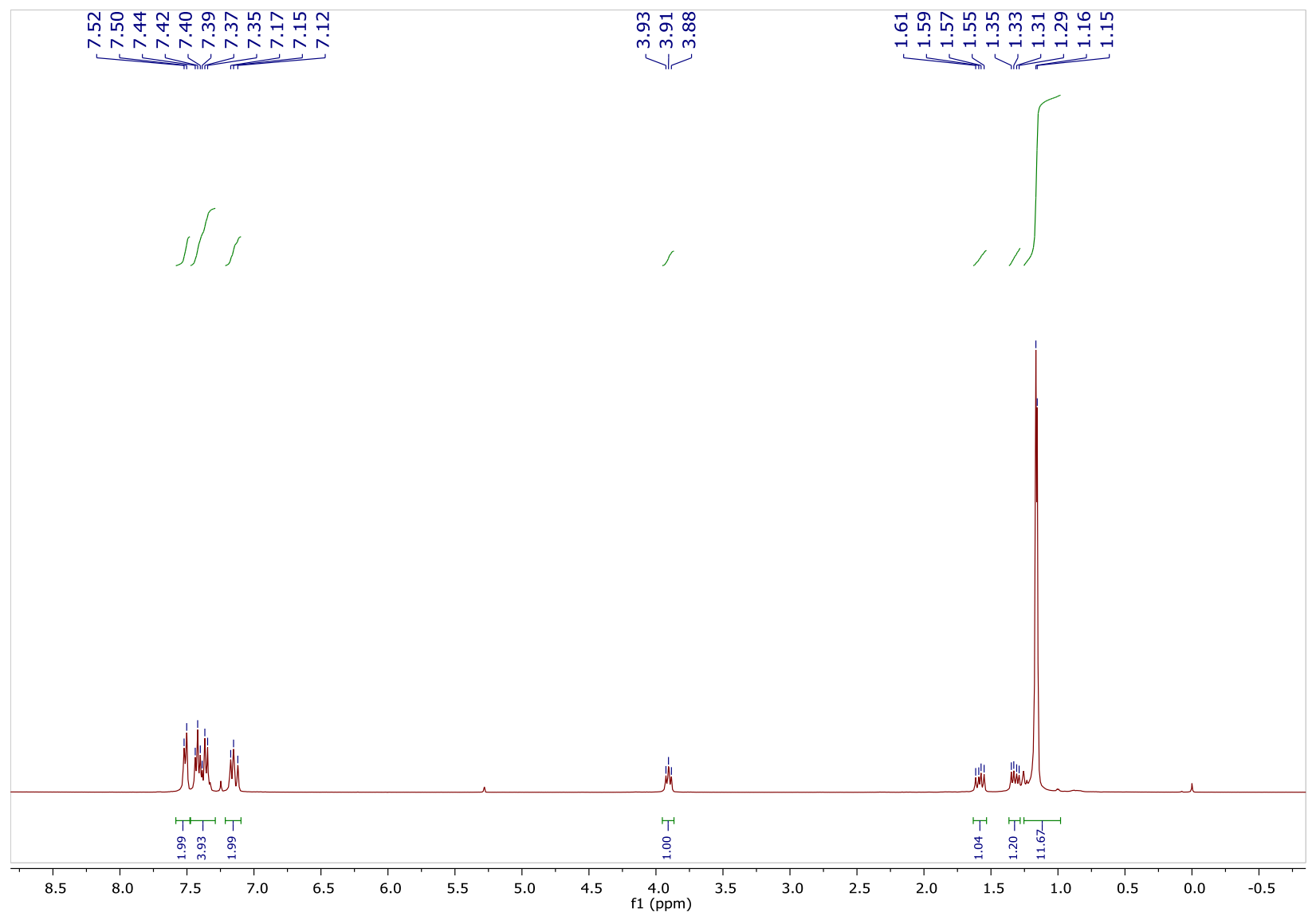


Figure A2.38 3-boronic acid pinacol ester-2-(3-fluorobiphenyl) propionic acid (21) - ${ }^{13} \mathrm{C}$ NMR

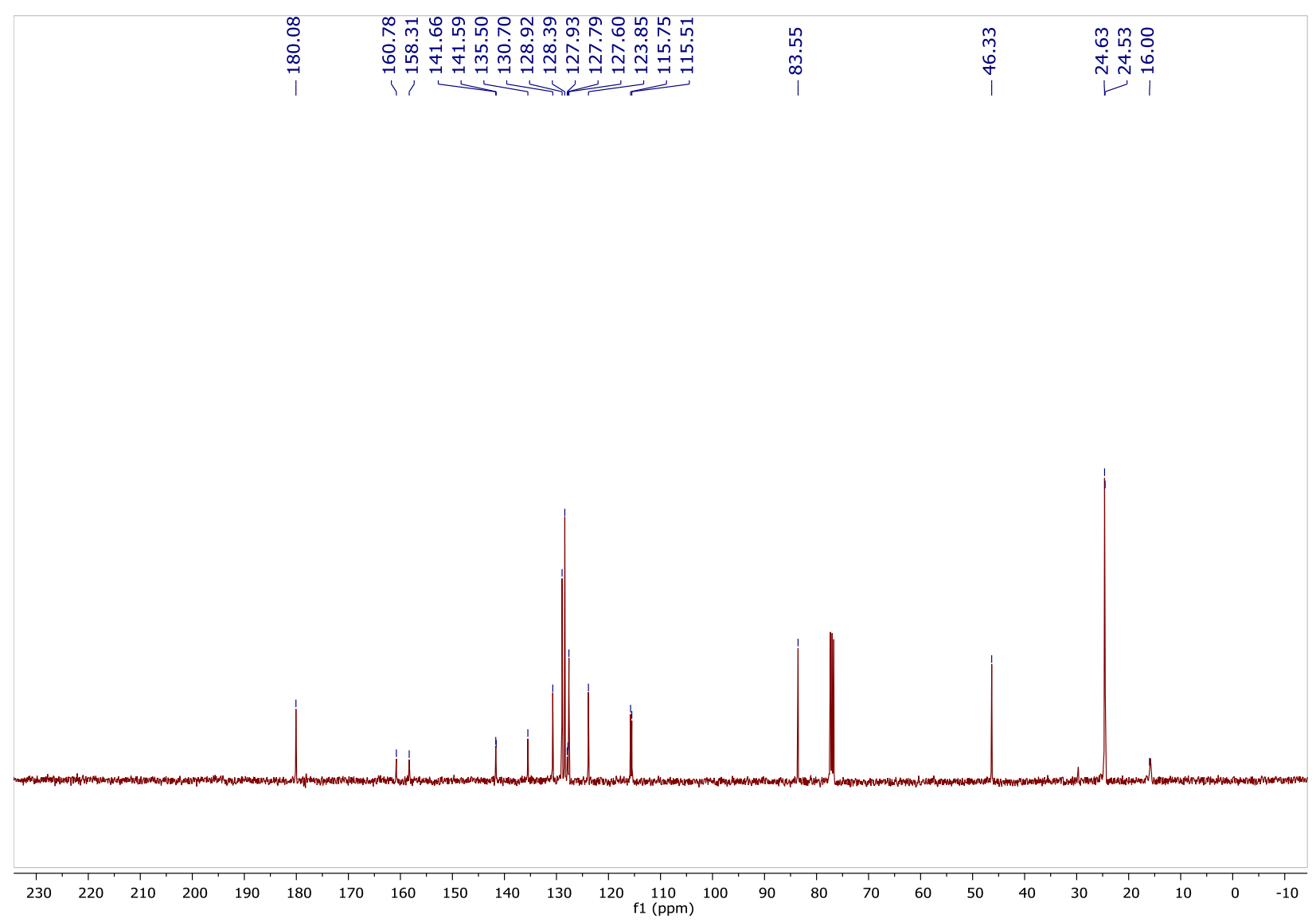


Figure A2.39 3-boronic acid pinacol ester-2-(3-fluorobiphenyl) propionic acid (21) - ${ }^{11} \mathrm{~B}$ NMR

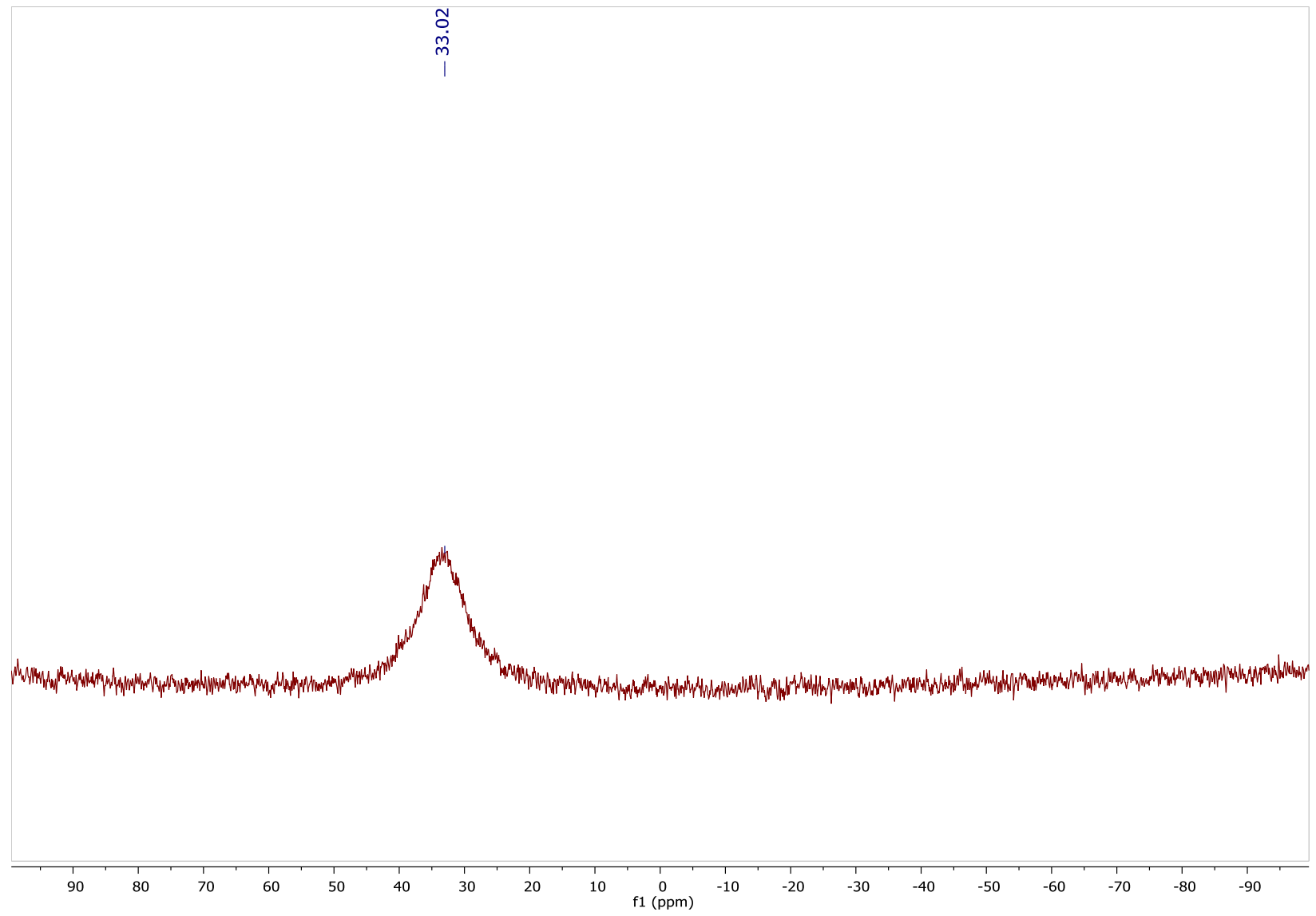


Figure A2.40 3-boronic acid pinacol ester-2-(3-fluorobiphenyl) propionic acid (21) - ${ }^{19} \mathrm{~F}$ NMR

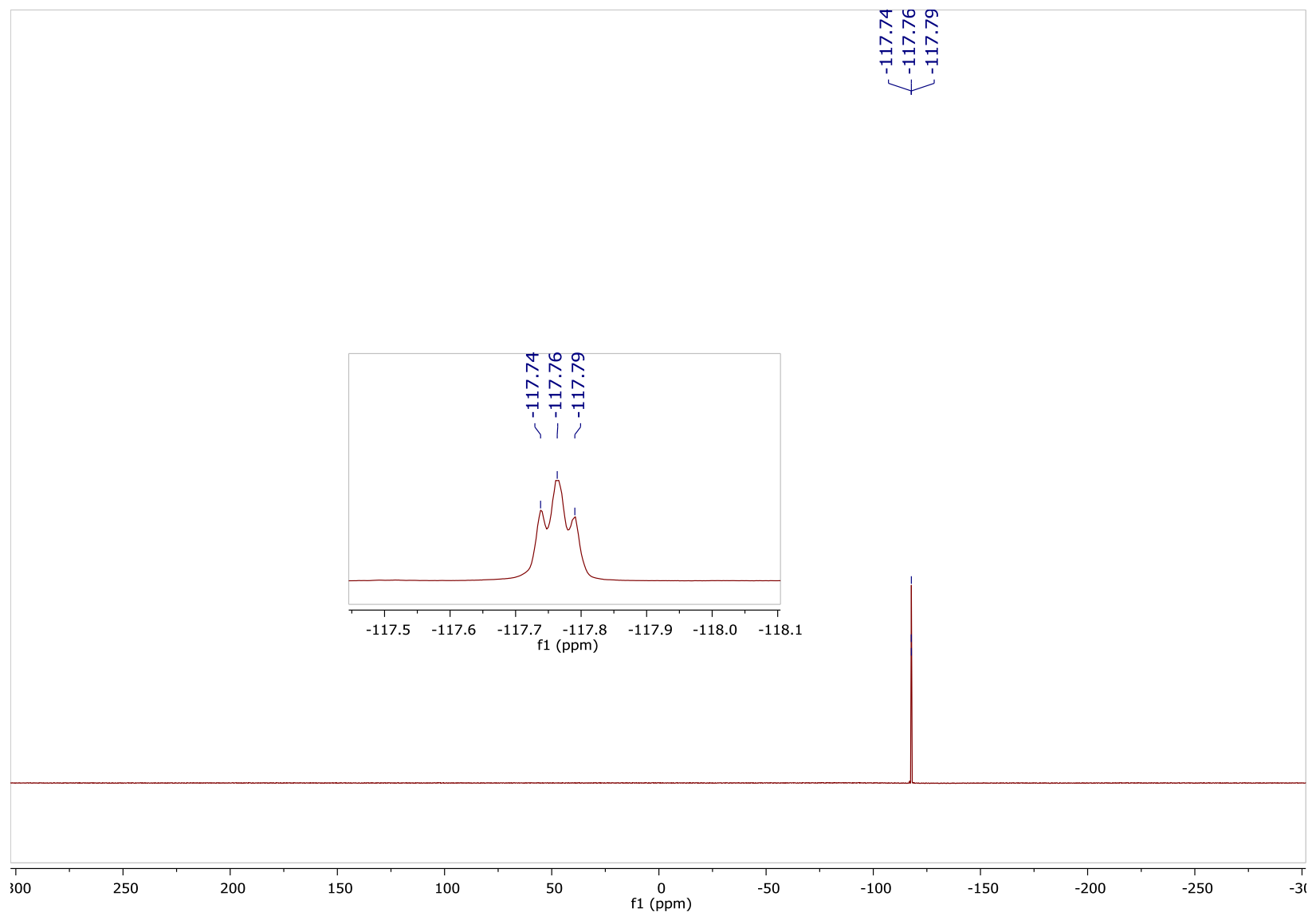


Figure A2.41 3-boronic acid pinacol ester-2-(4-trifluoromethylphenyl) propionic acid (2m) ${ }^{1} \mathrm{H}$ NMR

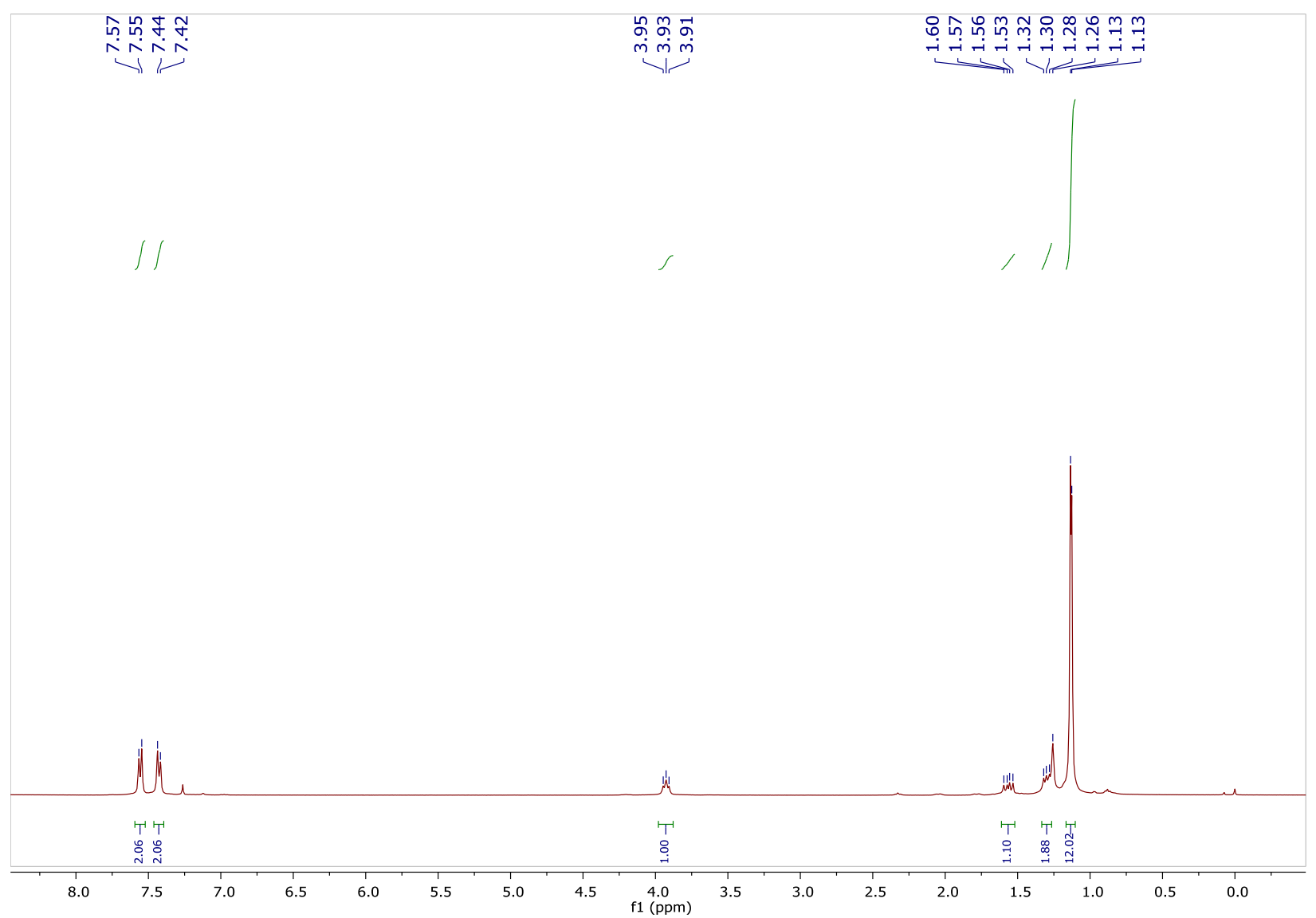


Figure A2.42 3-boronic acid pinacol ester-2-(4-trifluoromethylphenyl) propionic acid (2m) ${ }^{13} \mathrm{C}$ NMR

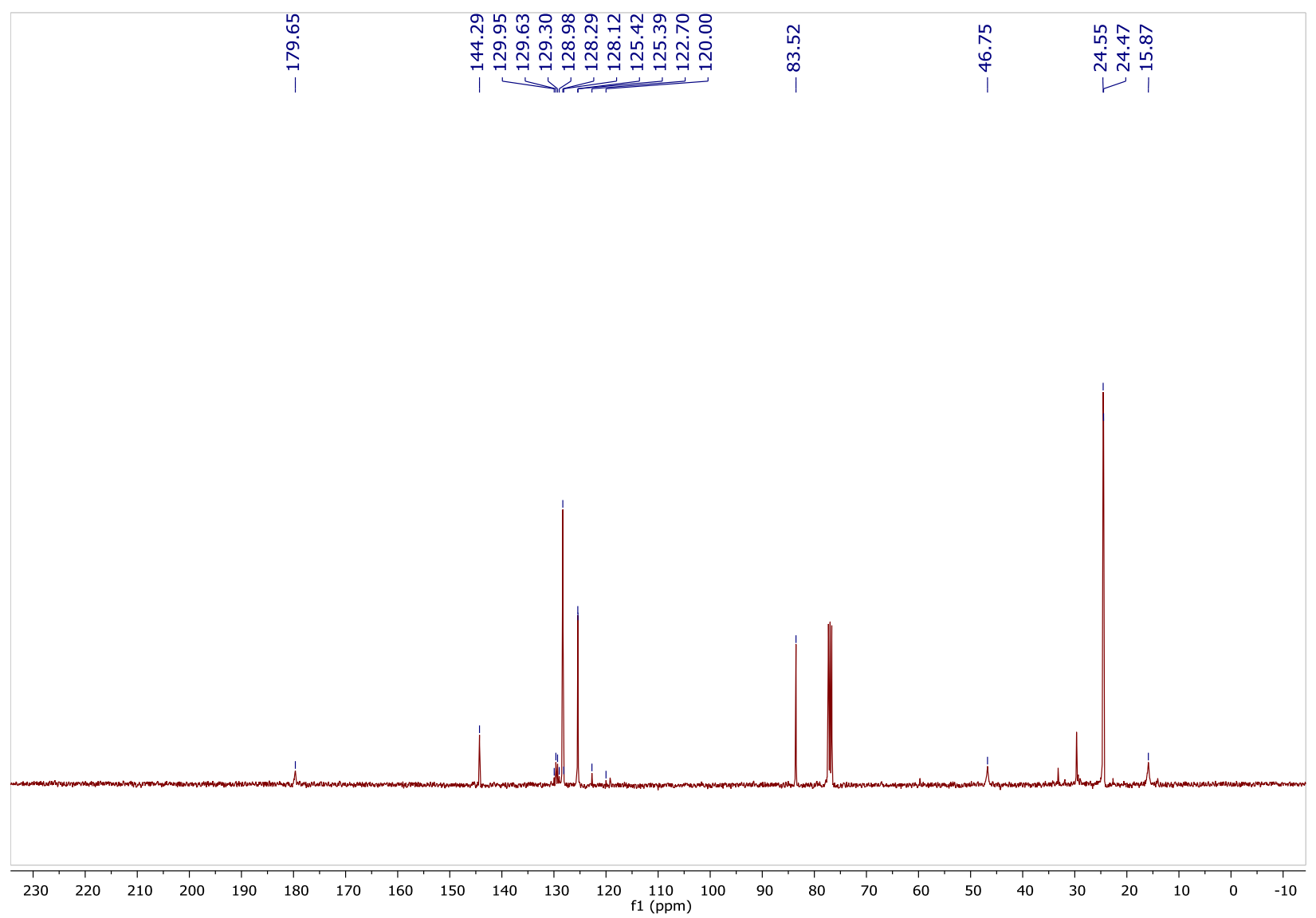


Figure A2.43 3-boronic acid pinacol ester-2-(4-trifluoromethylphenyl) propionic acid (2m) ${ }^{11}$ B NMR

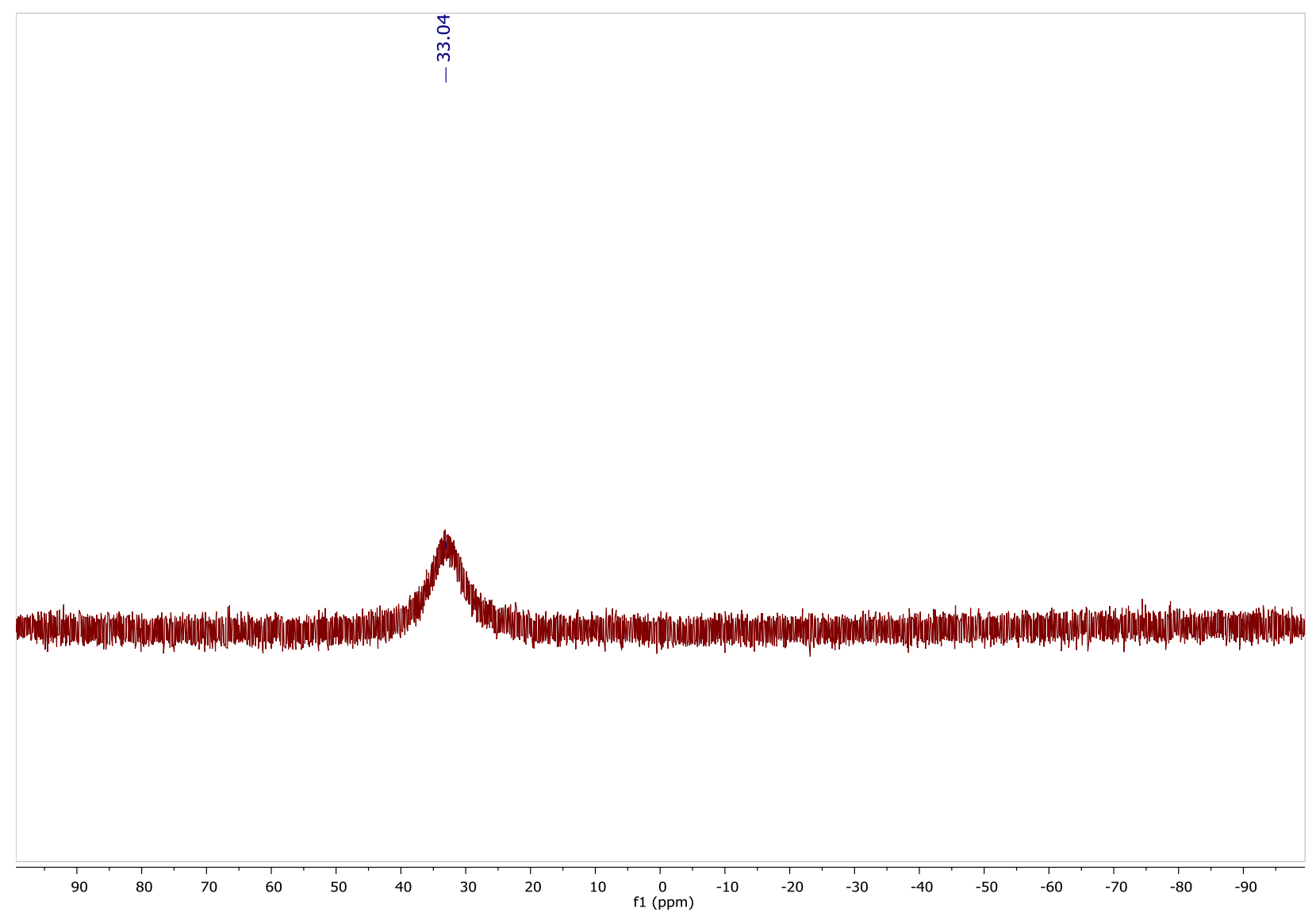


Figure A2.44 3-boronic acid pinacol ester-2-(4-trifluoromethylphenyl) propionic acid (2m) ${ }^{19}$ F NMR

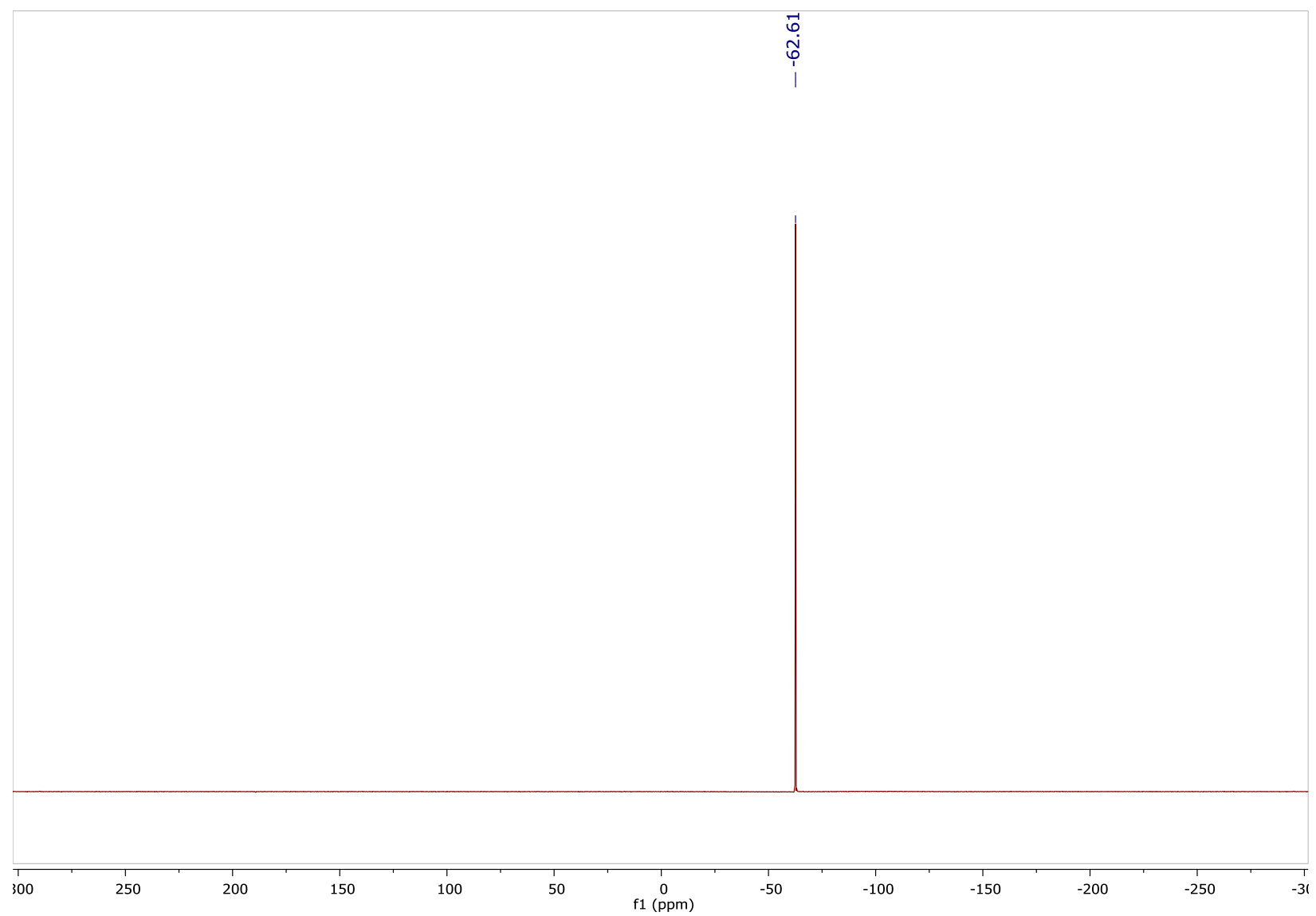


Figure A2.45 3-boronic acid pinacol ester-2-(4-cyanophenyl) propionic acid (2n) - ${ }^{1} \mathrm{H}$ NMR

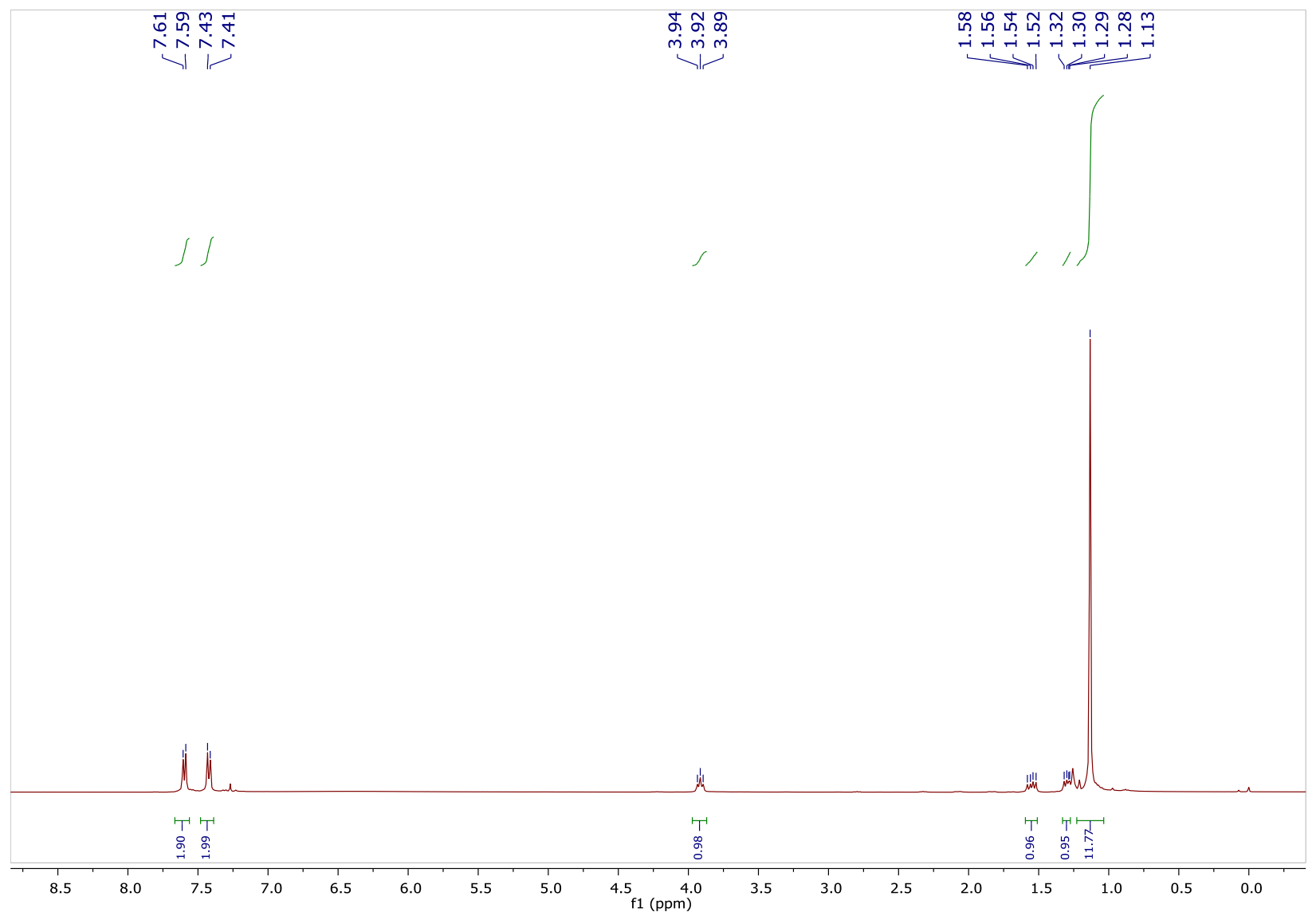


Figure A2.46 3-boronic acid pinacol ester-2-(4-cyanophenyl) propionic acid (2n) $-{ }^{13} \mathrm{C}$ NMR

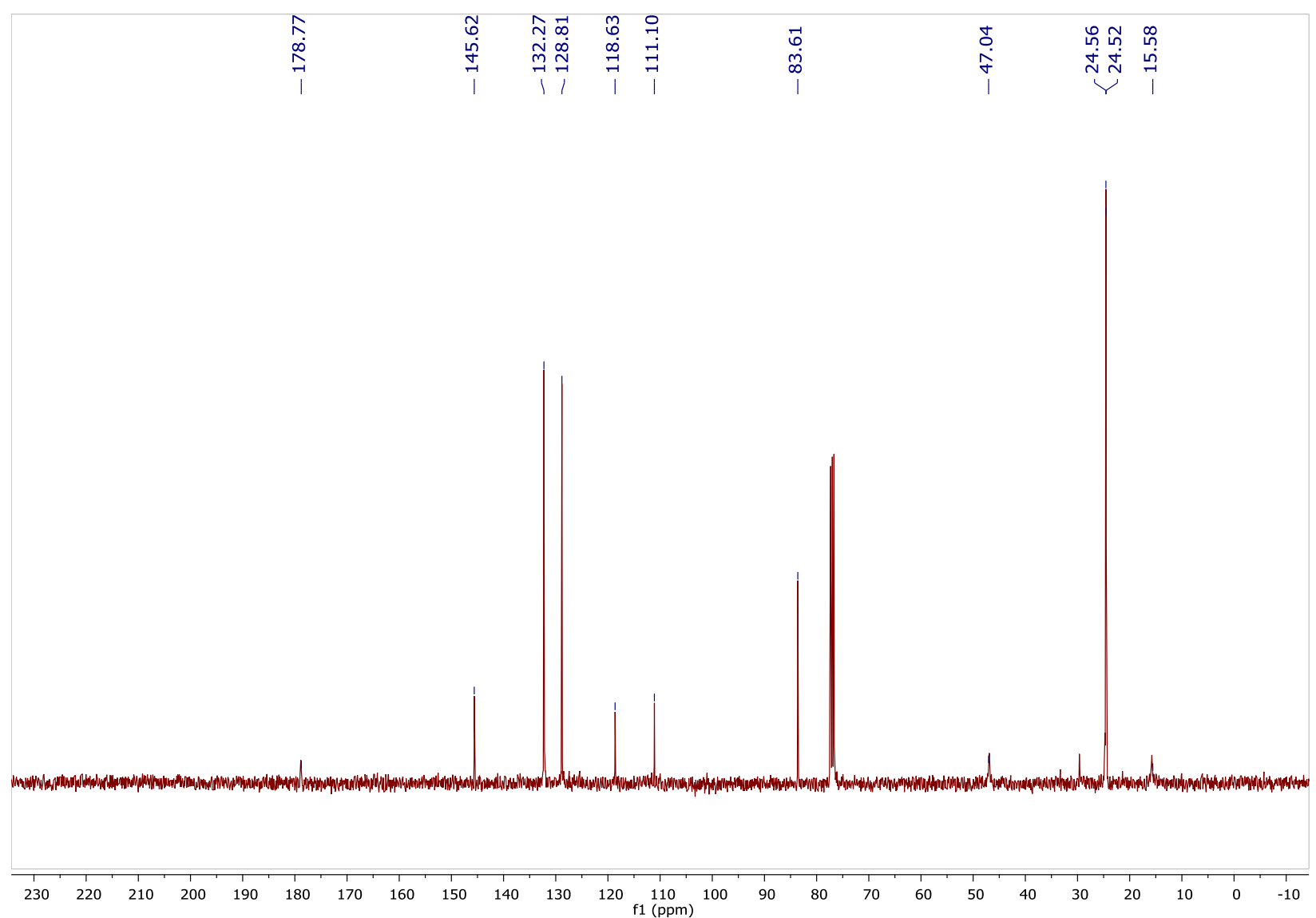


Figure A2.47 3-boronic acid pinacol ester-2-(4-cyanophenyl) propionic acid (2n) - ${ }^{11}$ B NMR

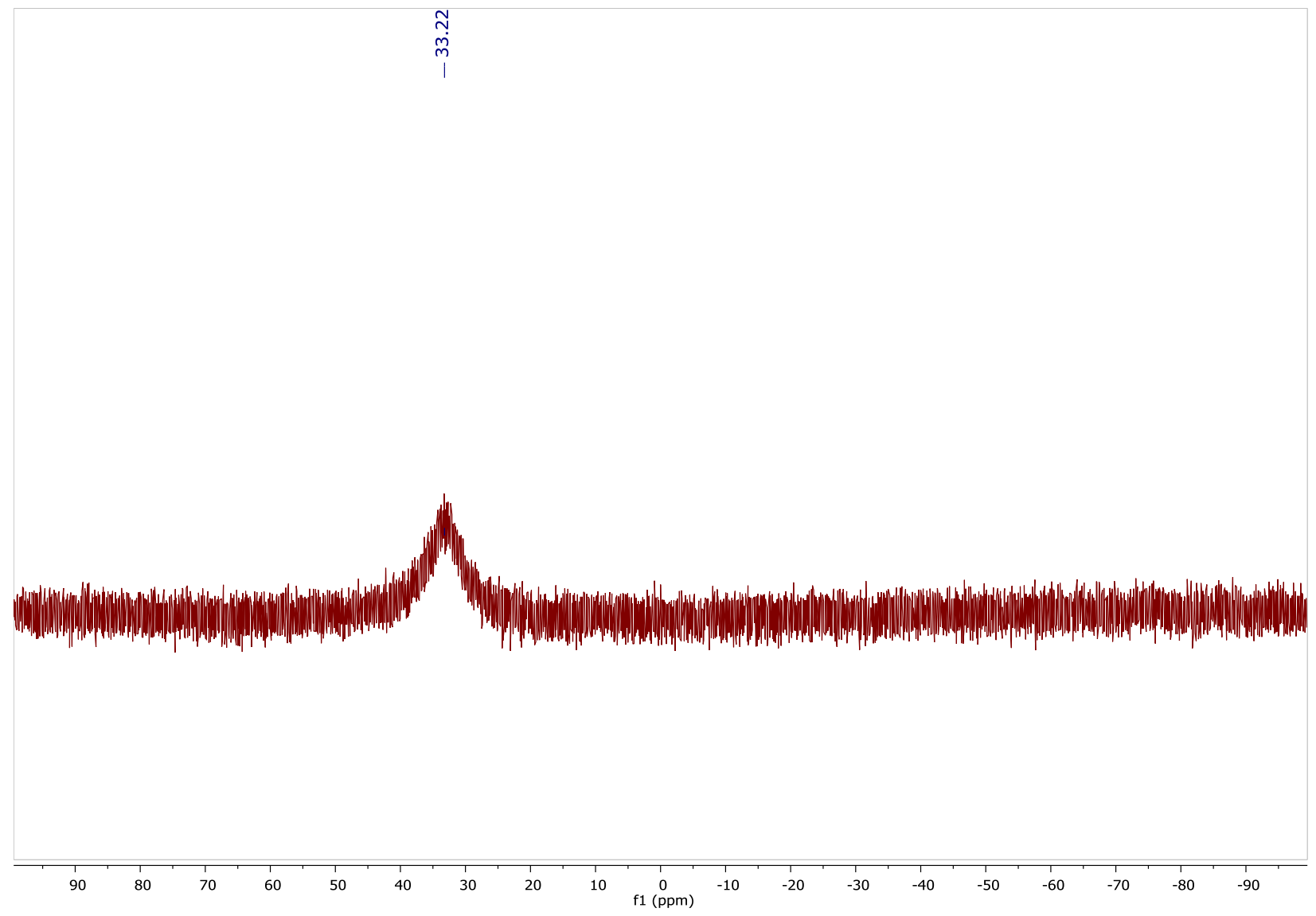


Figure A2.48 3-boronic acid pinacol ester-2-(4-acetoxyphenyl) propionic acid (2o) - ${ }^{1} \mathrm{H}$ NMR

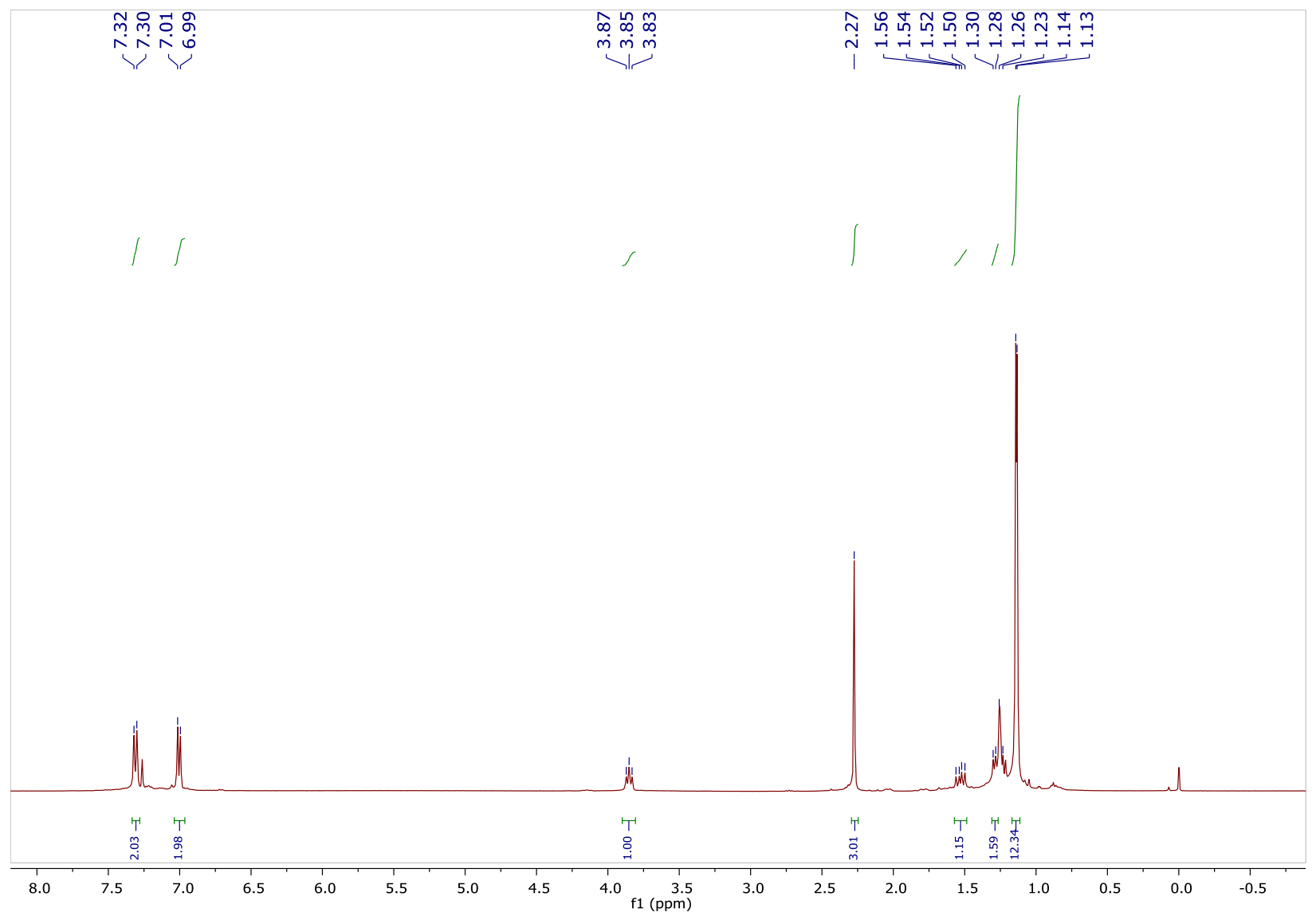


Figure A2.49 3-boronic acid pinacol ester-2-(4-acetoxyphenyl) propionic acid (2o) - ${ }^{13} \mathrm{C}$ NMR

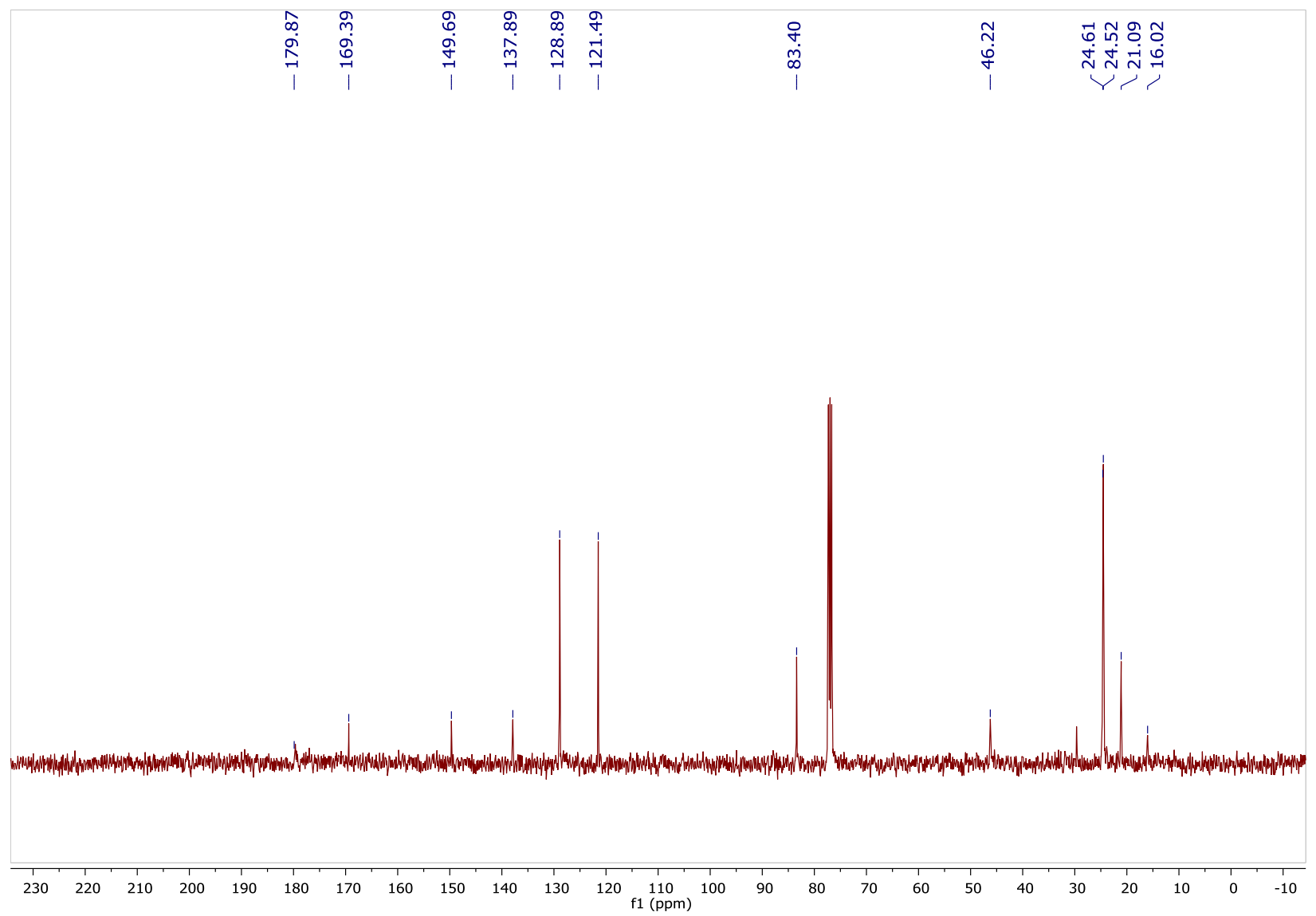


Figure A2.50 3-boronic acid pinacol ester-2-(4-acetoxyphenyl) propionic acid (2o) - ${ }^{11} \mathrm{~B}$ NMR

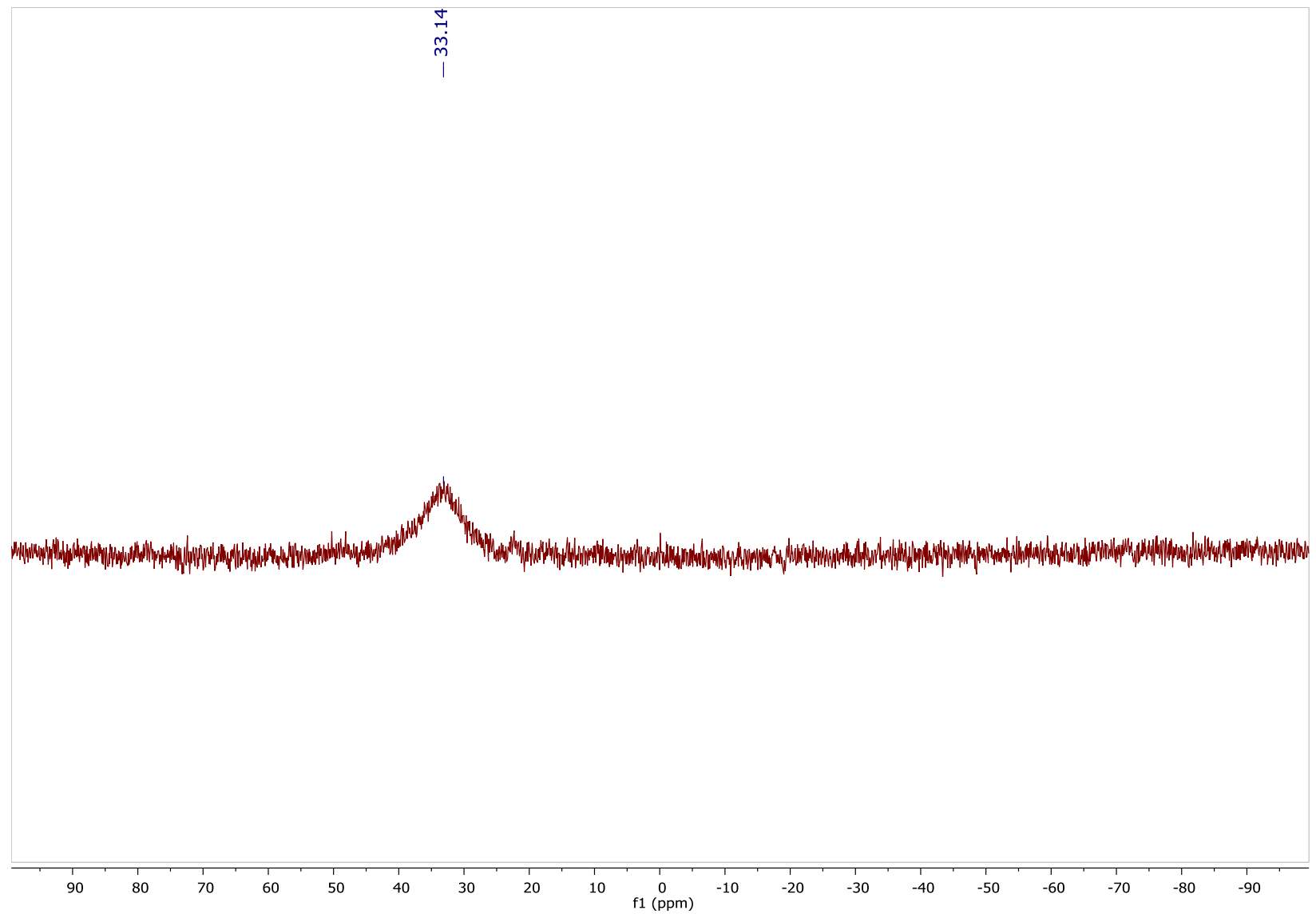


Figure A2.51 3-boronic acid pinacol ester-2-naphthyl propionic acid (2t) - ${ }^{1} \mathrm{H}$ NMR

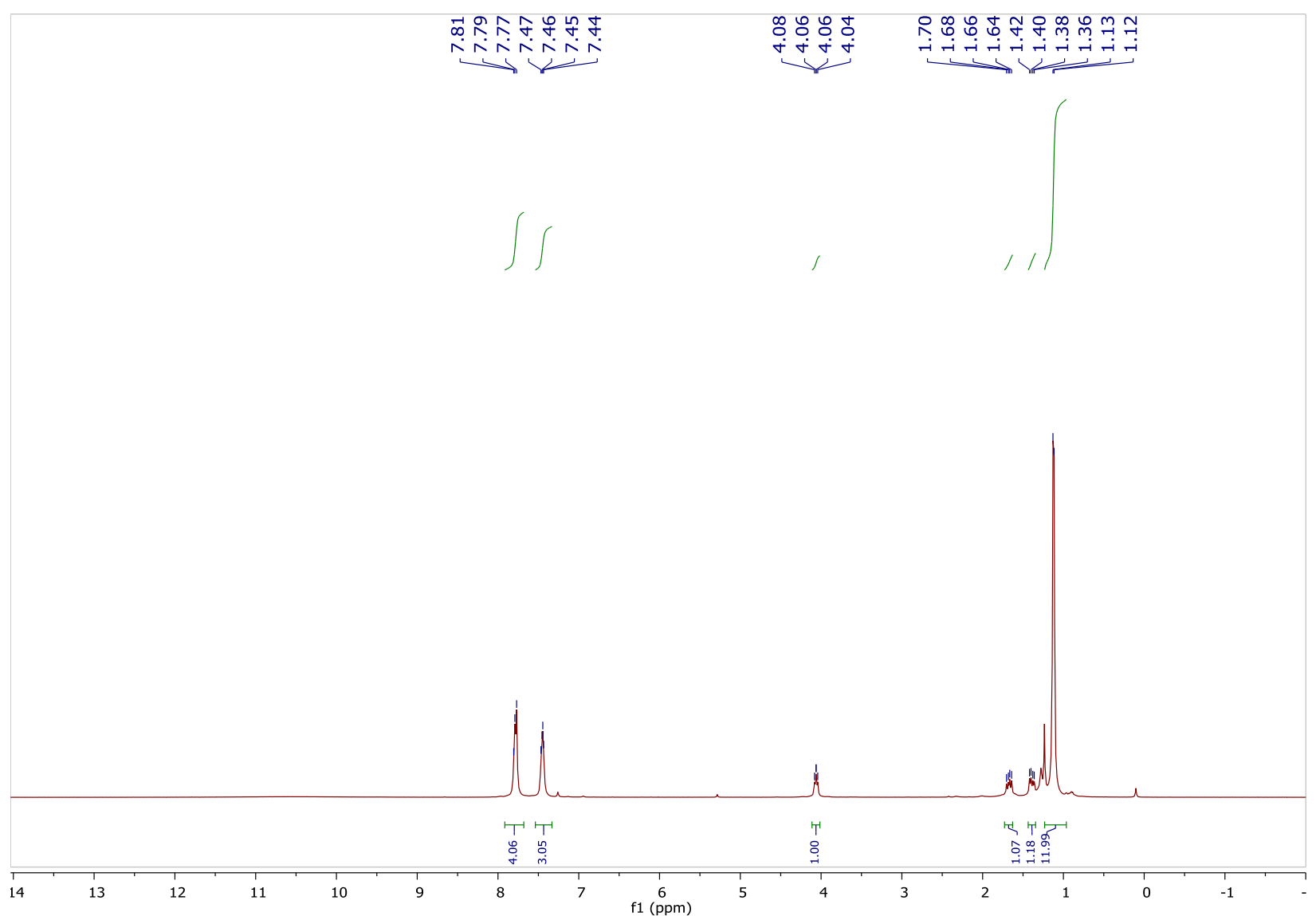


Figure A2.52 3-boronic acid pinacol ester-2-naphthyl propionic acid $(2 \mathrm{t})-{ }^{13} \mathrm{C}$ NMR

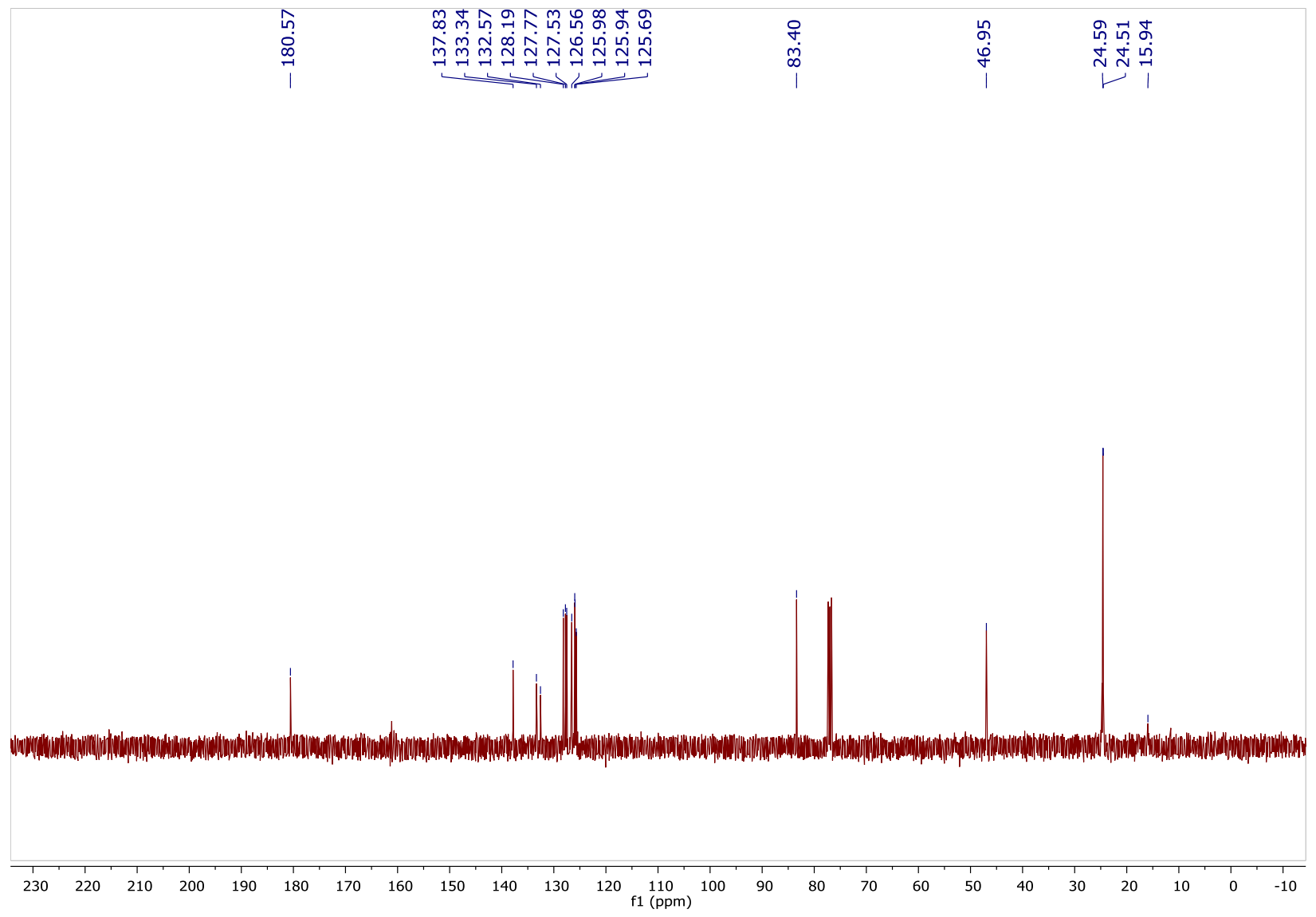


Figure A2.53 3-boronic acid pinacol ester-2-naphthyl propionic acid (2t) - ${ }^{11} \mathrm{~B}$ NMR

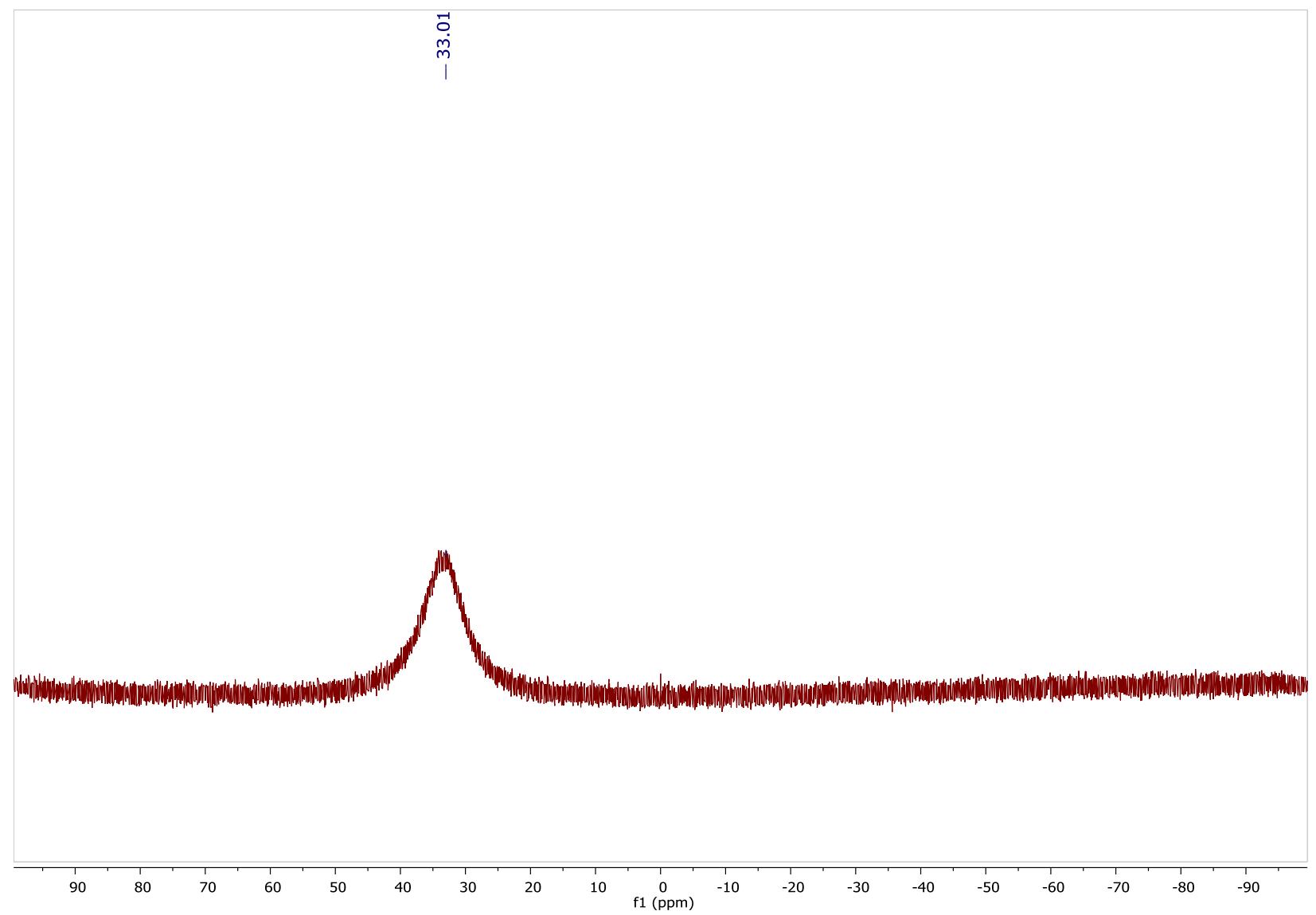


Figure A2.54 3-fluoro-2-phenyl propionic acid (5a) - ${ }^{1} \mathrm{H}$ NMR

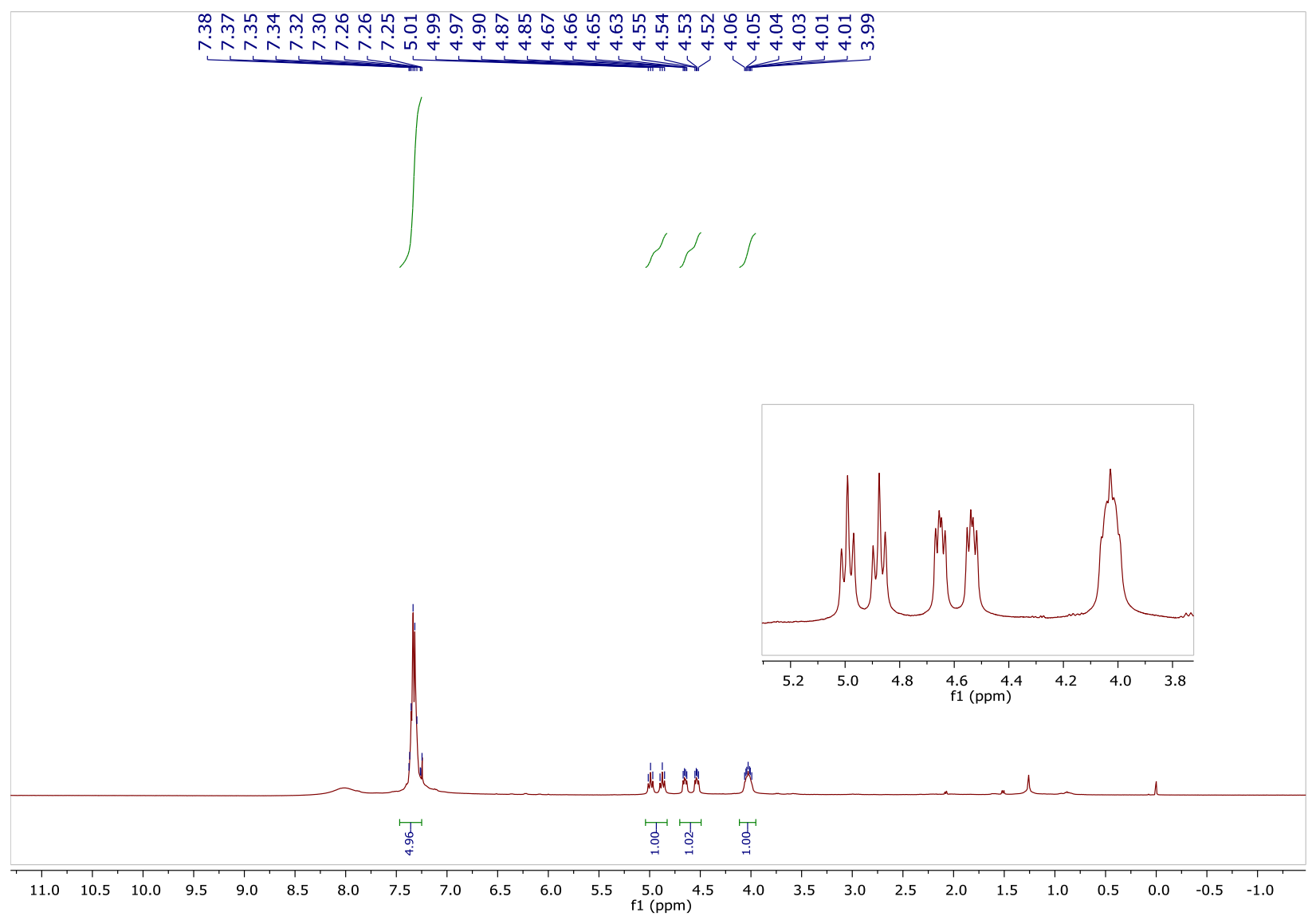


Figure A2.55 3-fluoro-2-phenyl propionic acid (5a) - ${ }^{13} \mathrm{C}$ NMR

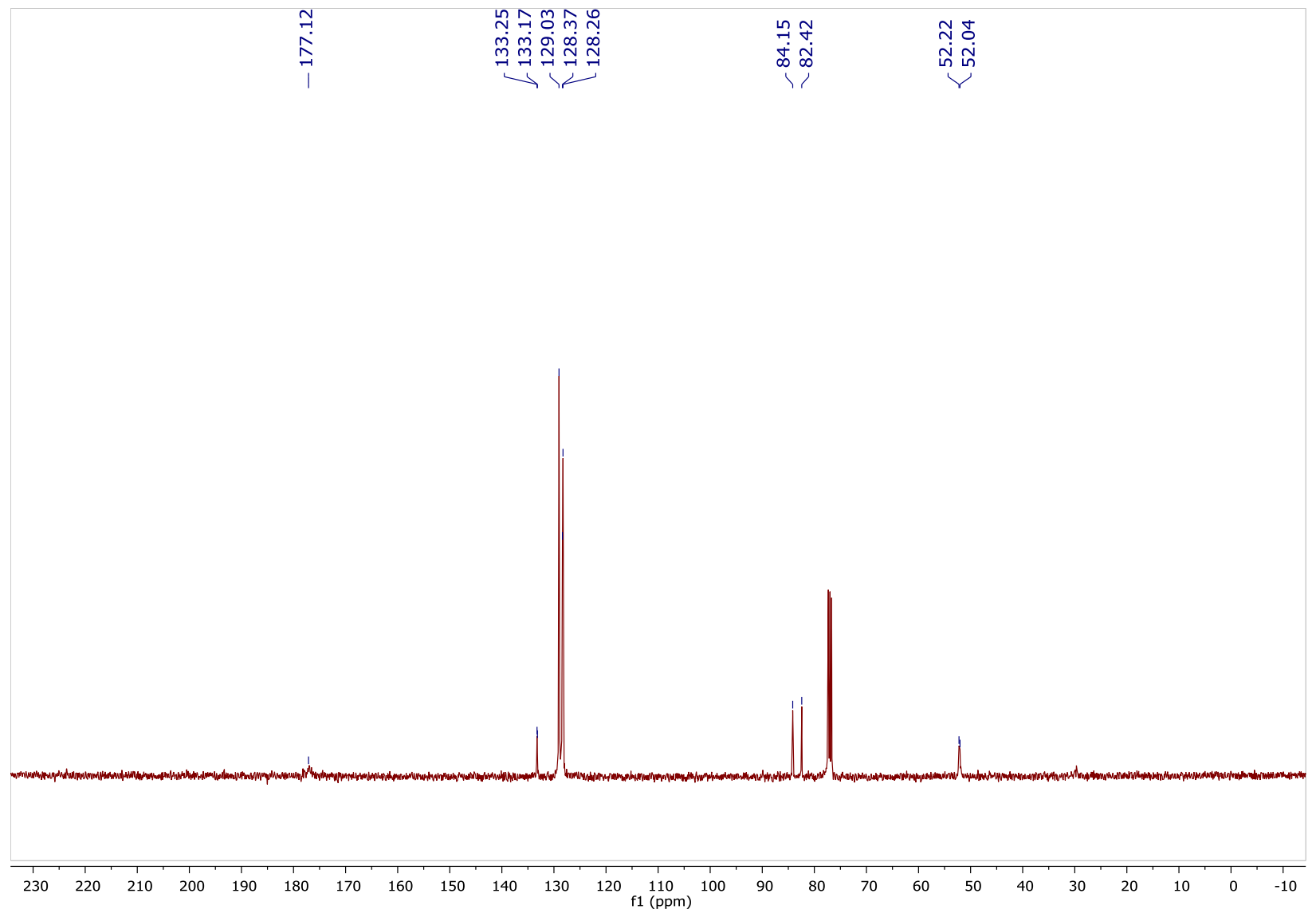


Figure A2.56 3-fluoro-2-phenyl propionic acid (5a) - ${ }^{19}$ F NMR

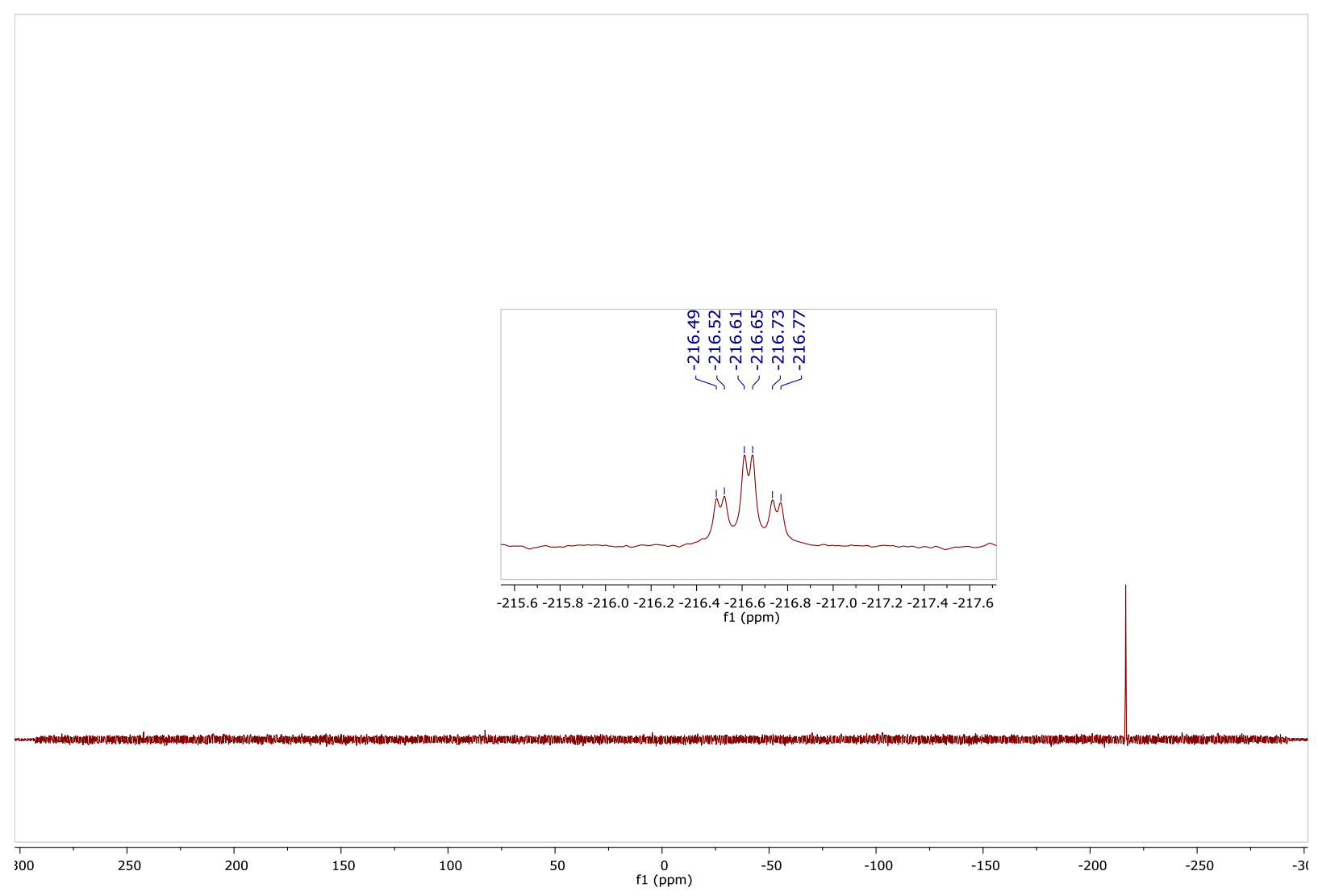


Figure A2.57 3-fluoro-2-(4-tertbutylphenyl) propionic acid (5b) - ${ }^{1} \mathrm{H}$ NMR

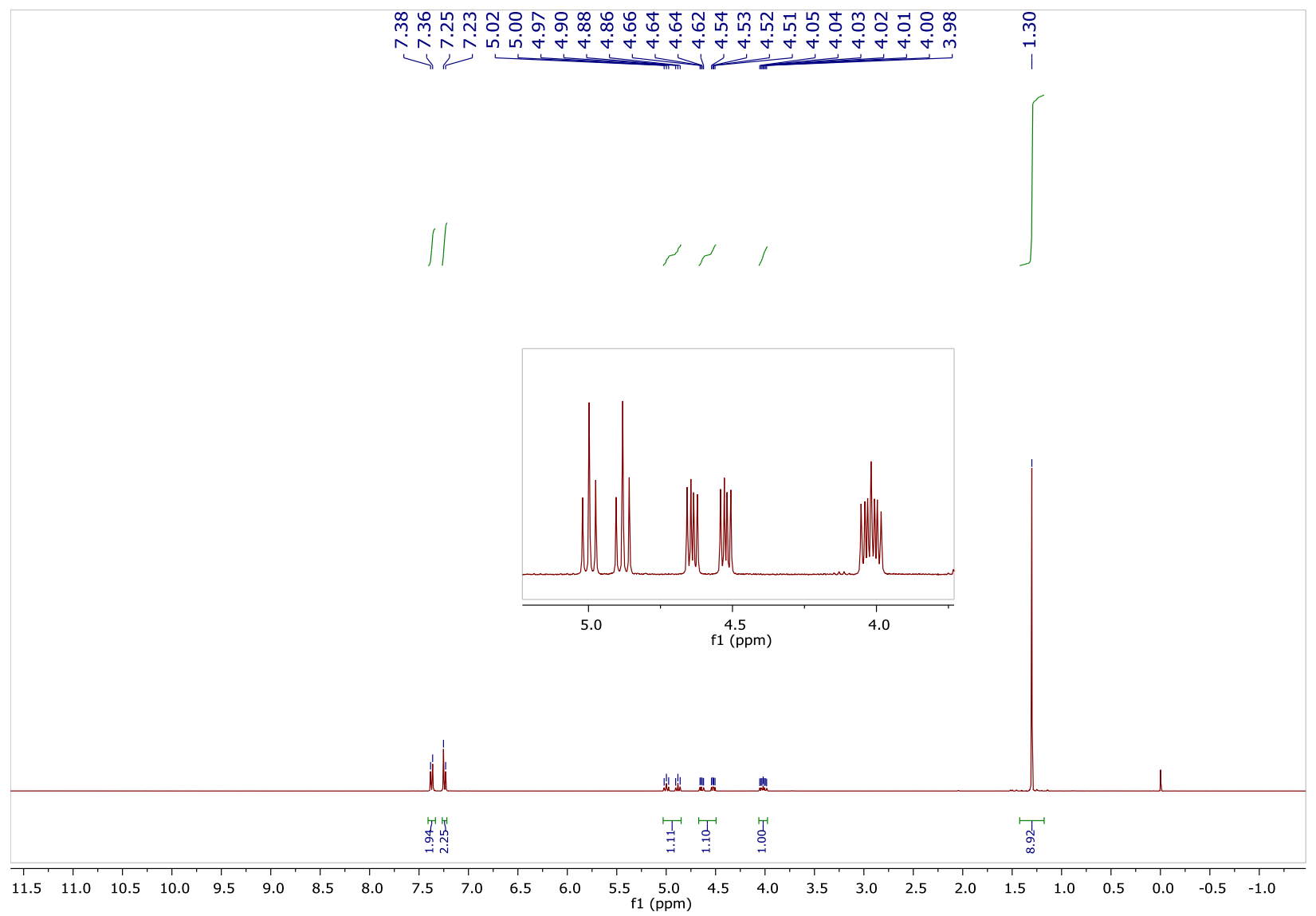


Figure A2.58 3-fluoro-2-(4-tertbutylphenyl) propionic acid (5b) $-{ }^{13} \mathrm{C}$ NMR

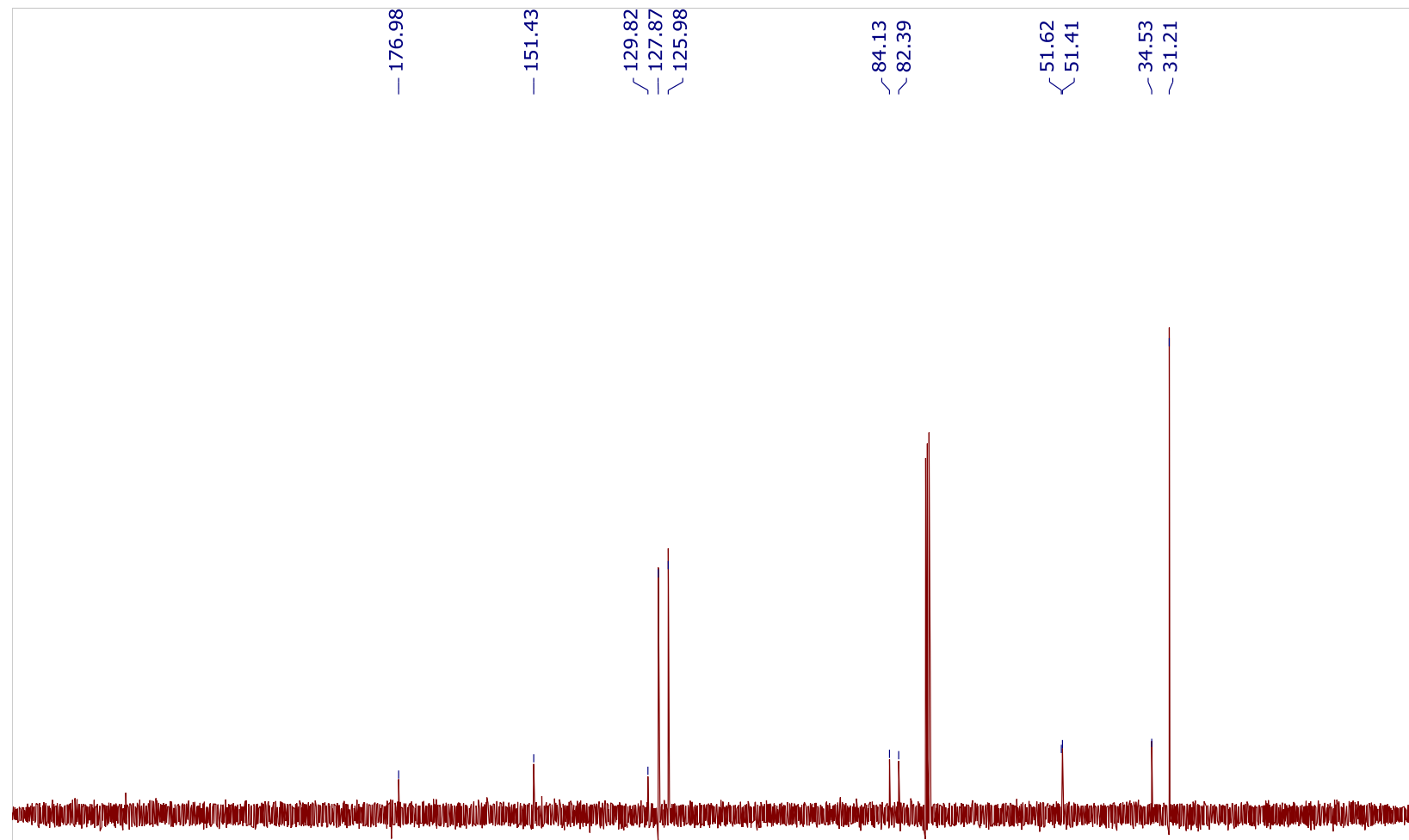

$\begin{array}{llllllllllllllllllllllllllllllllllllllllll}50 & 240 & 230 & 220 & 210 & 200 & 190 & 180 & 170 & 160 & 150 & 140 & 130 & 120 & 110 & 100 & 90 & 80 & 70 & 60 & 50 & 40 & 30 & 20 & 10 & 0 & -10\end{array}$ 
Figure A2.59 3-fluoro-2-(4-tertbutylphenyl) propionic acid (5b) - ${ }^{19} \mathrm{~F}$ NMR

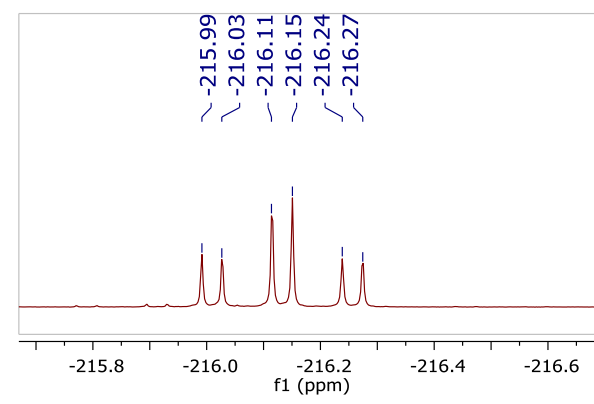

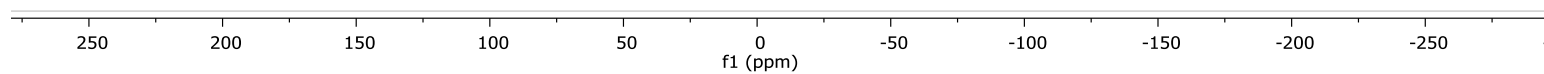


Figure A2.60 3-fluoro-2-(4-methylphenyl) propionic acid (5c) - ${ }^{1} \mathrm{H}$ NMR

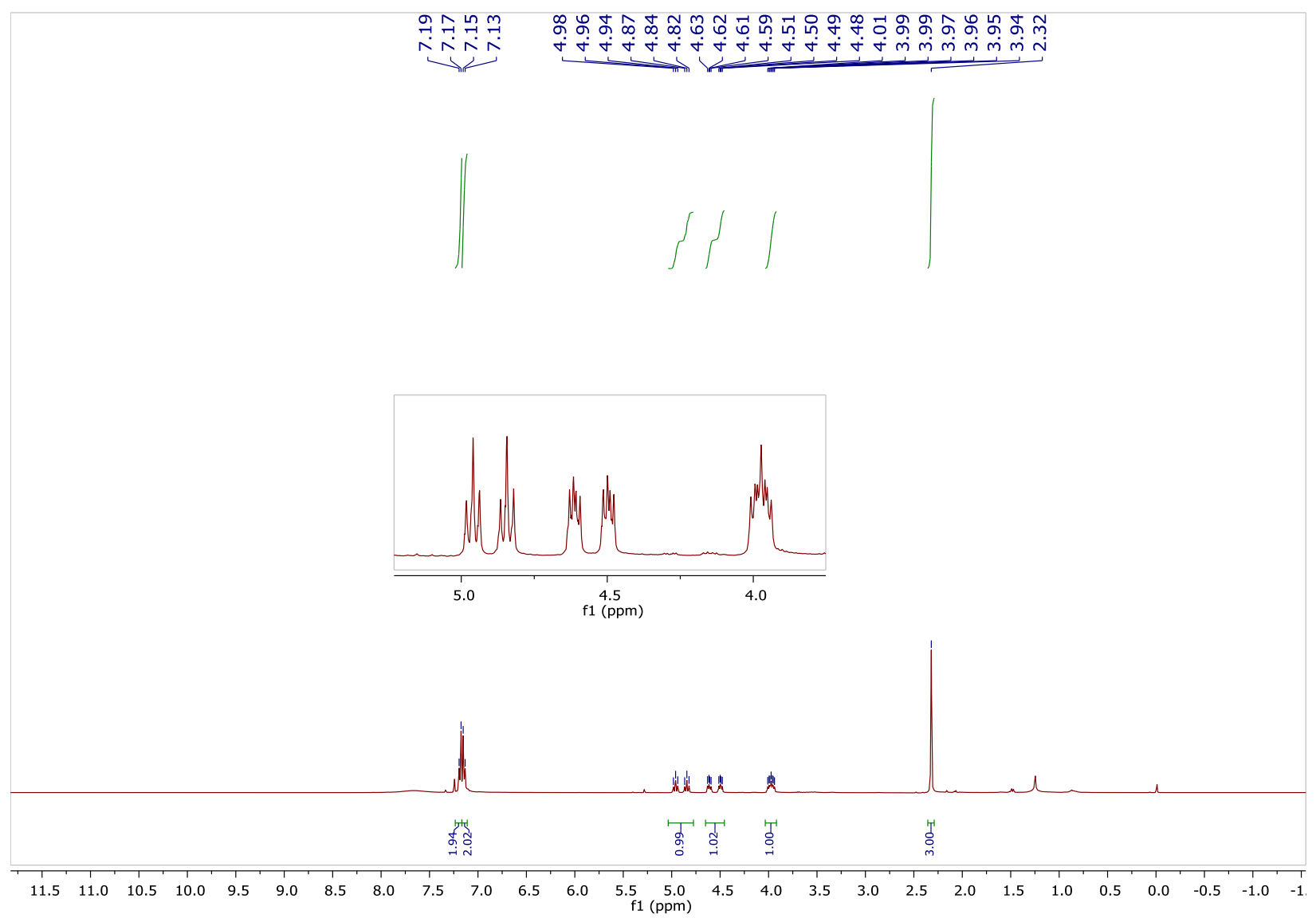


Figure A2.61 3-fluoro-2-(4-methylphenyl) propionic acid (5c) - ${ }^{13} \mathrm{C}$ NMR

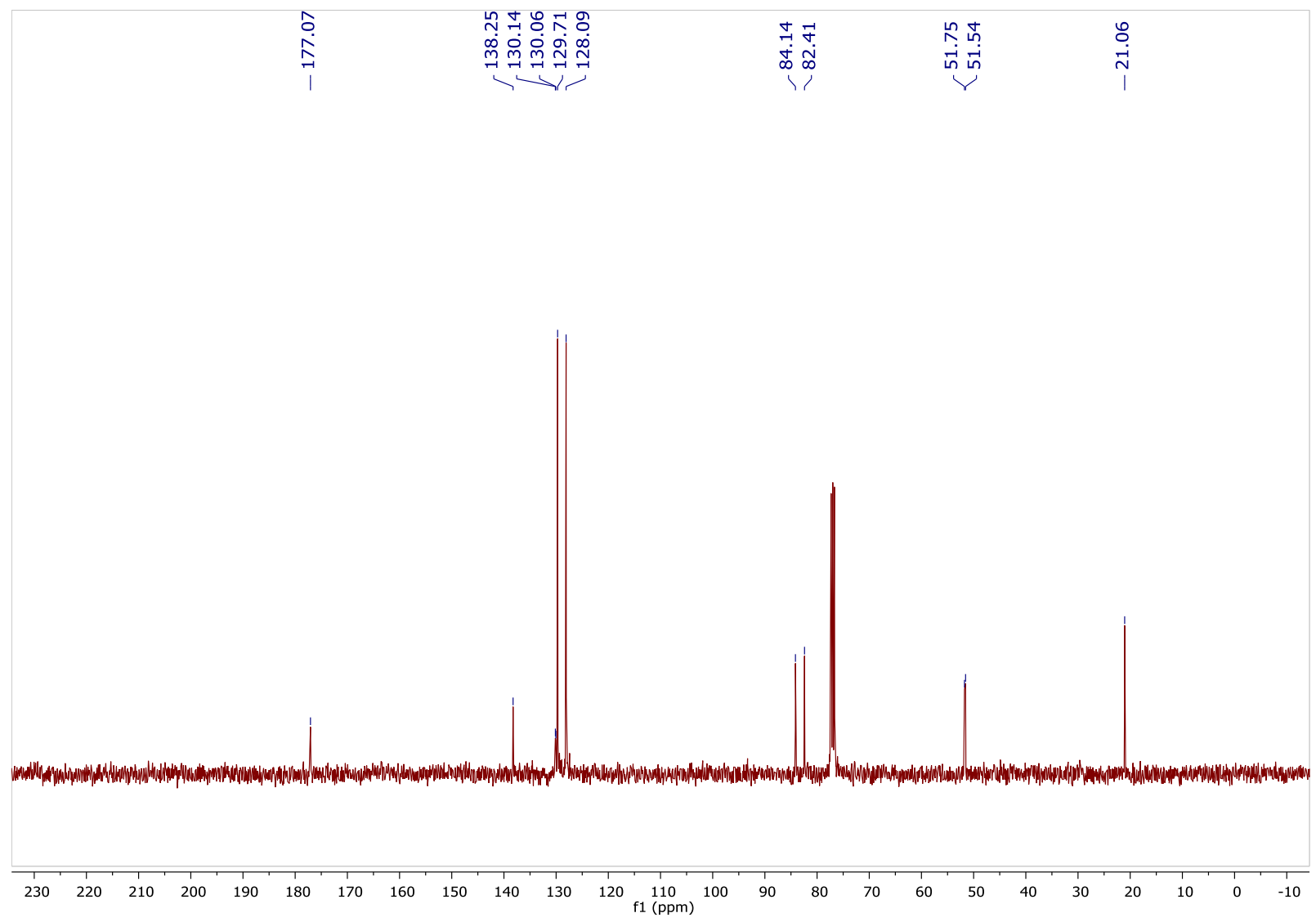


Figure A2.62 3-fluoro-2-(4-methylphenyl) propionic acid (5c) - ${ }^{19} \mathrm{~F}$ NMR

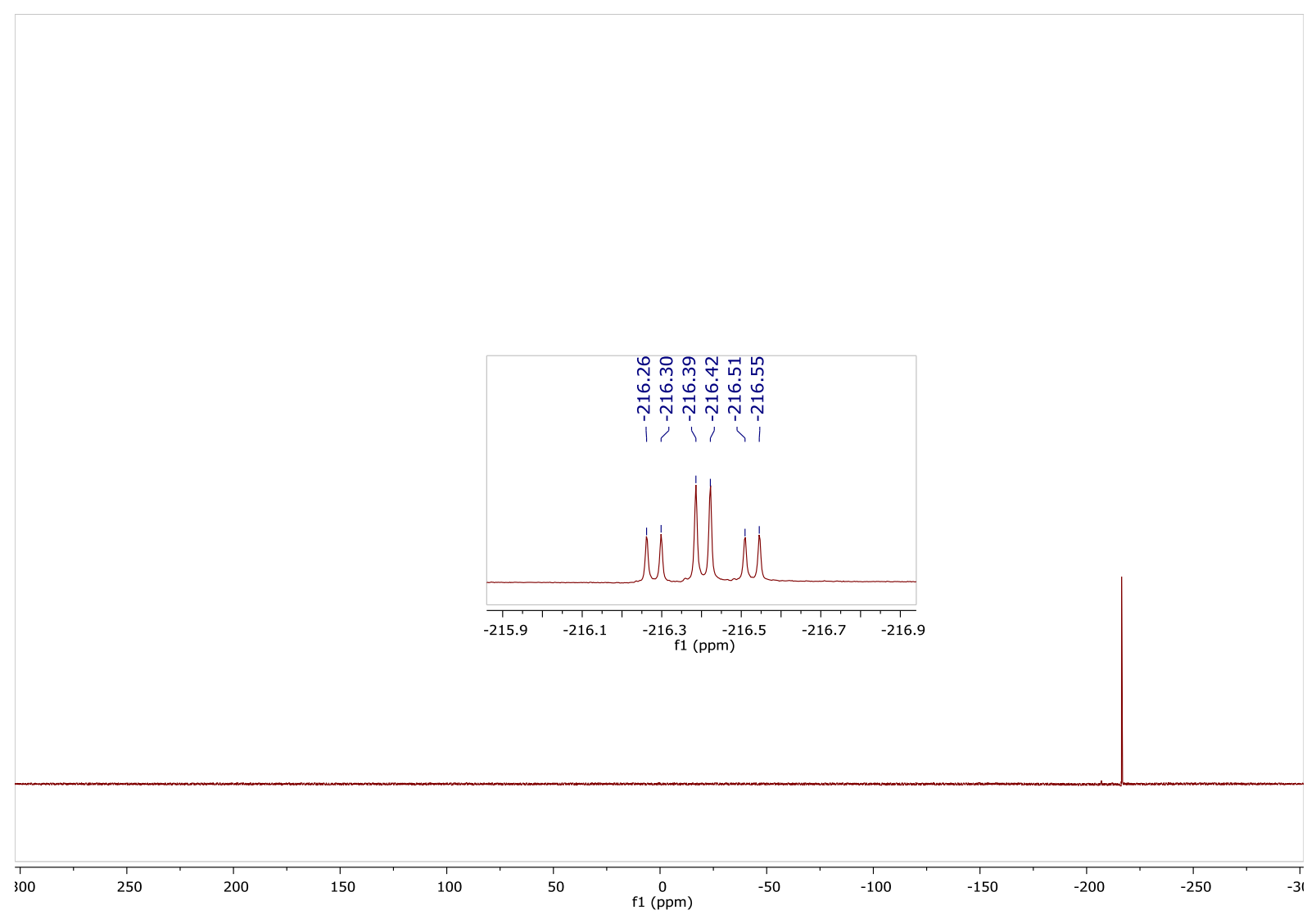


Figure A2.63 3-fluoro-2-(4-isobutylphenyl) propionic acid (5d) - ${ }^{1} \mathrm{H}$ NMR

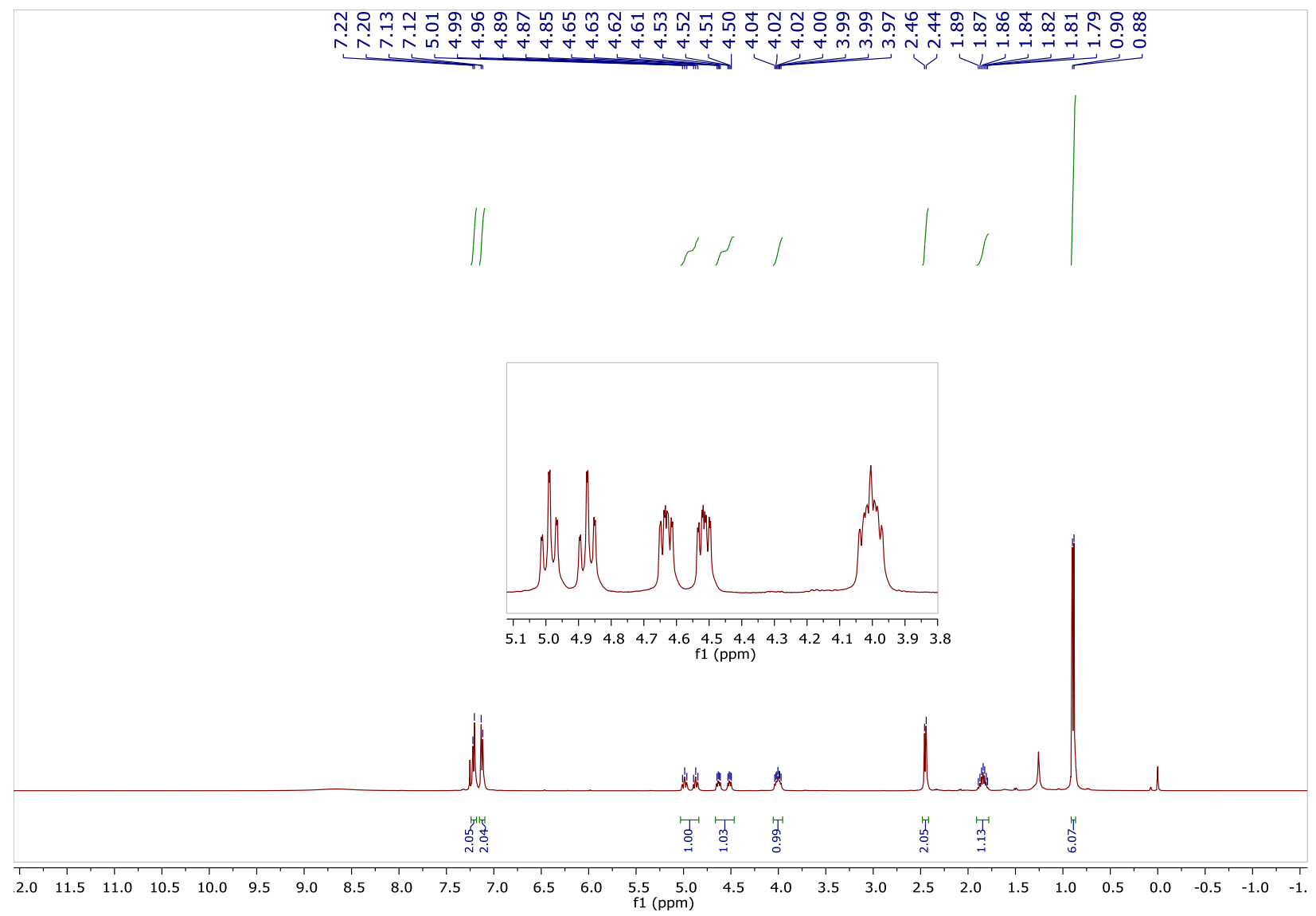


Figure A2.64 3-fluoro-2-(4-isobutylphenyl) propionic acid (5d) - ${ }^{13} \mathrm{C}$ NMR

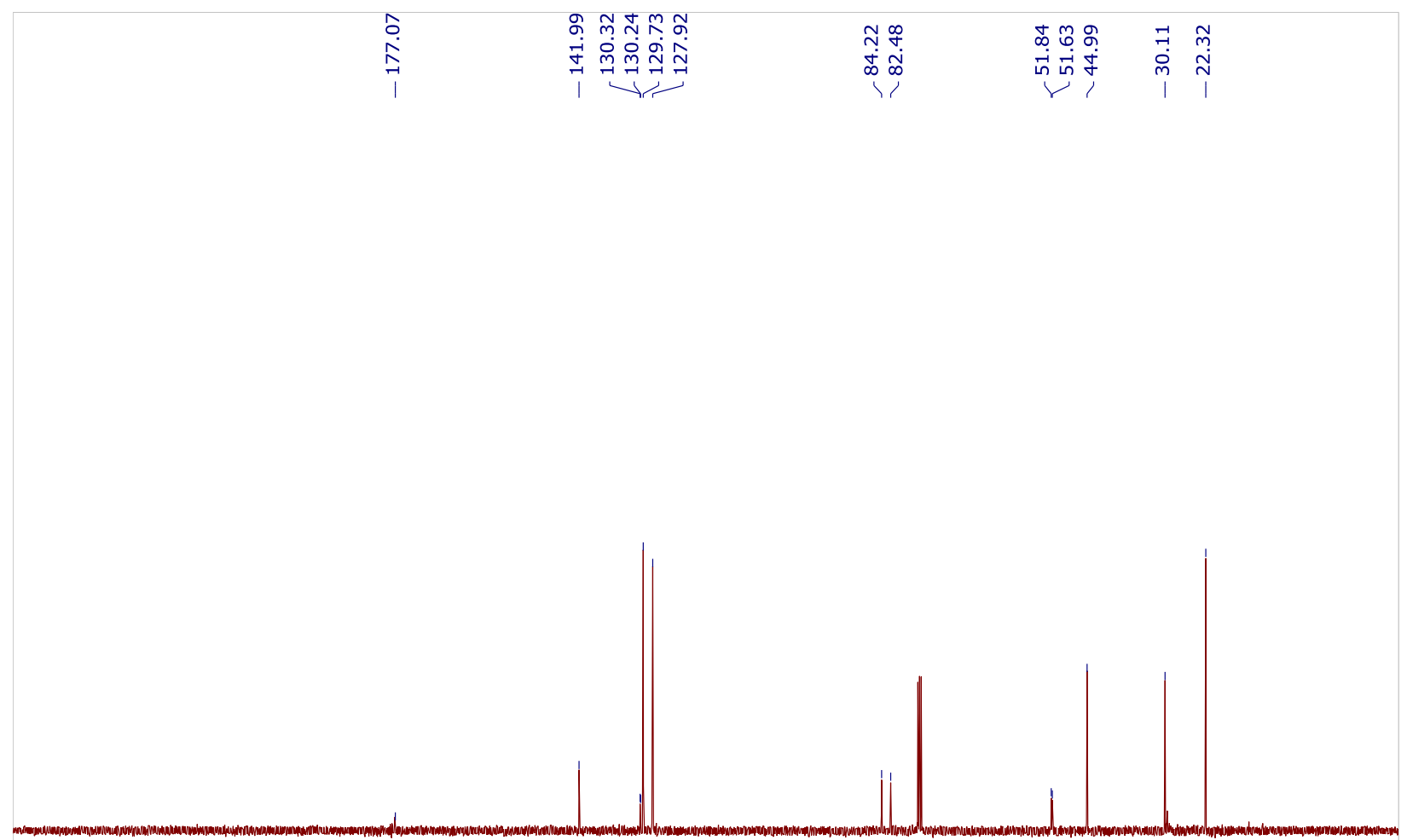

$\begin{array}{lllllllllllllllllllllllllllllll}50 & 240 & 230 & 220 & 210 & 200 & 190 & 180 & 170 & 160 & 150 & 140 & 130 & 120 & 110 & 100 & 90 & 80 & 70 & 60 & 50 & 40 & 30 & 20 & 10 & 0 & -10\end{array}$ 
Figure A2.65 3-fluoro-2-(4-isobutylphenyl) propionic acid (5d) - ${ }^{19}$ F NMR

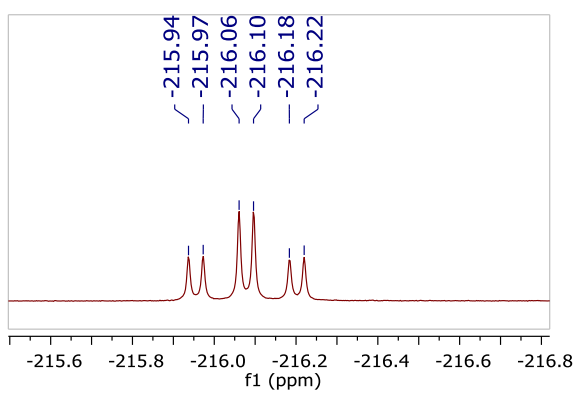

\begin{tabular}{rrrr}
\hline & 1 & 1 & 1 \\
0 & 250 & 150 & 100
\end{tabular}

50

$\underset{\substack{1 \\ \text { f1 }(\mathrm{ppm})}}{(}$

$-50$

$-100$

$-150$

$-200$ 
Figure A2.66 3-fluoro-2-(4-fluorophenyl) propionic acid (5g) - ${ }^{1} \mathrm{H}$ NMR

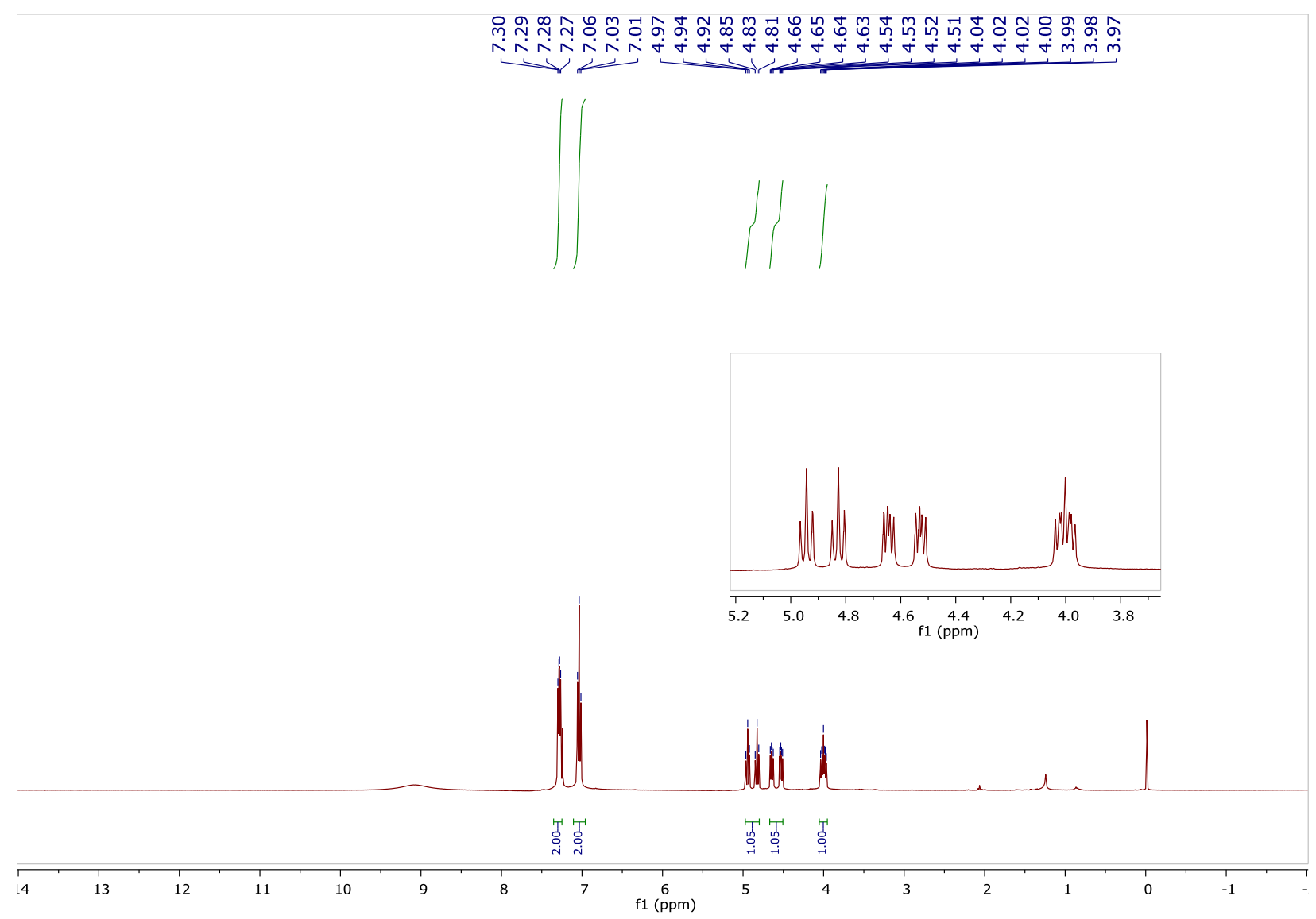


Figure A2.67 3-fluoro-2-(4-fluorophenyl) propionic acid (5g) - ${ }^{13} \mathrm{C}$ NMR

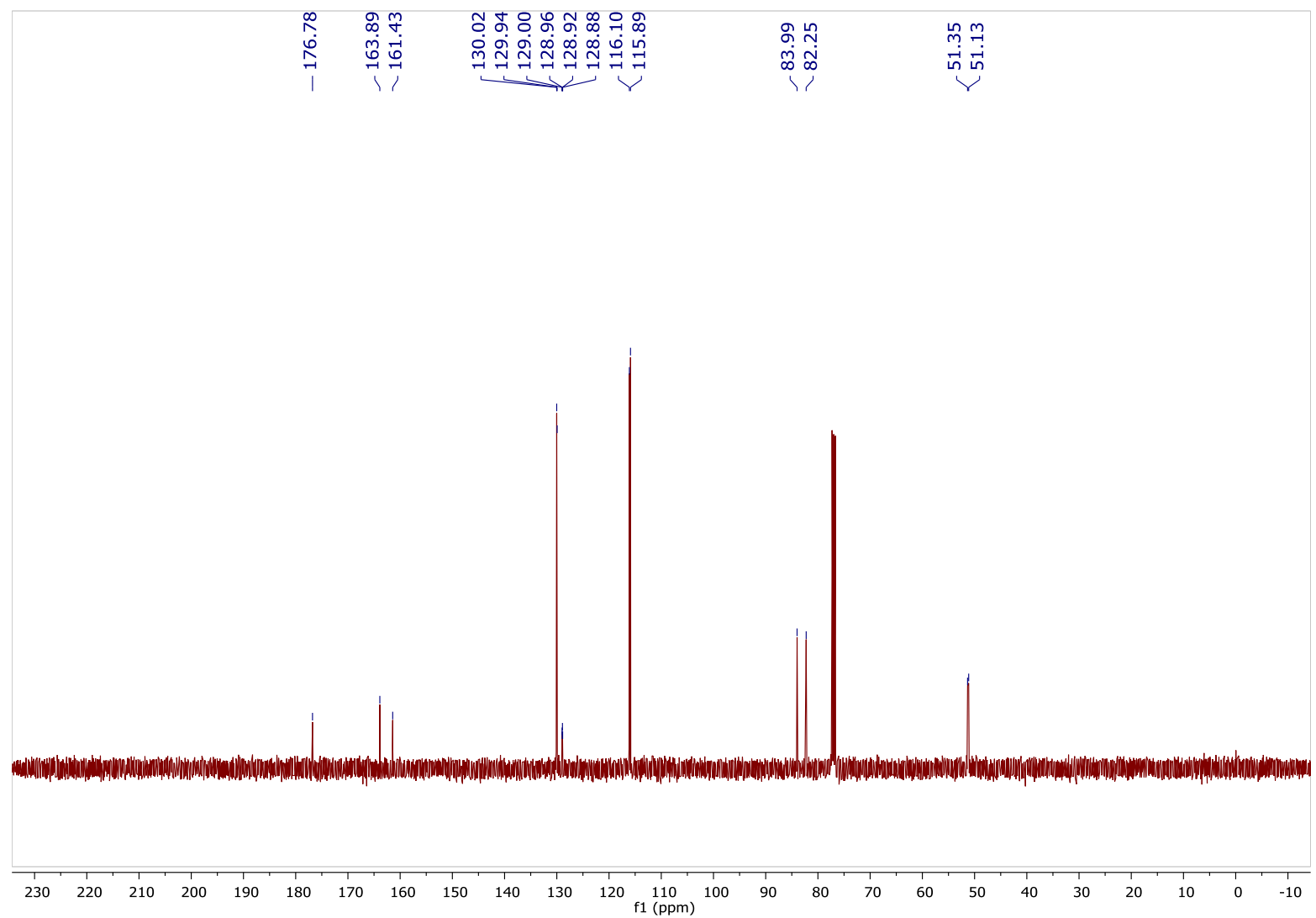


Figure A2.68 3-fluoro-2-(4-fluorophenyl) propionic acid (5g) - ${ }^{19}$ F NMR

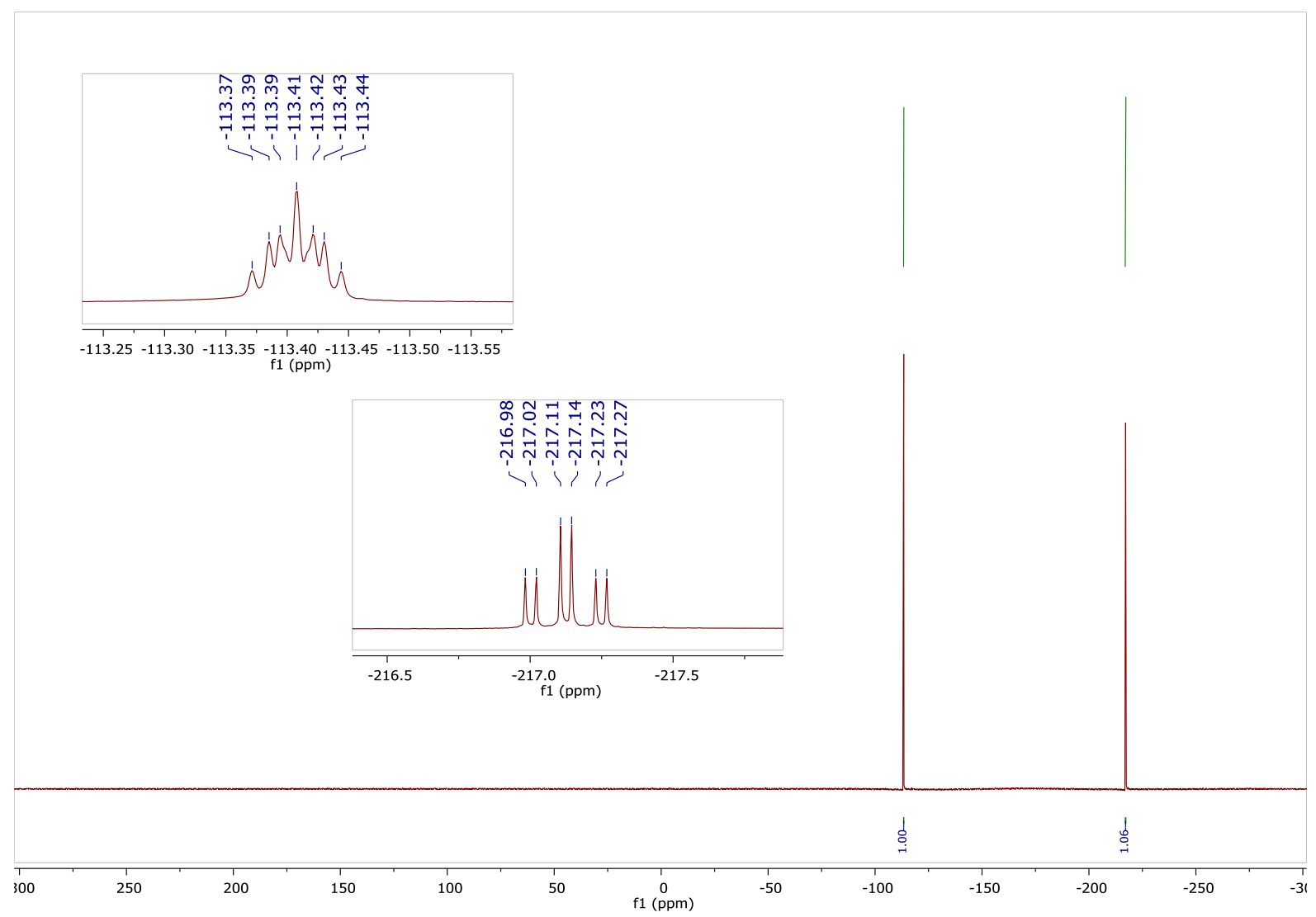


Figure A2.69 3-fluoro-2-(3-fluorobiphenyl) propionic acid (51) - ${ }^{1} \mathrm{H}$ NMR

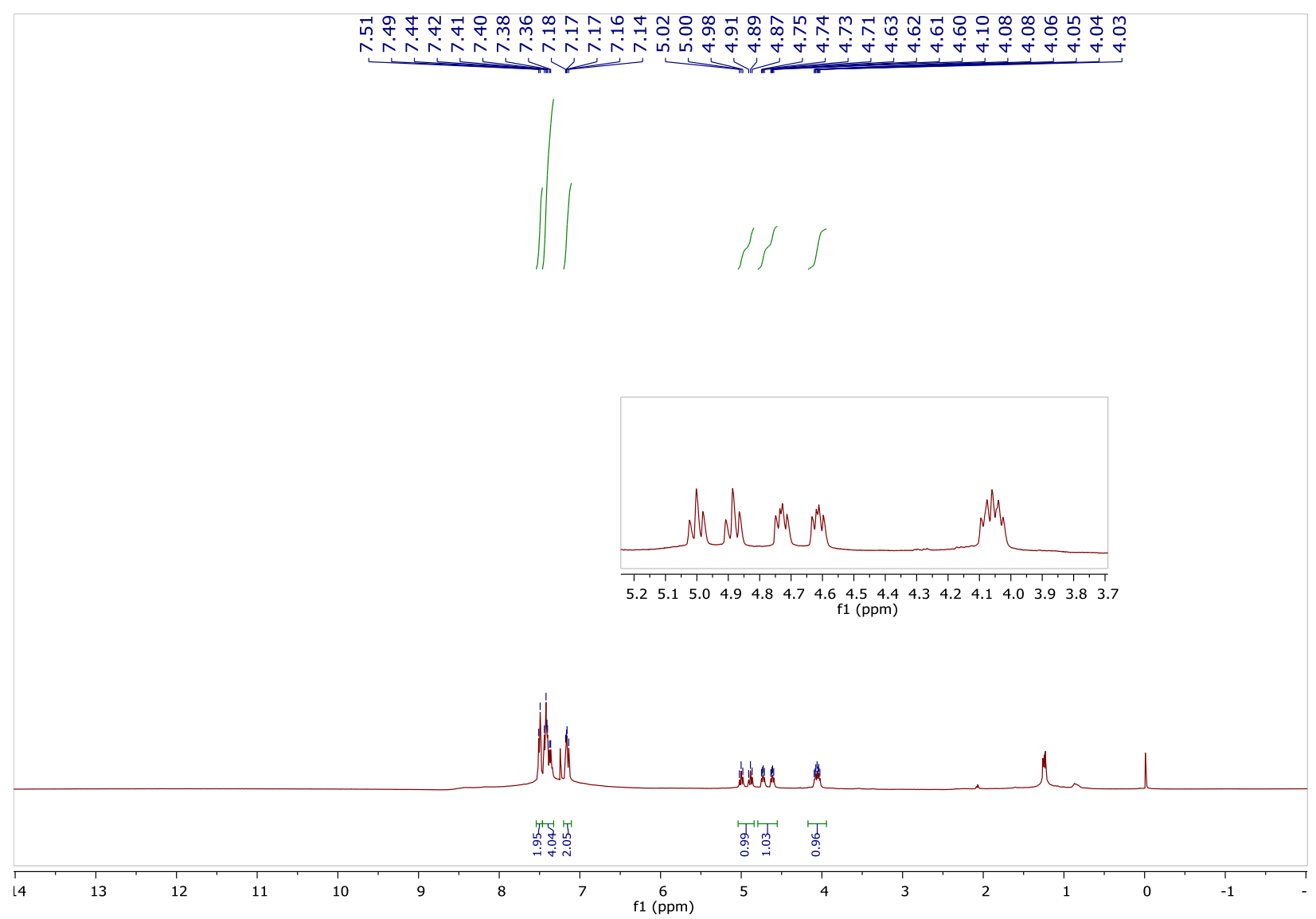


Figure A2.70 3-fluoro-2-(3-fluorobiphenyl) propionic acid (51) - ${ }^{13} \mathrm{C}$ NMR

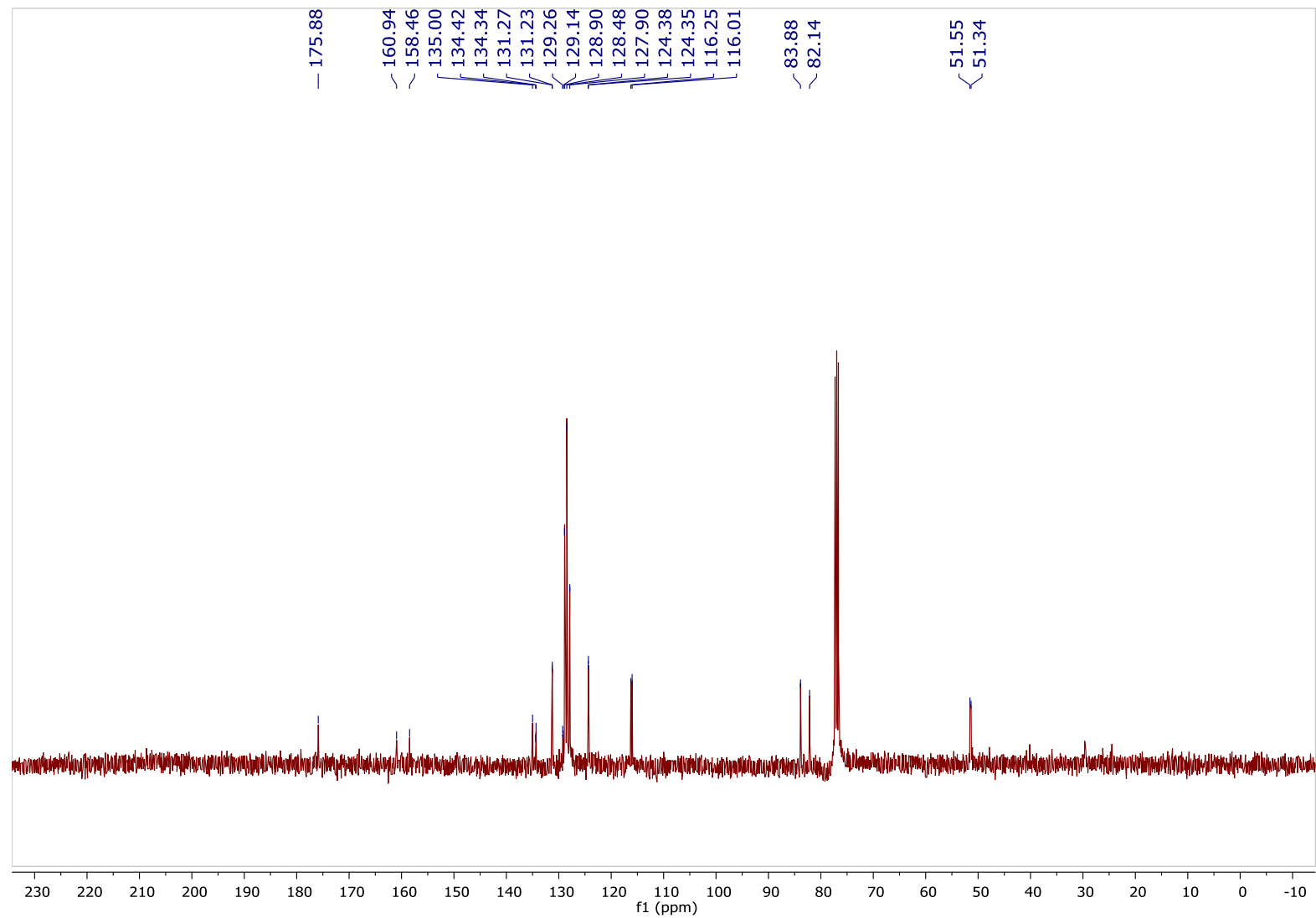


Figure A2.71 3-fluoro-2-(3-fluorobiphenyl) propionic acid (51) - ${ }^{19} \mathrm{~F}$ NMR

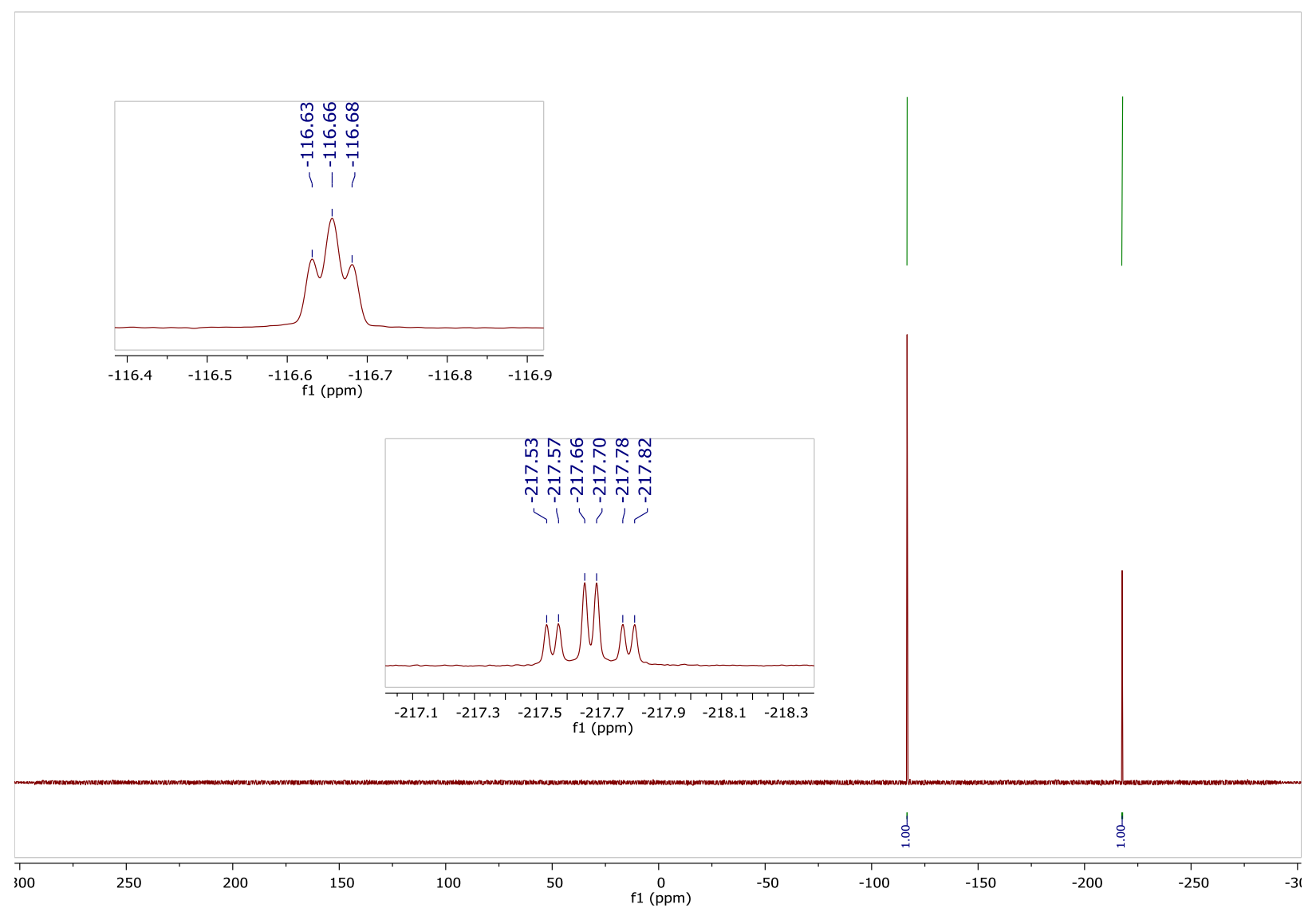


Figure A2.72 3-fluoro-2-biphenyl propionic acid (5u) - ${ }^{1} \mathrm{H}$ NMR

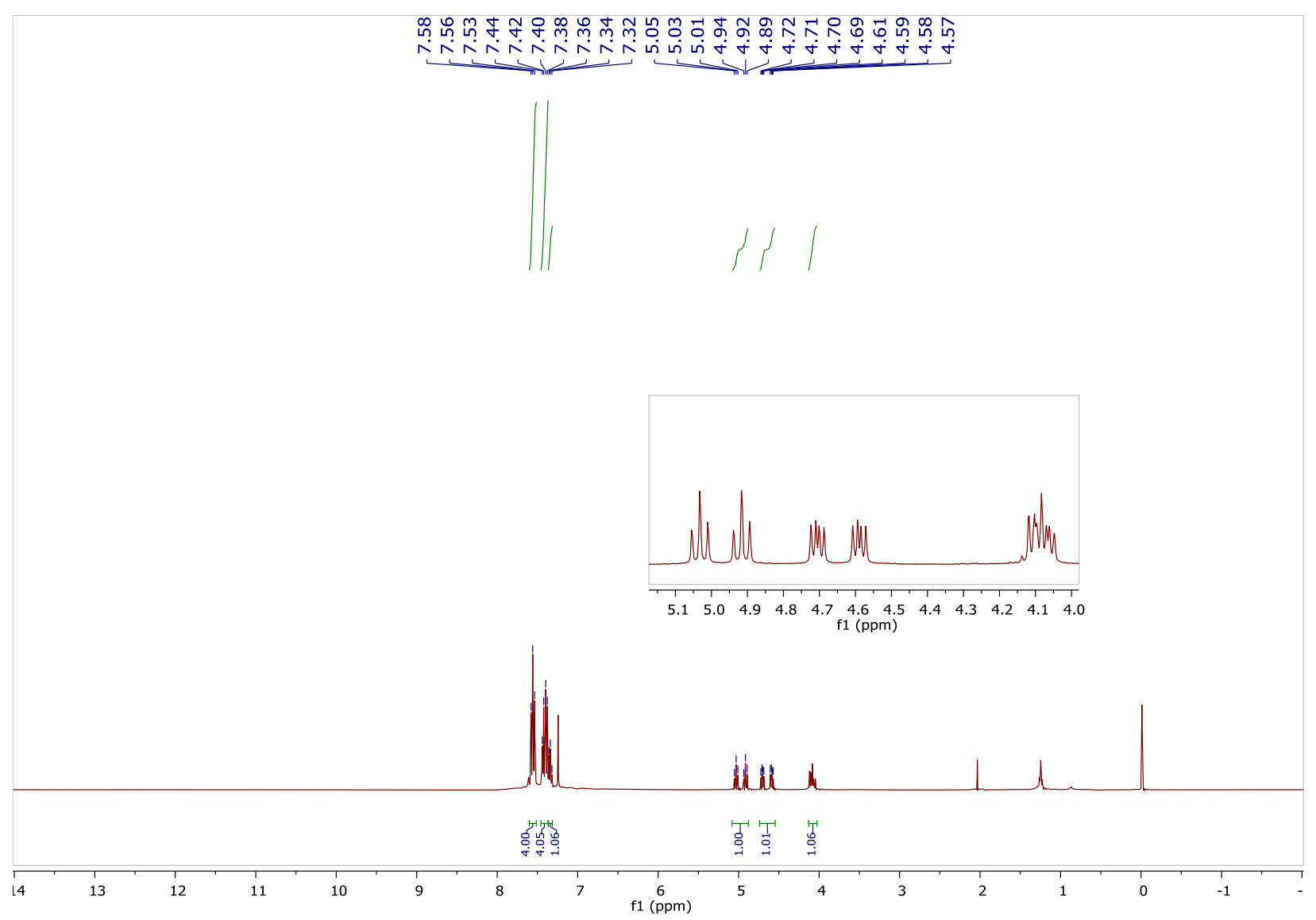


Figure A2.73 3-fluoro-2-biphenyl propionic acid (5u) $-{ }^{13} \mathrm{C}$ NMR

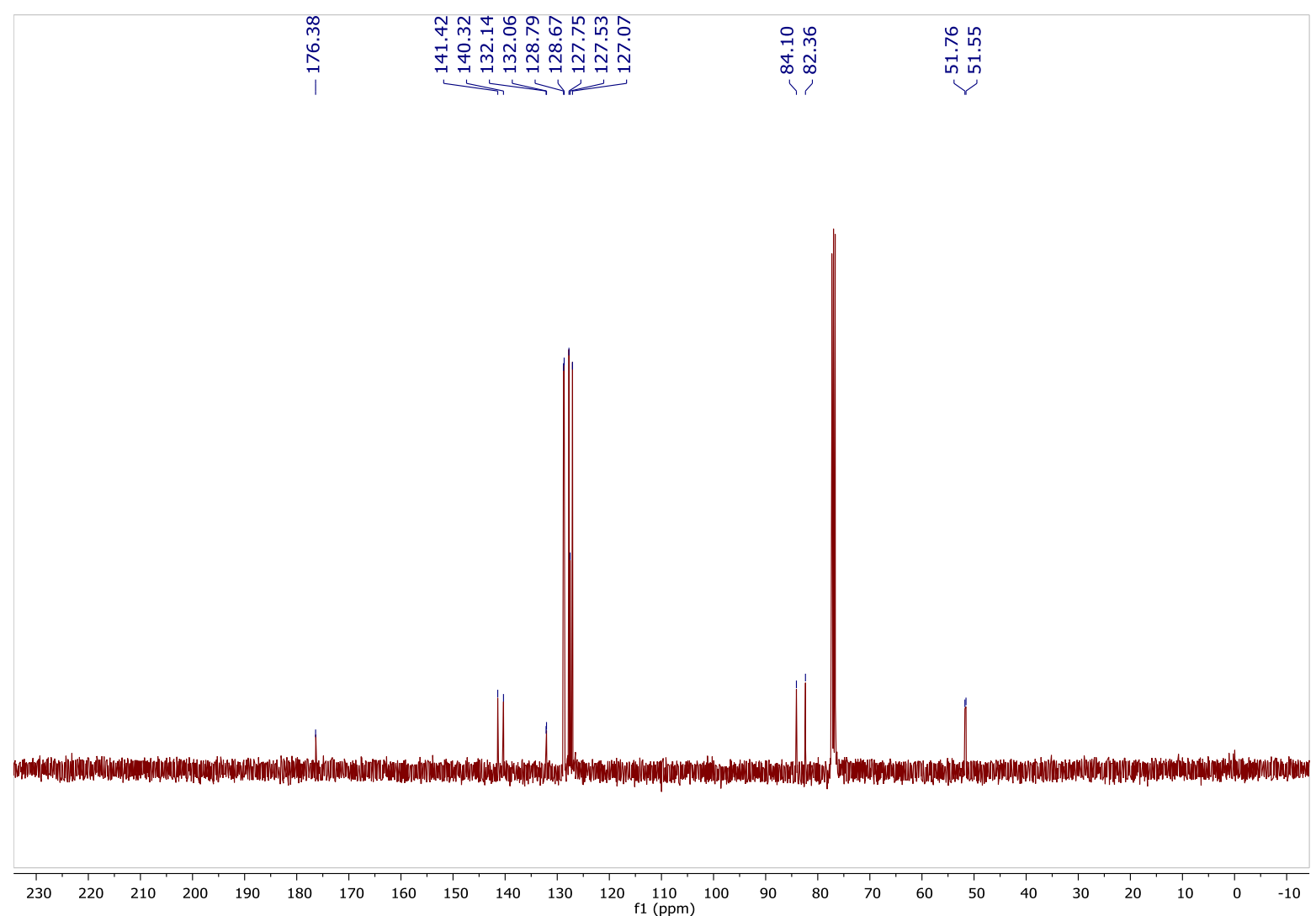


Figure A2.74 3-fluoro-2-biphenyl propionic acid (5u) - ${ }^{19}$ F NMR

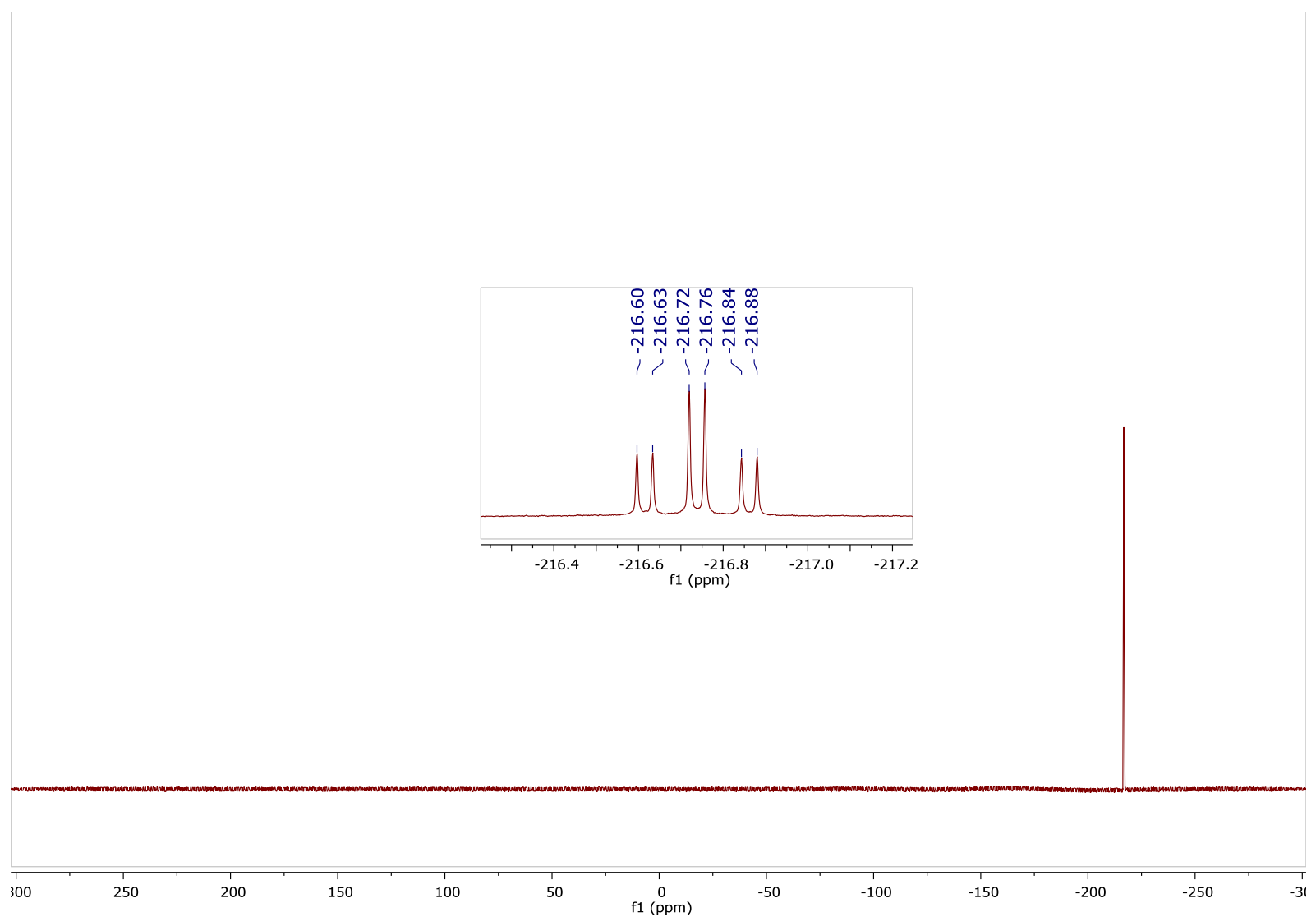

